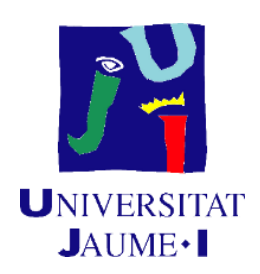

\title{
PERSONALITY \& VIDEO GAMES
}

THE ROLE OF PERSONALITY IN NORMAL AND

DISORDERED VIDEOGAMING, MOTIVES TO PLAY,

AND AGGRESSION

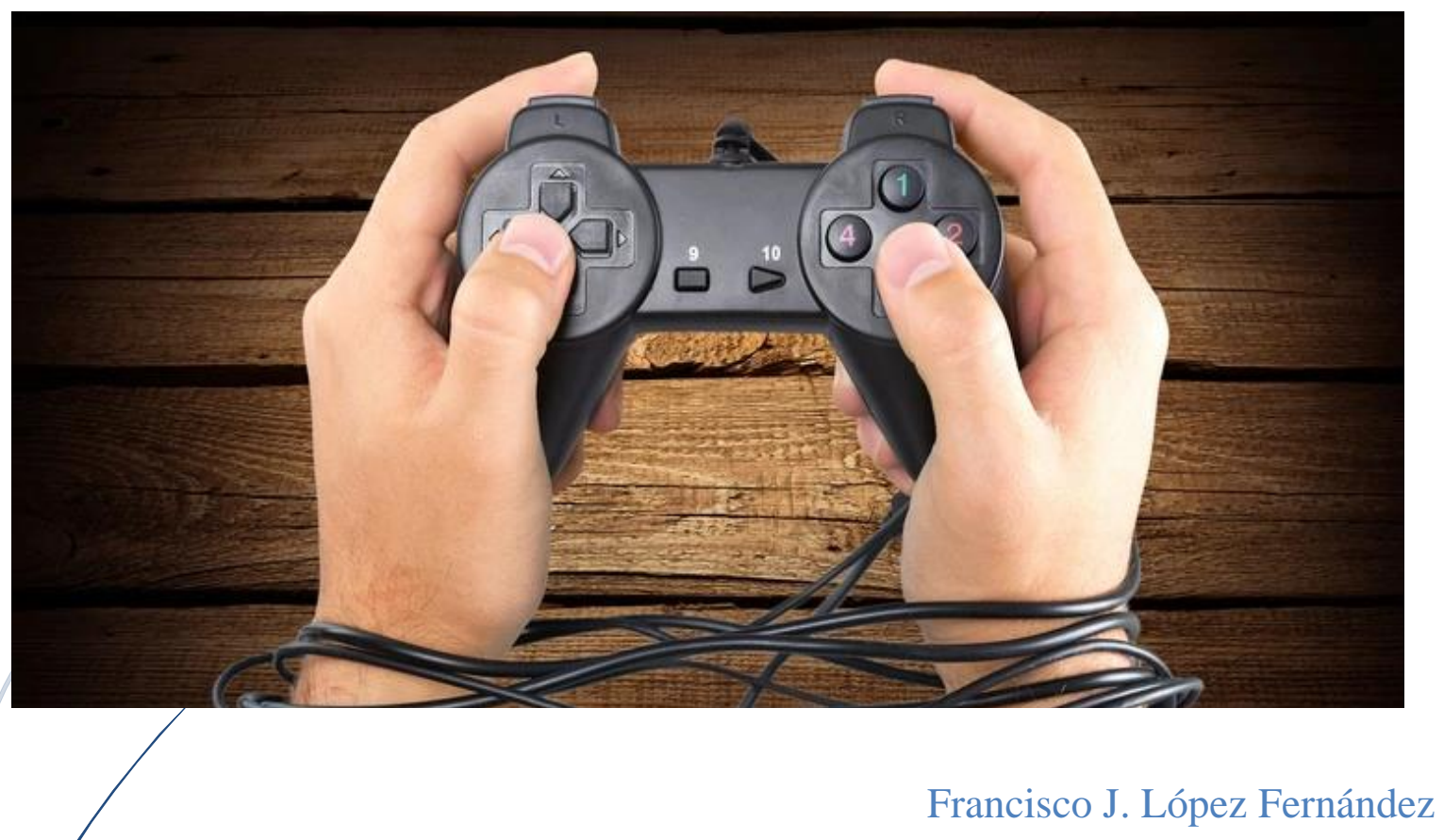

DOCTORAL THESIS

Directors:

Manuel I. Ibáñez Ribes

Laura Mezquita Guillamón

July, 2020 



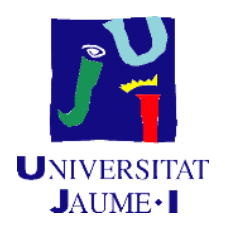

\section{Programa de Doctorat en Psicologia}

Escola de Doctorat de la Universitat Jaume I

Personality \& Video Games: the role of personality in normal and disordered videogaming, motives to play, and aggression

La personalitat i els videojocs: el seu rol sobre el joc normal i patològic, els motius per a jugar, i l'agressió

Memòria presentada per Francisco Javier López Fernández per a optar al grau de doctor/a per la Universitat Jaume I

Francisco Javier López Fernández

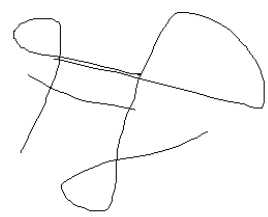

Manuel Ignacio Ibáñez Ribes

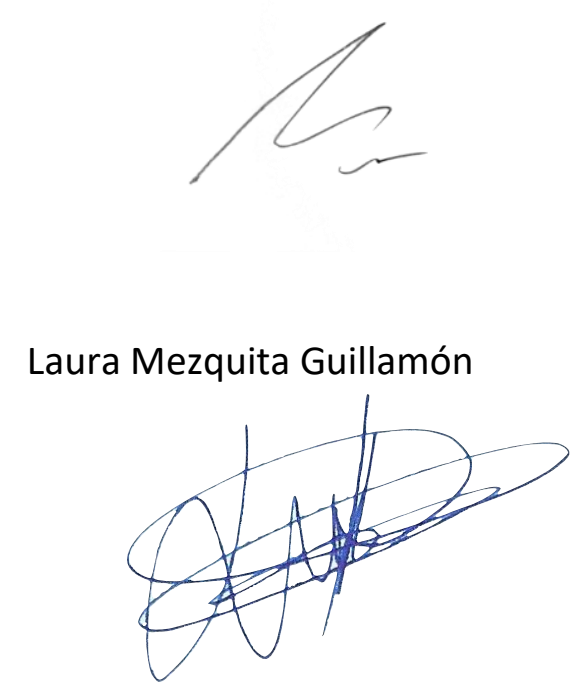





\section{Acknowledgements}

The current doctoral thesis has received the following financial support: SAM15PI01/2015 from the Banco de Instrumentos de Cibersam; PSI2015-67766-R from the Spanish Ministry of Economy and Competitiveness (MINECO/FEDER), RTI2018099800-B-I00 from the Spanish Ministry of Science, Innovation and Universities, GV/2016/158 from the Valencian Regional Government; and UJI-A2017-18, UJIB2017-74 and E-2018-16 from Universitat Jaume I. 

"The greatest enemy of

knowledge is not ignorance,

it is the illusion of knowledge"

Stephen Hawking
La hormiga medio muerta dice muy tristemente:

"Yo he visto las estrellas".

“¿Qué son las estrellas?”- dicen

las hormigas inquietas.

Y el caracol pregunta pensativo: “Estrellas?”

"Sí — repite la hormiga, he visto las estrellas.

Subí al árbol más alto que tiene la alameda y vi miles de ojos dentro de mis tinieblas". El caracol pregunta: “Pero, ¿qué son las estrellas?” "Son luces que llevamos sobre nuestras cabezas". "Nosotras no las vemos" las hormigas comentan. Y el caracol: "Mi vista sólo alcanza a las hierbas". Los encuentros de un caracol aventurero Federico García Lorca 



\section{Personal Acknowledgements}

Dicen que la gratitud es uno de los mejores sentimientos que se puede experimentar. Confiando en este dogma, quisiera empezar agradeciendo a mis directores, Nacho y Laura; así como a mi tutor, Generós, su trabajo y apoyo para la consecución de esta tesis. Sé que esto puede sonar banal, aunque no lo sea, pero son buenas personas, y agradezco haberlos conocido. Por otra parte, quería darle las gracias al profesor Griffiths por su afabilidad en la acogida y supervisión de la estancia internacional.

Quisiera dar las gracias especialmente a mis compañeros del laboratorio: Paula, Jordi y Vero. Su colaboración y apoyo han sido determinantes para seguir adelante en los momentos de flaqueza. Ellos forman parte de esta tesis.

He de dar las gracias también a mi madre por imperativo moral. Y a mi hermana, y amiga.

A Isabel, que, a pesar de todo, es la chica que hace salir el Sol.

Y, por último, me gustaría dar las gracias a todos los profesores y profesoras que he tenido y tendré. 



\section{Index}

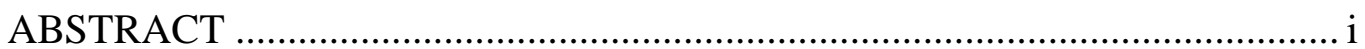

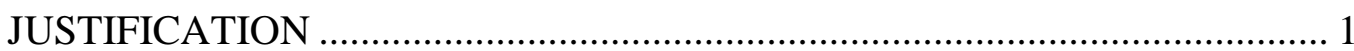

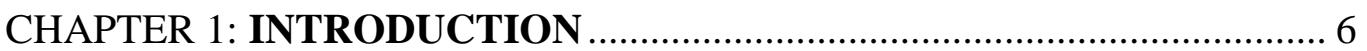

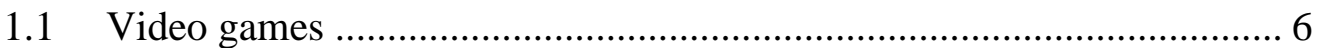

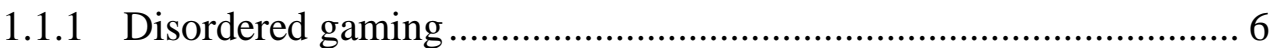

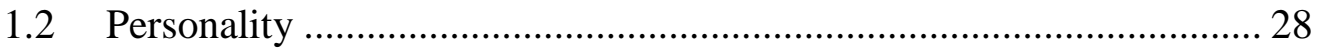

1.2.1 Personality and video gaming behaviors .................................. 29

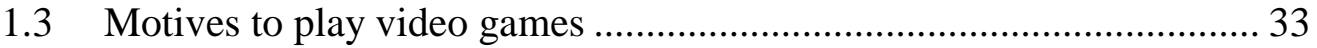

1.3.1 Motives and video game behaviors ........................................... 43

1.4 Interrelation between personality and motives to play video games .... 47

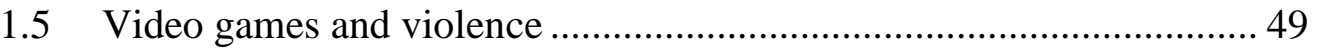

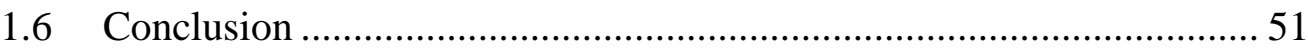

CHAPTER 2: EXPERIMENTAL FRAMEWORK ................................... 53

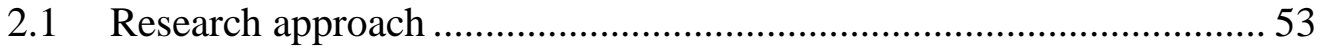

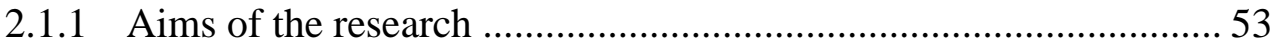

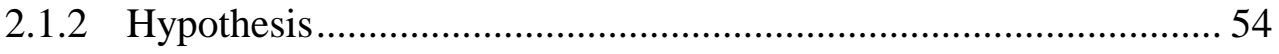

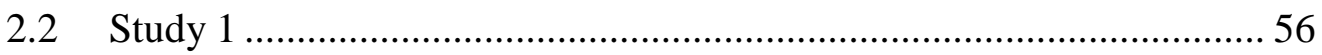

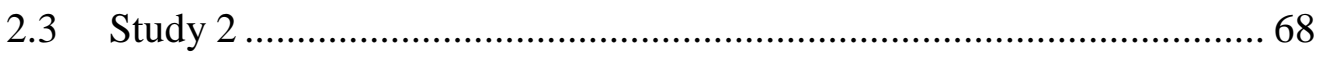

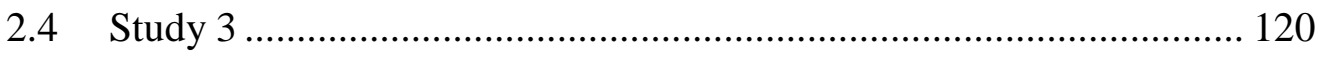

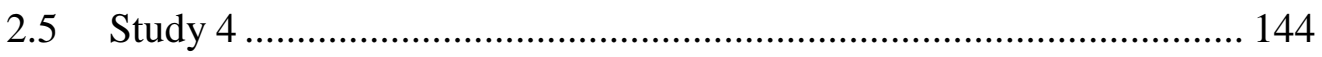




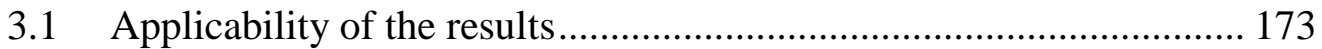

3.2 Limitations and future lines of research ..................................... 176

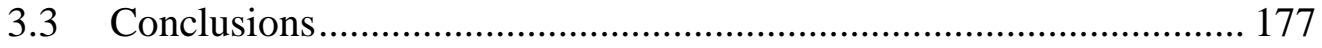

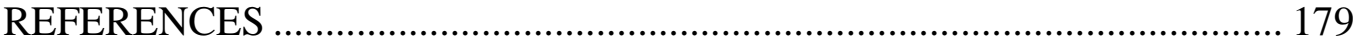

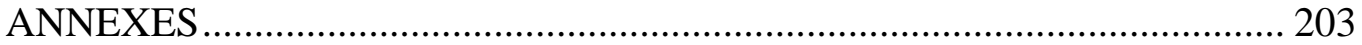




\section{List of tables}

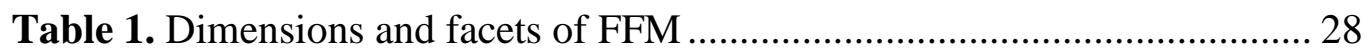

Table 2. Studies of personality (FFM) and disordered gaming ....................... 31

Table 3. Studies of video games motivational scales....................................... 34

\section{List of figures}

Figure 1. Psycho-structural factors of video games.

Figure 2. Comparison of structural characteristics of the 3 main MMO games 23

Figure 3. A cognitive-behavioral model of IGD

Figure 4. An Interaction of I-PACE for specific Internet Use disorders 26

Figure 5. Variables effecting the development of gaming habits 27

Figure 6. Overview of the General Aggression Model 50 



\section{ABSTRACT}

Video games are popular pastimes in the developed world especially at young ages. Despite not having negative effects for the vast majority of people, a minority of players can display a disordered use with an addictive symptomatology. Furthermore, it has been claimed violent video game use could make young players more aggressive.

Video gaming is a complex behavior and is influenced by the interplay of factors of a different nature, such as psychological, social, biological or video game structural variables. From these factors, personality arises as a key element in explaining video game-related behaviors. Additionally, personality may impact on motives to play which are considered other relevant psychological variables related to different video gaming behaviors.

This doctoral thesis aims to provide empirical data about the associations between personality, motives to play and video game related behaviors, as well as about the role of personality and violent video game use in aggressive behaviors. To do so, the thesis consists of 4 studies.

Study 1 explores the role of the five-factor model personality traits on disordered gaming and video game preferences in adolescents. Furthermore, the differential role according to gender and the possible moderating effect between personality traits and video gaming frequency is also examined. By the use of multiple regression analyses, the results of the study show low conscientiousness is strongly related to disordered gaming and its effect is moderated by video game frequency. Moreover, low agreeableness among boys and high introversion in girls display relevant associations in the personalitydisordered gaming relationship. In addition, significant associations are found between personality and video game genre preferences. 
Study 2 aims to develop and validate a scale in which the motives most recurrently found in research are reflected under unified labels, on two different samples of adolescents and young adults. Through a scoping review, the most frequent motives are tested and related to disordered gaming, gaming use and game genre uses. The scale consists of 8 motives displaying suitable scores in reliability and concurrent validity. Through multiple regression analyses, coping and social interaction motives are extensively related to disordered gaming, whereas social interaction displays a strong association with gaming time, in adolescents and young adults.

Study 3 analyzes the direct and indirect effects of personality through motives (extracted from Study 2) on weekly and disordered gaming, on a sample of adolescents. Via structural equation modeling analyses, high neuroticism and low conscientiousness are directly associated with disordered gaming; on the other hand, low agreeableness and high introversion are directly related to weekly gaming. With regard to the effects of mediation by motives, coping partially mediates between neuroticism and disordered gaming, whereas social interaction partially mediates between low agreeableness and disordered gaming.

Study 4 examines the additive and moderating role of violent video game use, personality and deviant peers in aggression among adolescents, cross-sectionally and longitudinally. The results of the study show deviant peers and low agreeableness are key factors influencing adolescent aggressive behavior. Furthermore, violent video game use displays a small association with aggressive behavior, which becomes non-significant when controlling for other potential variables. Accordingly, no longitudinal associations are found between violent gaming and aggressive behavior one year apart. Furthermore, two moderating effects are showed regarding the number of deviant peers. Thus, violent video game use has a higher association with aggression when players report having more 
deviant peers. Likewise, less agreeable players display more aggressive behaviors when they have a higher number of deviant peers.

The findings provided highlight the importance of studying individual differences in the understanding of regular and disordered use of video games. Therefore, personality, directly, through motives to play, and moderated by other factors, play a crucial role to explain disordered gaming, video game use and video game genre preferences. Knowing the effects of personality traits and motives to play as well as their different impact according to gender may be useful in the development of prevention and treatment programs for disordered gaming. Likewise, the additive and moderating effect of personality in aggressive behaviors, together with deviant peers, allow us to clarify the real effect of playing violent video games in aggression among adolescents. 


\section{JUSTIFICATION}

Currently video games represent one of the world's most popular pastimes showing the largest prevalence of use among children and teenagers, especially in males (AEVI, 2018; ESA, 2018). Although video game use is generally harmless for most players, a minority of them can suffer negative addiction-related effects. Thus, during the last decades the research of such negative effects has grown in relation to the pace of video games' popularity, employing different labels for the video game-related problems such as problematic gaming, video game addiction or pathological gaming, to mention a few (Griffiths, Kuss, \& King, 2012). In this sense, the American Psychiatric Association (APA), in Section 3 (Conditions for Further Study), as well as the World Health Organization (WHO) have recently introduced this addictive disorder in their respective medical handbooks (APA, 2013; WHO, 2017). As with regular use, the highest incidence of addictive playing of video games is mainly found among adolescent males (Fam, 2018; Mihara \& Higuchi, 2017; Paulus, Ohmann, von Gontard, \& Popow, 2018). The development and maintenance of both video game use and problematic gaming may be explained by the interplay of different factors such as structural characteristics of the video games, gamers' social factors like problematic interpersonal relationships with peers or family, and most importantly, gamers' psychological variables like personality and motives to play (Király, Griffiths, \& Demetrovics, 2015a; Mihara \& Higuchi, 2017; Paulus et al., 2018).

Personality is defined as the relatively stable and consistent organization of affective and cognitive dispositions that exhibit behavioral tendencies and determines a characteristic adaptation to a single environment (Eysenck \& Eysenck, 1985). Currently, the five-factor model (FFM) is the most used personality paradigm (John et al., 2008). The model is composed by five personality dimensions: neuroticism, extraversion, 
openness to experience, agreeableness and conscientiousness (McCrae \& Costa, 2008). With regard to the relationships between FFM and problematic gaming in adults, high neuroticism has been widely related to disordered gaming (Braun, Stopfer, Müller, Beutel, \& Egloff, 2016; Jeong, Lee, \& Yoo, 2015; Lehenbauer-Baum et al., 2015; Müller, Beutel, Egloff, \& Wölfling, 2014; Peters \& Malesky, 2008; Wittek et al., 2016) as well as low conscientiousness (Andreassen et al., 2013; Braun et al., 2016; Lehenbauer-Baum et al., 2015; Müller et al., 2014; Peters \& Malesky, 2008; Wittek et al., 2016). However, the examination of these relationships among adolescents is scarce. In this sense, problematic video gaming among teenagers was associated with low conscientiousness (García-Oliva \& Piqueras, 2016; Vollmer, Randler, Horzum, \& Ayas. 2014; Wang, Ho, Chan, \& Tse, 2015) and, to a lesser extent, to low extraversion (García-Oliva \& Piqueras, 2016; Vollmer et al., 2014). These studies suggest that neuroticism may play a more important role on problematic gaming in adulthood, whereas extraversion would become important in teenagers. Therefore, one of the aims of the thesis is to explore the role of personality on gaming behaviors, pathological use and genre preferences among adolescents (Study 1).

Motives influence players' expectations that drive them to play in order to obtain emotional and cognitive gratifications (e.g., Greenberg, Sherry, Lachlan, Lucas, \& Holmstrom, 2010; Klimmt \& Hartmann, 2006; Sherry, Lucas, Greenberg, \& Lachlan, 2006). Thereby, motives to play may constitute relevant factors in understanding variability in gaming behaviors. Particularly, escapism-coping motives are clearly associated with pathological gaming (Ballabio et al., 2017; Billieux et al, 2011; Billieux et al, 2013; Chang \& Lin, 2019; Hagström \& Kaldo, 2014; Kardefelt-Winther, 2014a; Kim et al., 2016; Király et al., 2015b; Király, Tóth, Urbán, Demetrovics, \& Maraz, 2017a; Kirby, Jones, \& Copello, 2014; Kircaburun et al., in press; Kneer \& Glock, 2013; Kuss, 
Louws \& Wiers, 2012; Laconi, Pirès, \& Chabrol, 2017; Männikkö, Billieux, Nordström, Koivisto, \& Kääriäinen, 2017; Montag et al., 2019; Plante, Gentile, Groves, Modlin, \& Blanco-Herrera, 2018; Wu, Lai, Yu, Lau, \& Lei, 2016; Yee, 2006a; Zanetta et al., 2011). In addition, achievement motives, such as competition or advancement, have been related to this pathological use to a lesser extent (Billieux et al, 2011; Kardefelt-Winther, 2014a; Király et al., 2015b; Kircaburun et al., in press; Männikkö et al., 2017; Montag et al., 2019; Yee, 2006a; Zanetta et al., 2011). Finally, some studies have shown that social motives have a significant role on problematic gaming (Laconi et al., 2017; Männikkö et al., 2017; Zanetta et al., 2011) as well as fantasy motives (Ballabio et al., 2017; Billieux et al, 2011; Laconi et al., 2017).

Regarding the assessment of motives to play, different approaches have been employed in motives' categorization. However, research presents some limitations such as motives limited to specific games or genres (e.g., Fuster et al., 2012; Yee, 2006a; Yee Ducheneaut, \& Nelson, 2012) and more importantly, different labels for similar conceptual motives across studies. Thus, one of the aims of the present research is to develop a new scale of gaming motives in which the most recurrent motivational components found in research are reflected under unified labels that can be used for any gaming genre (Study 2). Furthermore, the relationships between motives and disordered gaming, gaming time and gaming genre uses will be examined. A young adult and an adolescent sample will be employed for the development and validation of the scale.

Personality and gaming motives, apart from their direct role on gaming behaviors, may be correlated between themselves. Accordingly, FFM traits have been associated with motivations to play video games (Bean \& Groth-Marnat, 2016; Graham \& Gosling, 2013; Jeng \& Teng, 2008; Park, Song, \& Teng, 2011; Shceck, Lee, \& Pyo, 2015). Thus, personality as a more distal variable may influence on gaming behaviors through motives 
to play as more proximal variables. In this line, escapism-coping motives extensively mediate the associations between psychological problems and disordered gaming (Ballabio et al., 2017; Király et al., 2015b; Montag et al., 2019; Plante et al., 2018). To date, very few studies have examined the mediating role of motives on the relationship between personality traits and problematic gaming (Kircaburun, Jonason, \& Griffiths, 2018; Kircaburun et al., in press). One study is based on the Dark Tetrad traits Machiavellianism, psychopathy, narcissism and sadism- (Kircaburun, Jonason, \& Griffiths, 2018), and the other on trait emotional intelligence (Kircaburun et al., in press); thus, mediation analyses focused on basic personality traits have not been considered. Therefore, another aim of the current research is to explore associations of the FFM traits with pathological and regular gaming via gaming motives in adolescents (Study 3).

On the other hand, the effects of playing violent video games on players' aggression is a hot topic in psychological research (Calvert et al., 2017). Meta-analyses show a small but significant relationship between violent video game use and aggressive outcomes (Anderson \& Bushman, 2002; Anderson et al., 2010; Calvert et al., 2017; Ferguson \& Kilburn, 2009; Greitemeyer \& Mügge, 2014; Prescott, Sargent, \& Hull, 2018; Sherry, 2001). These minor effects could be explained by the fact that some people may be susceptible to violent videogame exposure (VVE) whereas other people present null effects (Markey, 2015; Valkenburg \& Peter, 2013). Thus, some studies have found the effects of VVE on aggression are larger when individuals display higher levels of traits related to aggressiveness (e.g., Markey \& Markey, 2010; Markey \& Scherer, 2009). In addition, the moderating effect of deviant peers in the VVE-aggression relationship has not yet been examined, despite the strong and direct effect of deviant peers on aggressiveness (Thompson, Mehari, \& Farrell, 2019). Therefore, the final aim of the 
present research is to explore the additive and moderating role of VVE, personality and deviant peers in adolescent aggressive behaviors (Study 4).

To sum up, the purpose of this doctoral thesis is to provide empirical data about the relationship between personality (FFM), directly and via motives to play, motives and gaming behaviors (disordered gaming, gaming time and game genre preferences); and the additive and moderating role of FFM traits and VVE in aggressive behaviors considering the influence of other potential variables. The findings provided would be useful in the development and improvement of prevention and treatment programs for problematic video game use, and to clarify the impact of violent video gaming on aggressive behaviors. 


\section{CHAPTER 1: INTRODUCTION}

\subsection{Video games}

Video games are currently one of the commonest leisure activities. Thus, particularly in Spain, the video game industry has invoiced 1.53 billion euros during 2018 , with a growth rate of $12.6 \%$ with regard to the previous year (AEVI, 2018). This fact turns video games into the first audiovisual industry in Spain over cinema and music (AEVI, 2018), with a similar pattern around the developed world (ESA, 2018). Thereby, 16.8 million Spaniards play video games regularly (47\% of the population from 6 to 64 years old) with a mean of 6.2 hours a week and a higher time spent by males (AEVI, 2018). In this manner, $59 \%$ of players are males and the highest rates of prevalence are found at young ages. For instance, $80 \%$ of children from 6 to 10 years old play video games, as well as $78 \%$ of youngsters from 11 to 14 and $66 \%$ of people from 15 to 24 (AEVI, 2018).

\subsubsection{Disordered gaming}

Playing video games is generally a pleasurable entertainment option. However, a minority of players may develop a pathological use showing addictive symptomatology (Griffiths, 2005; Petry, Rehbein, Ko, \& O’Brien, 2015).

According to Sussman et al. (2011), in the addictive process "initially one may pursue some course of action for appetitive effects such as pain reduction, affect enhancement, arousal manipulation, or fantasy. Over repeated engagement in the behavior, the individual becomes intensely preoccupied with the behavior despite diminishing appetitive effects. Subsequently, the individual, if desiring to control or stop the behavior, experiences subjective loss of control over when the behavior is initiated, how it is manifested, or when it will stop. Finally, one incurs negative consequences (e.g., social, role, physical, emotional) while continuing to engage in the self-defeating 
behavior. Stopping the behavior becomes difficult for several reasons, including having a lack of awareness of the "stimuli" or triggers that influence the behavior and the cognitive salience of immediate gratification relative to delayed adverse effects. That is, the behavior becomes increasingly more automatic and less under one's control-ability. At this point, the individual also may fear having to cope with day-to-day perceived stress and other life experiences upon cessation... as well as having to suffer withdrawalrelated phenomena". Therefore, this process may be common for both substance-related disorders and behavioral addictions, such as pathological gambling and disordered gaming.

Accordingly, the fifth edition of the Diagnostic and Statistical Manual of Mental Disorders (DSM-5) considers the Internet Gaming Disorder (IGD) as a potential behavioral addiction in Section 3 (Conditions for Further Study), despite an ongoing debate about its prevalence, etiology and course (APA, 2013). The disorder is focused on online games, however, offline games could also be incorporated, although these have been less studied. In this line, the World Health Organization (WHO) has introduced Gaming Disorder (GD), involving both online and offline gaming, in the section Disorders due to substance use or addictive behaviors in the $11^{\text {th }}$ revision of the International Classification of Disease (ICD-11) (WHO, 2017).

In the DSM-5 the diagnosis of IGD is defined as a "persistent and recurrent use of the Internet to engage in games, often with other players, leading to clinically significant impairment or distress by endorsing five or more out of nine criteria over a period of 12 months" (APA, 2013; p.795). The nine criteria are: 1) preoccupation with Internet games; 2) withdrawal symptoms when Internet games are taken away; 3) tolerance, the need to spend more time engaged in Internet games; 4) unsuccessful attempts to control participation in Internet games; 5) loss of interest in previous hobbies 
and entertainment as a result of, and with the exception of Internet games; 6) continued excessive use of Internet games despite knowledge of psychosocial problems; 7) deceiving family members, therapists, or others regarding the amount of time spent participating in Internet gaming; 8) use of Internet games to escape or relieve negative moods; and finally 9) jeopardizing or losing a significant relationship, job or education or career opportunity because of participation in Internet games. On the other hand, GD is defined as a problematic pattern of gaming behavior within a timeframe of 12 months characterized by impaired control over gaming, increasing its priority to the extent that gaming takes precedence over other interests and daily activities, and continuation or escalation of the gaming activity despite the occurrence of negative consequences.

Unlike most substance use disorders which require two criteria for the diagnosis, IGD must present at least five criteria due to the extended video game use (Ko, 2014). In this line, the threshold of five criteria seems suitable for distinguishing clinically significant levels of play (Király et al., 2017b; Ko et al., 2014; Koo et al., 2017; Petry et al., 2015).

The initial studies of the DSM-5 classification of IGD have shown that the criteria with highest diagnostic accuracy are giving up other activities (Carras et al., 2018; Rehbein, Kliem, Baier, Mößle, \& Petry, 2015), loss of control (Carras et al., 2018; Király et al., 2017b), continued use despite negative consequences (Carras et al., 2018; Wu, Chen, Tong, Yu, \& Lau, 2018), and tolerance (Carras et al., 2018; Rehbein et al., 2015). On the other hand, the lowest diagnostic accuracy is clearly displayed by the escape criterion (Király et al., 2017b; Ko et al., 2014; Lemmens, Valkenburg, \& Gentile, 2015; Petry et al., 2015; Rehbein et al., 2015). In addition, some studies have found a poor validity of the preoccupation criterion (Király et al., 2017b; Rehbein et al., 2015). 
Accordingly, Charlton \& Danforth (2007) distinguished between core and peripheral criteria for video game addiction on MMORPGs -Massively Multiplayer Online Role Playing Games- players, extracting two different factors: the addictive and the engagement factor. The addictive factor consisted of conflict, withdrawal symptoms, relapse and reinstatement and behavioral salience; whereas the engagement factor loaded on cognitive salience, tolerance and euphoria. Likewise, Brunborg, Hanss, Mentzoni \& Pallesen (2015) conducted a confirmatory factor analysis of a scale measuring gaming addiction in adolescents on a large Norwegian population $(\mathrm{n}=10,081$; aged 16-74 years), finding separated peripheral criteria and core criteria factors, the criteria of which resemble those from Charlton \& Danforth (2007). Thus, this distinction has been validated in a large number of studies. Thereby, Pontes, Kiraly, Demetrovics \& Griffiths (2014) found that engaged players low in addiction risk scored high on peripheral criteria and low on the core criteria. In addition, Deleuze, Long, Liu, Maurage \& Billieux (2018) found that gaming addiction, compared with engagement, presented more pronounced relationship with IGD scores and also revealed significant relationships with impulsivity and depression. Furthermore, players addicted versus engaged have shown differences in personality (Charlton \& Danforth, 2010; Lehenbauer-Baum \& Fohringer, 2015); scholastic performance (Skoric, Teo, \& Neo, 2009); attentional bias (Metcalf \& Pammer, 2011); quality of life, hours of gaming and immersive tendency (Lehenbauer-Baum \& Fohringer, 2015); immersion motives, significantly related to engagement but not addiction (Deleuze et al., 2018); and on direct associations with internalizing symptoms controlled for coping (Loton, Borkoles, Lubman, \& Polman, 2016).

The DSM-5 definition of IGD is a good starting point and research must keep examining the roles of each criterion to reach an academic consensus that could clarify the diagnosis (Griffiths et al., 2016; Petry, Zajac, \& Ginley, 2018). In this sense, IGD 
diagnosis, especially in epidemiological studies, might be improved establishing the functional impairment as a key criterion (Kardefelt-Winther et al., 2017) such as ICD-11 does (Pontes et al., 2019; WHO, 2017); or distinguishing between primary and secondary criteria (Kuss, Griffiths, \& Pontes, 2017) in order to obtain more realistic disorder prevalences. Accordingly, when comparing between APA and WHO frameworks concerning disordered gaming, even though both are pretty similar in the psychometric prediction of disordered gaming in relation to psychological independent variables such as gaming motives and psychopathological symptoms (Montag et al., 2019) and present similar neurobiological associations (Zhou, et al., 2019), the WHO diagnostic criteria presents a significantly lower prevalence rate than APA criteria (Montag et al., 2019). Furthermore, the exclusion of other IGD criteria such as preoccupation or escape may be considered due to their weak diagnostic accuracy. In this line, Carras \& KardefeltWinther (2018) found that IGD criteria misclassify engaged gamers who show poor wellbeing without gaming-related problems. In addition, some criteria must be clarified in the context of IGD (Kardefelt-Winther et al., 2015). For instance, King, Herd \& Delfabbro (2018) showed that the tolerance factor of inadequacy, the need to rectify perceived insufficiencies in gaming, was significantly related to other IGD symptoms (whereas other tolerance factors showed no relationships). Thus, the impairment in the way in which the player sets goals and perceives their outcomes is what may promote time investment in gaming leading to problematic gaming. Therefore, the focus on "time" in tolerance criterion may be reconsidered.

Research has shown a large variability on disordered gaming prevalence. Thus, it has ranged from 0.7 to $27.5 \%$ (Feng, Ramo, Chan, \& Bourgeois, 2017; Mihara \& Higuchi, 2017). A large portion of this variability may be due to the different criteria employed for the assessment of disordered gaming until the inclusion of IGD in the DSM-5. In this 
sense, based on the IGD definition, the prevalence rates range between 1 and $9 \%$ depending on age and socio-cultural differences (Gentile et al., 2017). Adolescents, especially males, are particularly vulnerable to suffer IGD (Mihara \& Higuchi, 2017; Paulus et al., 2018). Accordingly, a study of a multi-national sample of 12.938 adolescents in seven European countries showed a prevalence for IGD of 1.6\%, with a further $5.1 \%$ being at risk for IGD (Müller et al., 2015). In this sense, a meta-analysis among adolescents found an overall IGD prevalence of $4.6 \%, 6.8 \%$ for boys and $1.3 \%$ for girls (Fam 2018). Specifically in Spain, 7.7\%-8.3\% of adolescents have been labeled as pathological gamers (Buiza-Aguado, Alonso-Canovas, Conde-Mateos, BuizaNavarrete, \& Gentile, 2018; Lopez-Fernandez, Honrubia-Serrano, Baguley, \& Griffiths, 2014).

\subsubsection{Biological basis of disordered gaming}

Bechara (2005) claims that "addiction is the product of an imbalance between two separate, but interacting neural systems that control decision making: an impulsive, amygdala system for signaling pain or pleasure of immediate prospects, and a reflective, prefrontal cortex system for signaling pain or pleasure for future prospects". Accordingly, Kuss and Griffiths (2012a) explained the addictive process in the brain in detail. Thus, the neural correlates of drug addiction develop via classical and operant conditioning. During the initial stages of the voluntary and controlled usage of a substance, the decision to use the drug is conducted by specific brain regions (prefrontal cortex and ventral striatum). As habituation to use and compulsion develops, brain activity changes, the activity in the dorsal regions of the striatum become increasingly activated via dopaminergic innervation. Long term use of drug use leads to change in the brain dopaminergic pathways (the anterior cingulate, orbitofrontal cortex and the nucleus accumbens) which may lead to a reduction of sensitivity to biological rewards and it 
decreases the individual's control over seeking and taking drugs. On a molecular level, the long-term depression (LTD) of synaptic activity has been linked to the adaptation of the brain as a result of substance-related addictions. Drug addicts become sensitized to the drug because in the course of prolonged intake, the synaptic strength in the ventral tegmental area increases, as the LTD of glutamate occurs in the nucleus accumbens, which will result in craving. Thus, the brain becomes increasingly responsive to drug cues via craving. Activity in the nucleus accumbens following recurrent drug intake leads to learning associations between drug cues and the reinforcing effects of the drug. Natural rewards gradually lose their hedonic valence. Due to habituation to rewarding behaviors and intake of drugs, increasing amounts of substance is needed in order to produce the desired effect (tolerance). As a result, the reward system becomes deficient. This leads to the activation of the antireward system that decreases the addict's capacity for experiencing biological reinforcers as pleasurable. Thus, the addicted individual requires stronger reinforcers to experience reward (e.g., larger drug intake). In addition, the lack of dopamine in the mesocorticolimbic pathways during abstinence explains characteristic withdrawal symptoms. Relapse and the development of a vicious circle of use are the results. This process would similarly occur on behavioral addictions.

The first study that examined the effects of video gaming on the brain was Koepp et al. (1998), which found that the striatal dopamine released during video game play was similar to that following amphetamine or methylphenidate injections. Since then, a great number of studies have explored the functional and structural effects of gaming, and particularly its disordered use, on the brain.

In this way, a meta-analysis of fMRI studies demonstrated that individuals with IGD showed higher significant activations on certain regions of the prefrontal lobe, compared with healthy controls, revealing dysfunctional reward and self-regulatory 
systems (Meng, Deng, Wang, Guo, \& Li, 2015). Online time was also correlated with alterations in prefrontal lobe. In addition, disturbances on IGD subjects were found in the middle temporal gyrus and fusiform gyrus, similar findings as in other addiction studies.

Several systematic reviews have been carried out about neurobiological correlates in IGD. For instance, Kuss, Pontes \& Griffiths (2018) indicated that gaming addicts, compared to healthy controls, have poorer response-inhibition and emotion regulation, impaired prefrontal cortex (PFC) functioning and cognitive control, poorer working memory and decision-making capabilities, decreased visual and auditory functioning, and a deficiency in their neuronal reward system. Likewise, Weinstein, Livny \& Weizman (2017) showed that IGD individuals displayed alterations in brain regions responsible for the reward mechanism, attention and control, impulse control, decision-making, emotional regulation, motor function and sensory-motor coordination.

Thus, Weinstein \& Lejoyeux, (2015) through a revision on neuroscience studies on IGD concluded that:

- Brain imaging studies of resting state showed that long-term Internet game playing affected regions associated with reward, impulse control and sensory-motor coordination.

- Brain activation studies showed that video game playing involves changes in reward areas and depletion of control regions. There are other regions that may be exclusively altered by playing video games due to cognitive-motor function such as sensory motor areas (SMA and thalamus), vision (occipital lobe), memory (temporal lobe) and attention (cingulate cortex).

- Structural studies showed alteration in the volume of the ventral striatum as a result of changes in reward processes. 
These neurobiological alterations have an impact on cognitive processes. Accordingly, a systematic review (Nuyens, Kuss, Lopez-Fernandez, \& Griffiths, 2017) and a meta-analysis (Argyriou, Davison, \& Lee, 2017) have displayed that IGD players present impaired inhibition and decision-making processes that are improved by IGD treatment (Lim et al., 2016). Apart from these cognitive deficits, IGD is also characterized by cognitive biases such as attentional biases and maladaptive cognitions (Billieux et al., 2020).

On the other hand, the development of biological vulnerabilities for IGD may be predisposed by genetic factors. Reward Deficiency Syndrome (RDS) refers to an absence of usual feelings of satisfaction and a failure of the system that normally confers gratification, leading to addictive behaviors to compensate this deficit. In this line, the Genetic Addiction Risk Score (GARS) model proposed a number of gene variants predisposing for reward deficiency syndrome, focused on dopaminergic genes, and gene variants of methylation and deacetylation (Blum, Oscar-Berman, Demetrovics, Barh, \& Gold, 2014) that might be relevant to test their relationship with substance-related and behavioral addictions (Kotyuk et al., 2018). Thus, few studies have examined the specific role of some genes on disordered gaming. Han et al. (2007) found that adolescents who were excessive Internet game players presented higher prevalence of the Taq1A1 allele of the dopamine D2 receptor, related to reward dependence, and lower Val158Met in the Catecholamine-O-Methyltransferase (COMTL) allele, involved in dopamine degradation. In this line, a lower level of dopamine D2 receptor availability (Kim, Baik, Park, Kim, Choi, \& Kim, 2011) and striatal dopamine transporter (DAT) in the striatum (Hou et al., 2012) are found in Internet addictions. Elevated dopamine increases the responses to rewarding Pavlovian stimuli (De Lecea et al. 2006) and may play an 
important role in the self-reinforcing nature of the addictive process (Di Chiarra and Bassareo, 2007).

Despite not assessing specific genes or environment, quantitative genetic studies, which compare identical and fraternal twins, allow us to know what individual differences (e.g., addictions) are due to, and to what extent, additive genetic influence (hereditary biological characteristics), shared environmental influence (which affect children equally, such as parental education) and non-shared environmental influence (experiences affecting a particular individual, such as the peers group) (Plomin, DeFries, Knopik, \& Neiderhiser, 2013). Thus, the heritability of compulsive Internet use in adolescents (including gaming) was 48 percent, whereas $52 \%$ of the variance was due to non-shared environmental influences (Vink, van Beijsterveldt, Huppertz, Bartels, \& Boomsma, 2016). No differences were found between genders. Thus, the heritability of compulsive Internet use is comparable to the heritability of substance and behavioral addictions, such as in the use and abuse of alcohol (around 40\%, Mezquita, 2011) and gambling and disordered gambling (about 50\%, Xuan et al., 2017).

In conclusion, gaming addiction may be similar to substance related addictions on three levels (Billieux, Deleuze, Griffiths, \& Kuss, 2015). On the level of neural networks, brain alterations appear as a result of excessive gaming engagement. The brain adapts to the perpetual reinforcing stimulation of gaming and becomes desensitized to natural reinforces. On a cognitive level, gaming addiction presents cognitive deficits, including impairments in executive and attention controls. Nevertheless, gaming addiction shows the improvement of some skills such as the integration of perceptual information and hand-eye coordination. Finally, on a biochemical level, gaming engagement has shown to alter neuronal dopamine levels via reductions in dopamine transporter availability that lead to molecular dysfunctions in the dopaminergic system. 


\subsubsection{Comorbidity in disordered gaming}

IGD has been extensively related to externalizing and internalizing symptomatology, especially to ADHD, depression, anxiety, social anxiety and OCD (Andreassen et al., 2016; Kim et al., 2016; Pearcy, McEvoy, \& Roberts, 2017; Starcevic \& Khazaal, 2017; for a comprehensive review, González-Bueso et al., 2018). This tendency has also been replicated in adolescents. Thus, IGD and at risk adolescent gamers showed high scores in Externalizing problems (Aggressive behavior, Rule-Breaking Behavior, Social Problems, and Thought Problems) as well as Internalizing problems (Anxious-depressed, withdrawn-depressed and Somatic complaints) (Müller et al., 2015). Wartberg et al. (2017) found associations between IGD and adolescent antisocial behavior, anger control problems, emotional distress, self-esteem problems and hyperactivity/inattention. Furthermore, Dreier et al. (2017) showed that adolescent players who met the diagnostic criteria for IGD displayed more severe behavioral problems, hyperactivity and emotional problems, as well as higher levels of perceived stress and coping strategies. In this line, adolescent IGD has been related to depressive symptoms as well as to low interpersonal trust and family functioning (Wartberg, Kriston, \& Thomasius, 2020).

Some studies in adolescents and young adults suggest that disordered gaming also co-occurs with other addictions. In this line, Estévez, Jáuregui, Sánchez-Marcos, LópezGonzález, \& Griffiths (2017) showed that video game addiction was mainly related to gambling disorder and, to a lesser extent, drug and alcohol abuse. Poor emotion regulation was a common predictive factor for each addiction, whereas low attachment predicted non-substance related addictions. In addition, another study showed that boys with cannabis, alcohol and nicotine use were almost twice more likely to report high problematic video gaming (van Rooij et al., 2014). However, other studies have shown 
mixed findings. For example, Walther, Morgenstern, \& Hanewinkel (2012) observed that problematic computer gaming co-occurred with problematic gambling and cannabis use but not with tobacco and alcohol use. High impulsivity was associated with every addictive behavior. Furthermore, Desai, Krishnan-Sarin, Cavallo, \& Potenza (2010) displayed that problematic gaming was related to regular smoking and the use of caffeine and "other drugs", finding no relationships with alcohol and marijuana consumption. Regarding multinational samples, people displaying IGD were more likely to use illicit drugs and caffeine but not alcohol (Porter, Starcevic, Berle, \& Fenech, 2010). Therefore, the associations between IGD and drug use is still unclear. Such relationships could perhaps be gender dependent and clearer results may be found in boys (van Rooij et al., 2014). On the other hand, there seems to be a strong relationship between problematic gaming and problematic gambling. In this line, Wood, Gupta, Derevensky, \& Griffiths (2004a) found that adolescent video game use was clearly associated with gambling, with problematic gamblers being more likely to spend an excessive amount of time playing video games. Accordingly, in a sample of athletes, a significant association was found between problematic gaming and problematic gambling (Håkansson, Kenttä, \& Åkesdotter, 2018). Furthermore, disordered gaming has been also related to problematic social networking (Andreassen et al., 2016; Kircaburun, Griffiths, \& Billieux, 2019; Pontes, 2017; Wartberg et al., 2020).

These co-occurrences between addictive behaviors may be explained by common risk factors such as low emotion regulation (Estévez et al., 2017), high impulsivity (Walther et al., 2012), interpersonal problems (Wartberg et al., 2020) or externalizing and internalizing symptomatology (Andreassen et al., 2016; Wartberg et al., 2020); furthermore their severity could be reduced by common protective factors such as practice of mindfulness (Kircaburun et al., 2019). Interestingly, the comorbidity of IGD with other 
addictions such as alcohol use disorder (Na, Lee, Choi, \& Kim, 2017), gambling disorder (Jiménez-Murcia, et al., 2014) or problematic social networking (Pontes 2017) seems to present higher psychopathology problems.

A reduced number of studies have examined the longitudinal associations between disordered gaming and other psychological variables. A 2-year longitudinal study among children showed that lower social competence and greater impulsivity predicted pathological gaming, whereas depression, anxiety, social phobias and lower school performance were consequences of pathological gaming (Gentile et al., 2011). Accordingly, low social competence and emotion regulation at age 8 predicted more IGD symptoms two years later (Wichstrøm, Stenseng, Belsky, von Soest, \& Hygen, 2019). In addition, Mößle \& Rehbein (2013) found that playing in reaction to problems, low academic self-concept and peer problems predicted problematic gaming one year later among school children. The bulk of these kinds of studies have focused on adolescents. Thus, low social competence, low self-esteem and high loneliness predicted pathological gaming six months later whereas loneliness was also a consequence (Lemmens, Valkenburg, \& Peter, 2011a). In addition, higher pathological gaming with violent content predicted physical aggression in boys 6 months later (Lemmens, Valkenburg, \& Peter, 2011b). Video game addiction was related to depression, lower academic performance and conduct problems two years later (Brunborg, Mentzoni, \& Frøyland, 2014). In addition, adolescents from single parent families, with low school well-being and low social integration presented higher video game addiction scores 5 years later (Rehbein \& Baier, 2013). Peeters, Koning \& van den Eijnden (2018) revealed that social vulnerability and attention problems increased problematic gaming one year later. Furthermore, Wartberg, Kriston, Zieglmeier, Lincoln \& Kammerl (2019) showed that hyperactivity/inattention and self-esteem problems were predictors of IGD one year 
before whereas emotional distress was a consequence of IGD. Accordingly, a study with a small sample of young adults suggested that a gamer-avatar relationship could moderate the association between depression and IGD over time (Burleigh, Stavropoulos, Liew, Adams, \& Griffiths, 2018). According to data in children and adolescents, Teng, Griffiths, Nie, Xiang \& Guo (2020) showed a negative bidirectional association between peer attachment and IGD over time among undergraduates. However, in contrast with all these

findings, Scharkow, Festl \& Quandt (2014) found that problematic gaming was not related to changes in psychosocial wellbeing in a 2-year longitudinal study among adolescents and adults.

Therefore, IGD may increase players' emotional and behavioral problems such as depression, whereas the development of IGD may be influenced by low social integration as well as low self-esteem, impulsivity, and attention problems.

\subsubsection{What makes video games addictive?}

The structural characteristic of video games may play an important role in the initiation, development and maintenance of problem video playing, just as gambling addiction. Fisher and Griffiths (1995) argued that both video games and gambling machines have similar features: the requirement of response to stimuli that are predictable and governed by a software loop, the requirement of total concentration and hand-eye coordination, rapid span of play negotiable to some extent by the skill of the player, the provision of aural and visual rewards for a win, the provision of an incremental reward for a winning move, digitally displayed scores of 'correct' behavior, and the opportunity for peer group attention and approval through competition. Nevertheless, these activities present aspects that distinguish each one. Thus, video gaming is characterized by interactivity, skill-based play and contextual indicators of progression and success, whereas gambling is defined by betting and wavering mechanics, chance determined 
outcomes and monetization features (King, Gainsbury, Delfabbro, Hing, \& Abarbanel, 2015).

Wood, Griffiths, Chappell \& Davies (2004b) were the first to publish a framework of the psycho-structural features of video games to identify the most appealing features for players. Later, King, Delfabbro \& Griffiths (2010) expanded this Wood et al.'s (2004b) psycho-structural features list (see Figure 1). They organized the characteristics in five main clusters: social features (social aspects of the video game), manipulation and control features (the ways that the player interacts with and controls in-game properties), narrative and identify features (the ways in which the player can take on another character in the game), reward and punishment features (the ways in which players are reinforced for winning and punished for losing), and presentation features (aesthetic qualities of the video game). 


$\begin{array}{lll}\text { Feature type } & \text { Sub-features } & \text { Example } \\ \text { Social features } & \text { Social utility features } & \text { In-game voice and text chat } \\ & \text { Social formation/institutional features } & \text { Guilds/clans in MMORPGs } \\ & \text { Leader board features } & \text { "Hall of fame" high score list } \\ & \text { Support network features } & \text { Internet forums, strategy guides } \\ \text { Manipulation and control features } & \text { User input features } & \text { "Combos", "hot keys" } \\ & \text { Save features } & \text { Checkpoints, "quick-save" } \\ & \text { Player management features } & \text { Managing multiple resources } \\ & \text { Non-controllable features } & \text { Scripted events, loading screens } \\ \text { Narrative and identity features } & \text { Avatar creation features } & \text { Choice of sex, race, attributes } \\ & \text { Storytelling device features } & \text { Cut-scenes, mission briefing } \\ & \text { Theme and genre features } & \text { "Role-playing", "shooting" } \\ \text { Reward and punishment features } & \text { General reward type features } & \text { Experience points, bonuses } \\ & \text { Punishment features } & \text { Losing a life, restarting a level } \\ & \text { Meta-game reward features } & \text { Xbox 360 Achievement points } \\ \text { Intermittent reward features } & \text { Increasing difficulty of levels } \\ \text { Negative reward features } & \text { Gaining health, repairing items } \\ \text { Near miss features } & \text { Difficult "boss" at end of level } \\ & \text { Event frequency features } & \text { Unlimited replayability of game } \\ \text { Event duration features } & \text { MMORPGs have no endpoint } \\ & \text { Payout interval features } & \text { Rewarded instantly for playing } \\ \text { Graphics and sound features } & \text { Realistic graphics, fast music } \\ \text { Franchise features } & \text { Trademarked names, e.g. Mario } \\ & \text { Explicit content features } & \text { Violence, drug use, nudity } \\ & \text { In-game advertising features } & \text { Real-life brands, sponsors logos } \\ & & \\ & & \end{array}$
2010).

Figure 1. Psycho-structural factors of video games (extracted from King et al.,

Players with problematic tendencies were more likely to look for games characterized by reward and social features (King et al., 2010; Hull, Williams, \& Griffiths, 2013). In line with these findings, players at risk of suffering addiction reported significantly higher enjoyment on highly time-consuming features (e.g. earning points, levelling up, getting $100 \%$ in the game, ...) and also cooperative elements of social features (Király et al., 2015a). Therefore, players are rewarded intermittently through partial reinforcement effects, being an important mechanism that can generate a persistent in-game behavior despite suffering negative consequences. Accordingly, in-game positive reinforcement was related to a higher propensity to continue and return to play, 
whereas in-game negative reinforcement, defined as a game condition that was more difficult and involves more challenges leading to more failure experiences, was related to frustration (Chumbley \& Griffiths, 2006). However, such negative reinforcement features were not associated with the termination of play. Other experimental studies have found how in-game reward characteristics influence players' moods and feelings (Larche, Musielak, \& Dixon, 2017; Reiten et al., 2018).

\subsubsection{The most addictive game genres}

Some video games may be more addictive than others due to their own structural characteristics. In this way, Internet games appear to have higher addictive potential than offline games (Kuss \& Griffiths, 2012b; Lemmens \& Hendriks, 2016; Rehbein, Kleimann, \& Mößle, 2010; Schmidt et al., 2011; van Rooij et al., 2014). In this manner, MMORPGs are the kind of video games more frequently found related to disordered gaming (Subramaniam et al., 2016). Thus, MMROPG players present high IGD prevalence, for instance, 27.5\% (Achab et al., 2011) or 39\% (Charlton \& Danforth, 2007). Therefore, MMROPG may present some structural characteristics that make them so addictive (Billieux et al., 2015): 1) a persistent world that exists independently of the players and may compel players to play),2) the advancement that derives from collecting new powers or skills and items by the avatar as rewards for succeeding in missions; and 3) social interaction, in the game, communication is easily produced among players through written chat or audio, in addition players can meet themselves in guilds with common objectives and backgrounds. Moreover, these kinds of games allow gamers to escape from their real world problems by the immersion in a fantasy world, adopting the role of a character. In this sense, addicted players are more proud of their avatars (Smahel, Blinka, \& Ledabyl, 2008) and feel a higher identification with their avatars' body (Liew, Stavropoulos, Adams, Burleigh, \& Griffiths, 2018). 
Apart from MMROPGs, other Massively Multiplayer Online games (MMOs) have been frequently related to disordered gaming such as First Person Shooter (FPS) (Elliot et al., 2012; Festl, Scharkow, \& Quandt, 2013; Kim et al., 2016; Lemmens \& Hendriks, 2016; Männikkö et al., 2017; Mößle \& Rehbein, 2013; Müller et al., 2015) and Multiplayer Online Battle Online Arena (MOBA) (Eichenbaum, Kattner, Bradford, Gentile, \& Green, 2015; Fuster et al., 2016; Kim et al., 2016; Männikkö et al, 2017; Müller et al., 2015). Deleuze, Christiaens, Nuyens \& Billieux (2017) compared the structural characteristics of these 3 MMO games (see Figure 2). Thus, similar features were shared among MMO games such as achievement components and social aspects.

\begin{tabular}{|c|c|c|}
\hline $\begin{array}{l}\text { Massively multiplayer online role-playing game } \\
\text { (MMORPG) }\end{array}$ & Multiplayer online battle arena (MOBA) & Online first person shooter (online FPS) \\
\hline Persistent virtual worlds & Achievement (with rankings) & Action, precision, reflexes \\
\hline Advancement system & Social aspects (cooperation and battles PvP) & Competition and cooperation \\
\hline Achievement (quests, battles, events) & Short and intense play sessions & $\begin{array}{l}\text { Achievement (defeating the enemy, accomplishing } \\
\text { missions, reaching objectives) }\end{array}$ \\
\hline $\begin{array}{l}\text { Exploration and immersion (virtual worlds, lore, } \\
\text { stories) }\end{array}$ & Necessity to play regularly (to maintain level/ranking) & Rewards (better items and weapons) \\
\hline $\begin{array}{l}\text { Social aspects (competition, cooperation, creation of } \\
\text { guilds) }\end{array}$ & $\begin{array}{l}\text { eSport (broadcast of international tournament, millions } \\
\text { of viewers) }\end{array}$ & eSport \\
\hline
\end{tabular}

Note: $\mathrm{PvP}=$ player versus player.

Figure 2. Comparison of structural characteristics of the 3 main MMO games (extracted from Deleuze et al., 2017).

\subsubsection{Models for disordered gaming}

Certain psychological models have been developed in order to explain disordered gaming. Some of them have been proposed under a cognitive-behavioral approach (Dong \& Potenza, 2014; Haagsma, Caplan, Peters, \& Pieterse; 2013) in which impairments in reward sensation, decision making and executive control contribute to IGD and vice versa (see Figure 3). Therefore, IGD individuals may present enhanced reward sensitivity and 
decreased loss sensitivity, reduced response-inhibition and cognitive-control tendencies; as well as decision making deficits.

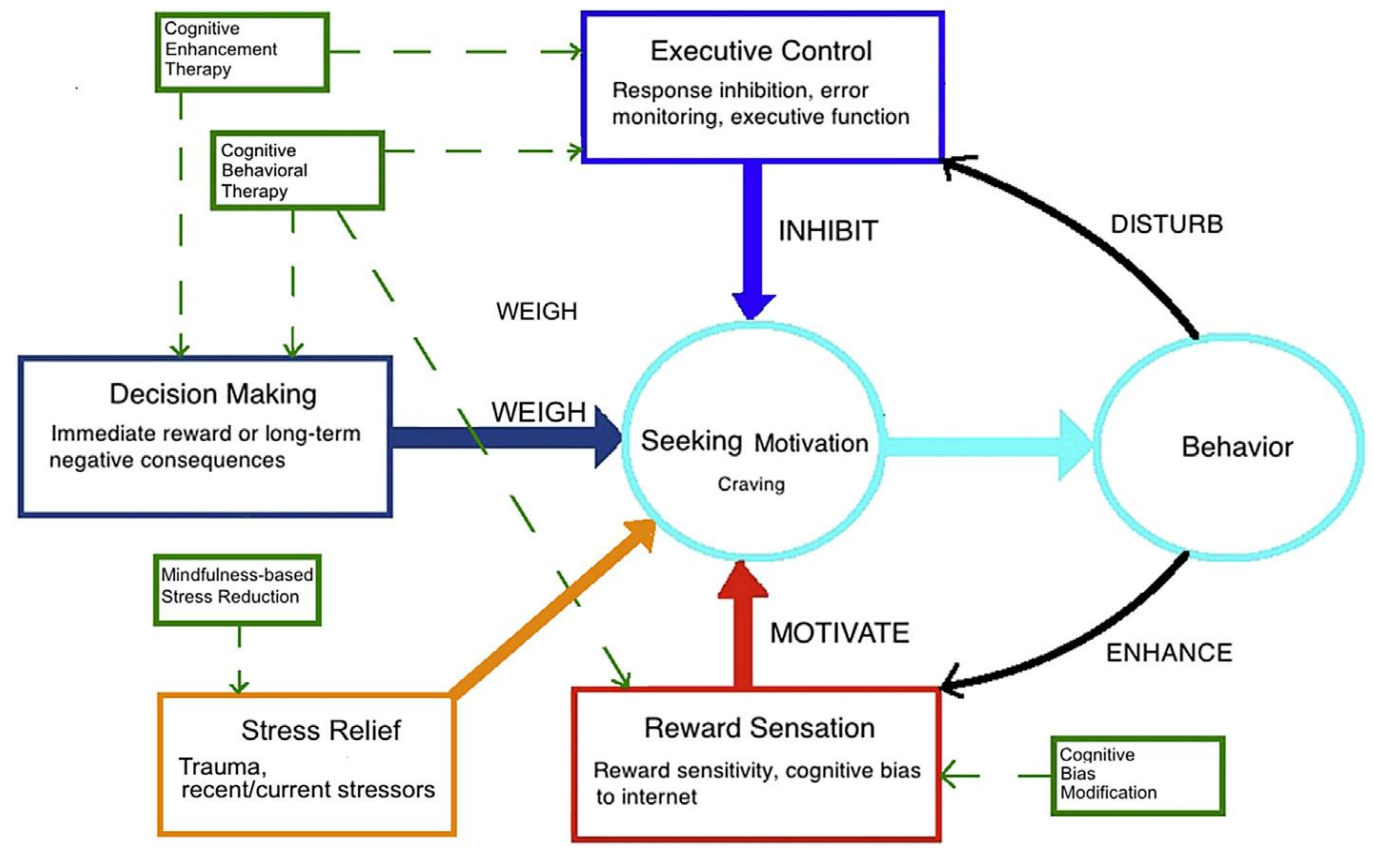

Figure 3. A cognitive-behavioral model of IGD. This figure shows proposed cognitive domains associated with IGD. The model focuses on three cognitive domains and their possible roles in addictive behaviors. The three domains include motivational drives related to reward-seeking and stress reduction, behavioral control relating to executive inhibition, and decision-making that weighs the consequences of engaging in motivated behaviors. Online gaming behaviors might further disturb executive control and reinforce rewarding online experiences, which may lead to a vicious cycle of addictive Internet game-playing. The contents framed in green boxes show potential psychological and cognitive treatments for IGD. Dashed lines indicate potential targets of intervention strategies, with further studies needed to investigate efficacies and possible mechanisms of action (extracted from Dong \& Potenza, 2014).

Other models display interactions between biological, psychological and social variables in the development of disordered gaming (Brand, Young, Laier, Wölfling \& Potenza, 2016; Dreier, Wölfling \& Müller, 2013; Paulus et al., 2018).

For instance, Brand, Young, Laier, Wölfling \& Potenza (2016) postulated an Interaction of Person-Affect-Cognition-Execution (I-PACE) model to explain the development and maintenance of specific Internet-use disorders in which the following components are considered (see Figure 4): 
The P-component of the model. Predisposition variables (biopsychological factors, psychopathological features, personality traits, social cognitions and motives) contribute to a person's core characteristics which make them more vulnerable to suffer Internet-use disorders.

The A- and C-components of the model. Internal and external stimuli may be conditioned within an addiction process. Therefore, stimuli (e.g. cues or withdrawal) may trigger affective and cognitive processes (e.g. craving or urge for mood regulation) resulting in the decision to use the Internet application/site of choice.

The E-component of the model. Reductions in executive functions are present in individuals with Internet-use disorders. Thus, a dysfunctional interaction between poor executive control and an accelerated reward-seeking disruption may promote disadvantageous decision-making, by seeking a short-term attractive behavior despite negative long-term consequences.

Due to the addictive process, the addictive behavior becomes habitual and/or compulsive, resulting in negative consequences in life. Thus, whereas the level of experienced gratification decreases, the level of compensating effects increases to cope with those negative consequences. 


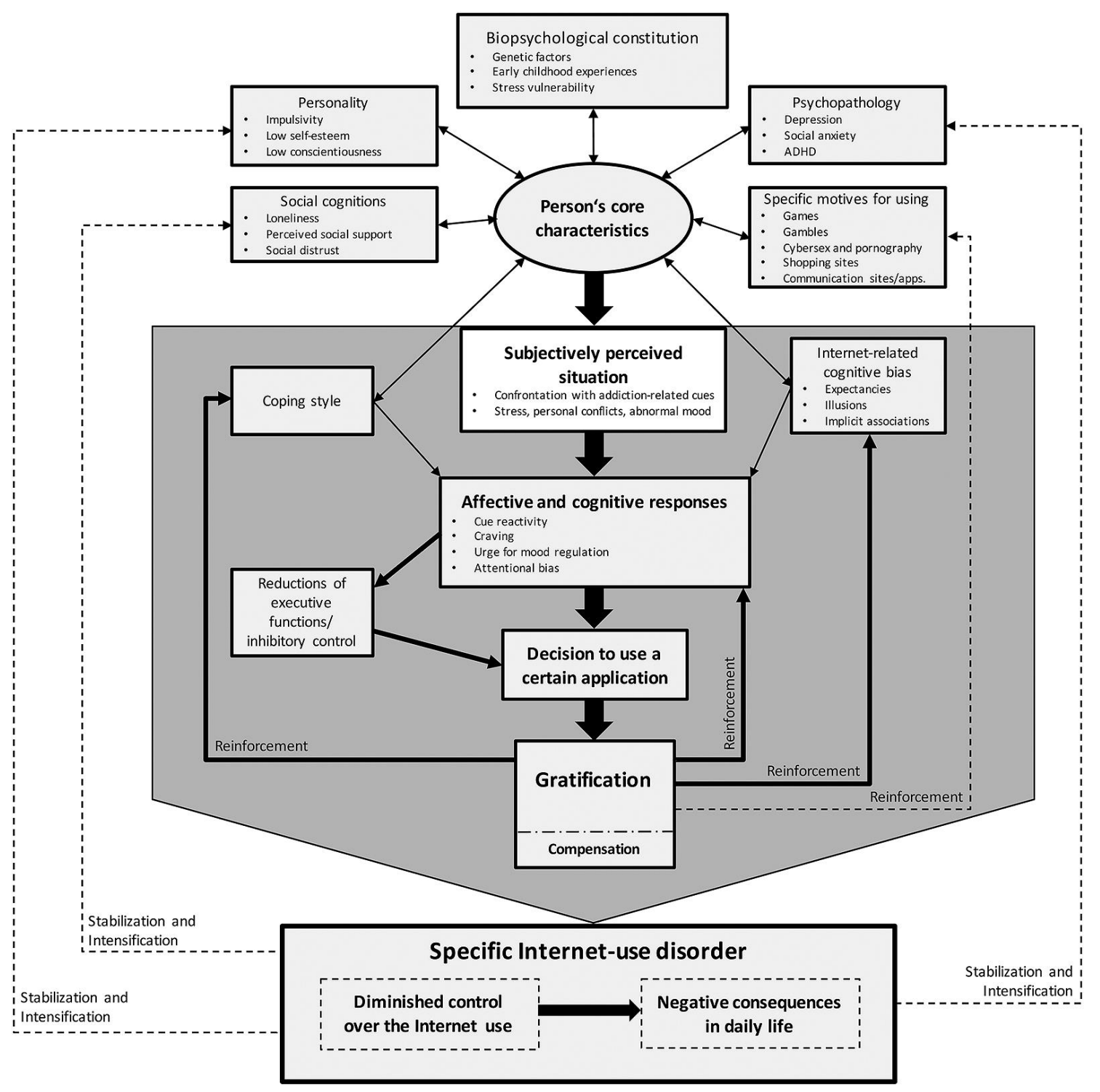

Figure 4. An Interaction of I-PACE for specific Internet Use disorders (extracted from Brand et al., 2016).

The authors suggested that treatments should primarily address moderating and mediating variables such as coping styles because vulnerability factors may be relatively stable.

Likewise, Dreier, Wölfling \& Müller (2013) proposed a multidisciplinary etiopathogenetic model where personality and motivations, the two variables in which the current thesis is focused, present a crucial role for the development of disordered gaming (see Figure 5). Thus, higher neuroticism, as well as lower conscientiousness and 
extraversion are considered risk factors. In addition, personality may also play an important role when gamers feel attracted to video games. Therefore, personality may have an impact in the development of motivations to play, such as coping, escapism, socialization or role-playing, what would produce a higher in-game engagement.

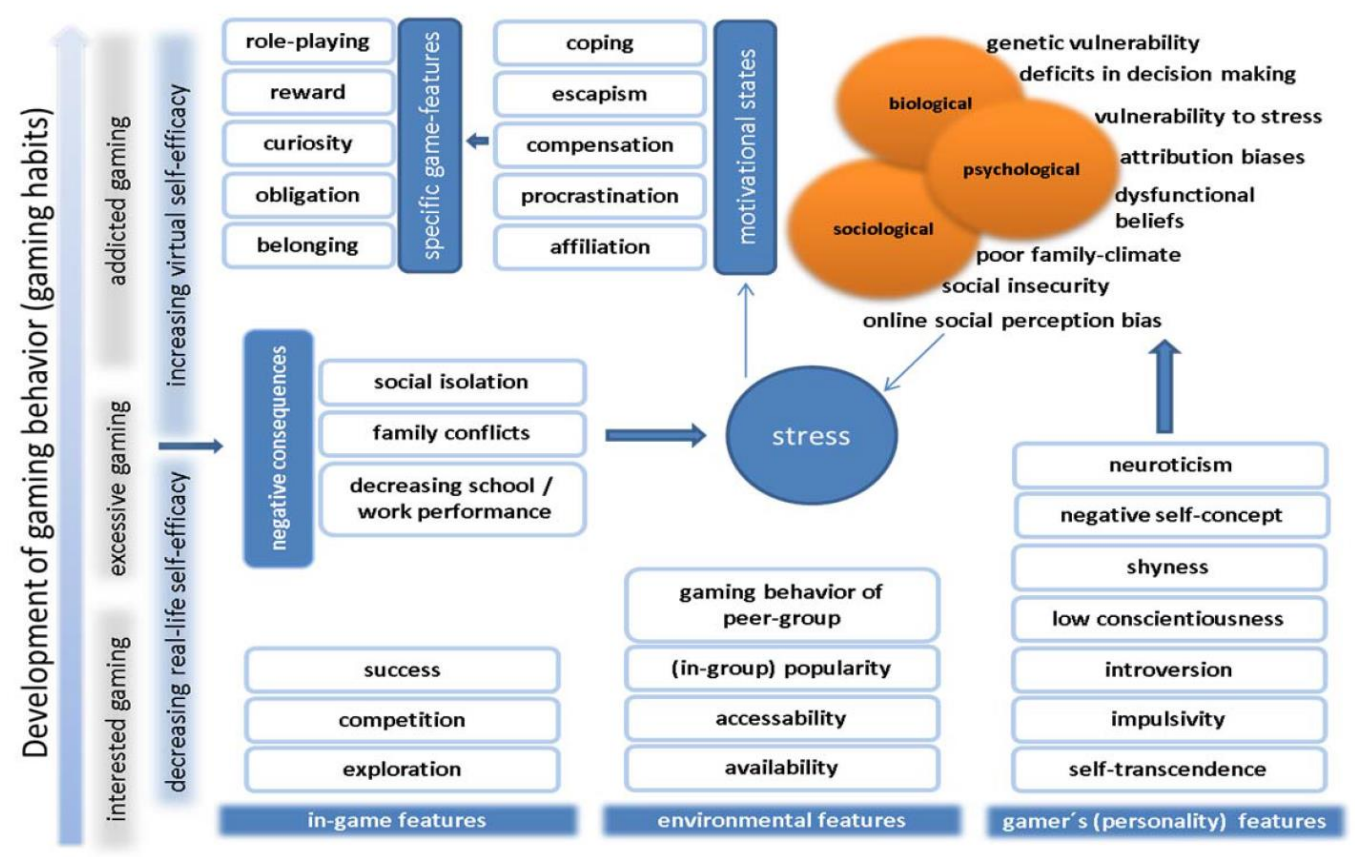

Figure 5. Variables affecting the development of gaming habits (extracted from Dreier et al., 2013).

In conclusion, the models show the relevance of studying the impact of psychological variables (such as personality or motives) on disordered gaming, because they represent potential targets where prevention and treatment can act. 


\subsection{Personality}

Personality is defined as the relatively stable and consistent organization of affective and cognitive dispositions that exhibit behavioral tendencies and determines a characteristic adaptation to a single environment (Eysenck \& Eysenck, 1985). The Five Factor Model (FFM) is currently the most agreed model by personality psychologists (John et al., 2008), with Costa \& McCrae (1992)'s categorization being the most accepted (de Raad \& Perugini, 2002). This model states that personality dimensions exist in language and proposes a taxonomy of personality based on it. Thus, such factors would reflect the way in which people describe themselves and others. Costa \& McCrae's model presents five personality dimensions: neuroticism, extraversion, openness to experience, agreeableness and conscientiousness; each one composed by 6 facets (see Table 1).

Table 1. Dimensions and facets of FFM (Costa \& McCrae. 1992).

\begin{tabular}{|c|c|c|c|c|c|}
\hline \multirow[t]{4}{*}{ Factors } & Neuroticism & Extraversion & Openness & Agreeableness & Conscientiousness \\
\hline & - Anxiety & - Warmth, & - Fantasy & - $\quad$ Trust & - Competence \\
\hline & - Angry Hostility & - Gregariousness & - Aesthetics & - $\quad$ Straightforwardness & - $\quad$ Order \\
\hline & - Depression & - Assertiveness & - Feelings & - $\quad$ Altruism & - Dutifulness \\
\hline \multirow{5}{*}{$\underset{\tilde{E}}{\mathbb{\Xi}}$} & - Self-Consciousness & - Activity & - Actions & - Compliance & - Achievement \\
\hline & - Impulsiveness & - Excitement- & - $\quad$ Ideas & - Modesty & Striving \\
\hline & - Vulnerability & Seeking & - Values & - $\quad$ Tender-mindedness & - $\quad$ Self-Discipline \\
\hline & & - Positive & & & - Deliberation \\
\hline & & Emotions & & & \\
\hline
\end{tabular}

Neuroticism is defined as a proneness to suffer unpleasant feelings such as nervousness, anxiety or sadness. Extraversion describes a tendency to be thrill-seekers, feel positive emotions and be sociable. Openness to experience is characterized by the tendency toward curiosity, creativity and seeking for new and varied experiences. Agreeableness is defined as a tendency to cooperate with others rather than compete. 
Agreeable people tend to be altruistic and empathetic. Finally, conscientiousness is characterized by self-discipline, along with a tendency toward being organized and acting dutifully.

From a biological approach, Eysenck \& Eysenck (1985) proposed three basic biological dimensions of personality: extraversion, including aspects of sociability, sensation seeking and positive emotiveness; neuroticism, based on negative emotiveness; and psychoticism, the disposition to be impulsive, aggressive and unempathetic. Later, Gray (1991) and Gray \& McNaughton (2000) established a neuropsychological model of personality according to the Reinforcement Sensitivity Theory. Thus, three basic neuroemotional systems emerge to explain individual differences in personality traits and consequently in human behavior (for one empirical example, López Fernández \& Avila; 2017): the Behavioral Inhibition System related to neuroticism, the Behavioral Activation System associated with extraversion and impulsivity facets (Smilie, Pickering, \& Jackson, 2006); and the Fight/Flight System.

Thus, personality models from different approaches present a high convergence displaying a hierarchical structure of personality (Markon, Krueger, \& Watson, 2005).

\subsubsection{Personality and video gaming behaviors}

Research has shown the significant role of personality on disordered gaming (for some systematic reviews, see Gervasi et al., 2017; Mihara \& Higuchi, 2017; Paulus et al., 2018; Şalvarlı \& Griffiths, 2019). Apart from that, personality displays relevant relationships with being a regular player (Braun et al., 2016; Teng, 2008; Witt, Massman, \& Jackson, 2010), as well as preferences in video game genre (e.g., Braun et al., 2016), styles of playing (e.g., Bean \& Groth-Marnat, 2016), in-game behaviors (Yee, Ducheneaut, Nelson, \& Likarish; 2011) and motives to play (e.g., Graham \& Gosling, 2013). 
A great number of studies have examined the role of FFM dimensions on disordered gaming, mainly in adults (see Table 2). Accordingly, studies have shown that adult pathological gaming is mainly related to higher neuroticism (Braun et al., 2016; Charlton \& Danforth, 2010; Cole \& Hooley, 2013; Jeong et al., 2015; Lehenbauer-Baum et al., 2015; Montag et al., 2011; Müller et al., 2014; Peters \& Malesky, 2008; Wittek et al., 2016) and lower conscientiousness (Andreassen et al., 2013; Braun et al., 2016; Lehenbauer-Baum et al., 2015; Montag et al., 2011; Müller et al., 2014; Peters \& Malesky, 2008; Wittek et al., 2016). Furthermore, disordered use has inconsistently been related to low extraversion (Braun et al., 2016; Cole \& Hooley, 2013; Montag et al., 2011; Müller et al., 2014; Peters \& Malesky, 2008) as well as low agreeableness (Collins, Freeman, \& Chamarro-Premuzick, 2012; Lehenbauer-Baum et al., 2015; Montag et al., 2011; Peters \& Malesky, 2008).

With regard to adolescents, the association between FFM traits and disordered gaming has been scarcely explored. At these ages, disordered gaming has been related to low conscientiousness (García-Oliva \& Piqueras, 2016; Vollmer et al., 2014; Wang et al., 2015) and low extraversion (García-Oliva \& Piqueras, 2016; Vollmer et al., 2014). In addition, low agreeableness, high neuroticism (Vollmer et al. 2014) and low openness (Wang et al. 2015) displayed inconsistent findings. Therefore, further research in adolescence, where the highest pathological gaming prevalence is observed, should be carried out. Furthermore, the relationships between pathological gaming and personality could be moderated by gender. As far as we know, only one study tested this, finding no significant associations in girls (García-Oliva \& Piqueras, 2016).

Apart from its pathological use, some studies have examined the impact of personality on video gaming frequency and gamers' profiles. Thus, inconsistent results are found, Braun et al. (2016) displayed that regular players showed lower neuroticism 
and lower conscientiousness compared to non-players. Potard et al. (2019) found that daily players reported lower levels of extraversion and conscientiousness than less frequent players. On the other hand, another study focused on online gaming displayed that players compared to non-players showed a relationship with higher extraversion, openness and conscientiousness (Teng, 2008).

With regard to associations between personality and video game genre preferences, just a couple of studies have checked this issue systematically. In this sense, higher neuroticism has been related to higher use of action adventure games (Potard et al., 2019); in addition, higher extraversion was associated with sport and action games (Braun et al., 2016; Potard et al., 2019) whereas introversion displayed relationships with RPG and FPS (Potard et al., 2019). On the other hand, openness has been related to RPGs and negatively to sports and FPS (Braun et al., 2016; Potard et al., 2019). Finally, low conscientiousness presented significant associations with the following video game genres: action adventure, RPG, strategy and FPS (Potard et al., 2019).

Table 2. Studies of personality (FFM) and disordered gaming

\begin{tabular}{|c|c|c|c|c|}
\hline Study & $\begin{array}{l}\text { Sample ( } \mathrm{n} \text { and } \\
\text { description) }\end{array}$ & FFM assessment & $\begin{array}{l}\text { Kinds of } \\
\text { games }\end{array}$ & Findings \\
\hline $\begin{array}{l}\text { Lehenbauer- } \\
\text { Baum et al. } \\
(\mathbf{2 0 1 5})\end{array}$ & $\begin{array}{l}682 \text { participants } \\
\text { (mean age of } \\
23.26 \text { years; } \\
84.9 \% \text { male), } \\
\text { ranged from } 16 \\
\text { to } 51 \text { years. }\end{array}$ & $\begin{array}{l}\text { The Big-Five } \\
\text { Inventory with } 10 \\
\text { items (BFI-10) }\end{array}$ & WoW & $\begin{array}{l}\text { After comparing } \\
\text { engaged and addicted } \\
\text { players, addicted players } \\
\text { showed lower scores of } \\
\text { conscientiousness and } \\
\text { agreeableness; and } \\
\text { higher levels of } \\
\text { neuroticism }\end{array}$ \\
\hline $\begin{array}{l}\text { Müller et al. } \\
(2014)\end{array}$ & $\begin{array}{l}115 \text { patients } \\
\text { meeting the } \\
\text { criteria for IGD } \\
\text { compared to } 167 \\
\text { control subjects }\end{array}$ & $\begin{array}{l}\text { NEO } \quad \text { Five-Factor } \\
\text { Inventory (60 items) }\end{array}$ & - & $\begin{array}{l}\text { IGD was associated with } \\
\text { higher neuroticism and } \\
\text { lower conscientiousness } \\
\text { and extraversion }\end{array}$ \\
\hline $\begin{array}{l}\text { Peters and } \\
\text { Malesky } \\
(\mathbf{2 0 0 8 )}\end{array}$ & $\begin{array}{l}196 \text { participants } \\
\text { (173 males) aged } \\
\text { ranged from } 18 \text { to } \\
43 \text {, with a mean }\end{array}$ & $\begin{array}{l}\text { 50-question short } \\
\text { version of Mc-Cord's } \\
\text { M5 Questionnaire, (an } \\
\text { adaptation of the NEO }\end{array}$ & WoW & $\begin{array}{lr}\text { One factor } & \text { of } \\
\text { problematic } & \text { usage- } \\
\text { engagement } & \text { was } \\
\text { extracted and } & \text { was } \\
\text { correlated to low } \\
\text { agreeableness, } & \text { low }\end{array}$ \\
\hline
\end{tabular}




\begin{tabular}{|c|c|c|c|c|}
\hline & $\begin{array}{l}\text { of 24.34, }(\mathrm{SD}= \\
5.36)\end{array}$ & $\begin{array}{l}\text { Personality Inventory- } \\
\text { Revised-NEO-PI-R). }\end{array}$ & & $\begin{array}{ll}\text { extraversion, } & \text { low } \\
\text { conscientiousness } & \text { and } \\
\text { high neuroticism } & \end{array}$ \\
\hline $\begin{array}{l}\text { Vollmer, } \\
\text { Randler, } \\
\text { Horzum \& } \\
\text { Ayas }(2014)\end{array}$ & $\begin{array}{l}741 \text { adolescents } \\
(60.2 \% \text { males), } \\
\text { aged ranged } \\
\text { from } 11 \text { to } 16, \\
\text { with a mean age } \\
\text { of } 12.89 \text { (SD = } \\
1.05)\end{array}$ & $\begin{array}{l}\text { The BIG-5 Inventory } \\
\text { (10 items) }\end{array}$ & - & $\begin{array}{l}\text { Computer game } \\
\text { addiction was related to } \\
\text { low agreeableness, high } \\
\text { neuroticism and low } \\
\text { extraversion }\end{array}$ \\
\hline $\begin{array}{l}\text { Jeong, Lee \& } \\
\text { Yoo, (2015) }\end{array}$ & $\begin{array}{l}789 \text { participants } \\
\text { ranged from } 16 \\
\text { to } 59 \quad(50.1 \% \\
\text { males) }\end{array}$ & $\begin{array}{l}\text { 44-item Big Five } \\
\text { Inventory -BFI- }(9 \\
\text { items for each of the } \\
\text { following dimensions: } \\
\text { extraversion, } \\
\text { conscientiousness and } \\
\text { agreeableness; } 10 \\
\text { items for openness; } \\
\text { and } 8 \text { for neuroticism) }\end{array}$ & - & $\begin{array}{lr}\text { Game addiction } & \text { was } \\
\text { associated } & \text { with } \\
\text { neuroticism } & \end{array}$ \\
\hline $\begin{array}{l}\text { Wittek et al. } \\
(2016)\end{array}$ & $\begin{array}{l}3,389 \\
\text { participants, } \\
\text { aged } 16 \quad-74 \\
\text { years } \\
\text { females, } \quad(1351 \\
\text { age }=32.6 \text { years })\end{array}$ & $\begin{array}{l}\text { The Mini International } \\
\text { Item Pool -Mini-IPIP- } \\
\text { (20 items) }\end{array}$ & - & $\begin{array}{l}\text { Video game addiction } \\
\text { was negatively related to } \\
\text { conscientiousness and } \\
\text { positively to neuroticism }\end{array}$ \\
\hline $\begin{array}{l}\text { Braun, } \\
\text { Stopfer, } \\
\text { Müller, } \\
\text { Beutel \& } \\
\text { Egloff (2016) }\end{array}$ & $\begin{array}{l}2,891 \\
\text { participants } \\
(2421 \text { males }) \\
\text { between } 12 \text { and } \\
65 \text { years }(\mathrm{M}= \\
23.2, \mathrm{SD}=5.99)\end{array}$ & $\begin{array}{l}\text { The Big Five Inventoy- } \\
\text { SOEP-BFI-S- } \\
\text { items })\end{array}$ & - & $\begin{array}{l}\text { Comparing non-gamers, } \\
\text { regular gamers and } \\
\text { gaming addicts, gaming } \\
\text { addicts have higher } \\
\text { scores of neuroticism } \\
\text { and lower of } \\
\text { extraversion } \\
\text { conscientiousness }\end{array}$ \\
\hline $\begin{array}{l}\text { Garcia-Oliva } \\
\& \quad \text { Piqueras } \\
(2016)\end{array}$ & $\begin{array}{l}317 \text { participants } \\
\text { aged between } 12 \\
\text { and } 18 \text { years } \\
(51.4 \% \text { males }) \\
\text { with a mean age } \\
\text { of } 16.64 \text { years } \\
(\mathrm{SD}=1.73)\end{array}$ & $\begin{array}{l}\text { A Spanish adaptation } \\
\text { of the Ten-Item } \\
\text { Personality Inventory } \\
\text {-TIPI- (10 items) }\end{array}$ & - & $\begin{array}{l}\text { Video game addiction } \\
\text { was associated with low } \\
\text { conscientiousness and } \\
\text { low extraversion. }\end{array}$ \\
\hline $\begin{array}{ll}\text { Wang, Ho, } \\
\text { Chan \& } & \text { Tse } \\
(2015) & \end{array}$ & $\begin{array}{l}920 \text { secondary } \\
\text { school } \\
\text { participants } \\
(36.6 \% \text { males }) \\
\text { with a mean age } \\
\text { of } 15.03 \text { years }\end{array}$ & $\begin{array}{l}\text { The } 10 \text {-item short } \\
\text { version of the Big Five } \\
\text { Inventory }\end{array}$ & - & $\begin{array}{ll}\text { Gaming addiction } & \text { was } \\
\text { related to } & \text { low } \\
\text { conscientiousness } & \text { and } \\
\text { low openness } & \end{array}$ \\
\hline $\begin{array}{l}\text { Andreassen et } \\
\text { al. (2013) }\end{array}$ & $\begin{array}{l}218 \\
\text { undergraduate } \\
\text { participants }(45 \\
\text { males) with a } \\
\text { mean age of } 20.7 \\
\text { years }(\mathrm{SD}=3)\end{array}$ & $\begin{array}{l}\text { The Revised NEO } \\
\text { Five-Factor Inventory- } \\
\text { Revised-NEO-FFI-R- } \\
(60 \text { items) }\end{array}$ & - & $\begin{array}{l}\text { Video game addiction } \\
\text { was associated with low } \\
\text { conscientiousness }\end{array}$ \\
\hline
\end{tabular}




\begin{tabular}{|c|c|c|c|c|}
\hline $\begin{array}{lr}\text { Cole } & \& \\
\text { Hooley } & (2013)\end{array}$ & $\begin{array}{l}163 \text { participants } \\
(92 \text { males }) \text { with a } \\
\text { mean age of } 27.3 \\
\text { years }(S D=9.1)\end{array}$ & $\begin{array}{l}\text { The NEO Personality } \\
\text { Inventory-Revised ( } 60 \\
\text { items) }\end{array}$ & $\begin{array}{l}\text { MMO } \\
\text { games }\end{array}$ & $\begin{array}{l}\text { Compared two groups } \\
\text { (high vs low problematic } \\
\text { Internet use), high } \\
\text { problematic group } \\
\text { showed higher levels of } \\
\text { introversion and } \\
\text { neuroticism }\end{array}$ \\
\hline $\begin{array}{l}\text { Montag et al. } \\
\text { (2011) }\end{array}$ & $\begin{array}{l}610 \text { participants } \\
(592 \text { males }) \text { with } \\
\text { a mean age of } \\
19.32 \text { (SD }= \\
4.40)\end{array}$ & $\begin{array}{l}\text { The NEO Five-Factor } \\
\text { Inventory (NEO-FFI; } \\
60 \text { items) }\end{array}$ & FPS & $\begin{array}{l}\text { Internet addiction was } \\
\text { strongly corelated to low } \\
\text { conscientiousness and } \\
\text { high neuroticism. In } \\
\text { addition, to a lesser } \\
\text { degree, significant } \\
\text { relationships were found } \\
\text { between Internet } \\
\text { addiction and low } \\
\text { agreeableness, low } \\
\text { extraversion and low } \\
\text { openness }\end{array}$ \\
\hline $\begin{array}{l}\text { Collins, } \\
\text { Freeman \& } \\
\text { Chamarro- } \\
\text { Premuzick } \\
(2012)\end{array}$ & $\begin{array}{l}225 \text { participants } \\
(129 \text { males }) \text { ages } \\
\text { ranged from } 13 \\
\text { to } 60(\mathrm{M}=26.55, \\
\mathrm{SD}=9.48) 66 \\
\text { played } \\
\text { MMORPGs }\end{array}$ & $\begin{array}{l}\text { The International } \\
\text { Personality Item Pool } \\
\text { (IPIP) Big-Five Factor } \\
\text { Markers questionnaire } \\
\text { (50 items) }\end{array}$ & MMORPGs & $\begin{array}{l}\text { Comparing problematic } \\
\text { and non-problematic } \\
\text { players, problematic } \\
\text { players depicted lower } \\
\text { agreeableness }\end{array}$ \\
\hline $\begin{array}{l}\text { Charlton \& } \\
\text { Danforth } \\
(2010)\end{array}$ & $\begin{array}{l}388 \text { participants } \\
(86 \% \text { males }) \\
\text { aged from } 18 \text { to } \\
67(\mathrm{M}=29.27 \\
\mathrm{SD}=8.74)\end{array}$ & $\begin{array}{l}\text { The International } \\
\text { Personality Item Pool } \\
\text { (IPIP) extraversion, } \\
\text { agreeableness and } \\
\text { emotional stability } \\
\text { were assessed } \\
\text { (altogether } 30 \text { items) }\end{array}$ & MMORPGs & $\begin{array}{l}\text { Addiction scores were } \\
\text { associated with low } \\
\text { emotional stability }\end{array}$ \\
\hline
\end{tabular}

\subsection{Motives to play video games}

Different approaches have been employed in the categorization of gaming motivations in which motives appear in order to satisfy psychological needs through playing. For instance, the uses and gratification theory (Sherry et al., 2006), the selfdetermination theory, SDT (Ryan, Rigby, \& Przybylski, 2006), the needs theory of humanistic psychology (Wan \& Chiou, 2006) and the social cognitive theory (De Grove, Cauberghe, \& Van Looy, 2016). Apart from that, other empirical studies aimed to develop video game motivations scales (see Table 3). For instance, based on Bartle's (1996) types of Multi-User Dungeon players, Yee (2006a) conducted a large survey on a sample of 
MMORPG players in order to identify their motivations. As a result, three categories of motivations comprising ten subcategories were formulated: achievement (advancement, mechanics and competition), social (socializing, relationship, and teamwork), and immersion (discovery, role-playing, customization, and escapism). Furthermore, together with Yee's (2006a), another scale frequently used in research is the motives for online gaming questionnaire (MOGQ) from Demetrovics et al. (2011). This scale, focused on online games, displays the following motivations: escape, coping, fantasy, skill development, recreation, competition and social.

Despite the high number of studies on development of gaming motivations scales, the research presents some limitations. First, a great number of studies have focused on specific games or genres such as MMORPGs, and more importantly, different labeling and different numbers of dimensions for similar motivational components have been found across motive scales studies (see Table 3), which ultimately impedes comparisons between studies.

Table 3. Studies of video games motivational scales

\begin{tabular}{|c|c|c|c|c|}
\hline Study & $\begin{array}{c}\text { Sample } \\
\text { Information }\end{array}$ & $\begin{array}{c}\text { Kind of } \\
\text { video games }\end{array}$ & Motivations (items examples) & $\begin{array}{c}\text { Total } \\
\text { number } \\
\text { of items }\end{array}$ \\
\hline Yee (2006a) & $\begin{array}{l}\mathrm{n}=3,000 \\
92.3 \% \text { males } \\
\text { mean age }=26\end{array}$ & MMORPG & $\begin{array}{l}\text { Achievement: } \\
\text { Advancement } \\
\text { (e.g., "How important is it for you } \\
\text { to become powerful?") } \\
\text { Mechanics } \\
\text { (e.g., "How important is it to you } \\
\text { that your character is as optimized } \\
\text { as possible for their profession / } \\
\text { role?") } \\
\text { Competition } \\
\text { (e.g., "How much do you enjoy } \\
\text { competing with other players?") } \\
\text { Social: } \\
\text { Socializing } \\
\text { (e.g., "How much do you enjoy } \\
\text { helping other players?") } \\
\text { Relationship }\end{array}$ & 40 \\
\hline
\end{tabular}




\begin{tabular}{|c|c|c|}
\hline & & $\begin{array}{l}\text { (e.g., How often do you find } \\
\text { yourself having meaningful } \\
\text { conversations with other } \\
\text { players?") } \\
\text { Teamwork } \\
\text { (e.g., "How much do you enjoy } \\
\text { working with others in a group?") } \\
\text { Immersion: } \\
\text { Discovery } \\
\text { (e.g., "How much do you enjoy } \\
\text { exploring every map or zone in the } \\
\text { world?") } \\
\text { Role-playing } \\
\text { (e.g., "How much do you enjoy } \\
\text { being immersed in a fantasy } \\
\text { world?") } \\
\text { Customization } \\
\text { (e.g., "How much time do you } \\
\text { spend customizing your character } \\
\text { during character creation?") } \\
\text { Escapism } \\
\text { (e.g., "How often do you play to } \\
\text { relax from the day's work?") }\end{array}$ \\
\hline Yee (2006b) & $\begin{array}{l}\mathrm{n}=6,675 \\
88.97 \% \text { males }\end{array}$ & 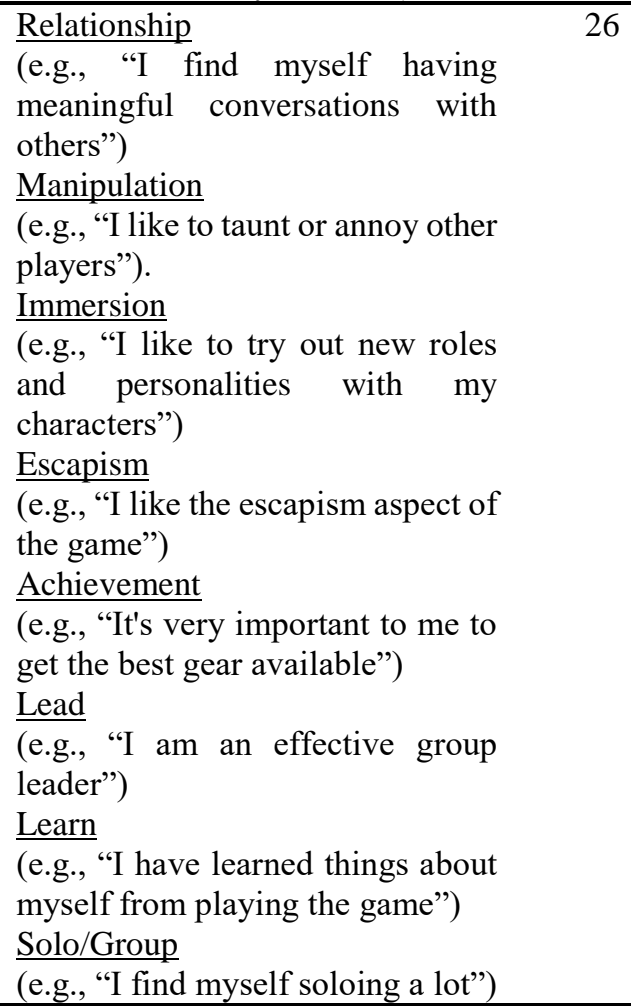 \\
\hline
\end{tabular}




\begin{tabular}{|c|c|c|c|c|}
\hline $\begin{array}{l}\text { Fuster } \\
(2012)\end{array} \quad$ et al. & $\begin{array}{l}\mathrm{n}=253 \\
100 \% \text { males } \\
\text { mean age }=22.2 \\
(\mathrm{SD}=4.4)\end{array}$ & $\begin{array}{l}\text { World of } \\
\text { Warcraft }\end{array}$ & $\begin{array}{l}\text { Socialisation } \\
\text { (e.g., "Me atrae de WoW poder } \\
\text { hacer buenos amigos en el juego") } \\
\text { (Being able to make good friends } \\
\text { in the game attracts me to WoW) } \\
\text { Exploration } \\
\text { (e.g., "Me atrae de WoW que no } \\
\text { paro de descubrir cosas nuevas") } \\
\text { (Constantly discovering new } \\
\text { things attracts me to WoW ) } \\
\text { Achievement } \\
\text { (e.g., "Me atrae de WoW dominar } \\
\text { a otros jugadores") (Dominating } \\
\text { other players attracts me to WoW) } \\
\text { Dissociation } \\
\text { (e.g., "Dedico más tiempo al WoW } \\
\text { que a otras actividades de ocio") (I } \\
\text { spend more time on WoW than on } \\
\text { other leisure activities) }\end{array}$ & 20 \\
\hline $\begin{array}{l}\text { Yee, } \\
\text { Ducheneaut \& } \\
\text { Nelson (2012) }\end{array}$ & $\begin{array}{l}\text { Sample from US } \\
\mathrm{n}=2,071 \\
65.57 \% \% \text { males } \\
\text { mean age }=29.95 \\
(\mathrm{SD}=9.2) \\
\\
\text { Sample from Asia } \\
\mathrm{n}=645 \\
79.64 \% \text { males } \\
\text { mean age }=23.59 \\
(\mathrm{SD}=5.16)\end{array}$ & $\begin{array}{l}\text { World of } \\
\text { Warcraft }\end{array}$ & $\begin{array}{l}\text { Social } \\
\text { (e.g., "Keeping in touch with your } \\
\text { friends") } \\
\text { Immersion } \\
\text { (e.g., "Exploring the world just for } \\
\text { the sake of exploring it") } \\
\text { Achievement } \\
\text { (e.g., Becoming powerful") }\end{array}$ & 12 \\
\hline $\begin{array}{l}\text { Demetrovics et } \\
\text { al. (2011) }\end{array}$ & $\begin{array}{l}\mathrm{n}=3,818 \\
90.6 \% \text { males } \\
\text { mean age }=20.9 \\
(\mathrm{SD}=5.81)\end{array}$ & $\begin{array}{l}\text { Online } \\
\text { games }\end{array}$ & $\begin{array}{l}\text { Escape } \\
\text { (e.g., "I play online games because } \\
\text { it makes me forget real life") } \\
\text { Coping } \\
\text { (e.g., "... because it helps me } \\
\text { channel my aggression") } \\
\text { Fantasy } \\
\text { (e.g., "... to feel as if I was } \\
\text { somebody else") } \\
\text { Skill development } \\
\text { (e.g. "... because it improves my } \\
\text { coordination skills") } \\
\text { Recreation } \\
\text { (e.g., “... for recreation") } \\
\text { Competition } \\
\text { (e.g., "... for the pleasure of } \\
\text { defeating others") } \\
\underline{\text { Social }} \\
\text { (e.g., “... because it is a good } \\
\text { social experience") }\end{array}$ & 27 \\
\hline $\begin{array}{l}\text { Kahn, } \\
(2015)\end{array}$ et al. & $\begin{array}{l}\text { Sample from } \\
\text { North America } \\
\mathrm{n}=18,627 \\
95.9 \% \text { males } \\
\text { mean age = } 23 \\
\text { Sample from } \\
\text { China } \\
\mathrm{n}=18,819\end{array}$ & $\begin{array}{l}\text { League of } \\
\text { Legends } \\
\text { (MOBA) } \\
\text { Chevalier's } \\
\text { Romance } 3 \\
\text { (MMO) }\end{array}$ & $\begin{array}{l}\text { Socializers } \\
\text { (e.g., "I like to chat with my } \\
\text { friends while playing a video } \\
\text { game") } \\
\text { Completionists } \\
\text { (e.g., "I like to master all elements } \\
\text { of a game") } \\
\text { Competitors }\end{array}$ & 15 \\
\hline
\end{tabular}




\begin{tabular}{|c|c|c|c|}
\hline & $\begin{array}{l}75 \% \text { males } \\
\text { mean age }=23.9\end{array}$ & $\begin{array}{l}\text { (e.g., "Winning is a big reason for } \\
\text { me to play video games") } \\
\text { Escapists } \\
\text { (e.g., "I like to do things in games } \\
\text { which I cannot do in real life") } \\
\text { Story-driven } \\
\text { (e.g., "I like the feeling of being } \\
\text { part of a story") } \\
\text { Smarty-pants } \\
\text { (e.g., "I play games to enhance my } \\
\text { intellectual abilities") }\end{array}$ & \\
\hline $\begin{array}{l}\text { Sherry et al. } \\
(2006)\end{array}$ & $\begin{array}{ll}\mathrm{n}=1,236 & \text { In general } \\
44.75 \% \text { males } & \\
\text { mean age }=16.72 & \\
(\mathrm{SD}=3.22) & \end{array}$ & $\begin{array}{l}\text { Competition } \\
\text { (e.g., "I like to play to prove to my } \\
\text { friends that I am the best") } \\
\text { Challenge } \\
\text { (e.g., "I feel proud when I master } \\
\text { an aspect of a game") } \\
\text { Social Interaction } \\
\text { (e.g., "My friends and I use video } \\
\text { games as a reason to get together") } \\
\text { Diversion } \\
\text { (e.g., "I play video games when I } \\
\text { have other things to do") } \\
\text { Fantasy } \\
\text { (e.g., "I play video games because } \\
\text { they let me do things I can't do in } \\
\text { real life") } \\
\text { Arousal } \\
\text { (e.g., "I find that playing video } \\
\text { games raises my level of } \\
\text { adrenaline") } \\
\text { Ego } \\
\text { (e.g., "I play video games because } \\
\text { I can be strong") } \\
\text { Hi-tech } \\
\text { (e.g., "I like to play video games } \\
\text { because they look very cool") } \\
\text { Realism } \\
\text { (e.g., "I play video games because } \\
\text { the characters in the games are a lot } \\
\text { like real people") }\end{array}$ & 36 \\
\hline $\begin{array}{l}\text { Rodríguez de } \\
\text { Sepúlveda \& } \\
\text { Igartua }(2011)\end{array}$ & $\begin{array}{l}\mathrm{n}=400 \\
49.3 \% \text { males } \\
\text { mean age }=14.78 \\
(\geq 99 \%, \text { ranged } \\
\text { from } 12 \text { to } 18)\end{array}$ & $\begin{array}{l}\text { Fantasía/búsqueda de Aventura } \\
\text { (e.g., "Con los videojuegos puedo } \\
\text { explorar y conocer mundos y } \\
\text { personajes imaginarios") (With } \\
\text { video games, I can explore and } \\
\text { discover imaginary worlds and } \\
\text { characters) } \\
\text { Entretenimiento-diversión } \\
\text { (e.g., "Juego para matar el } \\
\text { tiempo") (I play to kill time) } \\
\text { Estimulación socioemocional } \\
\text { (e.g., "Me gusta jugar para hacer } \\
\text { nuevos amigos") (I like playing to } \\
\text { make new friends) } \\
\text { Competición } \\
\text { (e.g., "Es importante para mí ser el } \\
\text { mejor jugando a un juego) (It is }\end{array}$ & \\
\hline
\end{tabular}




\begin{tabular}{|c|c|c|c|c|}
\hline & & & $\begin{array}{l}\text { important to me to be the best } \\
\text { player in a game) }\end{array}$ & \\
\hline Olson (2010) & $\begin{array}{l}\mathrm{n}=1,254 \\
47 \% \text { males } \\
(\geq 98 \%, \text { ranged } \\
\text { from } 12 \text { to } 14)\end{array}$ & In general & $\begin{array}{l}\text { (Originally Non-categorized) } \\
\text { Diversion } \\
\text { (e.g., "I play electronic games } \\
\text { because it's just fun") } \\
\text { Arousal } \\
\text { (e.g., “... it's exciting”) } \\
\text { Competition } \\
\text { (e.g., “... like to compete with } \\
\text { others and win") } \\
\text { Exploration/immersion } \\
\text { (e.g., “... challenge of figuring } \\
\text { thing out”) } \\
\text { Coping } \\
\text { (e.g., “... it helps me relax") } \\
\text { Escapism } \\
\text { (e.g., “... helps me forget my } \\
\text { problems") } \\
\text { Social } \\
\text { (e.g., “... my friends like to play”) }\end{array}$ & 17 \\
\hline $\begin{array}{l}\text { Hilgard, } \\
\text { Engelhardt \& } \\
\text { Bartholow } \\
\text { (2013) }\end{array}$ & $\begin{array}{l}\text { Internet sample } \\
\mathrm{n}=1,689 \\
87 \% \text { males } \\
\text { mean age }=23.4 \\
(\mathrm{SD}=6.03) \\
\\
\text { College students } \\
\text { sample } \\
\mathrm{n}=300 \\
27 \% \text { males } \\
\text { mean age }=18.4 \\
(\mathrm{SD}=1.21)\end{array}$ & In general & $\begin{array}{l}\text { Story } \\
\text { (e.g., "Video game stories aren't } \\
\text { important to me") } \\
\text { Violence Catharsis } \\
\text { (e.g., "Violent games allow me to } \\
\text { release negative energy") } \\
\text { Violent Reward } \\
\text { (e.g., "Killing things in the game } \\
\text { makes me feel powerful") } \\
\text { Social Interaction } \\
\text { (e.g., "I make more friends by } \\
\text { playing video games") } \\
\text { Escapism } \\
\text { (e.g., "I play video games to keep } \\
\text { my mind off my problems") } \\
\text { Loss-Aversion } \\
\text { (e.g., "Winning is fun; losing } \\
\text { isn't") } \\
\text { Customization } \\
\text { (e.g., "I like making things in the } \\
\text { video game, like houses or } \\
\text { outfits") } \\
\text { Grinding/Completion }\end{array}$ & 59 \\
\hline
\end{tabular}




\begin{tabular}{|c|c|c|c|c|}
\hline & & & $\begin{array}{l}\text { (e.g., "I rarely complete } \\
\text { collections of in-game items") } \\
\text { Autonomy/Exploration } \\
\text { (e.g., "I like having a choice of } \\
\text { several different places or levels to } \\
\text { try") }\end{array}$ & \\
\hline $\begin{array}{l}\text { Floros } \quad \& \\
\text { Siomos (2012) }\end{array}$ & $\begin{array}{l}\mathrm{n}=1,971 \\
51.7 \% \text { males } \\
\text { mean age }=15.07 \\
(\mathrm{SD}=2.4)\end{array}$ & In general & $\begin{array}{l}\text { (Originally Non-categorized) } \\
\text { Competition } \\
\text { (e.g., "Enjoy the competition } \\
\text { against the computer") } \\
\text { Social } \\
\text { (e.g., "Like cooperation with other } \\
\text { players") } \\
\text { Immersion } \\
\text { (e.g., "Seek the creation of an } \\
\text { alternate identity") } \\
\text { Challenge } \\
\text { (e.g., "Become renown for my } \\
\text { gaming successes) } \\
\text { Escapism } \\
\text { (e.g., "Seek to forget everyday } \\
\text { life") }\end{array}$ & 13 \\
\hline $\begin{array}{lr}\text { Nije, Bijvank, } \\
\text { Konijn } \\
\text { Bushman } \\
(\text { (2012) }\end{array}$ & $\begin{array}{l}\mathrm{n}=830 \\
100 \% \text { males } \\
\text { mean age }=13.9 \\
(\mathrm{SD}=1.38)\end{array}$ & In general & $\begin{array}{l}\text { Social Interaction } \\
\text { (e.g., "To get in touch with new } \\
\text { people") } \\
\text { Competition } \\
\text { (e.g., "To be the strongest") } \\
\text { Fantasy-escape } \\
\text { (e.g., "To do things I wish to do in } \\
\text { real life too") } \\
\text { Fantasy-arousal } \\
\text { (e.g., "It gets me excited") } \\
\text { Unwind } \\
\text { (e.g., "To release aggression") } \\
\text { Challenge } \\
\text { (e.g., "To get to the next level") } \\
\text { Diversion } \\
\text { (e.g., "Because I have nothing } \\
\text { better to do") }\end{array}$ & 22 \\
\hline $\begin{array}{l}\text { Wallenius, } \\
\text { Rimpelä, } \\
\text { Punamäki } \quad \text { \& } \\
\text { Lintonen } \\
(2009)\end{array}$ & $\begin{array}{l}\mathrm{n}=4,085 \\
61.2 \% \text { males } \\
\text { mean age }=14.95 \\
(\mathrm{SD}=1.83)\end{array}$ & In general & $\begin{array}{l}\text { Instrumental motives } \\
\text { ("Learn new things and functions", } \\
\text { "Common topic for conversation", } \\
\text { "Use and develop game playing } \\
\text { skills", "Experiences, different } \\
\text { roles and worlds" } \\
\text { Ritualized motives } \\
\text { ("Pass the time, entertainment", } \\
\text { "Recover, relax", "Get away from } \\
\text { everyday life, forget worries") }\end{array}$ & 7 \\
\hline
\end{tabular}




\begin{tabular}{|c|c|c|c|c|}
\hline $\begin{array}{l}\text { Scharkow, } \\
\text { Festl, } \\
\text { Vogelgesang \& } \\
\text { Quandt (2015) }\end{array}$ & $\begin{array}{l}\mathrm{n}=4,500 \\
56.6 \% \text { males } \\
\text { mean age }=38.8 \\
\text { (ranged from } 14 \\
\text { to } 90 \text { ) }\end{array}$ & In general & $\begin{array}{l}\text { Individual gratifications: } \\
\text { Fantasy } \\
\text { (e.g., "Slip into different roles") } \\
\text { Competence } \\
\text { (e.g., "Achieve better and better } \\
\text { results") } \\
\text { Exploration } \\
\text { (e.g., "Explore and investigate the } \\
\text { game world") } \\
\text { Social gratifications } \\
\text { (I use video games in order to...): } \\
\text { Social Capital } \\
\text { (e.g., "Make friends") } \\
\text { Team Play } \\
\text { (e.g., "Conjointly play with } \\
\text { others") } \\
\text { Competition } \\
\text { (e.g., "Beat my co-players") } \\
\text { Content Gratifications } \\
\text { (The game attribute is important to } \\
\text { me...): } \\
\text { Mechanics } \\
\text { (e.g., "Graphics") } \\
\text { Narration } \\
\text { (e.g., "Story of the game") }\end{array}$ & 15 \\
\hline $\begin{array}{l}\text { Hamutoğlu, } \\
\text { Topal, Samur, } \\
\text { Gezgin \& } \\
\text { Griffiths (2020) }\end{array}$ & $\begin{array}{l}\mathrm{n}=1,479 \\
53.6 \% \text { boys } \\
\text { students } \\
\text { attending grades } \\
5 \text { to } 8\end{array}$ & $\begin{array}{c}\text { MMO } \\
\text { videogames }\end{array}$ & $\begin{array}{l}\text { Achievement-oriented } \\
\text { (e.g., "I find it important to gain } \\
\text { experience points when playing } \\
\text { online games") } \\
\text { Socialization-oriented } \\
\text { (e.g., "It is important for me to join } \\
\text { a group of warriors in a } \\
\text { multiplayer game") } \\
\text { Exploration-oriented } \\
\text { (e.g., "It is important to discover } \\
\text { new places while wandering in } \\
\text { online games") } \\
\text { Competition-oriented } \\
\text { (e.g., "I find it amusing to defeat an } \\
\text { enemy in online games") }\end{array}$ & 38 \\
\hline 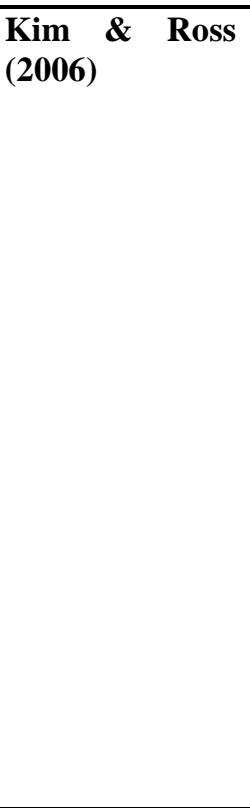 & $\begin{array}{l}\mathrm{n}=214 \\
68.7 \% \text { males } \\
\text { Ages: } \\
<20(33.6 \%) \\
20-29(40.2 \%) \\
30-39(19.6 \%) \\
>40(6.54 \%)\end{array}$ & $\begin{array}{c}\text { Sport } \\
\text { videogames }\end{array}$ & $\begin{array}{l}\text { Competition } \\
\text { (e.g., "I like to play to prove to } \\
\text { others that I am the best") } \\
\text { Social Interaction } \\
\text { (e.g., "I use video games as a } \\
\text { reason to get together with others") } \\
\text { Diversion } \\
\text { (e.g., "Video gaming provides a } \\
\text { change of pace from what I } \\
\text { regularly do") } \\
\text { Entertainment } \\
\text { (e.g., "I play SVGS -sport video } \\
\text { games-because it is fun") } \\
\text { Fantasy } \\
\text { (e.g., "I enjoy the excitement of } \\
\text { assuming an alter ego in a sport } \\
\text { game") } \\
\text { Knowledge Application } \\
\text { (e.g., "I simulate my strategies at } \\
\text { the video game") }\end{array}$ & 20 \\
\hline
\end{tabular}




\begin{tabular}{|c|c|c|c|c|}
\hline & & & $\begin{array}{l}\text { Identification with Sport } \\
\text { (e.g., "My favorite sport is a sport } \\
\text { the SVG is modeled on") }\end{array}$ & \\
\hline $\begin{array}{l}\text { Tondello et al. } \\
(2016)\end{array}$ & $\begin{array}{l}\mathrm{n}=133 \\
47.97 \% \text { males } \\
\text { mean age }=23.5 \\
(\mathrm{SD}=3.3)\end{array}$ & In general & $\begin{array}{l}\text { Philanthropists } \\
\text { (e.g., "It makes me happy if I am } \\
\text { able to help others") } \\
\text { Socializers } \\
\text { (e.g., "Interacting with others is } \\
\text { important to me") } \\
\text { Free Spirits } \\
\text { (e.g., "I often let my curiosity } \\
\text { guide me") } \\
\text { Achievers } \\
\text { (e.g., "I like defeating obstacles") } \\
\text { Players } \\
\text { (e.g., "If the reward is sufficient I } \\
\text { will put in the effort") } \\
\text { Disruptors } \\
\text { (e.g., "I like to provoke") }\end{array}$ & 24 \\
\hline $\begin{array}{l}\text { Ryan et al. } \\
(2006) \\
\text {-Study } 1-\end{array}$ & $\begin{array}{l}\mathrm{N}=89 \\
25.84 \% \text { males } \\
\text { undergraduates }\end{array}$ & $\begin{array}{l}\text { Platform } \\
\text { game (Super } \\
\text { Mario 64) }\end{array}$ & $\begin{array}{l}\text { Player experience of Need for } \\
\text { satisfaction: } \\
\text { In-Game competence } \\
\text { e.g., "I felt very capable and } \\
\text { effective") } \\
\text { In-Game autonomy } \\
\text { e.g., "I did things in the game } \\
\text { because they interested me") } \\
\text { Presence } \\
\text { e.g., "I experience feelings as } \\
\text { deeply in the game as I have in real } \\
\text { life") } \\
\text { Intuitive controls } \\
\text { e.g., "When I wanted to do } \\
\text { something in the game it was easy } \\
\text { to remember the corresponding } \\
\text { control") }\end{array}$ & 16 \\
\hline $\begin{array}{l}\text { Lafrenière, } \\
\text { Verner-Filion } \\
\text { \& Vallerand } \\
(2012)\end{array}$ & $\begin{array}{l}\mathrm{n}=276 \\
69.93 \% \text { males } \\
\text { mean age }=26.15 \\
(\mathrm{SD}=8.26)\end{array}$ & In general & $\begin{array}{l}\text { Why do you play video games? } \\
\text { Intrinsic motivation } \\
\text { (e.g., "Because it is stimulating to } \\
\text { play") } \\
\text { Integrated regulation } \\
\text { (e.g., "Because it is an extension of } \\
\text { me") } \\
\text { Identified regulation } \\
\text { (e.g., "Because it is a good way to } \\
\text { develop important aspects of } \\
\text { myself") } \\
\text { Introjected regulation } \\
\text { (e.g., "Because I feel that I must } \\
\text { play regularly") } \\
\text { External regulation } \\
\text { (e.g., "For the prestige of being a } \\
\text { good player") } \\
\text { Amotivation } \\
\text { (e.g., "It is not clear anymore, I } \\
\text { sometimes ask myself if it is good } \\
\text { for me") }\end{array}$ & 18 \\
\hline $\begin{array}{l}\text { De Grove et al. } \\
(2016)\end{array}$ & $\begin{array}{l}\text { Study } 5 \\
\mathrm{n}=232 \\
28.9 \% \text { males }\end{array}$ & In general & $\begin{array}{l}\text { Habit } \\
\text { (e.g., "Gaming is part of my } \\
\text { normal routine") }\end{array}$ & 43 \\
\hline
\end{tabular}




\begin{tabular}{|c|c|c|c|c|}
\hline & $\begin{array}{l}\text { mean age }=20.83 \\
(\mathrm{SD}=2.58) \\
\text { Study } 6 \\
\mathrm{n}=296 \\
30.7 \% \text { males } \\
\text { mean age }=20.94 \\
(\mathrm{SD}=3.52) \\
\text { Study } 7 \\
\mathrm{n}=545 \\
30.1 \% \text { males } \\
\text { mean age }=14.87 \\
(\mathrm{SD}=2)\end{array}$ & & $\begin{array}{l}\text { Moral and self-reaction } \\
\text { (e.g., "I feel good about playing } \\
\text { games") } \\
\text { If you were to play games in the } \\
\text { near future how likely is it that } \\
\text { you: } \\
\text { Agency } \\
\text { (e.g., "can do your own thing } \\
\text { during the game") } \\
\text { Narrative } \\
\text { (e.g., "are immersed in the events } \\
\text { of the game") } \\
\text { Escapism } \\
\text { (e.g., "forget about the daily } \\
\text { routine") } \\
\text { Pastime } \\
\text { (e.g., "play to pass the time") } \\
\text { Performance } \\
\text { (e.g., "perform well") } \\
\underline{\text { Social }} \\
\text { (e.g., "play with other players") }\end{array}$ & \\
\hline $\begin{array}{l}\text { Lee \& LaRose } \\
(2007)\end{array}$ & $\begin{array}{l}\mathrm{n}=388 \\
59 \% \text { males } \\
\text { mean age }=19\end{array}$ & In general & $\begin{array}{l}\text { Thinking about your experience } \\
\text { when you have recently played } \\
\text { your favorite video games: } \\
\text { Enjoyment } \\
\text { (e.g., "I love the feeling of my } \\
\text { gaming") } \\
\text { Merge of action and awareness } \\
\text { (e.g., "My performance is } \\
\text { automatically done") } \\
\text { Concentration } \\
\text { (e.g., "I am totally concentrated") } \\
\text { Self-Reactive } \\
\text { Expectations } \\
\text { (e.g., "Feel relaxed") } \\
\text { Deficient Self-Regulation } \\
\text { (e.g., "I feel my game playing is } \\
\text { out of control") } \\
\text { Habit Strength } \\
\text { (e.g., "Playing video games is a } \\
\text { habit I have gotten into") }\end{array}$ & 18 \\
\hline $\begin{array}{l}\text { Li, Liau, } \\
\text { Gentile, Khoo } \\
\text { \& Cheong } \\
(2012)\end{array}$ & $\begin{array}{l}\text { Study } 1 \\
\mathrm{n}=219 \\
41 \% \text { males } \\
\text { mean age }=14 \\
(\mathrm{SD}=.77)\end{array}$ & $\mathrm{MMO}$ & $\begin{array}{l}\text { Achievement } \\
\text { (e.g., "It is important to be well } \\
\text { known in the game") } \\
\text { Socialization } \\
\text { (e.g., "I enjoy chatting with } \\
\text { others") } \\
\text { Immersion } \\
\text { (e.g., "I often role-play my } \\
\text { character") }\end{array}$ & 12 \\
\hline $\begin{array}{l}\text { Nackle, } \\
\text { Bateman, } \\
\text { Mandryk } \\
(\mathbf{2 0 1 3 )}\end{array}$ & $\begin{array}{l}\mathrm{n}=50,423 \\
88.6 \% \text { males } \\
\text { mean age }=14 \\
(\mathrm{SD}=.77)\end{array}$ & In general & $\begin{array}{l}\text { Seeker } \\
\text { (e.g., "Exploring to see what can } \\
\text { find") } \\
\text { Survivor } \\
\text { (e.g., "Frantically escaping from } \\
\text { terrifying foes") } \\
\text { Daredevil } \\
\text { (e.g., "Responding quickly to an } \\
\text { exciting situation") } \\
\text { Mastermind }\end{array}$ & 21 \\
\hline
\end{tabular}




\begin{tabular}{|c|c|c|c|c|}
\hline & & & $\begin{array}{l}\text { (e.g., "Working out how to crack a } \\
\text { challenging puzzle") } \\
\text { Conqueror } \\
\text { (e.g., "The struggle to defeat a } \\
\text { difficult boss") } \\
\text { Socializer } \\
\text { (e.g., "Playing in a group, online or } \\
\text { in the same room") } \\
\text { Achiever } \\
\text { (e.g., "Picking up every single } \\
\text { collectible in an area") }\end{array}$ & \\
\hline $\begin{array}{l}\text { Westwood \& } \\
\text { Griffiths (2010) }\end{array}$ & $\begin{array}{l}\mathrm{n}=40 \text { gamers } \\
38 \text { males } \\
90 \% \text { below } 30 \\
\text { years }\end{array}$ & In general & $\begin{array}{l}\text { Story-driven solo gamer } \\
\text { (e.g., "I game for personal } \\
\text { enjoyment, not to be better than } \\
\text { others") } \\
\text { Social gamer } \\
\text { (e.g., "I prefer playing alone, or } \\
\text { playing single-player Games") } \\
\text { Solo limited gamer } \\
\text { (e.g., "It is important for me to be } \\
\text { top of a leader board within a } \\
\text { game") } \\
\text { Hardcore online gamer } \\
\text { (e.g., "It is important for } \\
\text { me to be top of a leader board } \\
\text { within a game"") } \\
\text { Control/identity solo gamer } \\
\text { (e.g., "It annoys me and breaks up } \\
\text { my enjoyment of a game when I } \\
\text { have to sit through cut scenes or } \\
\text { loading screens") } \\
\text { Casual gamer } \\
\text { (e.g., "I game for personal } \\
\text { enjoyment, not to be better than } \\
\text { others") }\end{array}$ & 56 \\
\hline $\begin{array}{l}\text { Wu, Wang \& } \\
\text { Tsai, (2010) }\end{array}$ & $\begin{array}{l}\mathrm{n}=337 \\
67.4 \% \text { males } \\
\text { Ages: } \\
<15(15) \\
15-18(29) \\
19-23(197) \\
24-28(86) \\
29-35(9) \\
>36(1)\end{array}$ & $\begin{array}{l}\text { Online } \\
\text { games }\end{array}$ & $\begin{array}{l}\text { Gratifications: } \\
\text { Achievement } \\
\text { (e.g., "I have more power than } \\
\text { other players in the online game") } \\
\text { Enjoyment } \\
\text { (e.g., "Playing the online game is } \\
\text { exciting") } \\
\text { Social interaction } \\
\text { (e.g., "I have a network of friends } \\
\text { made online") } \\
\text { Spatial presence (non-included as } \\
\text { a gratification) } \\
\text { (e.g., "The online game came to } \\
\text { me and became part of my world") }\end{array}$ & 12 \\
\hline
\end{tabular}

\subsubsection{Motives and video game behaviors}

Video game motives have been related to a set of different video game-related behaviors such as disordered gaming (e.g., Yee, 2006a), time spent on gaming (e.g., Yee, 
2006b), types of passions (e.g., Fuster, Chamarro, Carbonell, \& Vallerand, 2014), ingame behaviors (e.g., Yee et al., 2012), and video game preferences (e.g., Ghuman \& Griffiths, 2012).

With regard to disordered gaming, most studies have focused on MMORPGs. Thus, problematic gaming has been mainly related to higher levels of immersion motives (Billieux et al., 2011; Kirby et al., 2014; Kneer \& Glock, 2013), particularly to escapism (Billieux et al., 2013; Hagström \& Kaldo, 2014; Kardefelt-Winther, 2014a; Kuss et al., 2012; Yee, 2006a; Zanetta et al., 2011). Accordingly, these findings in which escapismcoping is highly related to disordered gaming in MMORPGs are replicated for general gaming (Chang \& Lin, 2019; Kim et al., 2016; Király et al., 2017a; Laconi et al., 2017; Montag et al., 2019; Moudiab \& Spada, 2019; Wu et al., 2016) and among adolescents (Männikkö et al., 2017). Furthermore, achievement-competition motives are also frequently associated with disordered gaming in both adult gaming in MMORPG (Billieux et al., 2013; Yee, 2006a; Zanetta et al., 2011) and adult general gaming (Ballabio et al., 2017; Chang \& Lin, 2019; Király et al., 2015b; Laconi et al., 2017; Montag et al., 2019), as well as in the adolescent population (Männikkö et al., 2017).

Time spent on gaming has been principally associated with social motives in both MMORPGs players (Yee, 2006b; Williams, Yee \& Caplan, 2008) and general players (Király et al., 2017a; Wu et al., 2016). Furthermore, social interaction motives together with diversion (recreation) are the most important motives explaining video game time on children and adolescents (Greenberg, et al., 2010; Sherry et al., 2006). Achievement and escapism motives also showed a relevant role on gaming time among MMORPGs players (Billieux et al, 2013; Yee, 2006b).

Passion is defined as a strong inclination towards a self-defining activity that an individual enjoys, values, and invests time and energy. The Dual Model of Passion sets 
up two types of passion, harmonious passion that you can control and obsessive passion characterized by an uncontrollable urge (Vallerand et al, 2007). In this sense, harmonious passion was related to hours of playing whereas both passions were associated with preference for MMORPGs (Puerta-Cortés, Panova, Carbonell, \& Chamarro et al., 2017). Additionally, in a sample of MMO players, harmonious passion was associated with positive affective experiences, life satisfaction and self-realization; whereas obsessive passion was linked to positive and negative in-game affective experiences, problematic behavior, physical symptoms, weekly playing and low self-realization (Lafreniere, Vallerand, Donahue, \& Lavigne, 2009). Similarly, Wang \& Chu (2007) found obsessive passion was related to problematic gaming. In this line, Allen \& Anderson (2018) showed that the frustration of SDT needs (competence, autonomy and relatedness) in the real world but also in video games was associated with higher IGD severity. On the other hand, harmonious passion was associated with exploration, achievement and socialization motives, whereas obsessive passion was linked to dissociation to a larger extent, as well as achievement and socialization motives (Fuster et al., 2014).

Additionally, motives impact on Avatar's behavior on MMORPGs' players. For instance, World of Warcraft players with higher achievement motivations tend to play more for Player versus Player achievements, based on fighting other players (Billieux et al, 2013; Yee et al., 2012). In addition, this impact of motives on in-game behaviors may be extrapolated to other video game genres (Kahn, et al., 2015).

On the other hand, motives may influence player's video game genre preferences. With regard to MMO games, FPS players showed the highest score in achievement whereas RPG players displayed the highest immersion levels (Ghuman \& Griffiths, 2012). Accordingly, Kim et al. (2016) found RPG use was strongly related to social, fantasy and coping motivations. On the other hand, playing FPS was mainly associated 
with fantasy, social and skill development. Finally, RTS use was principally related to competition, skill development and social motives. Regarding other non-MMO genres, Scharkow et al. (2015) displayed how in-game gratifications (as they called them) were associated with genre preferences. For example, according to Individual gratifications: the highest correlation of exploration motives was found among adventure genre, puzzle genre preferences were related to competence motive, and RPG preferences showed a strong relationship with fantasy. With regard to Social gratifications, teamplay motive was mainly related to music and sports genre preferences, whereas competition displayed the highest association with action and sport genres and was negatively related to puzzle preferences. Finally, the Content gratification of narration showed the highest relationships with strategy and RPG genres, whereas mechanics was strongly related to sport and action genres. Greenberg et al. (2010) examined the role of Sherry et al.'s (2006) motives on 3 factors of video game genre preferences: imagination (strategy, fantasy and adventure genres), traditional (classic arcade games, card/dice games, quiz/trivia, board games and puzzle games genres), and physical competition (sports, fighters, shooters and racing/speed genres). Thus, the physical competition factor was mainly related to competition motive whereas imagination was also linked to competition, to a lesser degree, as well as fantasy. In addition, the traditional factor was highly associated with challenge and negatively with social interaction. Apart from that, motives to play have been related to favorite video game franchises (Hilgard et al., 2013). For example, customization and story motives have been associated with preferences for the popular RPGs Final Fantasy and Skyrim, as well as escapism motives with World of Warcraft, or violent reward with Grand Theft Auto. 
Taken together, research displays the key role of motives to understand individual differences on video gaming behaviors. However, the interrelation between motives and players' personality has been scarcely examined.

\subsection{Interrelation between personality and motives to play video games}

As happens with other addictions (e.g., Mezquita, 2011), distal and nonspecific variables (e.g., personality) may influence video game behaviors through affectivemotivational variables more proximal to video gaming. However, the mediating role of motives on the relationship between personality and disordered gaming has hardly been explored. In this sense, only Kircaburun et al. (2018) and Kircaburun et al. (in press) have checked this mediation, displaying how traits of the Dark Tetrad (Machiavellianism, psychopathy, narcissism and sadism) (Kircaburun et al., 2018) and trait emotional intelligence (Kircaburun et al., in press) mediated between personality and problematic gaming. Thus, to date, it has not yet been explored the mediating role of gaming motives among the relationship between basic personality traits and pathological gaming.

Despite this fact, personality has been extensively related to motives to play. Under the FFM, neuroticism displayed a relevant link with immersion or role-playing components, such as playing for discovering or collecting items (Bean \& Groth-Marnat, 2016; Graham \& Gosling, 2013). Neuroticism may also be especially relevant for the escapism dimension (Shceck et al., 2015). Accordingly, some studies have found that escapism motives highly mediate associations between psychological problems, which are closely related to neuroticism, and disordered gaming (Ballabio et al., 2017; Király et al., 2015b; Montag et al., 2019; Plante et al., 2018). In this line, MMORPG players with poor coping strategies presented higher associations between escapism and problematic gaming compared to those with more adaptive coping styles (Bowditch, Chapman, \& 
Naweed, 2018). Likewise, psychosocial problems like stress and self-esteem acted as moderators in the relationship between escapism and negative outcomes in video gaming (Kardefelt-Winther, 2014b). Furthermore, extraversion was mainly associated with social and achievement motives, such as competition (Bean \& Groth-Marnat, 2016; Jeng \& Teng, 2008; Graham \& Gosling, 2013; Shceck et al., 2015). On the other hand, openness has presented a strong link with immersion motives (Bean \& Groth-Marnat, 2016; Graham \& Gosling, 2013; Jeng \& Teng, 2008; Shceck et al., 2015). Additionally, agreeableness was related to social motivations (Graham \& Gosling, 2013; Jeng \& Teng, 2008; Park et al., 2011; Shceck et al., 2015). In this line, the big five dimensions have been related to video game player types (Tondello et al., 2016). Thus, philanthropists, motivated by in-game altruistic behaviors, were extensively associated with high agreeableness; socializers, motivated by social connections, with high extraversion and agreeableness; free spirits, those whose behaviors are guided by the feeling of freedom, with high openness and low neuroticism; achievers, motivated by self-competence, with high conscientiousness; and disruptors, those players who test the boundaries of the game to force changes, with low neuroticism.

The HEXACO model of personality, including the FFM dimensions as well as an honesty-humility dimension which expresses the tendency to express fairness and modesty (Ashton \& Lee, 2007), has also been employed in order to examine associations between personality and motives. Thereby, emotionality (low neuroticism according to FFM) was associated with getting in-game achievements (Worth \& Book, 2014; ZeiglerHill \& Monica, 2015) whereas low emotionality was associated with competitive and aggressive characteristics (Worth \& Book, 2015). Extraversion was highly related to playing for social considerations (Worth \& Book, 2014; Zeigler-Hill \& Monica, 2015). On the other hand, openness to experience was largely linked to exploration and 
immersion (Worth \& Book, 2014; Zeigler-Hill \& Monica, 2015). Furthermore, agreeableness as well as honesty-humility was strongly related to help other players in the game (Worth \& Book, 2014; Worth \& Book, 2015), whereas honesty-humility, on its own, was associated with lower behaviors related to compete or damage others (Worth \& Book, 2014; Worth \& Book, 2015). Finally, conscientiousness was associated with playing to accomplish objectives or achievements, and was also negatively related to compete or damage others (Worth \& Book, 2014; Worth \& Book, 2015; Zeigler-Hill \& Monica, 2015).

This data suggests basic personality dimensions may impact video game behaviors, such as disordered gaming or gaming time, through motives to play. As far as we know, it has yet to be explored.

\subsection{Video games and violence}

Systematic meta-analyses conducted on experimental and correlational studies converge on the finding that VVE increases aggressive behavior, cognition and affect with a small effect $(\mathrm{r} \simeq .10-.20$; Anderson \& Bushman, 2002; Anderson et al., 2010; Calvert et al., 2017; Ferguson \& Kilburn, 2009; Greitemeyer \& Mügge, 2014; Prescott et al, 2018; Sherry, 2001).

Different theories have been developed to explain the influence of violent media in people's aggressive outcomes. One of the most popular psychological framework is the General Aggression Model (Anderson \& Bushman, 2002, 2018; see Figure 6). The model claims social-cognitive learning processes influence aggressiveness. Thus, violent videogame exposure may increase short-term aggression by enabling aggressive predispositions, in line with experimental research in the topic (Calvert et al., 2017). Furthermore, repeated violent media exposure may impact on personality characteristics, such as changing aggressive beliefs and attitudes or increasing aggression desensitization, 
what would make the individual more aggressive in the long-term, in line with longitudinal studies which find a small but significant effect over time (Prescott et al, 2018).

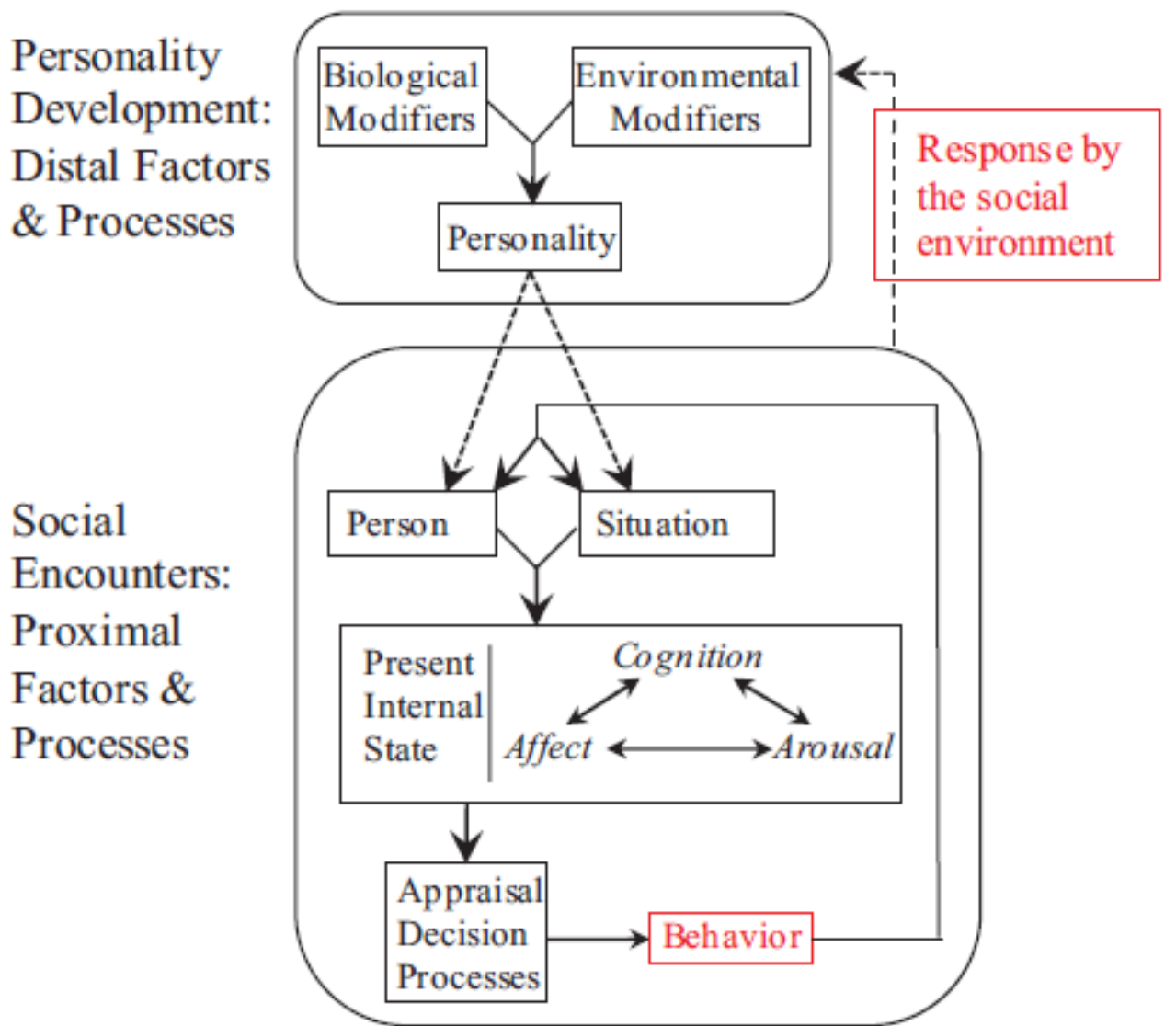

Figure 6. Overview of the General Aggression Model. Behavioral responses are due to the interaction of Social Encounters (e.g., VVE) and personality. Aggressive predispositions can be mitigated or encouraged by social learning processes. Extracted from Anderson \& Bushman (2018).

Other theoretical frameworks in aggression have diminished the role of social learning, and therefore the impact of VVE on aggression outcomes. For instance, the catalyst model affirms violent behaviors are mainly produced by genetic variables, and social environments are just means that could facilitate the expression of intrinsic aggressive predispositions (Tremblay, Vitaro, \& Côté, 2018). Thus, in the model, social or environmental factors, such as VVE or peers' influences, are seen as stylistic catalysts: aggressive individuals would act violently according to what they observe in media. 
Finally, the Differential Susceptibility to Media Effects Model (Valkenburg \& Peter, 2013) emerges as a framework to integrate social learning and biodispositional views in the study of the effects of media on individuals. Accordingly, media use may impact people differently according to individual differences, such as personality traits, and social context, such as group of friends. In this manner, VVE would influence aggressive behaviors in some people and not others because of their personal susceptibilities. This fact could explain why the link found between VVE and aggression is consistently so minor (Calvert et al., 2017). In this line, some studies have found moderating effects between VVE and personality traits on aggressive behaviors, such as in the case of aggressiveness traits (Anderson \& Dill, 2000; Markey \& Scherer, 2009) anger (Engelhardt, Bartholow, \& Saults, 2011; Giumetti \& Markey, 2007), psychoticism (Markey \& Scherer, 2009), and a combination of high neuroticism, low agreeableness and low conscientiousness (Markey \& Markey, 2010).

\subsection{Conclusion}

Personality and motives are two psychological variables extensively related to video game behaviors. Nevertheless, there are issues about their roles that must be looked into.

First of all, despite the fact that youngsters present the highest prevalence, the FFM personality studies focused on adolescents are scarce as well as the studies examining the relationship between personality and video game genre preferences. In addition, moderation associations in explaining disordered gaming should be explored, such as the combined effect of gender, personality and gaming frequency.

Secondly, although many studies have developed gaming motivations scales, a new scale must be built, where the motivational aspects most frequently observed in 
research are represented and could be used for general video gaming independently from game genre. It could unify the motivation research under the same labeling facilitating the comparison between studies.

Finally, as far as we know, the direct and indirect effects of basic personality traits through gaming motives on gaming behaviors have not been explored yet. Due to the important role of these variables to explain individual differences on gaming behaviors, this examination may be essential.

To solve these gaps found in research, the current thesis will try to add new empirical data in order to gain further knowledge about the relationships between these psychological variables with gaming behaviors. For that purpose, the influences of FFM personality and motives on different video gaming behaviors will be examined: disordered gaming, video gaming time and video game preferences.

On the other hand, with regard to the association of VVE and aggressive behaviors, research shows a small short-term effect of VVE on aggressive behaviors in adults. However, the association between VVE and aggressive behaviors has scarcely been examined controlling for other potential risk factors for aggression, such as personality and deviant peers, nor has their interaction been examined. Therefore, in order to overcome such limitations, it will be explored the additive and moderating role of VVE, personality and deviant peers in adolescent aggressive behaviors cross-sectionally and longitudinally. 


\section{CHAPTER 2: EXPERIMENTAL FRAMEWORK}

\subsection{Research approach}

\subsubsection{Aims of the research}

The aims of the current thesis are:

1. Study 1. Examining the role of FFM traits of personality on disordered gaming and video game preferences among adolescents. In addition, the differential role according to gender and moderation effect of gaming frequency among such personality associations was explored.

2. Study 2 . Given the diversity among gaming motives categorization found in the literature, the aim of the study was to develop and validate a questionnaire in which the motives most represented are reflected under unified labels, on adolescents and young adults. For that purpose, through a scoping review, the most frequent motives were extracted and related to disordered gaming, gaming use and game genre uses.

3. Study 3. Analyzing the direct and indirect effects of FFM factors through motives (those from study 2) on weekly and disordered gaming, on a sample of adolescents.

4. Study 4. Exploring the additive role of VVE, personality and deviant peers in aggression among adolescents, cross-sectionally and longitudinally (one year apart), and examining their possible interactions on aggressive behaviors. 


\subsubsection{Hypotheses}

Based on the previous literature review, the following findings are expected:

Study 1. The role of personality on disordered gaming and game genre preferences in adolescence: gender differences and person-environment transactions.

$\checkmark$ Personality will show a significant role on gaming behaviors, and its effects will be modulated according to gender and video game frequency.

- Low conscientiousness and high introversion will be associated with disordered gaming.

- Low agreeableness will be related to higher playing of fighting games.

- High openness will be associated with higher RPG use.

Study 2. The development and validation of the Videogaming Motives Questionnaire (VMQ).

$\checkmark$ The VMQ will show suitable reliability and validity scores.

$\checkmark$ The same factor structure will be reflected in both adolescent and young adult samples.

$\checkmark$ The motives will be related to gaming behaviors.

- Coping will be mainly related to disordered gaming.

- Social interaction will be principally associated with gaming use.

Study 3. Direct and indirect effects of personality through gaming motives on weekly and disordered gaming.

$\checkmark$ Personality will show direct and indirect effects through motives on gaming behaviors.

- Neuroticism will be related to disordered gaming due to its effect on coping motives. 
- Extraversion will be associated with social interaction and have a negative relationship with disordered gaming.

- Low conscientiousness will have a strong, direct effect on disordered gaming.

- Openness will show firm relationships with fantasy and customization.

- Low agreeableness will be associated with violent reward and competition.

Study 4. The role of violent videogame exposure, personality and deviant peers in aggressive behaviors among adolescents: a two-wave longitudinal study.

$\checkmark$ Personality and deviant peers will show a close relationship with adolescent aggressive behaviors.

$\checkmark$ VVE will have a slight but significant link with aggressive behaviors.

$\checkmark$ Moderation effects between VVE and deviant peers, and VVE and those personality traits more associated with aggressiveness will be found on aggressive behaviors.

- VVE will have a small long-term effect on aggression.

- Low agreeableness will be strongly associated with adolescent aggression. 


\subsection{Study 1}

Title: The role of personality on disordered gaming and game genre preferences in adolescence: gender differences and person-environment transactions.

Authors: Francisco J. López-Fernández, Laura Mezquita, Mark D. Griffiths, Generós Ortet and Manuel I. Ibáñez.

Journal: Adicciones 


\title{
The role of personality on disordered gaming and game genre preferences in adolescence: gender differences and person-environment transactions
}

\section{El papel de la personalidad en el juego problemático y en las preferencias de géneros de videojuegos en adolescentes}

\author{
Francisco J. López-Fernández*, Laura Mezquita****, Mark D. Griffiths****, Generós Ortet*,**, \\ MANUEL I. IBÁÑEZ***. \\ * Department of Basic and Clinical Psychology and Psychobiology, Universitat Jaume I, Castellón, Spain. \\ ** Instituto de Salud Carlos III, Centro de Investigación Biomédica en Red de Salud Mental (CIBERSAM), Castellón, Spain. \\ *** International Gaming Research Unit, Psychology Department, Nottingham Trent University, Nottingham, England, UK.
}

\begin{abstract}
Playing video games is one of the world's most popular leisure activities, especially for teenagers. The main aim of the present study was to examine additive and moderation effects of gender and personality to explain individual differences in problematic gaming and video game genre preferences in adolescence. 776 Spanish high school students (mean age $=14.29$ years, $S D=1.59,50.64 \%$ girls) completed the questionnaires of the Five-Factor Model of personality, frequency of video gaming, disordered use, and the video games they mostly played. Gender differences were observed for gaming behaviors: boys played more and presented much more disordered gaming than girls. Boys preferred competitive genres; for example, action-shooters, sport, fight and strategy games. Girls preferred nonviolent and ocasional game genres; for example, social simulation, and brain and skill games. Gender moderated the association between personality and disordered gaming: disordered gaming was associated with low agreeableness and low conscientiousness in boys, and with low extraversion and low conscientiousness in girls. Low consciousnness moderated the association between gaming frequency and problematic use of video games: playing more video games led to disordered gaming, mainly in irresponsible and impulsive individuals. Though small, significant associations were found among all of the personality domains and video game genre preferences. These findings highlight the relevance of gender and personality for gaming behaviors in adolescence, and suggest paying more attention to gender-dependent differences and person-environment transactional processes when studying gaming-related behaviors.

Keywords: Video games; Addiction; Game genres; Personality; Gender.
\end{abstract}

\section{Resumen}

Jugar a videojuegos es una de las actividades de ocio más populares en adolescentes. El principal objetivo de este estudio fue examinar los efectos aditivos y de moderación del género y la personalidad en el juego problemático y en la preferencia en géneros de videojuegos durante la adolescencia. 776 estudiantes españoles (media de edad = 14,$29 ; D T=1,59 ; 50,64 \%$ chicas) cumplimentaron cuestionarios del Modelo de los cinco grandes de personalidad y de conductas relacionadas con videojuegos. Se observaron diferencias de género en conductas relacionadas con videojuegos: los chicos jugaban más y presentaron mucho más uso problemático que las chicas. Ellos prefirieron géneros competitivos; por ejemplo, juegos de acción-shooters, deportes, lucha y estrategia. Las chicas prefirieron géneros no violentos y ocasionales; por ejemplo, simulación social, y juegos de habilidad y lógica. El género moderó las asociaciones entre personalidad y juego problemático: el juego problemático se asoció a baja amabilidad y baja responsabilidad en chicos, y a baja extraversión y baja responsabilidad en chicas. La baja responsabilidad moderó las asociaciones entre frecuencia de juego y uso problemático: jugar más a videojuegos conducía a un uso problemático de éstos, principalmente en individuos irresponsables e impulsivos. Se encontraron asociaciones pequeñas pero significativas entre la personalidad y preferencias en géneros de videojuegos. Estos hallazgos destacan la relevancia del género y la personalidad en las conductas relacionadas con videojuegos durante la adolescencia, y animan a prestar más atención a las diferencias dependientes del género y a las transacciones persona-ambiente al estudiar estas conductas.

Palabras clave: Videojuegos; Adicción; Géneros de videojuegos; Personalidad; Género.

Received: July 2019; Accepted: October 2019.

Send correspondence to: Manuel I. Ibáñez

Depart. of Basic and Clinical Psych. and Psychobiology, Univer. Jaume I, Av. de Vicent Sos Baynat, s/n, 12071 Castellón, Spain. Phone +34 964729690 E-mail: iribes@uji.es 
$\mathbf{P}$

laying video games has become one of the world's most popular leisure activities in recent decades (Entertainment Software Association -ESA2018). Approximately $47 \%$ of the Spanish population regularly plays video games (Asociación Española de Videojuegos -AEVI- 2018). For a minority of players, gaming can lead to negative effects that resemble the addiction components of other addictive disorders, including salience, mood modification, tolerance, withdrawal or relapse (Griffiths, 2005). Accordingly, DSM-5 (American Psychiatric Association -APA - 2013) has included Internet Gaming Disorder (IGD) as a potential behavioral addiction that deserves further study. Recently Gaming Disorder diagnosis has been incoporated into ICD-11 (Bobes, Flórez, Seijo \& Bobes, 2019; World Health Organization -WHO- 2017).

The prevalence of disordered gaming is estimated between 1-9\%, depending on cut-off criteria, age, gender or socio-cultural differences (Gentile, 2009; Gentile et al., 2017; Mihara \& Higuchi, 2017; Paulus, Ohmann, Von Gontard \& Popow, 2018). Disorder gaming may lead to loneliness and poor academic performance (Gentile et al., 2011; Lemmens, Valkenburg \& Peter, 2011), and has shown strong associatons with symptoms of affective, emotional and attention deficit hyperactivity disorders (González-Bueso et al., 2018; Mihara \& Higuchi, 2017; Müller et al., 2015). Therefore, a better understanding of the factors that facilitate disordered gaming would help prevent such detrimental effects.

One widely studied risk factor for IGD is personality (Gervasi et al., 2017; Mihara \& Higuchi, 2017; Paulus et al., 2018; Şalvarlı \& Griffiths, 2019). Personality traits have shown to be relevant in a wide variety of life outcomes (Ozer \& Benet-Martínez, 2006), including several addictive-related behaviors (Andreassen et al., 2013; Ibáñez et al., 2010; Mezquita et al., 2015). Nowadays, the most accepted personality framework of personality is the Five-Factor Model (FFM) (John, Naumann, \& Soto, 2008), which proposes five basic dimensions: extraversion, neuroticism, agreeableness, conscientiousness, and openness to experience (McCrae \& Costa, 2008). According to recent systematic reviews, the most consistently FFM personality domains related to IGD are neuroticism, low conscientiousness and low agreeableness (Gervasi et al., 2017; Şalvarlı \& Griffiths, 2019).

Most of these studies have been conducted with adults (e.g., Braun, Stopfer, Müller, Beutel \& Egloff, 2016; Charlton \& Danforth, 2007). Therefore, their relevance in preadolescence and adolescence is still not well-stablished. This is a major gap in IGD research because this lifespan stage is particularly important for the development of psychological problems associated with problematic video gaming (Mihara \& Higuchi, 2017; Paulus et al., 2018). As far as we know, very few studies have explored the association of FFM domains and disordered gaming in preadolescents and adolescents. At these ages, problematic video gaming has been consistently associated with low conscientiousness (García-Oliva
\& Piqueras, 2016; Vollmer, Randler, Horzum \& Ayas, 2014; Wang, Ho, Chan \& Tse, 2015). However, and with regard to other FFM dimensions, the results are less conclusive: low extraversion has been shown to be associated in two studies (García-Oliva \& Piqueras, 2016; Vollmer et al., 2014), whereas low agreeableness, high neuroticism (Vollmer et al., 2014) and low openness (Wang et al., 2015) only in one study. This scarce and somewhat inconsistent finding reveals the necessity for more research in the additive effects of personality on disordered video gaming during adolescence, which is our first study aim.

Another scarcely explored issue in the video games and personality field is person-environment transactional processes; i.e., how personality complexly interplays with the environment to influence behavior (Caspi \& Roberts, 2001). Such processes have been described in the video games and aggressivity field, with some studies suggesting that exposure to violent video games may promote aggressive behavior, but mainly in individuals with an aggressive personality (e.g., Anderson \& Dill, 2000; Markey \& Markey, 2010). This data may be indicative of a reactive transaction, i.e. different individuals face the same environment but react to it differently according to personality characteristics (Caspi \& Roberts, 2001). However, and as far as we know, the role of person-environment transactions in the development of disordered gaming remains uncharted. One environmental risk factor for IGD is the amount of time spent playing video games (Gentile, 2009; Mihara \& Higuchi, 2017), although only a minority of enganged players tends to develop problematic gaming (Charlton \& Danforth, 2007). This may be suggestive of a person-environment transactional process, i.e. higher gaming frequency would impact more negatively to certain gamers but not others because of their personal characteristics. Exploring if personality moderates the association of exposure to video games on gaming disorder is our second study aim.

Personality may also be relevant for genre gaming preferences but, as far as we know, this topic has not yet been explored in adolescents. Studies suggest that low agreeable adults would prefer violent video games (Chory \& Goodboy, 2011; Greitemeyer \& Sagioglou, 2017), extraverted gamers would prefer action games, and players high in openness would opt for role-playing games -RPGs- (Braun et al., 2016). It has been suggested that some genres may be more potentially addictive than others (Rehbein, Staudt, Hanslmaier, \& Kliem, 2016). Particularly, it has shown that preference of Role Playing Games (RPGs), shooter and simulation games contributes to elevated gaming time (Rehbein et al., 2016), and that RPGs, specially Massively Multiplayer Online Role-Playing Games (MMORPGs), and shooter games, tend to present the stronger associations with disordered gaming (Lemmens \& Hendrix, 2016; Müller et al., 2015). Therefore, exploring the personality characterstics related to genre preferences in adolescence is also a relevant issue, and is our third study aim. 
Last, another well-established risk factor for gaming-related behaviors is gender. Males play video games and experience disordered gaming much more than females (Mihara \& Higuchi, 2017; Paulus et al., 2018). Males also tend to prefer more competitive and aggressive video games genres, e.g. action-shooters or sports games. Females tend to prefer more casual nonviolent games, e.g., puzzles or platform genres (Lemmens \& Hendriks, 2016; Rehbein et al., 2016; Scharkow, Festl, Vogelgesang, \& Quandt, 2015). Yet despite these clear gender differences, the possibility that risk factors for disordered gaming were different for males and females has scarcely been studied. Regarding personality, as far as we know, only one study has explored the association between personality and adolescents disordered gaming separately for boys and girls (Garcia-Oliva \& Piqueras, 2016). It found that low conscientiousness and low extraversion were associated with addiction to video games in boys, but no significant effects of personality were noted for girls. Although this preliminary finding requires replication, it indicates that the possible gender-dependent role of personality on video game-related behaviors deserves more research attention, which is our fourth study aim.

In short, we have reviewed some relevant gaps regarding the role of gender and personality in the field of adolescent video game-related behaviors, and our main aim is to systematically explore them. Specifically, the additive role of gender and FFM personality traits will be examined in disordered gaming and game genres preferences. Additionally, we will explore the moderation role (a) of personality on the association between video game frequency and disordered gaming; and (b) of gender on the association between personality and video game-related behaviors. It was hypothesized that boys would present more problematic video gaming than girls, and that boys would prefer competitive and aggressive genres, whereas girls would opt for puzzle and casual games. Regarding the role of personality, low conscientiousness and low extraversion would be associated with disordered gaming, principally among boys. As studies about personality and genre preferences are scarce, no systematic hypotheses were proposed, but it could be expected low agreeableness to be associated with competitive genres, extraversion with action games, and openness with RPGs. Last, according to previous data on other topics such as violent video games and aggressive behavior, it was hypothetized that those personality risk factors for disordered gaming would interact with gaming frequency in predicting disordered gaming.

\section{Method}

\section{Participants and procedure}

The participants were recruited from two public high schools in the urban area of Castellón de la Plana, located in the east of Spain. Of the 1106 students invited to participate, 835 returned signed parental written consent. Of these, 59 participants did not attend asssessment sessions or did not complete all the questionnaires. The final sample consisted of 776 adolescents (393 girls), whose ages range was 12-17 years, with a mean age of 14.29 years $(S D=1.59)$.

This ex post facto and transversal study (Montero \& León, 2005) formed part of broader research about psychosocial risk factors involved in adolescent mental health. Trained research assistants administered a battery of questionnaires in three one-hour sessions separated by one week. Those students previously authorized by their parents/legal guardians voluntarily completed a socio-demographic survey together with the rest of the battery of self-administered and paper-pencil questionnaires. Research assistants gave detailed instructions to the students, highlighted the confidentiality of the data and the importance of the honesty in their responses, and helped the students when necessary (for more details see Moya-Higueras et al., 2018).

\section{Measures}

The JS NEO-A60, (Walker, López, \& Mezquita, 2018) was used to assess the FFM personality dimensions of neuroticism, extraversion, openness, agreeableness and conscientiousness. This scale is a 60-item abridged form of the Junior Spanish version of the NEO-PI-R (Costa \& McCrae, 1992), namely the JS NEO (Ortet et al., 2012), which replicated satisfactorily the adult NEO-PI-R factor structure in samples aged from 12 to 17 years and showed adequate scores in reliability (every personality trait showed a coefficient $\alpha$ higher than .82) and construct validity (a joint factor analysis of the test and a Big Five questionnaire focused on children was provided). The Cronbach's alphas for this study were .83 for neuroticism, .83 for extraversion, .75 for openness, .82 for agreeableness, and .89 conscientiousness.

Gaming frequency was reported on a 6-point Likert scale (from $0=$ "never or almost never" to $5=$ "between 3 to 5 hours a day"). Furthermore, players reported up to five of their most frequently played video games, which were categorized according to previous studies (e.g., Lemmens \& Hendriks, 2016; Rehbein et al., 2016) as: action-shooter (e.g., Call of Duty); sports (e.g., FIFA, also including driving sports like MotoGP); strategy (mainly MOBA games, e.g. Clash Royale); brain+skill (including highly intercorrelated genres - Rehbein et al., 2016-: puzzle brain games, e.g. Candy Crush Saga; puzzle skills games, e.g. Piano Tiles; fitness games, e.g. Wii Sports; and skill platform games, e.g. Super Mario Bros); adventure (including adventure games without shooter components, e.g. Assassins' Creed); social simulation (e.g., The Sims); construction (e.g., Minecraft); RPGs (e.g., Skyrim, including MMORPGs, e.g. World of Warcraft ); and fighting (e.g., Mortal Kombat).

A Spanish adaptation of a disordered gaming scale for youths was employed (Gentile, 2009). The original 11 items was back-translated, which included addiction components such as salience, mood modification, tolerance, withdraw- 
al or relapse. Those participants considered pathological gamers by the original scale's study displayed higher spent time on gaming, lower academic performance, and attention problems (Gentile, 2009). For the current study, the participants indicated their frequency of video game-related problems on a 4-point Likert scale (from $0=$ "never or almost never" to 3 "almost always or always") during the last 12 months. According to the parallel analysis run using Monte Carlo PCA (Watkins, 2006), a one-factor structure was obtained with the EFA, where all items presented adequate factor loadings ranging from .49 to .81. Cronbach's alpha in this sample was .88. In order to establish the cut-off point for the categorization of disordered gamer, we followed the procedure of the original study (Gentile, 2009). Specifically, we coded categories "almost always or always" and "many times" as 1 , category "sometimes" as .5, and "never or almost never" as 0 , and those adolescents who exhibited at least 6 of the 11 criteria assessed by the scale were considered pathological gamers.

\section{Statistical analysis}

Version 21 of the SPSS statistic package was used to calculate the descriptive statistics, correlations, t-test analyses and multiple linear regression analyses. Those missing values that represented less than $5 \%$ in a questionnaire were replaced with the mean score of the items remaining in that scale. In order to depict graphically interactions between personality risk factors and gaming frequency in disordered gaming; it was employed the InterActive software, an open-source analysis and data-visualization application (McCabe, Kim \& King, 2018).

\section{Ethics}

This research was approved by the Ethical Committee of the Universitat Jaume I, and was authorized by the School Board of the participating high schools and by the Regional Valencian Authorities. Participants and their parents/legal guardians were informed about the study and provided parental informed consent. All the study procedures were followed in accordance with the Declaration of Helsinki.

\section{Results}

Regarding the descriptive data, 560 of the 776 participants reported playing video games in the last month, $92.69 \%$ for 383 boys and $52.16 \%$ for 393 girls. In addition, $38.9 \%$ of boys and $8.3 \%$ of girls played daily. Moreover, $6.4 \%$ of all the participants were labeled as "disordered gamers", $11.1 \%$ boys (43 individuals) and $0.8 \%$ girls (3). The $t$-test analyses showed that girls presented lower gaming frequency (Cohen's $d=1.26, p<.001$ ), and higher scores for openness (Cohen's $d=.54, p<.001$ ), neuroticism (Cohen's $d=$ $.43, p<.001$ ), agreeableness (Cohen's $d=.30, p<.001$ ) and conscientiousness (Cohen's $d=.23, p<.001$ ) than boys.
Multiple linear regression analyses were run to explore if personality predicted gaming frequency, but only openness presented a significative association that explained $1.3 \%$ of variance $(b=.08, p=.01)$ after controlling for age and gender (age; $b=-.05, p=.070$; gender; $b=.54, p=.000$ ). The additive role of age, gender, personality and gaming frequency was explored on disordered gaming. In addition, it was also examined in a last step: a) if gender moderated the prediction of personality and gaming frequency on disordered gaming; and b) the moderation role of personality in the gaming frequency-disordered gaming association. All the possible relevant interactions were included in the regression model in this last step to control for potential confounders, according to the recommendations by Keller (2014). Interactions between personality and gaming frequency were found (conscientiousness x gaming $b=-.09 ; p=.007$ ) as well as between gender and personality (agreeableness $\mathrm{x}$ gender, $b=.09 ; p$ $=.008$; conscientiousness $\mathrm{x}$ gender; $b=.15 ; p=.000)$. These two last interactions indicated that the association between some personality domains and disordered gaming differed for boys and girls. Consequently, the regression analyses were performed separately for each gender.

Table 1 presents the regression analyses for the whole sample, and also for boys and girls separately. Low conscientiousness was associated with disordered gaming for both genders. Low agreeableness was related to pathological gaming among males, whereas low extraversion and high openness were associated with disordered gaming in females. Gaming frequency was also related to disordered gaming for both genders. A significant gaming frequency-low conscientiousness interaction was found for both boys and girls.

Table 1. Multiple Linear Regressions of Disordered Gaming as Dependent Variable.

\begin{tabular}{|c|c|c|c|c|}
\hline & & \multicolumn{3}{|c|}{ Disordered gaming } \\
\hline & & $\begin{array}{c}\text { Total sample } \\
(776)\end{array}$ & $\begin{array}{c}\text { Males } \\
(383)\end{array}$ & $\begin{array}{c}\text { Females } \\
(393)\end{array}$ \\
\hline \multicolumn{5}{|l|}{$\overline{\text { Step } 1}$} \\
\hline & Gender & $-.44 * \star \star$ & - & - \\
\hline & Age & $.07^{\star}$ & .09 & .05 \\
\hline & $\Delta \mathrm{R}^{2}$ & $.20^{\star \star \star}$ & .01 & .01 \\
\hline \multicolumn{5}{|l|}{ Step 2} \\
\hline & Neuroticism (N) & .04 & .09 & .03 \\
\hline & Extraversion (E) & -.06 & -.01 & $-.20 * \star \star$ \\
\hline & Openness (0) & .06 & .04 & $.11^{\star}$ \\
\hline & Agreeableness (A) & $-.13^{\star \star}$ & $-.17^{\star \star}$ & -.05 \\
\hline & Conscientiousness (C) & $-.18^{\star \star \star}$ & $-.27^{\star \star \star}$ & $-.12^{\star}$ \\
\hline & $\Delta \mathrm{R}^{2}$ & $.07^{\star \star \star}$ & $.15^{\star \star \star}$ & $.08^{\star \star \star}$ \\
\hline \multicolumn{5}{|l|}{ Step 3} \\
\hline & Gaming frequency & $.25^{\star \star \star}$ & $.24^{\star \star \star}$ & $.30 * \star \star$ \\
\hline & $\Delta \mathrm{R}^{2}$ & $.04^{\star \star \star}$ & $.06^{\star \star \star}$ & $.09^{\star \star \star}$ \\
\hline \multicolumn{5}{|l|}{ Step 4} \\
\hline & NxGaming frequency & .01 & .04 & .02 \\
\hline & ExGaming frequency & .00 & .01 & -.03 \\
\hline & OxGaming frequency & .01 & .00 & .05 \\
\hline & AxGaming frequency & .05 & .05 & .09 \\
\hline & CxGaming frequency & $-.08 *$ & $-.11^{\star}$ & $-.13^{\star}$ \\
\hline & $\Delta R^{2}$ & .01 & .01 & .02 \\
\hline & $\mathrm{R}^{2}$ & .32 & .22 & .19 \\
\hline
\end{tabular}

Note. Males were assigned 1 and females were assigned 2

${ }^{\star} p<.05 .{ }^{\star \star} p<.01 .{ }^{\star \star \star} p<.001$. 

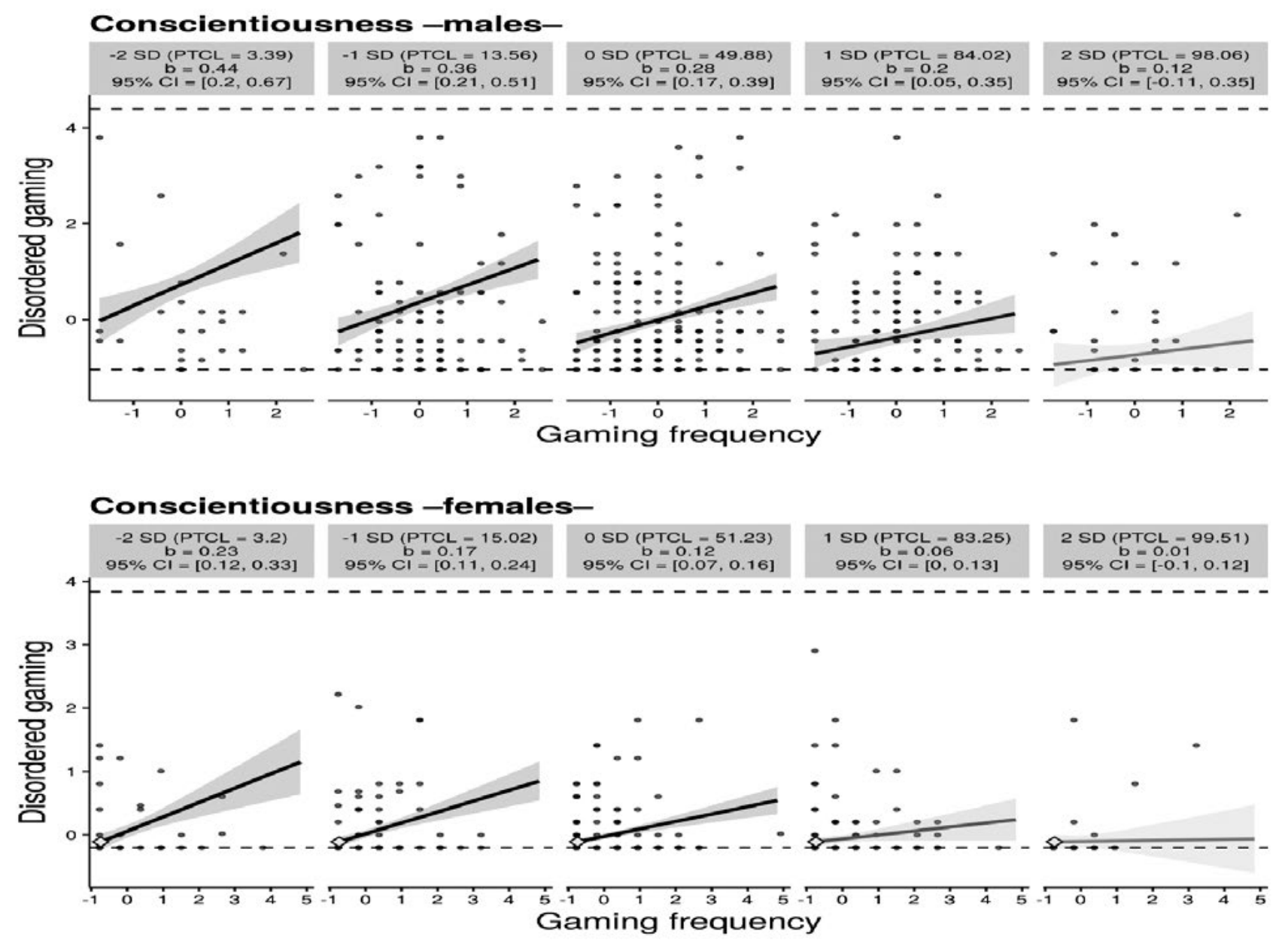

Figure 1. Illustrations of moderating effects between conscientiousness with gaming frequency on disordered gaming. Simple slopes are provided for levels of the moderator 2 SD and 1 SD below the mean, at the mean, and 1 SD and 2 SD above the mean. Each graphic shows the computed $95 \%$ confidence region (shaded area), the observed data (gray circles), the maximum and minimum values of the outcome (dashed horizontal lines), and the crossover point (diamond). The $x$-axes represent the full range of the focal predictor. $\mathrm{Cl}=$ confidence interval; PTCL = percentile.

Figure 1 graphically presents the interactions found in the regression analyses. It depicts the negative impact of gaming frequency on problematic gaming according to different levels of conscientiousness as a moderator. The results showed that gaming frequency was highly associated with disordered gaming at low conscientiousness levels, whereas no associations appeared at high conscientiousness levels.

Multiple linear regressions were peformed for each game genre with 547 participants (375 males, 172 females) who indicated the name of at least one played video game. The role of age, gender, personality and gender-personality interactions was explored. It was found no moderation effects of gender on most genres, except for action-shooter (extraversion x gender; $b=-.09 ; p=.032$ ) and social simulation (openness $\mathrm{x}$ gender; $b=.10 ; p=.03$ ) games. The regression analyses for the whole sample are presented in Table 2.

Regarding gender and genre preferences, the regression coefficients indicated that boys prefered playing more competitive games, (action shooter, sports games, strategy and fighting games), and girls reported using more social simulation and brain+skill games. For personality, all the dimensions presented minor associations with genre preferences. The most played genres (action-shooter, sports) presented a similar pattern of associations, with less openness and more extraverted teenagers prefering these games (in action-shooter, this pattern was found only for boys; for extraversion, $b=.15 ; p=.006$; for openness, $b=-.10 ; p=$ $.069)$. Strategy games were asociated with low aggreableness. Brain+skill category was associated with openness and conscientiousness. Social simulation and adventure games presented a similar pattern of relationships, with open to experience and introverted youngsters preferring these genres (in social simulation games, these effects were more evident in females; for extraversion, $b=-.15$; $p=.073$; for openness, $b=.14 ; p=.085)$. Construction games were predicted by neuroticism. Fighting games were associated with low aggreeableness, low consciousness and openness. Openness, low conscientiousness and introverson predicted preferences for RPGs games. 
Tabl6 2. Multiple Linear Regressions of the Videogame Genres as Dependent Variables.

\begin{tabular}{|c|c|c|c|c|c|c|c|c|c|c|}
\hline & $\begin{array}{l}\text { Game Genre } \\
\text { ( } n \text { of players) }\end{array}$ & $\begin{array}{l}\text { Action } \\
\text {-shooter } \\
\text { (292) }\end{array}$ & $\begin{array}{l}\text { Sport } \\
(251)\end{array}$ & $\begin{array}{c}\text { Strategy } \\
(175)\end{array}$ & $\begin{array}{l}\text { Brain +Skill } \\
\quad(152)\end{array}$ & $\begin{array}{l}\text { Adventure } \\
\text { (65) }\end{array}$ & $\begin{array}{c}\text { Social } \\
\text { simulation } \\
\quad(47)\end{array}$ & $\begin{array}{c}\text { Construction } \\
(40)\end{array}$ & $\begin{array}{l}\text { Fighting } \\
\text { (32) }\end{array}$ & $\begin{array}{l}\text { RPG } \\
(31)\end{array}$ \\
\hline \multirow[t]{3}{*}{ Step 1} & Gender & 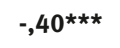 &,$- 26 * \star *$ & 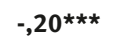 &, $41^{\star \star \star}$ &,- 06 &, $35^{\star \star \star *}$ &,- 09 &,$- 16 * * *$ &,- 06 \\
\hline & Age &,- 05 &,- 01 &,- 02 &,- 07 &,- 03 &,$- 12^{\star \star}$ &,$- 14^{\star *}$ & ,01 & ,02 \\
\hline & $\Delta R^{2}$ &, $15^{\star \star \star}$ &, $06 * * *$ &, $04^{\star \star \star}$ &, $17^{\star \star \star}$ & ,01 &, $15^{\star \star *}$ &, $03^{* *}$ &, $02^{* *}$ &, 00 \\
\hline \multirow[t]{7}{*}{ Step 2} & Neuroticism & ,03 &,- 05 &,- 04 &, 03 & ,02 &,- 02 &, $17^{\star \star \star}$ &,- 08 &, 05 \\
\hline & Extraversion &, $10^{*}$ &, $09 *$ &,- 05 &, 05 &,$- 09 *$ &,$- 09 *$ & 01 &, 00 &,$- 10^{*}$ \\
\hline & Openness &,$- 11^{*}$ &,$- 10^{\star *}$ &, 04 &, $12^{* *}$ &, $10^{*}$ &, $09 *$ &, 06 &, $10^{*}$ &, $19 * * *$ \\
\hline & Agreeableness & ,04 & ,03 &,$- 14^{\star \star}$ &, 05 &,- 03 &,- 03 &, 04 &,- 16 ** &,- 02 \\
\hline & Conscientiousness &, 06 &,- 03 &,- 01 &, $11^{*}$ &,- 03 &, 01 &, 00 &,$- 11^{*}$ &,$- 11^{*}$ \\
\hline & $\Delta R^{2}$ &, $02^{*}$ & $02^{*}$ &, 02 &, $04^{*}$ &, 02 &, 01 &, $03^{* *}$ &, $04^{\star \star}$ &, $05^{\star * *}$ \\
\hline & $R^{2}$ & ,17 & 10, & ,06 & ,21 & ,01 & 16, & ,06 & ,05 & ,05 \\
\hline
\end{tabular}

Note. RPG = Role-playing Game; $b=$ standardized beta; $\Delta R^{2}=$ change in variance; $R^{2}=$ total $R^{2}$. Males were assigned 1 and females were assigned 2 .

${ }^{\star} p<.05 .{ }^{\star *} p<.01,{ }^{\star \star *} p<.001$.

\section{Discussion}

The present study shows the relevance of personality and gender for disordered gaming and game genre preferences in adolescents. As it was hypothetized, boys showed much more disordered gaming and preferred different game genres than girls. Furthermore, specific profiles of personality seemed to modestly guide the preference for certain genres. Personality also showed rellevance for disordered gaming, with low conscientiousness to be related in both boys and girls, and other FFM dimensions showing gender-dependent associations: low agreeablennes in boys, and introversion and high openness in girls. Last, we also found person-environment transactional process in disordered gaming: a higher frequency of video gaming appeared to impact more negatively in some players than others, partially because of its personality characteristics; thus low conscioncious adolescents who played more frequenly tended to present higher disordered gaming levels than other youngsters.

In our sample, $72.16 \%$ played video games in the last month, which is a very similar percentage of gamers reported in Spain (Buiza-Aguado, Alonso-Canovas, Conde-Mateos, Buiza-Navarrete \& Gentile, 2018). Nevertheless, the percentage of daily gamers was much lower $(22.7 \%)$, another comparable result found among Spanish adolescents (Gonzálvez, Espada \& Tejeiro, 2016). In addition, 6.4\% of the total sample was categorized as disordered gamers, which is similar to the original study estimated prevalence of $7.5 \%$ (Gentile, 2009), to the estimates of $7.7 \%-8.3 \%$ of the pathological gaming prevalences in Spanish adolescents (Buiza-Aguado et al., 2018; Lopez-Fernandez, Honrubia-Serrano, Baguley \& Griffiths, 2014), and to the $5.1 \%$ estimate of IGD risk in a representative European adolescent sample (Müller et al., 2015).
Regarding the role of gender, boys were much more likely to play video games and to show disordered gaming than girls, as previously found (Mihara \& Higuchi, 2017; Paulus et al., 2018). Genre preferences were also affected by gender, with girls preferring social simulation and mental/skill puzzle games; while boys choose competitive and aggressive video games, e.g. action-shooter, sports, strategy and fighting games, which fall in line with previous research (e.g., Lemmens \& Hendriks, 2016; Rehbein et al., 2016; Scharkow et al., 2015). Gender differences on personality may partially explain these findings. Girls tend to show higher scores in openness whereas boys tend to present lower levels of agreeableness (e.g., Ortet et al., 2012; Costa \& McCrae, 1992), what may led girls to prefer more intellectual video games whereas led boys to play more competitive and violent ones. These gender-based differences on genre preferences may help to explain why males, who prefer games featuring more time-consuming and engagement characteristics, get more involved in gaming and are more hard-core players than females (Rehbein et al., 2016; Scharkow et al., 2015).

In relation to personality, our results replicated the role of low conscientiousness observed in adults (Gervasi et al., 2017; Şalvarlı \& Griffiths, 2019) and in the few studies done with adolescents (García-Oliva \& Piqueras, 2016; Vollmer et al., 2014; Wang et al., 2015). The other relevant personality domain for video game addiction in adulthood is neuroticism (Gervasi et al., 2017; Şalvarlı \& Griffiths, 2019). Nevertheless, no effect of this dimension was found in adolescent disordered gaming, which agrees with other studies in youngsters (García-Oliva \& Piqueras, 2016; Wang et al., 2015). Collectively, these results suggest that negative emotionality is less important for disordered gaming in adolescence than in later life stages. 
Other personality factors that have also been associated with adolescent disordered gaming are introversion (Garcia-Oliva \& Piqueras, 2016; Vollmer et al., 2014) and low agreeableness (Vollmer et al., 2014). Our data support the relevance of these personality characteristics, but suggest a differential role according to gender: introversion was related to disordered gaming in females while low agreeableness presented a significant relation for males. This latter association may imply that competitive and aggressive motives seem more relevant for boys and lead to greater gaming perseverance despite their negative consequences (Vollmer et al., 2014). The role of introversion in disordered gaming exclusively for girls can be explained by the gender differences associated with game genre preferences. Girls preferred social simulation and brain/skill games with fewer social and exciting components than other genres like action-shooter or sport games, which are mainly preferred by boys. Playing these games constitutes a solitary leisure activity, and girls with few social skills (Gentile et al., 2011; Kowert, Vogelgesang, Festl \& Quandt, 2015) and introverted characteristics (Garcia-Oliva \& Piqueras, 2016; Vollmer et al., 2014) would be at increased risk of disordered gaming. Although these suggestive findings require replication, they imply that future research should pay more attention to gender-dependent differences in risk and protective variables involved in gaming-related behaviors.

Another risk factor for IGD is gaming frequency (Gentile, 2009; Mihara \& Higuchi, 2017; Vollmer et al., 2014). In our study, gaming frequency was related to disordered gaming, but the magnitude of this association was between low and moderate. This effect size may suggest that the detrimental effects of longer video gaming would affect some adolescents but not others. Accordingly, it was found that the amount of time playing video games would more negatively impact those adolescents who are less responsible and more impulsive. The effects of this interaction have been found for both genders, and remained robust when controlling for other interaction confounders (Keller, 2014). Similar moderation effects have been described in video gaming-related behaviors. It has been shown that exposure to violent video games adversely affects mainly those individuals with aggressive-related personality dispositions, which make them susceptible to such violent media (e.g., Anderson \& Dill, 2000; Markey \& Markey, 2010). Similar effects have been observed in other addictive behaviors, such as alcohol use, where environmental risk factors (i.e. poor parental monitoring and high alcohol availability) seem to exert detrimental effects on drinking behavior mainly in disinhibited youngsters (Pedersen \& McCarthy, 2008). Altogether, these findings would reflect person-environment transactional processes (Caspi \& Roberts, 2001), which suggest that low conscientiousness and impulsive trais would exacerbate the harmful effects of environmental risk factors on addictive behaviors.
Regarding gaming genre preferences, the present study found a minor, but significant, role of personality. Openness was related to playing RPGs, brain+skills, adventure, fighting, and social simulation games. RPGs, adventure, and fighting games involve fantastic and unrealistic elements, so those youngsters with a fertile imagination can be more attracted by them (Braun et al., 2016). Open-to-experience individuals, especially girls, would also prefer less conventional and mentally challenging game genres, such as brain+skill and social simulation games, whereas low-open adolescents would prefer more conventional and realistic games like sports and action-shooter games. Extraversion also plays a significant role when choosing games. Action-shooters and sports genres were associated with extraversion, probably because these games contain a more social component (e.g., multiplayer online features) and tend to be more exciting and arousing (Braun et al., 2016; Chory \& Goodboy, 2011). In contrast, introverted adolescents tend to prefer RPG, adventure, and social simulation games. These data suggest that introverted players would prefer to spend their time playing more solitary games, some of them to cope with their social necessities by simulating social interactions in a virtual world (Kowert et al., 2015). Low agreeable players tend to choose fighting and strategy games (mainly MOBA), probably because of their competitive tendencies and the violent gratification of in-game fighting (Chory \& Goodboy, 2011; Greitemeyer \& Sagioglou, 2017). Consciousness was also relevant for game preferences, with high scores for choosing "positive" and "responsible" games like training games for cognitive and psychomotor abilities. Conversely, low consciousness predicted fighting and RPGs preferences, genres that usually involve a lot of time on gaming (Rehbein et al., 2016) and have been associated with an increased IGD risk (Lemmens \& Hendrix, 2016). Finally, neuroticism was associated with construction games (e.g., Minecraft). Neuroticism has been related to obsessive-compulsive symptoms (e.g., Samuels et al., 2000), which could explain why high players in neuroticism prefer playing them where the performed activity is repetitive.

This study presented some limitations. First, the study consisted of a convenience sample since the high schools were not randomly chosen. Second, the data were collected via self-report questionnaires, so data may be affected by biases such as social desirability. Third, the assignation of a given game to a specific genre was artificial to some extent because games usually include mixed features from different genres. Furthermore, there was a significant range restriction for the game genres variable (participants were allowed to mention up to five games, but of the nine genres, only one, presented a range from 0 to 5 ). This range restriction, together with the relative heterogeneity of the games included in each genre, may explain partially the small effect sizes found in the genres-personality as- 
sociation. Fourth, the 'disordered gamers' categorization should be better understood as an index of problematic video game use instead of a clinical IGD diagnosis. In addition, the original scale (Gentile, 2009) was developed before the inclusion of the IGD in the DSM-5. Therefore, the study's prevalence could be underestimated due to the fact that the DSM- 5 establishes 5 criteria for IGD diagnosis instead of the 6 that our study scale uses. Furthermore, the cut-off point could vary due to cultural differences and gamer profiles (Bernaldo-de-Quirós, Labrador-Méndez, Sánchez-Iglesias \& Labrador, 2019). Last, causal inferences should not be made because of this study's cross-sectional design. Personality traits may predispose to gaming behaviors, but video games have been shown to also influence certain personality characteristics (e.g., Greitemeyer \& Sagioglou, 2017). Further research should examine the longitudinal relationships between personality and gaming to establish the direction that underlies the associations of the examined variables. Despite these limitations, this study also presents some remarkable strengths. It deals with the relatively unexplored topic of the role of gender and personality on the use and abuse of video games in adeolescence. To this end, instruments with sound psychometric qualities were administered in a relatively wide sample of preadolescents and adolescents, and followed a novel approach by examining the moderator role of gender and personality in disordered gaming.

The present study highlights the importance of gender and personality in explaining gaming behavior. Boys prefer more competitive aggressive video games, whereas females opt for more nonviolent and occasional games. Distinct personality characteristics appeared to be differentially involved in disordered gaming for boys and girls: low conscientious and introverted girls and low conscientious and disagreeable boys presented higher disordered gaming levels. Personality moderated the negative impact of gaming frequency on problematic gaming: regular video game use was related to disordered gaming mainly in low conscientious adolescents. Last, different personality profiles would partly guide the choice of specific video games. These findings may help us to better understand the adolescent gaming field, and might be useful for developing personalized treatment programs and prevention strategies for problematic video game use based on gender and/or personality characteristics, in line with personality-targeted prevention and intervention programs developed for other addiction-related behaviors (Conrod, 2016).

\section{Acknowledgement}

This study was supported by grants from the Banco de Instrumentos de Cibersam; PSI2015-67766-R from the Spanish Ministry of Economy and Competitiveness (MINECO/FEDER), RTI2018-099800-B-I00 from the
Spanish Ministry of Science, Innovation and Universities, GV/2016/158 from the Valencian Regional Government; and UJI-A2017-18, UJI-B2017-74 and E-2018-16 from the Universitat Jaume I.

\section{Conflict of interest}

The authors declare no conflict of interests.

\section{References}

American Psychiatric Association (2013). Diagnostic and statistical manual of mental disorders (5th ed.). Arlington, VA: American Psychiatric Publishing. doi: 10.1176/appi. books.9780890425596.

Anderson, C. A. \& Dill, K. E. (2000). Video games and aggressive thoughts, feelings, and behavior in the laboratory and in life. Journal of Personality and Social Psychology, 78, 772-790. doi:10.1037/0022-3514.78.4.772.

Andreassen, C. S., Griffiths, M. D., Gjertsen, S. R., Krossbakken, E., Kvam, S. \& Pallesen, S. (2013). The relationships between behavioral addictions and the five-factor model of personality. Journal of Behavioral Addictions, 2, 90-99. doi:10.1556/jba.2.2013.003.

Asociación Española de Videojuegos (2018). The Yearbook of Videogames 2018. Retrieved at: http://www.aevi.org. es/web/wp-content/uploads/2019/05/AEVI_Anuario_2018.pdf.

Bernaldo-de-Quirós, M., Labrador-Méndez, M., Sánchez-Iglesias, I. \& Labrador, F.J. (2019). Measurement instruments of online gaming disorder in adolescents and young people according to DSM- 5 criteria: a systematic review. Adicciones. Advance publication online. doi:10.20882/adicciones.1277.

Bobes, B. M., Flórez, G., Seijo, P. \& Bobes, G. J. (2019). Does ICD-11 improve the epidemiological and nosological purposes of mental, behavioral and developmental disorders?. Adicciones, 31, 183-188. doi:10.20882/adicciones. 1368 .

Braun, B., Stopfer, J.,Müller, K., Beutel, E. \& Egloff, B. (2016). Personality and video gaming: Comparing regular gamers, non-gamers, and gaming addicts and differentiating between game genres. Computers in Human Behavior, 55, 406-412. doi:10.1016/j.chb.2015.09.041.

Buiza-Aguado, C., Alonso-Canovas, A., Conde-Mateos, C., Buiza-Navarrete, J. J. \& Gentile, D. (2018). Problematic video gaming in a young Spanish population: association with psychosocial health. Cyberpsychology, Behavior, and Social Networking, 21, 388-394. doi:10.1089/ cyber.2017.0599.

Caspi, A. \& Roberts, B. W. (2001). Personality development across the life course: The argument for change and continuity. Psychological Inquiry, 12, 49-66. doi:10.1207/ s15327965pli1202_01. 
Charlton, J. P. \& Danforth, I. D. (2007). Distinguishing addiction and high engagement in the context of online game playing. Computers in Human Behavior, 23, 15311548. doi:10.1016/j.chb.2005.07.002.

Chory, R. \& Goodboy, A. K. (2011). Is basic personality related to violent and non-violent video game play and preferences? Cyberpsychology, Behavior and Social Networking, 14, 191-198. doi:10.1089/cyber.2010.0076.

Conrod, P. J. (2016). Personality-targeted interventions for substance use and misuse. Current Addiction Reports, 3, 426-436. doi:10.1007/s40429-016-0127-6.

Costa, P. T. \& McCrae, R. R. (1992). Revised NEO personality inventory (NEO-PI-R) and NEO five-factor inventory (NEOFFI) professional manual. Odessa, FL: Psychological Assessment Resources.

Entertainment Software Association (2018). Essential facts about the computer and videogame industry. Retrieved at http://www.theesa.com/wp-content/uploads/2018/05/EF2018_FINAL.pdf.

García-Oliva, C. \& Piqueras, J. A. (2016). Experiential avoidance and technological addictions in adolescents. Journal of Behavioral Addictions, 5, 293-303. doi:10.1556/2006.5.2016.041.

Gentile, D. (2009). Pathological video-game use among youth ages 8 to 18: a national study. Psychological Science, 20, 594-602. doi:10.1111/j.1467-9280.2009.02340.x.

Gentile, D. A., Bailey, K., Bavelier, D., Brockmyer, J. F., Cash, H., Coyne, S. M., ... Young, K. (2017). Internet Gaming Disorder in children and adolescents. Pediatrics, 140, S81-S85. doi:10.1542/peds.2016-1758h.

Gentile, D. A., Choo, H., Liau, A., Sim, T., Li, D., Fung, D., ... Khoo, A. (2011). Pathological video game use among youths: A two-year longitudinal study. Pediatrics, 127, 319-329. doi:10.1542/peds.2010-1353.

Gervasi, A. M., La Marca, L., Costanzo, A., Pace, U., Guglielmucci, F. \& Schimmenti, A. (2017). Personality and Internet gaming disorder: a systematic review of recent literature. Current Addiction Reports, 4, 293-307. doi:10.1007/s40429-017-0159-6.

González-Bueso, V., Santamaría, J., Fernández, D., Merino, L., Montero, E. \& Ribas, J. (2018). Association between internet gaming disorder or pathological video-game use and comorbid psychopathology: a comprehensive review. International Journal of Environmental Research and Public Health, 15, 668-687. doi:10.3390/ijerph15040668.

Gonzálvez, M. T., Espada, J. P. \& Tejeiro, R. (2017). Problem video game playing is related to emotional distress in adolescents. Adicciones, 29, 180-185. doi:10.20882/ adicciones.745.

Greitemeyer, T. \& Sagioglou, C. (2017). The longitudinal relationship between everyday sadism and the amount of violent video game play. Personality and Individual Differences, 104, 238-242. doi:10.1016/j.paid.2016.08.021.
Griffiths, M. D. (2005). A 'components' model of addiction within a biopsychosocial framework. Journal of Substance Use, 10, 191-197. doi:10.1080/14659890500114359.

Ibáñez, M. I., Moya, J., Villa, H., Mezquita, L., Ruipérez, M. Á. \& Ortet, G. (2010). Basic personality dimensions and alcohol consumption in young adults. Personality and Individual Differences, 48, 171-176. doi:10.1016/j. paid.2009.09.017.

John, O. P., Naumann, L. P., \& Soto, C. J. (2008). Paradigm shift to the integrative big five trait taxonomy. Handbook of personality: Theory and research, 3, 114-158.

Keller, M. C. (2014). Genex environment interaction studies have not properly controlled for potential confounders: the problem and the (simple) solution. Biological Psychiatry, 75, 18-24. doi:10.1016/j.biopsych.2013.09.006.

Kowert, R., Vogelgesang, J., Festl, R. \& Quandt, T. (2015). Psychosocial causes and consequences of online video game play. Computers in Human Behavior, 45, 51-58. doi:10.1016/j.chb.2014.11.074.

Lemmens, J. S. \& Hendriks, S. J. F. (2016). Addictive online games: Examining the relationship between game genres and Internet Gaming Disorder. Cyberpsychology, Behavior, and Social Networking, 19, 270-276. doi:10.1089/ cyber.2015.0415.

Lemmens, J. S., Valkenburg, P. M. \& Peter, J. (2011). Psychosocial causes and consequences of pathological gaming. Computers in Human Behavior, 27, 144-152. doi:10.1016/j. chb.2010.07.015.

Lopez-Fernandez, O., Honrubia-Serrano, M. L., Baguley, T. \& Griffiths, M. D. (2014). Pathological video game playing in Spanish and British adolescents: Towards the exploration of Internet Gaming Disorder symptomatology. Computers in Human Behavior, 41, 304-312. doi:10.1016/j.chb.2014.10.011.

Markey, P. M. \& Markey, C. N. (2010). Vulnerability to violent video games: A review and integration of personality research. Review of General Psychology, 14, 82-91. doi:10.1037/a0019000.

McCabe, C., Kim, D. \& King, K. (2018). Improving Present Practices in the Visual Display of Interactions. Advances in Methods and Practices in Psychological Science, 1, 147-165. doi: $10.1177 / 2515245917746792$.

McCrae, R. R. \& Costa, P. T. (2008). Empirical and theoretical status of the five-factor model of personality traits. In: G. J. Boyle, G.Matthews, \& D. H. Sakloske (eds.). Personality theory and assessment. Personality theories and models, Vol. 1, (pp. 273-294). London: Sage. doi:10.4135/9781849200462.n13.

Mezquita, L., Ibáñez, M. I., Villa, H., Fañanás, L., Moya-Higueras, J. \& Ortet, G. (2015). Five-factor model and internalizing and externalizing syndromes: A 5-year prospective study. Personality and Individual Differences, 79, 98-103. doi:10.1016/j.paid.2015.02.002. 
Mihara, S. \& Higuchi, S. (2017). Cross-sectional and longitudinal epidemiological studies of internet gaming disorder: A systematic review of the literature. Psychiatry and Clinical Neurosciences, 71, 425-444. doi:10.1111/ pcn.12532.

Montero, I. \& León, O. G. (2005). Sistema de clasificación del método en los informes de investigación en Psicología. International Journal of Clinical and Health Psychology, 5, 115-127.

Moya-Higueras, J., Cuevas, A., Marques-Feixa, L., Mezquita, L., Mayoral, M., Fañanás, L., ... \& Ibáñez, M. I. (2018). Recent Stressful Life Events (SLE) and Adolescent Mental Health: Initial Validation of the LEIA, a New Checklist for SLE Assessment According to Their Severity, Interpersonal, and Dependent Nature. Assessment. Advance publication online. doi:10.1177/1073191118817648.

Müller, K. W., Janikian, M., Dreier, M., Wölfling, K., Beutel, M. E., Tzavara, C., Richardson, C. \& Tsitsika, A. (2015). Regular gaming behavior and internet gaming disorder in European adolescents: results from a cross-national representative survey of prevalence, predictors, and psychopathological correlates. European Child $\mathcal{E}$ Adolescent Psychiatry, 24, 565-574. doi:10.1007/s00787-014-0611-2.

Ortet, G., Ibáñez, M. I., Moya, J., Villa, H., Viruela, A. \& Mezquita, L. (2012). Assessing the five factors of personality in adolescents: The junior version of the Spanish NEO-PI-R. Assessment, 19, 114-130. doi:10.1177/1073191111410166.

Ozer, D. J. \& Benet-Martinez, V. (2006). Personality and the prediction of consequential outcomes. Annual Review of Psychology, 57, 401-421. doi:10.1146/annurev. psych.57.102904.190127.

Paulus, F. W., Ohmann, S., Von Gontard, A. \& Popow, C. (2018). Internet gaming disorder in children and adolescents: a systematic review. Developmental Medicine $\mathcal{E}^{2}$ Child Neurology, 60, 645-659. doi:10.1111/dmcn.13754.

Pedersen, S. L. \& McCarthy, D. M. (2008). Person-environment transactions in youth drinking and driving. Psychology of Addictive Behaviors, 22, 340-348. doi:10.1037/0893164x.22.3.340.

Rehbein, F., Staudt, A., Hanslmaier, M. \& Kliem, S. (2016). Video game playing in the general adult population of Germany: Can higher gaming time of males be explained by gender specific genre preferences? Computers in Human Behavior, 55, 729-735. doi:10.1016/j. chb.2015.10.016.

Şalvarlı, Ş. İ. \& Griffiths, M. D. (2019). Internet Gaming Disorder and Its Associated Personality Traits: A Systematic Review Using PRISMA Guidelines. International Journal of Mental Health and Addiction, 1-23. doi:10.1007/ s11469-019-00081-6.

Samuels, J., Nestadt, G., Bienvenu, O. J., Costa, P. T., Riddle, M. A., Liang, K. Y., ... \& Cullen, B. A. (2000). Personality disorders and normal personality dimensions in obsessive-compulsive disorder. British Journal of Psychiatry, 177, 457-462. doi:10.1192/bjp.177.5.457.

Scharkow, M., Festl, R., Vogelgesang, J. \& Quandt, T. (2015). Beyond the "core-gamer": Genre preferences and gratifications in computer games. Computers in Human Behavior, 44, 293-298. doi:10.1016/j.chb.2014.11.020.

Vollmer, C., Randler, C., Horzum, M. B. \& Ayas, T. (2014). Computer game addiction in adolescents and its relationship to chronotype and personality. SAGE Open, 4, 1-9. doi:10.1177/2158244013518054.

Walker, J. O., López, FJ. \& Mezquita, L. (2018, September). An abridge form of the Junior Spanish version of the NEO PI-R (JS NEO-A60). Poster submitted at the VII Jornada de la AIIDI, Palma de Mallorca, España.

Wang, C. W., Ho, R. T. H., Chan, C. L.W. \& Tse, S. (2015). Exploring personality characteristics of Chinese adolescents with internet-related addictive behaviors: Trait differences for gaming addiction and social networking addiction. Addictive Behaviors, 42, 32-35. doi:10.1016/j. addbeh.2014.10.039

Watkins, M. W. (2006). Determining parallel analysis criteria. Journal of Modern Applied Statistical Methods, 5, 344346. doi:10.22237/jmasm/1162354020.

World Health Organization (2017, July 14). ICD-11 Beta Draft. Mental, behavioural or neurodevelopmental disorders. Retrieved at https://icd.who.int/dev11/1-m/en. 


\section{$2.3 \quad$ Study 2}

Title: The development and validation of the Videogaming Motives Questionnaire (VMQ). 


\begin{abstract}
Gaming motives are important factors for explaining individual differences in videogame-related behaviors. The aim of the present study was to develop a new comprehensive but brief instrument - the Videogaming Motives Questionnaire (VMQ) which embraces some of the most relevant gaming motives. In a first study, a pilot exploratory factor analysis (EFA) with data from 140 undergraduates was performed on items from twelve potential motives. This identified eight main factors: recreation, social interaction, coping, violent reward, fantasy, cognitive development, customization, and competition. In Studies 2 and 3, an EFA and a confirmatory factor analysis were performed on two independent samples of 407 adolescents and 260 young adults, respectively. The VMQ presented a robust eight-factor structure, with all scales showing adequate reliability indices. In reference to criterion validity, all motives presented specific associations with hours spent playing videogames, disordered gaming, and game genre preferences. More specifically, and in both adolescents and young adults, social interaction was the main motive related to time spent gaming, whereas disordered gaming was related to both coping and social interaction motives. Based on these findings, it is concluded that the VMQ is a brief and psychometrically appropriate tool for assessing the most relevant videogaming motives.
\end{abstract}

Keywords: Gaming motives; Disordered gaming; Videogame use; Videogame genres; Psychometric properties; Coping 


\section{Highlights}

- The Videogaming Motives Questionnaire (VMQ) showed adequate psychometric properties

- Social interaction predicted time spent gaming among adolescents and adults

- Coping and social motives predicted disordered gaming among adolescents and adults

- Each motive presented associations with specific videogame genres 


\section{Introduction}

In the past three decades, videogame playing has become one of the most popular leisure activities worldwide (Egenfeldt-Nielsen, Smith, \& Tosca, 2019). In Spain (where the present study was carried out), 13 million people play videogames weekly and the highest rates of use are among children, adolescents, and young adults (Asociación Española de Videojuegos, 2018). Although most gamers play without any problems, there has been concern about the consequences of excessive use among a minority of individuals. This led to the introduction of Internet Gaming Disorder (IGD) in the Section 3 ("Conditions for Further Study") of the latest (fifth) edition of the Diagnostic and Statistical Manual of Mental Disorders (DSM-5; American Psychiatric Association, 2013). In addition, the World Health Organization (2017) included Gaming Disorder in the latest (eleventh) edition of the International Classification of Disease (ICD-11) in the section "Disorders due to substance use or addictive behaviors".

These inclusions in the DSM-5 and ICD-11 assume that gaming addiction shares a common symptomatology with substance use and gambling disorders (Petry, Rehbein, Ko, \& O'Brien, 2015). The worldwide prevalence rates among representative samples range between 1 to $9 \%$ depending on age groups and sociocultural differences (Gentile et al., 2017), with the highest prevalence rates observed among younger ages and males (Mihara \& Higuchi, 2017). In Spain, the prevalence of adolescent disordered gaming is around 7-8\% (Buiza-Aguado, Alonso-Canovas, Conde-Mateos, Buiza-Navarrete, \& Gentile, 2018; López-Fernández, Mezquita, Griffiths, Ortet, \& Ibáñez, 2020; LopezFernandez, Honrubia-Serrano, Baguley, \& Griffiths, 2014). Disordered gaming behavior can result in significant clinical impairment in the functioning of life areas (e.g., relationships, education and/or occupation, psychological wellbeing) (Gervasi et al., 2017; Griffiths, Kuss, \& King, 2012; Mihara \& Higuchi, 2017). Furthermore, some 
studies have demonstrated that disordered gaming predicts internalizing and externalizing problems as well as poor academic performance over time (e.g., Brunborg, Mentzoni, \& Frøyland, 2014; Gentile et al., 2011; Lemmens, Valkenburg, \& Peter, 2011a, 2011b, van Rooij et al, 2011).

Although structural and situational characteristics are involved in the acquisition, development, and maintenance of disordered gaming (Griffiths \& Nuyens, 2017; King, Delfabbro, \& Griffiths, 2010), personal variables of the gamers are also important, including motives for playing. Some models that contemplate the interrelated role of biological, psychological and social variables in the development of regular and pathological video gaming consider motives as important predisposition components in gaming behavior (Brand, Young, Laier, Wölfling, \& Potenza, 2016; Dreier, Wölfling, \& Müller, 2013). Motives have shown to be especially relevant in other addictive-related behaviors, such as in the use and abuse of alcohol (Cooper, 1994; Bravo et al., 2018), marijuana (Mezquita, Ruiz-Valero, Martínez-Gómez, Ibáñez, \& Ortet, 2019; Simons, Correia, Carey, \& Borsari, 1998) and gambling (Lee, Chae, Lee, \& Kim, 2007; Stewart \& Zack, 2008).

In the past few decades, different gaming motives questionnaires have been developed following two main approaches. From a more theoretical approach, research has attempted to identify relevant gaming motives based on well-stablished theories, such as self-determination theory (Ryan \& Deci, 2000), uses and gratification theory (Blumler \& Katz, 1974) and social cognitive theory (Bandura, 1986). For instance, based on selfdetermination theory, Ryan, Rigby and Przybylski (2006) postulated that players would seek to satisfy universal psychological needs, such as autonomy, competence, relatedness, and presence. On the other hand, Sherry et al. (2006) focused on why people use videogames to satisfy their psychological and social needs based on uses and gratification 
theory. Consequently, the scale developed by the authors comprised six motivational dimensions: arousal, competition, challenge, social interaction, recreation, and fantasy. More recently, De Grove, Cauberghe and Van Looy (2016) developed a motives scale for digital gaming based on the social cognitive theory. The main tenet of this theory is that individuals are motivated to act as a function of outcome expectancies, and according to their study, they identified eight main motives for playing: social, narrative, escapism, agency, performance, pastime, moral self-reaction, and habit.

Following an empirical approach, a number of scales to assess videogame motives have been developed using exploratory procedures, such as factor analysis. For example, Yee (2006a, b) conducted two large studies among players of Massively Multiplayer Online Role-Playing Game (MMORPG) in order to identify their motivations. In the first study, Yee (2006a) described a hierarchical structure of motives, with three supra-factors and ten sub-factors: achievement (advancement, mechanics, and competition), social (socializing, relationship, and teamwork), and immersion (discovery, role-playing, customization, and escapism). In the second study, Yee (2006b) identified five main motives: relationship, immersion, escapism, achievement, and manipulation. Other researchers have extended the examination of motives in general. For instance, one of the motives scale most used for general videogame playing is the Motives for Online Gaming Questionnaire from Demetrovics et al. (2011). This scale, based on a literature review and players' interviews, posited seven global motives to play videogames: escape, coping, fantasy, skill development, recreation, competition, and social. Table 1 summarizes most of scales developed during the past decades as well as the most common motives identified in them.

One of the videogame genres in which motives have been more extensively studied is MMORPGs, mainly because of the high IGD prevalence reported in this genre 
(Billieux, Deleuze, Griffiths, \& Kuss, 2015; Subramaniam et al., 2016; Thorens et al., 2013). Research examining MMORPGs has reported associations between gaming motives and disordered gaming (e.g., Billieux et al, 2011; Billieux et al, 2013; Yee, 2006a), time spent gaming (Williams, Yee \& Caplan, 2008; Yee, 2006b), types of positive and negative passion (or engagement) in gaming (Fuster, Chamarro, Carbonell, \& Vallerand, 2014), and in-game behaviors (Billieux et al, 2013; Kahn, et al., 2015; Yee, Ducheneaut, \& Nelson, 2012;). Motives have been also related to different uses of other Massively Multiplayer Online games such as Massively Online Battle Arena (MOBA) games, and First Person Shooter games (Ghuman \& Griffiths, 2012; Kim et al., 2016). Similarly, gaming motivations have been associated with disordered use in general gaming (Chang \& Lin, 2019; Kim et al., 2016; Király, Tóth, Urbán, Demetrovics, \& Maraz, 2017; Laconi, Pirès, \& Chabrol, 2017; Männikkö, Billieux, Nordström, Koivisto, \& Kääriäinen, 2017; Montag et al., 2019; Wu, Lai, Yu, Lau, \& Lei, 2016).

Other studies have demonstrated that some gaming motives mediate the relationships between psychiatric problems and problematic gaming (e.g., Ballabio et al., 2017; Király et al., 2015; Montag et al., 2019; Plante, Gentile, Groves, Modlin, \& BlancoHerrera, 2019). Additionally, motives have been associated with higher video gaming frequency (Greenberg et al., 2010; Király et al., 2017; Sherry et al., 2006; Wu et al., 2016), genre preferences (Greenberg et al., 2010; Kim et al., 2016; Scharkow, Festl, Vogelgesang, \& Quandt, 2015), and favorite game franchises (Hilgard, Engelhardt, \& Bartholow, 2013).

Taken together, these studies demonstrate the importance of motives in the psychological study of gaming behaviors, and the need to properly identify and assess them. However, research to date presents some limitations. As shown, utilizing different theoretical background results in a different number and nature of motives. Furthermore, 
some of the described motives suffer from of 'jingle-jangle' fallacies, that is, that apparently similar constructs are sometimes given different labels (jangle fallacy) whereas the same labels are sometimes applied to conceptually different constructs (jingle fallacy). For instance, in relation to the fantasy component of the game, some scales highlight different aspects within the same motive, such as discovery and role-playing (Yee, 2006a), fantasy, exploration and narration (Scharkow et al., 2015), and fantasyescape and fantasy-arousal (Nije, Bijvank, Konijn, \& Bushman, 2012). Conversely, different studies describe this component using distinct labels, such as immersion (Yee, 2006a; Yee et al., 2012), presence (Ryan et al., 2006), fantasy (Demetrovics et al., 2011; Sherry et al., 2006), narrative (De Grove et al., 2016), story-driven (Kahn, et al., 2015), story (Hilgard et al., 2013), and exploration (Fuster et al., 2012). Finally, many studies has focused on specific games or genres, especially MMORPGs (e.g., Fuster et al., 2012; Yee, 2006a; Yee et al., 2012), so it is unclear to what extent the proposed motives are specific to this genre, or common to all. All these deficiencies impede the development of generalizable taxonomies of video game motifs and hinder accurate communication in this field.

Therefore, and following an empirical approach, the main aim of present study was to develop a new scale of gaming motives in which the most relevant and recurrent motivational components found in previous studies were reflected under unified labels that can be used for any gaming genre. To do so, three studies were carried out. The first study identified some of the most relevant motives through literature-based scoping study, and comprised an initial exploratory factor analysis (EFA) on items reflecting these motives in data collected from a sample of young adults. In Study 2, an EFA of selected items encompassing the videogame motives more clearly identified in Study 1 was conducted using data from an adolescent sample. Finally, in Study 3, a confirmatory 
factor analysis (CFA) was performed using data from a sample of young adults. The role of the identified motives was explored in relation to the number of hours spent gaming, disordered gaming, and game genre preferences in Studies 2 and 3.

\section{Study 1. Literature-based scoping study and initial testing}

\subsection{Method}

\subsubsection{Participants and procedure}

For the development of a pilot scale and the initial selection of items, a convenience sample of 140 young adult players was used (76 undergraduates and 64 participants recruited from the LAN party "UJI Game Experience"; 79 males; mean age $=20.71$ years $[S D=3.55])$. Participants voluntarily completed an online survey via Google Forms comprising the pilot motive scale together with sociodemographic data.

\subsubsection{Measures}

\subsubsection{Pilot Videogamimg Motives Questionnaire (VMQ)}

Through an exhaustive scoping review of the literature concerning gaming motivation scales, 25 different gaming motive scales were identified. The nine most frequently found motives in the literature were: arousal, recreation, social interaction, escape-coping, fantasy, skill development, customization, achievement-challenge, and competition. Two other motives - violence catharsis and violent reward - from Hilgard et al.'s (2013) scale were also initially chosen given the potential relevance of violence and aggression in gaming (Calvert et al., 2017). Last, we also take into account the common motives for the consumption of different addictive substances, such as alcohol, tobacco and marijuana, i.e. enhancement/recreation, social, coping and conformity, so this last motive was also included (Cooper, Kuntsche, Levitt, Barber, \& Wolf, 2016). A total of 62 items based on these motives were selected, with five items per motive except 
violent catharsis and social interaction (six items each), and adapted to Spanish from the original scales utilizing an internationally standardized back-translation process (Blanch \& Aluja, 2016; Geisinger, 1994). Participants had to answer each item using a five-point Likert scale, from 1 (strongly disagree) to 5 (strongly agree).

\subsubsection{Statistical analysis}

The IBM SPSS Statistics V21.0 software was employed for the EFA, with principal axis factoring and oblimin rotation on the 62 items selected. For the parallel analyses, Monte Carlo PCA (Watkins, 2006) was utilized. Although the sample size was below the expected norms in relation to the number of items factorized (Lautenschlager, 1989), the pilot study was only exploratory and its main aim was to identify the clearer and more robust factors underlying the analyzed items.

\subsection{Results}

The eigenvalue criteria (Cliff, 1988) suggested 12 factors whereas parallel analyses (Lautenschlager, 1989) suggested seven factors. Consequently, six EFAs were performed extracting from 7 to 12 factors. Across different EFAs, eight factors became more robust and well-defined (see Supplementary material): recreation, social interaction, coping-scape, violent reward, fantasy, customization, competition, and skill development. The other four motives were not well identified in the 12-factor solution: achievement-challenge, conformity, and violent catharsis were formed by only two items with high loadings; whereas the arousal items were distributed along different factors. In the eight-factor solution, the arousal items loaded principally on the recreation and fantasy motivations; violent catharsis items loaded on the escape-coping and violent reward dimension; conformity items loaded mainly on social interaction dimension; and achievement-challenge items were distributed between different motives.

Insert Table 1 here 


\section{Study 2. Adolescent sample study}

\subsection{Method}

\subsubsection{Participants and procedures}

Adolescent participants were recruited from two Spanish high schools utilizing convenience sampling. Of the 1,106 students invited to participate, 835 adolescents returned signed written parental consent. From these, 407 reported a frequency of gaming of at least one hour weekly and completed the VMQ. Approximately two-thirds of the sample participants were male $(68.2 \%)$ with a mean age of 14.99 years $(\mathrm{SD}=1.13)$.

This study was part of broader research into psychosocial risk and protective factors affecting mental health (see Moya-Higueras et al. [2018] for more details). Trained research assistants administered the battery of questionnaires in two sessions, separated by approximately one week. A convenience sub-sample of 153 participants $(75.2 \%$ boys; mean age $=15.08, S D=1.09)$ completed a third session one month later, in order to explore test-retest reliability. 


\subsubsection{Measures}

\subsubsection{Videogaming Motives Questionnaire (VMQ)}

In order to develop a short instrument that includes scales with good reliability and adequate content validity, for each of the eight motives, three non-redundant items with high loadings and intercorrelations were selected and that adequately represented the content of the motive. Therefore, the 24-item definitive version of VMQ was used to assess eight gaming motivations: recreation, social interaction, coping, violent reward, fantasy, cognitive challenge, customization and competition using a five-point Likert scale $(0=$ strongly disagree; $4=$ strongly agree $)$. In relation to the coping-escape motive, the dimension became coping only because the three most representative items were exclusively related to coping aspects. Finally, the skill development motive became cognitive development because its most relevant items concerned mental challenge and development rather than improvement of abilities in general.

\subsubsection{Gaming behaviors}

Data were collected on the number of hours spent gaming daily online and offline per week (from Monday to Friday) and on weekends (Saturday and Sunday). Weekly number of gaming hours was obtained by adding online and offline daily hours and multiplying the days of these periods of the week with the total number of hours. Participants were also asked to provide up to five of their most played videogames. These games were then classified into the most popular videogame genres (based on LópezFernández et al., 2020). These gaming genres comprised: shooter games (e.g., Call of Duty), MOBA (e.g., League of Legends), strategy games (e.g., Clash of Clans), MMORPG (e.g., World of Warcraft), role-playing games (e.g., Dark Souls), actionadventure games (e.g., The Legend of Zelda), sport games (e.g., FIFA), casual games (e.g., Candy Crush), social simulation games (e.g., The Sims), construction games (e.g., 
Minecraft), platform games (e.g., Super Mario Bros), fighting games (e.g., Street Fighter) and other miscellaneous games.

\subsubsection{Disordered videogame use}

A measure especially developed to assess disordered adolescent videogame use was employed (Gentile, 2009). The 11-item scale is based on symptoms of addiction, such as withdrawal, conflict, tolerance, salience, mood modification and relapse. Participants indicate their frequency of videogame-related problems on a four-point Likert scale (from $0=$ "never or almost never" to 3 "almost always or always") during the past year. The Cronbach's alpha in the present study was very good (.85).

\subsubsection{Statistical analysis}

An EFA with principal axis factoring and oblimin rotation was performed for testing the VMQ with original eight-factor model using IBM SPSS Statistics V21.0. The Cronbach's alpha of each VMQ factor was calculated. Temporal stability reliability was computed utilizing a two-week test-retest correlation. In order to determine the criterion validity of the VMQ, the scores of the motives were correlated with number of weekly hours spent gaming, disordered gaming, gaming genre, age, and gender. Finally, hierarchical multiple regression analyses were carried out to examine the role of motives in hours spent gaming per week and disordered use, controlling for age and gender.

\subsection{Results}

\subsubsection{Gaming behavior}

Participants reported playing an average of 1.78 hours a day during the week $(S D=1.86)$, and four hours a day at the weekends $(S D=3.01)$. Therefore, the mean weekly time spent gaming was 16.89 hours $(\mathrm{SD}=13.45)$. The most played videogames reported by participants $(n=359)$ were classified according to gaming genre: shooter $(n=197)$, sports $(n=150)$, MOBA $(n=71)$, strategy $(n=64)$, action-adventure $(n=45)$, social 
simulation $(n=35)$, casual $(n=33)$, role-playing $(n=23)$, platform $(n=23)$, construction $(n=21)$, fighting $(n=20)$, MMORPGs (4) and other miscellaneous games $(n=58)$.

\subsubsection{Factor structure}

The EFA in the adolescent sample replicated the eight-factor solution found in Study 1 and explained $78.5 \%$ of the variance (see Table 2). The factor loadings for every item were greater than .50 except for Item 19 that had a factor loading of .36 . Furthermore, the internal consistency of each motive was good to excellent with Cronbach alphas ranging from .76 to .93 . The test-retest scores were acceptable regarding the low number of items per dimension, with all the values higher than .60 (DeVellis, 2016).

\subsubsection{Criterion validity}

Results showed that VMQ motives had significant correlations with various gaming-related indicators (see Table 3). All motives were associated with the number of hours spent gaming weekly and disordered use, although those motives that presented higher associations were social interaction, coping, and competition. Significant relationships were also found among gaming genres. For instance, according to those genres most consumed, shooters were mainly associated with violent reward, social interaction and competition, whereas playing MOBA games and sport games were strongly related to competition. All the motives were associated with male gender except customization. The largest associations among males were observed with competition, violent reward, and social interaction. Descriptive data by gender and correlations between motives are displayed in Supplementary material.

Multiple linear regressions analyses were conducted to identify the role of motives in number of hours spent gaming weekly and disordered use, controlling for gender and age (see Table 4). Higher social interaction and coping predicted greater gaming use, 
whereas coping, social interaction and, to a lesser extent, violent reward predicted disordered videogame use.

Insert Table 2 here

\section{Study 3. Emerging adulthood sample study}

\subsection{Method}

\subsubsection{Participants and procedure}

The convenience young adult sample comprised 260 undergraduate participants who played at least one hour a week (41.9\% males) with a mean age of 20.53 years $(\mathrm{SD}=3.63)$ participated in the survey. The survey was completed online via Google Forms.

\subsubsection{Measures}

\subsubsection{Videogamimg Motives Questionnaire (VMQ)}

The VMQ administered to adolescents was used in order to examine its psychometric properties as well as to confirm the eight-factor solution in the young adult sample. Please see Study 2 Methods section for details about the VMQ item structure.

\subsubsection{Gaming behaviors}

As in the adolescent sample (Study 2), participants reported the number of weekly hours spent gaming, online and offline, and provided up to five of their most played videogames. Videogame genres were classified in the same way as Study 2.

\subsubsection{Internet Gaming Disorder Test (IGD-20 Test)-Spanish version}

The Spanish version of the IGD-20 test (Fuster, Carbonell, Pontes, \& Griffiths, 2016) was used to assess disordered gaming in young adults. The scale includes 20 items answered using a 5-point Likert scale from 1 (strongly disagree) to 5 (strongly agree). 
The IGD-20 Test assesses disordered gaming activity during the past 12 months using the nine criteria for IGD. The Cronbach's alpha was very good in the present study (.86).

\subsubsection{Statistical analysis}

A CFA was performed on the VMQ testing the eight-factor model with robust methods using the EQS software, version 6.1 (Bentler \& Wu, 1995). The model's goodness-of-fit was assessed by employing the following fit indices: Satorra-Bentler chisquared $\left(\mathrm{S}-\mathrm{B} \chi^{2}\right)$, Satorra-Bentler normed chi-squared ( $\mathrm{S}-\mathrm{B} \chi^{2} / \mathrm{d} . \mathrm{f}$ ), the comparative fit index (CFI), the incremental fit index (IFI), the non-normed fit index (NNFI), and the root mean square error of approximation (RMSEA). For a good model fit, the fit indices must meet the following values: $\mathrm{S}-\mathrm{B} \chi^{2}$ (non-significant), $\mathrm{S}-\mathrm{B} \chi^{2} / \mathrm{df}$ (between 1 and 2), CFI, IFI, and NNFI $(\geq .95)$, and RMSEA $\leq .05$ (Byrne, 2013). Last, as the $\chi^{2}$ is very sensitive to the model complexity or sample size, we used the $\mathrm{S}-\mathrm{B} \chi^{2} / \mathrm{df}$ to overcome such problem (Byrne, 2013).

As with the adolescent sample (Study 2), the correlations between the VMQ subscales and the number of weekly hours spent gaming, disordered gaming, and gaming genre were calculated. Finally, in order to test the role of gaming motives in the number of hours spent gaming weekly and disordered gaming, hierarchical multiple regression analyses were conducted, controlling for age and gender.

\subsection{Results}

\subsubsection{Gaming behavior}

The young adult sample played an average of 9.26 hours a week $(\mathrm{SD}=11.97)$. The videogames played reported by participants $(n=250)$ were classified according to gaming genre: shooter $(n=89)$, MOBA $(80)$, casual $(n=71)$, role-playing $(n=70)$, strategy $(n=57)$, sports $(n=40)$, social simulation $(n=33)$, action-adventure $(n=28)$, platform $(n=17)$, 
MMORPGs $(n=11)$, fighting $(n=11)$, construction $(n=9)$ and other miscellaneous games $(n=33)$.

\subsubsection{Factor structure}

Results from the CFA demonstrated a good model fit $\left(\mathrm{S}-\mathrm{B} \chi^{2}=330.13, d f=224\right.$, $\left.p<.001 ; \mathrm{S}-\mathrm{B} \chi^{2} / \mathrm{df} .=1.47 ; \mathrm{CFI}=.97 ; \mathrm{IFI}=.97 ; \mathrm{NNFI}=.96 ; \mathrm{RMSEA}=.04\right)$, and the loadings ranged from .62 to .95 (see Figure 1).

\subsubsection{Criterion validity}

As with the adolescent sample (Study 2), VMQ motives demonstrated significant correlations with other relevant variables in gaming (see Table 3). The highest correlations between motivation scores and number of hours spent gaming weekly were for social interaction and recreation. In relation to disordered gaming, the highest correlations were with violent reward, social interaction, and coping. Regarding gaming genre, compared to the adolescent sample, similar findings were found among the most popular genres. Shooter games were strongly associated with violent reward and social interaction, and MOBA games were highly related to social interaction. As in the adolescent sample, male gender showed relationships with every motive except customization. The largest associations among males were violent reward, social interaction, and competition. In addition, customization was broadly associated with higher age. Descriptive data by gender and correlations between motives are displayed in Supplementary material.

Multiple linear regression analyses were carried out to identify the role of motives in number of hours spent gaming weekly and disordered gaming, controlling for age and gender (see Table 4). Results showed that social interaction was associated with higher gaming use whereas coping and, to a lesser extent, social interaction and violent reward mainly predicted disordered gaming. 
Insert Figure 1 and Tables 3 and 4 here

\section{Discussion}

The aim of the present study was to develop a new psychometrically robust scale for assessing motives for videogame playing, the Videogamimg Motives Questionnaire (VMQ). Motives are important antecedents of other addictive-related behavior such as using alcohol, tobacco, marijuana and gambling (e.g., Cooper et al., 2016; Stewart \& Zack, 2007). Based on the motivational model of Cox and Klinger (1988), three main and common motives to all these addictive behaviors have been identified: social, enhancement, and coping (Cooper, 1994; Simons et al., 1998; Stewart \& Zack, 2007). A fourth motive of conformity (drinking alcohol or smoking cigarettes in response to social pressures) have also been proposed (Cooper, 1994; Simons et al., 1998), although its role in substance use has usually been small or even negligible (Cooper et al., 2016; Mezquita et al., 2011). Accordingly, the main three common motives, coping, social, and enhancement (also labeled as diversion or recreation), have been identified in previous studies on videogame playing (see Table 1), and in the present study.

The coping motivation refers to playing for stress-reduction and mood enhancement. This motivation is widely represented in most gaming motive scales that include an escape/coping motivational component. Demetrovics et al. (2011), through a literature review, distinguished between escapism (playing to forget daily problems) and coping motives. However, these motives were highly correlated $(r>.6$; Király et al., 2017; Demetrovics et al., 2011) and, in the present study, both motives converged as a unique factor with coping items loading more strongly. In the current study, the coping motive was associated with shooter and action-adventure games both in adolescents and young adults, and with MMORPGs in young adults. Similarly, previous research has 
shown the escape/coping motivational component as being highly related to MMORPGs among adults (Hilgard et al., 2013; Kim et al., 2016).

In the present study, coping was the strongest predictor of disordered gaming scores among both adults and adolescents. Similarly, previous studies have shown that escape/coping is the motive with the highest association with disordered gaming (e.g., Chang \& Lin, 2019; Hilgard et al., 2013; Király et al., 2017; Laconi et al., 2017; Montag et al., 2019; Moudiab \& Spada, 2019; Wu et al., 2016). Therefore, disordered gaming may be developed in part as a mechanism to cope with social or psychological problems, such as depression symptoms or low self-esteem (Plante et al., 2019).

The social interaction motive is based on bonding with friends and making new ones. This motive is also widely represented in most of the scales. In the present study, social interaction was broadly associated with shooters and MOBAs both in adolescents and young adults, and MMORPGs among young adults, whereas the motive was negatively associated with games that are usually played alone, such as social simulation games (for both adolescents and young adults). Similarly, social interaction has been associated with higher preferences for online role-playing, shooters, and real time strategy games (Kim et al., 2016) and lower engagement in casual games (Greenberg et al., 2010). In the present study, social interaction was the highest predictor of number of hours spent gaming weekly among both samples, in line with other studies (e.g., Ferguson \& Olson, 2013; Greenberg et al., 2010; Király et al., 2017; Sherry et al., 2006; Wu et al., 2016). Therefore, more socially-motivated players like to spend their time playing videogames that offer social interactions such as MOBAs or/and shooters.

The present study also found that social interaction was highly associated with disordered gaming (after controlling for age, gender, and the remaining motives in both samples). Similarly, previous studies have found that after escape/coping, the gaming 
motive with the next highest relationship with disordered gaming is social interaction (Hilgard et al., 2013; Männikkö et al., 2017). It has been suggested that high scores in social interaction within gaming might reflect low social competence in real life, and that gaming compensates for this characteristic, resulting in disordered gaming (Gentile et al., 2011; Lemmens et al., 2011a).

Finally, recreation (enhancement or recreational) motives - focusing on the enjoyable and recreational gaming component - was mainly related to higher use of shooter and role-playing games in both samples. In addition, some studies have found that recreation is the major motivation related to greater gaming during college (Sherry et al., 2006; Greenberg et al., 2010). In the present study, recreation motives were correlated with frequency of gaming and disordered gaming, but when sociodemographic factors and other gaming motives were controlled for, these associations became nonsignificant, probably due to the interrelation with other motives. Therefore, in the samples here, other motives such as social interaction may explain better the variance in gaming frequency rather than playing for mere enjoyment.

In addition to these three common motives, specific motivational factors have also been identified for other addictive behaviors, such as expanse motives for marijuana use and abuse (Simons et al., 1998; Mezquita et al., 2019) or financial motives for gambling behavior (Lee et al., 2007). In the field of gaming, previous studies also have identified specific motives for playing videogames, such as arousal (playing to excite emotions), achievement-challenge (playing to obtain in-game rewards or prestige), skill development, fantasy, competition, and customization. In addition, Hilgard et al (2013) identified two additional relevant motives for playing - violence catharsis (in-game violence helping to release negative moods or aggression) and violent reward - which were included in present study due to the potential relevance of aggressive gaming in 
violent behaviors (Calvert et al., 2017). Of these specific motives, the study clearly identified skill development (cognitive development in the present study), fantasy, competition, customization, and violent reward. In Study 1, items from arousal motives mainly loaded on the recreation factor, violent catharsis items loaded on the escapecoping factor, and achievement-challenge items were distributed between different motives.

The cognitive development motive refers to the intellectual activity stimulation during videogame play. In the first study, this motive encompassed two previous motives: skill development (Demetrovics et al., 2011) and 'smarty-pants' (Kahn et al., 2015), although when selecting the items with higher loadings for the final VMQ, it became a more cognitive development and mental challenge factor. In the present study, this motive was associated with action-adventure and shooter games, in both samples, and with MOBA games among adolescents. Previous research has found that shooters and real time strategy genres have been highly associated with skill development (Kim et al., 2016). Consequently, individuals with higher levels in this motive may be more attracted to those games where improving skill and abilities are important elements of the in-game experience.

The fantasy motive is defined by playing for the immersion in the gaming world and the story's in-game characters. This motive has received different labels in gaming motive research such as immersion (Yee, 2006a), presence (Ryan et al., 2006), narrative (De Grove et al., 2016), story (Hilgard et al., 2013), or exploration (Fuster et al., 2012). In the present study, fantasy was significantly associated with game genre use in which a storyline is developed, usually through a campaign, such as action-adventure games, shooter game, role-playing games, and MMORPGs. 
Previous research has reported similar findings in which fantasy is strongly associated with the use and preference for shooters, role-playing, and action-adventure games (Greenberg et al., 2010; Ghuman \& Griffiths, 2012; Kim et al., 2016; Scharkow et al., 2015) as well as for franchises of such genres (Hilgard et al., 2013). In addition, the present study showed that fantasy significantly predicted higher disordered gaming among young adults, in line with some studies (Ballabio et al., 2017; Billieux et al, 2011; Laconi et al., 2017). Therefore, in-game immersion, at least among adults, could impair the player's life by neglecting important life domains. In other words, this higher immersion feeling in videogame playing may disrupt professional careers and social relationships affecting players' psychological wellbeing.

The competition motive - based on the pleasure of competing and winning against others - was strongly associated with competitive gaming genre use such as shooter games (in the adolescent sample), MOBA games and sports games (for both samples). In addition, competition was negatively related to the use of non-competitive genres such as casual games (in both samples). Similarly, the competition motive has been found to be strongly associated with competitive gaming genres, such as sports games, action games, or real time strategy games, and to a lesser extent noncompetitive games and genres such as casual games (Greenberg et al., 2010; Kim et al., 2016; Scharkow et al., 2015). Taken together, these studies highlight that the competition motive appears to play an important role in the player's game genre preferences.

Customization motives refers to the creation and design of things in-game. Consequently, this motive was highly associated with use of social simulation games in both samples. Customization was also extensively associated with construction (among adolescents) and role-playing games (among young adults). In previous research, customization has been positively associated with higher preferences for role-playing 
games such as Final Fantasy and Skyrim (Hilgard et al., 2013). Among the adult sample in the present study, customization may have acted as a protective factor in preventing disordered gaming. The gratification of creating and designing in-game things might underlie facets of conscientiousness that are negatively associated with disordered gaming (e.g., López-Fernández et al., 2020).

Finally, violent reward refers to the gratification obtained via in-game violence. Surprisingly, this motive has been very scarcely studied, despite its potential role in the development of aggressive preferences and violent behavior. Accordingly, this motive was strongly associated with use of shooters and negatively related to non-violent and more peaceful videogames such as casual games, both in adolescents and in young adults. Similarly, Hilgard et al. (2013) reported that this motive was strongly associated with preferences for the action shooter franchise of Grand Theft Auto. In addition, in the present study, violent reward also had a positive association with disordered gaming among both adolescents and young adults. As far as the present authors are aware, this is the first time that this association has been reported, although other studies have shown that the acceptance of violence is associated with higher disordered gaming (Rehbein, Kleimann, \& Mößle, 2010), and that MMORPG players attracted to the release of aggressive and antisocial feelings through gaming have a higher risk of addiction (Hussain, Williams, \& Griffiths, 2015). Overall, these relationships highlight the importance of this often-neglected motive in particularly harmful videogame behaviors, such as disordered gaming and the preference for violent games.

To sum up, adolescent and young adults displayed a similar pattern in the relationship between motives and gaming behaviors. For both samples, disordered gaming was strongly related to coping, followed by social interaction and violent reward, this last motive with a lower effect. In addition, a larger number of gaming hours was 
associated with higher scores in social interaction. However, slight differences exist between young adults and adolescents. For instance, disordered gaming was slightly related to fantasy and negatively to customization in young adults, whereas number of hours spent gaming weekly were also associated with coping in adolescents. With regard to videogame genres, a similar pattern was also found, replicating most of the highest associations between motives and games played in both samples.

The present study is not without its limitations. First, the studies only comprised Spanish adolescents and young adults. Therefore, validation of the VMQ in other sociocultural contexts are necessary to generalize the findings. Second, the present study was cross-sectional, consequently longitudinal studies are needed to approach to causal relationships between motives and gaming variables. Third, despite trying to be exhaustive, there could be other relevant motives not identified in the present study. Finally, in order to systematically explain individual differences in gaming behaviors, future studies should include other relevant variables such as personality, which may allow exploration of the complex interplay between these variables (e.g. the mediational role of motives in the personality-gaming associations) (Kircaburun, Jonason, \& Griffiths, 2018).

\subsection{Conclusion}

The Videogamimg Motives Questionnaire showed an underlying robust structure comprising eight motives: recreation, social interaction, coping, violent reward, competition, fantasy, cognitive development and customization. The VMQ' eight motives demonstrated good internal consistency and temporal stability reliability indices. In addition, it showed meaningful associations with different game-related behaviors in two independent samples of adolescents and young adults, such as weekly time spent gaming, disordered gaming, and gaming genres most played. 
Thus, VMQ constitutes a new psychometric instrument that produces valid and reliable scores for the assessment of some of the more representative gaming motives, and in a relatively brief way. The possibility to assess gaming motives briefly and comprehensively may help to incorporate the study of motives in the research of individual differences on gaming-related behaviors, and may be useful in the development of personalized programs to prevent and treat disordered gaming (Steadman, 2019).

\section{Ethics}

All participants were adequately informed about the study, confidentiality and treatment of data, as well as the data protection procedure. All adult participants, and the parents or legal guardians of the adolescents, gave written informed consent. This study was approved by the ethical committee from the Universitat Jaume I, and authorized by the school board of the participating high schools as well as by the Valencian regional education authorities, and has been carried out in accordance with the Declaration of Helsinki. 


\section{References}

American Psychiatric Association (2013). Diagnostic and statistical manual of mental disorders (DSM-5®). American Psychiatric Publishing.

Asociación Española de Videojuegos (AEVI) (2018) El anuario del videojuego 2018. [The yearbook of videogames 2018]. Retrieved April 2, 2020, from: http://www.aevi.org.es/web/wpcontent/uploads/2019/05/AEVI_Anuario_2018.pdf.

Ballabio, M., Griffiths, M. D., Urbán, R., Quartiroli, A., Demetrovics, Z., \& Király, O. (2017). Do gaming motives mediate between psychiatric symptoms and problematic gaming? An empirical survey study. Addiction Research \& Theory, 25, 397-408.

Bandura, A. (1986). Social foundations of thought and action: A social cognitive theory. Englewood Cliffs, NJ: Prentice-Hall.

Bentler, P. M. (1995). EQS structural equations program manual. Los Angeles: BDMP Statistical Software.

Billieux, J., Chanal, J., Khazaal, Y., Rochat, L., Gay, P., Zullino, D., \& Van der Linden, M. (2011). Psychological predictors of problematic involvement in Massively Multiplayer Online Role Playing Games (MMORPG): Illustration in a sample of male cybercafés players. Psychopathology, 44, 165-171.

Billieux, J., Deleuze, J., Griffiths, M. D., \& Kuss, D. J. (2015). Internet gaming addiction: The case of massively multiplayer online role-playing games. In Textbook of addiction treatment: International perspectives (pp. 1515-1525). Springer Milan.

Billieux, J., van der Linden, M., Achab, S., Khazaal, Y., Paraskevopoulos, L., Zullino, D., Thorens, G. (2013). Why do you play World of Warcraft? An in-depth exploration of self-reported motivations to play online and in-game behaviours in the virtual world of Azeroth. Computers in Human Behavior, 29,103-109. 
Blanch, A., \& Aluja, A. (2016). Text mining a self-report back-translation. Psychological Assessment, 28, 750-764.

Blumler, J. \& Katz, E. (1974). The uses of mass communications: Current perspectives on gratifications. Beverly Hills, CA: Sage.

Brand, M., Young, K. S., Laier, C., Wölfling, K., \& Potenza, M. N. (2016). Integrating psychological and neurobiological considerations regarding the development and maintenance of specific Internet-use disorders: An Interaction of Person-AffectCognition-Execution (I-PACE) model. Neuroscience \& Biobehavioral Reviews, 71, 252-266.

Bravo, A. J., Pilatti, A., Pearson, M. R., Mezquita, L., Ibáñez, M. I., \& Ortet, G. (2018). Depressive symptoms, ruminative thinking, drinking motives, and alcohol outcomes: A multiple mediation model among college students in three countries. Addictive behaviors, 76, 319-327.

Brunborg, G. S., Mentzoni, R. A., \& Frøyland, L. R. (2014). Is video gaming, or video game addiction, associated with depression, academic achievement, heavy episodic drinking, or conduct problems? Journal of Behavioral Addictions, 3, 27-32.

Buiza-Aguado, C., Alonso-Canovas, A., Conde-Mateos, C., Buiza-Navarrete, J. J., \& Gentile, D. (2018). Problematic video gaming in a young Spanish population: Association with psychosocial health. Cyberpsychology, Behavior, and Social Networking, 21, 388-394.

Byrne, B. M. (2013). Structural equation modeling with EQS: Basic concepts, applications, and programming. London: Routledge.

Calvert, S. L., Appelbaum, M., Dodge, K. A., Graham, S., Nagayama Hall, G. C., Hamby, S., ... \& Hedges, L. V. (2017). The American Psychological Association Task Force 
assessment of violent: Science in the service of public interest. American Psychologist, 72, 126-143.

Chang, S. M., \& Lin, S. S. (2019). Online gaming motive profiles in late adolescence and the related longitudinal development of stress, depression, and problematic internet use. Computers \& Education, 135, 123-137.

Cliff, N. (1988). The eigenvalues-greater-than-one rule and the reliability of components. Psychological Bulletin, 103, 276-279.

Cooper, M. L. (1994). Motivations for alcohol use among adolescents: Development and validation of a four-factor-model. Psychological Assessment, 6, 117-128.

Cooper, M. L., Kuntsche, E., Levitt, A., Barber, L. L, \& Wolf, S. (2016). Motivational models of substance use: A review of theory and research on motives for using alcohol, marijuana, and tobacco. In K. J. Sher (Ed.), Oxford library of psychology. The Oxford handbook of substance use and substance use disorders (pp. 375-421). Oxford University Press.

Cox, W. M., \& Klinger, E. (1988). A motivational model of alcohol use. Journal of Abnormal Psychology, 97, 168-180.

De Grove, F., Cauberghe, V., \& Van Looy, J. (2016). Development and validation of an instrument for measuring individual motives for playing digital games. Media Psychology, 19, 101-125.

Demetrovics, Z., Urbán, R., Nagygyörgy, K., Farkas, J., Zilahy, D., Mervó, B., ... Harmath, E. (2011). Why do you play? The development of the motives for online gaming questionnaire (MOGQ). Behavior Research Methods, 43, 814-825.

DeVellis, R. F. (2016). Scale development: Theory and applications (Vol. 26). London: Sage. 
Dreier, M., Wölfling, K., \& Müller, K. (2013). Psychological research and a sociological perspective on problematic and addictive computer game use in adolescence. International Journal of Child and Adolescent Health, 6, 422.

Egenfeldt-Nielsen, S., Smith, J. H., \& Tosca, S. P. (2019). Understanding video games: The essential introduction. Routledge.

Ferguson, C. J., \& Olson, C. K. (2013). Friends, fun, frustration and fantasy: Child motivations for video game play. Motivation and Emotion, 37, 154-164.

Floros, G., \& Siomos, K. (2012). Patterns of choices on video game genres and internet addiction. Cyberpsychology, Behavior, and Social Networking, 15, 417-424.

Fuster, H., Carbonell, X., Pontes, H. M., \& Griffiths, M. D. (2016). Spanish validation of the internet gaming disorder-20 (IGD-20) test. Computers in Human Behavior, 56, 215-224.

Fuster, H., Chamarro, A., Carbonell, X., \& Vallerand, R. J. (2014). Relationship between passion and motivation for gaming in players of massively multiplayer online roleplaying games. Cyberpsychology, Behavior, and Social Networking, 17, 292-297.

Fuster, H., Oberst, U., Griffiths, M., Carbonell, X., Chamarro, A. \& Talarn, A. (2012). Psychological motivation in online role-playing games: A study of Spanish World of Warcraft players. Anales de Psicologia, 28, 274-280.

Geisinger, K. F. (1994). Cross-cultural normative assessment: Translation and adaptation issues influencing the normative interpretation of assessment instruments. Psychological Assessment, 6, 304-312.

Gentile, D. (2009). Pathological video-game use among youth ages 8 to 18: A national study. Psychological Science, 20, 594-602. 
Gentile, D. A., Bailey, K., Bavelier, D., Brockmyer, J. F., Cash, H., Coyne, S. M., ... Young, K. (2017). Internet gaming disorder in children and adolescents. Pediatrics, 140, S81-S85.

Gentile, D. A., Choo, H., Liau, A., Sim, T., Li, D., Fung, D., et al. (2011). Pathological video game use among youths: A two-year longitudinal study. Pediatrics, 127, 319329.

Gervasi, A. M., La Marca, L., Costanzo, A., Pace, U., Guglielmucci, F., \& Schimmenti, A. (2017). Personality and Internet gaming disorder: A systematic review of recent literature. Current Addiction Reports, 4, 293-307.

Ghuman, D., \& Griffiths, M. (2012). A cross-genre study of online Gaming. International Journal of Cyber Behavior, Psychology and Learning, 2, 13-29.

Greenberg, B. S., Sherry, J., Lachlan, K., Lucas, K., \& Holmstrom, A. (2010). Orientations to video games among gender and age groups. Simulation \& Gaming, $41,238-259$.

Griffiths, M. D. \& Nuyens, F. (2017). An overview of structural characteristics in problematic videogame playing. Current Addiction Reports, 4, 272-283.

Griffiths, M. D., Kuss, D. J. \& King, D. L. (2012). Video game addiction: Past, present and future. Current Psychiatry Reviews, 8, 308-318.

Hilgard, J., Engelhardt, C. R., \& Bartholow, B. D. (2013). Individual differences in motives, preferences, and pathology in video games: The gaming attitudes, motives, and experiences scales (GAMES). Frontiers in Psychology, 4, 608.

Hussain, Z., Williams, G. A., \& Griffiths, M. D. (2015). An exploratory study of the association between online gaming addiction and enjoyment motivations for playing massively multiplayer online role-playing games. Computers in Human Behavior, 50, 221-230. 
Kahn, A. S., Shen, C., Lu, L., Ratan, R. A., Coary, S., Hou, J., ... Williams, D. (2015). The Trojan Player Typology: A cross-genre, cross-cultural, behaviorally validated scale of video game play motivations. Computers in Human Behavior, 49, 354-361.

Kim, N. R., Hwang, S. S. H., Choi, J. S., Kim, D. J., Demetrovics, Z., Király, O., ... \& Choi, S. W. (2016). Characteristics and psychiatric symptoms of internet gaming disorder among adults using self-reported DSM-5 criteria. Psychiatry Investigation, $13,58-66$.

Kim, Y., \& Ross, S. D. (2006). An exploration of motives in sport video gaming. International Journal of Sports Marketing and Sponsorship, 8, 28-40.

King, D. L., Delfabbro, P. H. \& Griffiths, M. D. (2010). Video game structural characteristics: A new psychological taxonomy. International Journal of Mental Health and Addiction, 8, 90-106.

Király, O., Tóth, D., Urbán, R., Demetrovics, Z., \& Maraz, A. (2017). Intense video gaming is not essentially problematic. Psychology of Addictive Behaviors, 31, 807817.

Király, O., Urbán, R., Griffiths, M. D., Ágoston, C., Nagygyörgy, K., Kökönyei, G., \& Demetrovics, Z. (2015). The mediating effect of gaming motivation between psychiatric symptoms and problematic online gaming: An online survey. Journal of Medical Internet Research, 17, 188-202.

Kircaburun, K., Jonason, P. K., \& Griffiths, M. D. (2018). The Dark Tetrad traits and problematic online gaming: The mediating role of online gaming motives and moderating role of game types. Personality and Individual Differences, 135, 298303.

Laconi, S., Pirès, S., \& Chabrol, H. (2017). Internet gaming disorder, motives, game genres and psychopathology. Computers in Human Behavior, 75, 652-659. 
Lafrenière, M. A. K., Verner-Filion, J., \& Vallerand, R. J. (2012). Development and validation of the Gaming Motivation Scale (GAMS). Personality and Individual Differences, 53, 827-831.

Lautenschlager, G. J. (1989). A comparison of alternatives to conducting Monte Carlo analyses for determining parallel analysis criteria. Multivariate Behavioral Research, 24, 365-395.

Lee, D., \& LaRose, R. (2007). A socio-cognitive model of video game usage. Journal of Broadcasting \& Electronic Media, 51, 632-650.

Lee, H. P., Chae, P. K., Lee, H. S., \& Kim, Y. K. (2007). The five-factor gambling motivation model. Psychiatry Research, 150, 21-32.

Lemmens, J. S., Valkenburg, P. M. \& Peter, J. (2011a). Psychosocial causes and consequences of pathological gaming. Computers in Human Behavior, 27, 144-152.

Lemmens, J. S., Valkenburg, P. M., \& Peter, J. (2011b). The effects of pathological gaming on aggressive behavior. Journal of Youth and Adolescence, 40, 38-47.

Li, D. D., Liau, A. K., Gentile, D. A., Khoo, A., \& Cheong, W. D. (2013). Construct and predictive validity of a brief MMO player motivation scale: Cross-sectional and longitudinal evidence based on Singaporean young gamers. Journal of Children and Media, 7, 287-306.

López-Fernández, F.J., Mezquita, L., Griffiths, M.D., Ortet, F. \& Ibáñez, M.I. (2020).

The role of personality on disordered gaming and game genre preferences in adolescence: gender differences and person-environment transactions. Adicciones. Advance publication online. doi: https://doi.org/10.20882/adicciones.0.0

Lopez-Fernandez, O., Honrubia-Serrano, M. L., Baguley, T., \& Griffiths, M. D. (2014). Pathological video game playing in Spanish and British adolescents: Towards the 
exploration of Internet Gaming Disorder symptomatology. Computers in Human Behavior, 41, 304-312.

Männikkö, N., Billieux, J., Nordström, T., Koivisto, K., \& Kääriäinen, M. (2017). Problematic gaming behaviour in Finnish adolescents and young adults: Relation to game genres, gaming motives and self-awareness of problematic use. International Journal of Mental Health and Addiction, 15, 324-338.

Mezquita, L., Ruiz-Valero, L., Martínez-Gómez, N., Ibáñez, M. I., \& Ortet, G. (2019). Desarrollo y validación de la versión breve del cuestionario de motivos de consumo de marihuana (MMM SF). Adicciones, 31, 106-116.

Mezquita, L., Stewart, S. H., Ibáñez, M. I., Ruipérez, M. A., Villa, H., Moya, J., \& Ortet, G. (2011). Drinking motives in clinical and general populations. European Addiction Research, 17, 250-261.

Mihara, S., \& Higuchi, S. (2017). Cross-sectional and longitudinal epidemiological studies of internet gaming disorder: A systematic review of the literature. Psychiatry and Clinical Neurosciences, 71, 425-444.

Montag, C., Schivinski, B., Sariyska, R., Kannen, C., Demetrovics, Z., \& Pontes, H. M. (2019). Psychopathological symptoms and gaming motives in disordered gamingA psychometric comparison between the WHO and APA diagnostic frameworks. Journal of Clinical Medicine, 8, 1691-1709.

Moudiab, S., \& Spada, M. M. (2019). The relative contribution of motives and maladaptive cognitions to levels of Internet Gaming Disorder. Addictive Behaviors Reports, 9, 100-160.

Moya-Higueras, J., Cuevas, A., Marques-Feixa, L., Mezquita, L., Mayoral, M., Fañanás, L., ... \& Ibáñez, M. I. (2018). Recent stressful life events (SLE) and adolescent mental health: initial validation of the LEIA, a new Checklist for SLE assessment 
according to their severity, interpersonal, and dependent nature. Assessment, Epub ahead of print. https://doi.org/10.1177/1073191118817648

Nacke, L. E., Bateman, C., \& Mandryk, R. L. (2014). BrainHex: A neurobiological gamer typology survey. Entertainment Computing, 5, 55-62.

Nije Bijvank, M., Konijn, E. A., \& Bushman, B. J. (2012). “We don’t need no education”: Video game preferences, video game motivations, and aggressiveness among adolescent boys of different educational ability levels. Journal of Adolescence, 35, 153-162.

Olson, C. K. (2010). Children's motivations for video game play in the context of normal development. Review of General Psychology, 14, 180-187.

Petry, N. M., Rehbein, F., Ko, C. H., \& O’Brien, C. P. (2015). Internet gaming disorder in the DSM-5. Current Psychiatry Reports, 17, 72-80.

Plante, C. N., Gentile, D. A., Groves, C. L., Modlin, A., \& Blanco-Herrera, J. (2019). Video games as coping mechanisms in the etiology of video game addiction. Psychology of Popular Media Culture, 8, 385-394.

Rehbein, F., Kleimann, M. \& Mößle, T. (2010). Prevalence and risk factors of video game dependency in adolescence: Results of a German nationwide survey. CyberPsychology, Behavior and Social Networking, 13, 269-277.

Rodríguez de Sepúlveda, D. e Igartua, J. J. (2011). Creación y validación de una escala de motivos para videojugar. En F. Ortega y L. Cardeñosa (Eds.), Nuevos medios, nueva comunicación (pp. 217-234). Salamanca: II Congreso Internacional Comunicación 3.0.

Ryan, R. M., \& Deci, E. L. (2000). Intrinsic and extrinsic motivations: Classic definitions and new directions. Contemporary Educational Psychology, 25, 54-67. 
Ryan, R. M., Rigby, C. S., \& Przybylski, A. (2006). The motivational pull of video games: A self-determination theory approach. Motivation and Emotion, 30, 344-360.

Scharkow, M., Festl, R., Vogelgesang, J., \& Quandt, T. (2015). Beyond the “core-gamer”: Genre preferences and gratifications in computer games. Computers in Human Behavior, 44, 293-298.

Sherry, J. L., Lucas, K., Greenberg, B. S., \& Lachlan, K. (2006). Video game uses and gratifications as predictors of use and game preference. In P. Vorderer \& J. Bryant (Eds.), Playing computer games: Motives, responses, and consequences (pp. 213224). Mahwah, NJ: Lawrence Erlbaum.

Simons, J., Correia, C. J., Carey, K. B., \& Borsari, B. E. (1998). Validating a five-factor marijuana motives measure: Relations with use, problems, and alcohol motives. Journal of Counseling Psychology, 45, 265.

Steadman, J. L. (2019). Gaming motivations as a guide to treating problematic gaming behaviors. Journal of Technology in Behavioral Science, 4, 332-339.

Stewart, S. H., \& Zack, M. (2008). Development and psychometric evaluation of a threedimensional Gambling Motives Questionnaire. Addiction, 103, 1110-1117.

Subramaniam, M., Chua, B. Y., Abdin, E., Pang, S., Satghare, P., Vaingankar, J. A., ... \& Chong, S. A. (2016). Prevalence and correlates of internet gaming problem among internet users: Results from an internet survey. Annals Academy of Medicine Singapore, $45,174-83$.

Thorens, G., Achab, S., Billieux, J., Khazaal, Y., Khan, R., Pivin, E., Gupta, V., \& Zullino D. (2013). Characteristics and treatment response of self-identified problematic Internet users in a behavioral addiction outpatient clinic. Journal of Behavioral Addiction, 3, 78-81. 
Tondello, G. F., Wehbe, R. R., Diamond, L., Busch, M., Marczewski, A., \& Nacke, L. E. (2016, October). The gamification user types hexad scale. In Proceedings of the 2016 annual symposium on computer-human interaction in play (pp. 229-243).

van Rooij, A. J., Schoenmakers, T. M., Vermulst, A. A., van den Eijnden, R. \& van de Mheen, D. (2011). Online video game addiction: Identification of addicted adolescent gamers. Addiction, 106, 205-212.

Wallenius, M., Rimpelä, A., Punamäki, R.-L., \& Lintonen, T. (2009). Digital game playing motives among adolescents: Relations to parent-child communication, school performance, sleeping habits, and perceived health. Journal of Applied Developmental Psychology, 30, 463-474.

Watkins, M. W. (2006). Determining parallel analysis criteria. Journal of Modern Applied Statistical Methods, 5, 344-346.

Westwood, D., \& Griffiths, M. D. (2010). The role of structural characteristics in videogame play motivation: A Q-methodology study. Cyberpsychology, Behavior, and Social Networking, 13, 581-585.

Williams, D., Yee, N., \& Caplan, S. E. (2008). Who plays, how much, and why? Debunking the stereotypical gamer profile. Journal of Computer-Mediated Communication, 13, 993-1018.

World Health Organization (2017). ICD-11 beta draft. Mental, behavioural or neurodevelopmental disorders. Retrieved April 2, 2020, from https://icd.who.int/dev11/lm/en\#/http\%3a\%2f\%2fid.who.int $\% 2$ ficd $\% 2$ fentity $\% 2 \mathrm{f3}$ $\underline{38347362 .}$.

Wu, A. M., Lai, M. H., Yu, S., Lau, J. T., \& Lei, M. W. (2016). Motives for online gaming questionnaire: Its psychometric properties and correlation with Internet gaming 
disorder symptoms among Chinese people. Journal of Behavioral Addictions, 6, 1120.

Wu, J. H., Wang, S. C., \& Tsai, H. H. (2010). Falling in love with online games: The uses and gratifications perspective. Computers in Human Behavior, 26, 1862-1871.

Yee, N. (2006a). Motivations for play in online games. CyberPsychology and Behavior, 9, 772-775.

Yee, N. (2006b). The demographics, motivations, and derived experiences of users of massively multi-user online graphical environments. Presence: Teleoperators and Virtual Environments, 15, 309-329.

Yee, N., Ducheneaut, N., \& Nelson, L. (2012). Online gaming motivations scale: Development and validation. Proceedings of the ACM International Conference on Human Factors in Computing Systems (CHI 2012), 2803-2806. New York: ACM. 

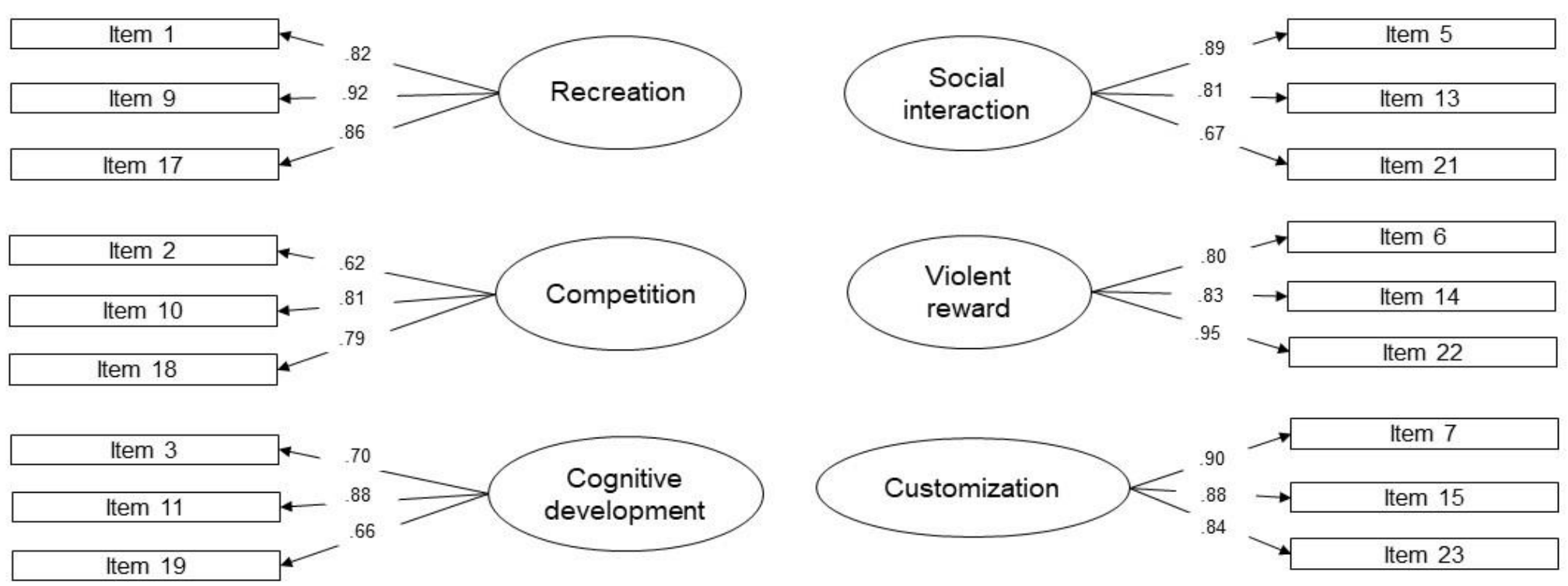

Cognitive
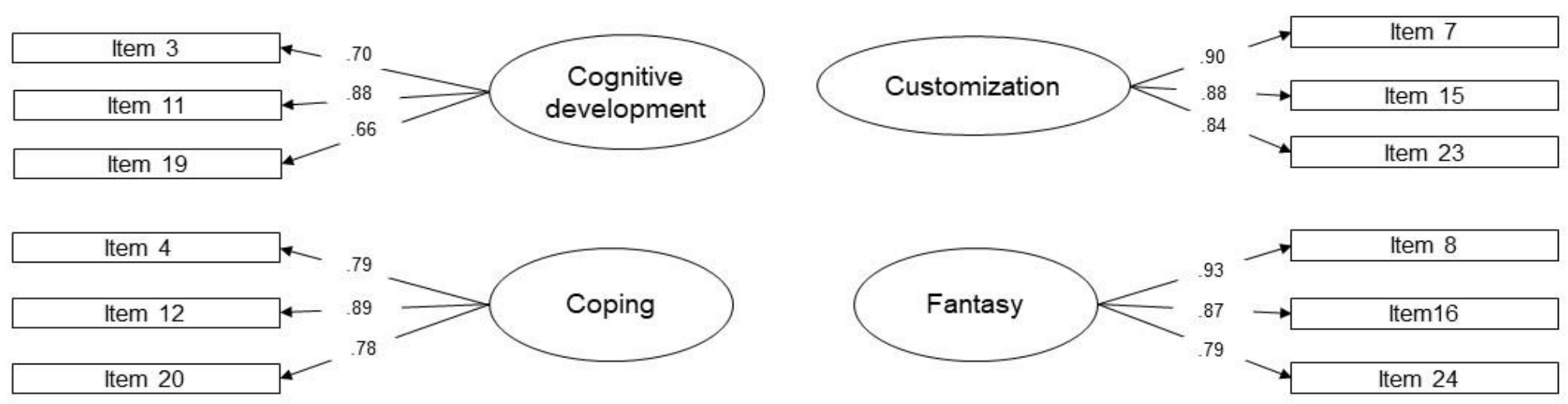
Figure 1. Confirmatory factor analysis of the VMQ among the young adult sample. For clarity, covariances between motives and errors were not depicted in figure.

All factor loadings were significant at $p<.001$. 


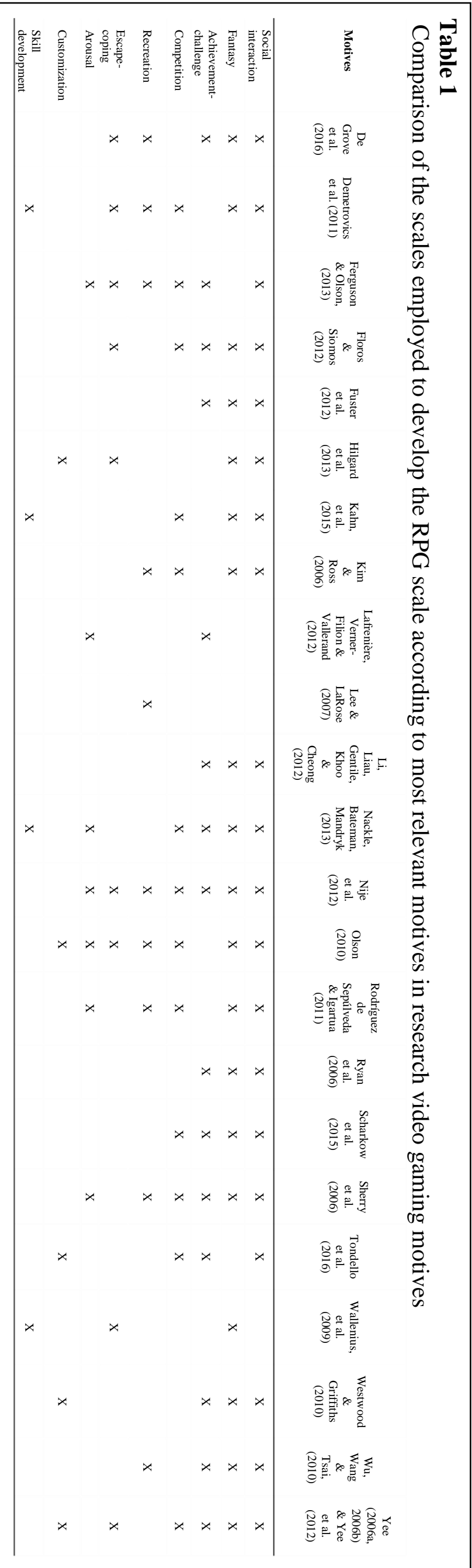


Table 2

Exploratory factor analysis and reliability of the VMQ

Item
Recreation
1. Disfruto jugando.
(I enjoy gaming).
9.Me lo paso bien.
(I have fun).
17. Es divertido.
(It is entertaining).
Competition
2. Me gusta ganar.
(I like to win).
10. Me gusta demostrar que soy mejor
que otros jugadores.
(I like to prove that I am better than
other players).
18. Disfruto compitiendo con otros.
(I enjoy competing with others).

\section{Cognitive development}

3. Me hacen pensar/calentarme la cabeza.

(Games make me thing).

11. Me suponen un reto mental.

(Games imply a mental challenge).

Alpha $=.76$

Retest $=.67 * *$

.55

.50

Alpha $=.81$

Retest $=.69 * *$

.88

.66

19. Me hacen más inteligente

(Games make me smarter).

\section{Coping}

4. Alivia mi estrés.

(It helps me get rid of stress).

12. Me ayuda a mejorar mi estado de ánimo.

(Gaming helps me improve my mood).

20. Me permite sentirme mejor cuando estoy frustrado.

(Gaming allows me to feel better when I am frustrated).
Alpha $=.87$

Retest $=.69 * *$

.81

\section{Social interaction}

5. Hago nuevos amigos.

(I make new friends).

13. Mediante el juego estoy en contacto con mis amigos.

(I keep in touch with my friends by gaming).

21. Así encajo en un grupo de gente que me gusta.

(Thus, I fit in a group I like).

\section{Violent reward}

6. Me gusta la violencia en el juego, cuanto más mejor.

(I like violence in video games, the more violent the better).

14. En el juego es divertido disparar a alguien en la cabeza.

(Shooting someone in the head in a game is deeply satisfying).

22. Disfruto de las peleas y luchas violentas en el juego.

(I enjoy the violent fights in video games).

\section{Customization}

7. Disfruto diseñando cosas en el juego.

(I enjoy customizing things in games).

15. Me gusta crear cosas en el juego, como casas u otras construcciones.

(I like making things in video games, like houses or other constructions).

. 236. Me gusta crear mi propio mundo en el juego.

(I like to create my own world in games).

\section{Fantasy}

8. Disfruto metiéndome en la piel de un nuevo personaje en cada juego.

(I enjoy putting myself into a new character's shoes in each game).

16. Me gusta sentirme parte de una historia.

(I like feeling myself part of a story).

24. Me siento inmerso en un mundo fantástico/ficticio.

(Ifeel immersed in a fantastic/fictitious world).
Factor Loading

Alpha $=.79$

Retest $=.78^{* *}$

.66

Alpha $=.93$

Retest $=.82 * *$

Alpha $=.88$

Retest $=.68 * *$

.95

Alpha $=.82$

Retest $=.68 * *$

.66 
Table 3

Correlation analysis between motivations of the VMQ and other relevant variables for Studies 2 and 3

\begin{tabular}{|c|c|c|c|c|c|c|c|c|c|c|c|c|c|c|}
\hline $\begin{array}{l}\text { Study } 2 \\
\text { Adolescent } \\
\text { sample }\end{array}$ & Age & Gender & $\begin{array}{l}\text { Gaming } \\
\text { hours }\end{array}$ & $\begin{array}{l}\text { Disordered } \\
\text { gaming }\end{array}$ & $\begin{array}{c}\text { Shooter } \\
\text { (197) }\end{array}$ & $\begin{array}{l}\text { MOBA } \\
(71)\end{array}$ & $\begin{array}{c}\text { Strategy } \\
(64)\end{array}$ & $\begin{array}{c}\text { MMORPG } \\
\text { (3) }\end{array}$ & $\begin{array}{l}\text { Role- } \\
\text { playing } \\
(23)\end{array}$ & $\begin{array}{l}\text { Action- } \\
\text { adventure } \\
\quad(45)\end{array}$ & $\begin{array}{l}\text { Sport } \\
(150)\end{array}$ & $\begin{array}{l}\text { Casual } \\
\text { (33) }\end{array}$ & $\begin{array}{c}\text { Social } \\
\text { simulation } \\
(35)\end{array}$ & $\begin{array}{c}\text { Construction } \\
\text { (21) }\end{array}$ \\
\hline Recreation & .00 & $-.17 * *$ & $.23 * *$ & $.18 * *$ & $.23 * *$ & .00 & -.08 & .05 & $.15^{* *}$ & .07 & .04 & -.06 & -.02 & .10 \\
\hline Competition & .03 & $-.46 * *$ & $.32 * *$ & $.39 * *$ & $.32 * *$ & $.20 * *$ & -.02 & .03 & -.06 & -.02 & $.25 * *$ & $-.12^{*}$ & $-.26 * *$ & -.04 \\
\hline $\begin{array}{l}\text { Cognitive } \\
\text { development }\end{array}$ & .05 & $-.20 * *$ & $.24 * *$ & $.37^{* *}$ & $.21 * *$ & $.12 *$ & .06 & .06 & .07 & $.19^{* *}$ & .03 & .03 & $-.15^{* *}$ & .03 \\
\hline Coping & .00 & $-.18 * *$ & $.34 * *$ & $.48^{* *}$ & $.20 * *$ & .03 & -.05 & .04 & .10 & $.14 * *$ & .10 & -.05 & $-.15 * *$ & .04 \\
\hline Social interaction & .02 & $-.34 * *$ & $.37 * *$ & $.51 * *$ & $.40 * *$ & $.15^{* *}$ & $-.13^{*}$ & .09 & -.02 & -.03 & .06 & -.03 & $-.20 * *$ & -.03 \\
\hline Violent reward & -.01 & $-.42 * *$ & $.28^{* *}$ & $.36^{* *}$ & $.47 * *$ & .09 & $-.15^{* *}$ & .00 & -.09 & -.02 & $.15^{* *}$ & $-.19 * *$ & $-.25 * *$ & .00 \\
\hline Customization & -.01 & .06 & $.19^{* *}$ & $.18^{* *}$ & .08 & .04 & .04 & .08 & .09 & $.12 *$ & $-.12 *$ & .07 & $.27 * *$ & $.18^{* *}$ \\
\hline Fantasy & -.05 & $-.15 * *$ & $.26^{* *}$ & $.31 * *$ & $20 * *$ & .06 & -.05 & $.14 * *$ & $.18^{* *}$ & $.22 * *$ & -.03 & -.01 & .04 & $.12 *$ \\
\hline $\begin{array}{l}\text { Study } 3 \\
\text { Young adult } \\
\text { sample }\end{array}$ & Age & Gender & $\begin{array}{l}\text { Gaming } \\
\text { hours }\end{array}$ & $\begin{array}{l}\text { Disordered } \\
\text { gaming }\end{array}$ & $\begin{array}{c}\text { Shooter } \\
\text { (77) }\end{array}$ & $\begin{array}{l}\text { MOBA } \\
(74)\end{array}$ & $\begin{array}{c}\text { Strategy } \\
(46)\end{array}$ & $\begin{array}{l}\text { MMORPG } \\
\text { (11) }\end{array}$ & $\begin{array}{l}\text { Role- } \\
\text { playing } \\
(61)\end{array}$ & $\begin{array}{l}\text { Action- } \\
\text { adventure } \\
\quad(25)\end{array}$ & $\begin{array}{l}\text { Sport } \\
\text { (33) }\end{array}$ & $\begin{array}{l}\text { Casual } \\
\text { (51) }\end{array}$ & $\begin{array}{c}\text { Social } \\
\text { simulation } \\
(23)\end{array}$ & $\begin{array}{c}\text { Construction } \\
\text { (8) }\end{array}$ \\
\hline Recreation & $.14^{*}$ & $-.30 * *$ & $.29 * *$ & $.29 * *$ & $.26 * *$ & $.19 * *$ & -.05 & $.15^{*}$ & $.23 * *$ & $.20 * *$ & .12 & $-.18 * *$ & $.13 *$ & .02 \\
\hline Competition & .00 & $-.36 * *$ & $.15^{*}$ & $.28 * *$ & .12 & $.18 * *$ & .03 & $.13^{*}$ & -.04 & -.03 & $.19 * *$ & $-.26 * *$ & -.12 & .02 \\
\hline $\begin{array}{l}\text { Cognitive } \\
\text { development }\end{array}$ & $.19 * *$ & $-.18 * *$ & $.12 *$ & $.21 * *$ & $.13 *$ & .06 & .03 & .04 & .06 & $.17 * *$ & .01 & .08 & -.03 & -.02 \\
\hline Coping & $.15^{*}$ & $-.16^{*}$ & $.24 * *$ & $.39 * *$ & $.18 * *$ & .06 & -.10 & $.18^{* *}$ & .11 & $.22 * *$ & .11 & -.11 & -.02 & .00 \\
\hline Social interaction & -.02 & $-.40 * *$ & $.42 * *$ & $.41 * *$ & $.30 * *$ & $.43 * *$ & -.05 & $.26^{* *}$ & $.17 * *$ & .04 & .02 & $-.31 * *$ & $-.16^{* *}$ & .05 \\
\hline Violent reward & -.06 & $-.46^{* *}$ & $.21 * *$ & $.43 * *$ & $.37 * *$ & .11 & $-.14 *$ & .08 & $.14^{*}$ & $.24 * *$ & $.18^{* *}$ & $-.34 * *$ & -.11 & -.03 \\
\hline Customization & .06 & .09 & $.15^{*}$ & .10 & $.13^{*}$ & -.04 & -.04 & .08 & $.20 * *$ & .07 & -.04 & $-.16^{* *}$ & $.35^{* *}$ & .12 \\
\hline Fantasy & .04 & $-.17 *$ & $.24 * *$ & $.34 * *$ & $.25 * *$ & .07 & -.09 & $.18^{* *}$ & $.30 * *$ & $.32 * *$ & .06 & $-.29 * *$ & $.13^{*}$ & .01 \\
\hline
\end{tabular}

Note. $* p<.05, * * p<.01$

Gender: $1=$ males, $2=$ females

The number of players by genre are indicated between parentheses 
Table 4

Multiple linear regressions of hours spent gaming and disordered gaming for Studies 2 and 3

Study $2 \quad$ Study 3

Adolescent sample $\quad$ Young adult sample

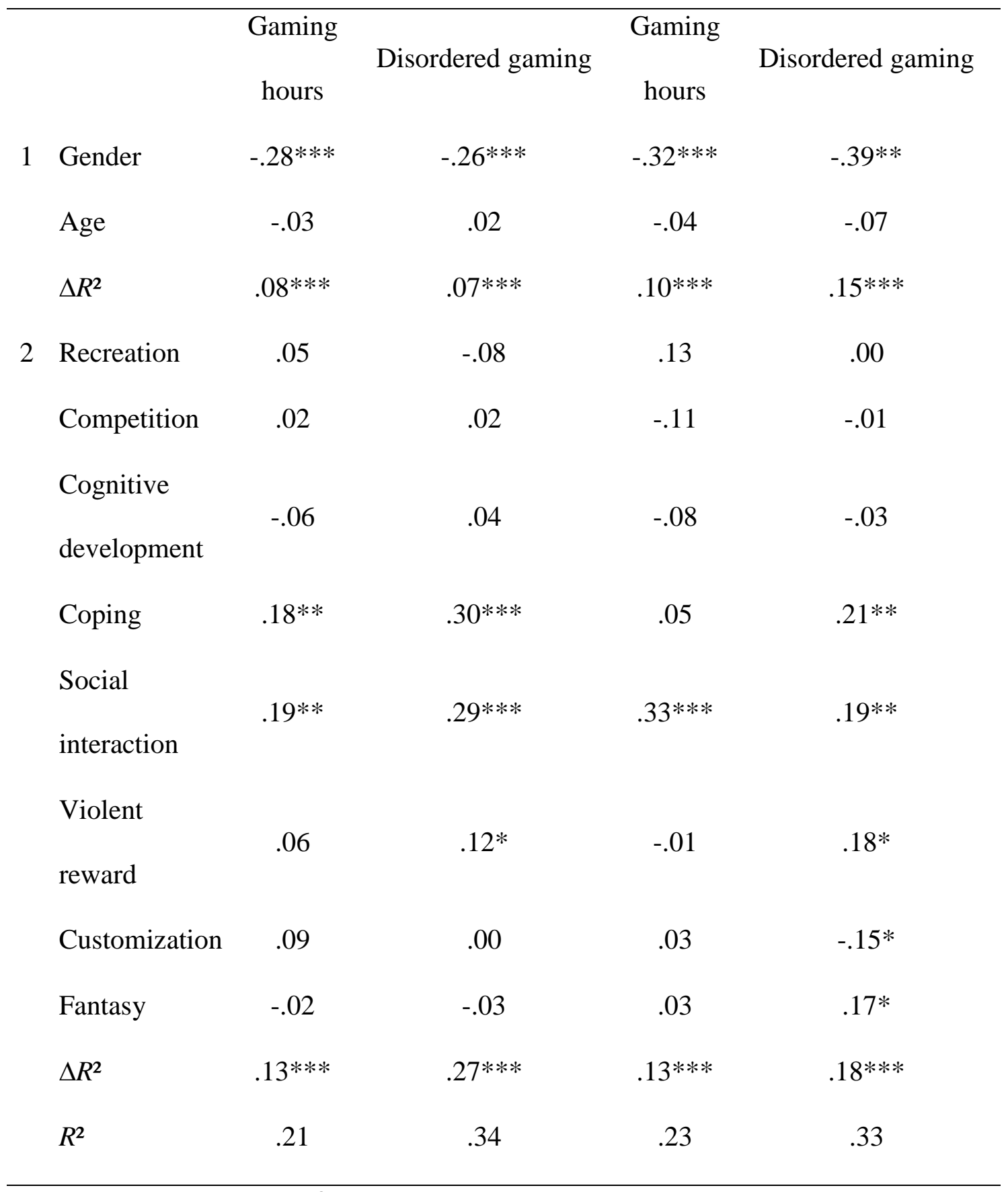

Note. $1=$ males, $2=$ females. $\beta=$ standardized beta; $\Delta \mathrm{R}^{2}=$ change in variance; $\mathrm{R}^{2}=$ total $\mathrm{R}^{2}$.

$* p<.05 . * * p<.01 . * * * p<.001$ 


\section{Supplementary Material:}

Study 1: Pattern Matrix for Oblimin Eight-Factor Solution Extracted from Pilot Videogamimg Motives Questionnaire (VMQ)

\begin{tabular}{|c|c|c|c|c|c|c|c|c|}
\hline $\begin{array}{l}\text { Juego a videojuegos porque: } \\
\text { I play video games because: }\end{array}$ & Recreation & $\begin{array}{c}\text { Social } \\
\text { interaction }\end{array}$ & $\begin{array}{l}\text { Coping- } \\
\text { escape }\end{array}$ & $\begin{array}{l}\text { Violent } \\
\text { reward }\end{array}$ & Fantasy & Customization & Competition & $\begin{array}{c}\text { Skill } \\
\text { development }\end{array}$ \\
\hline $\begin{array}{l}\text { Disfruto jugando } \\
\text { I enjoy gaming }\end{array}$ & .72 & & & & & & & \\
\hline Me entretienen & .66 & & & & & & & \\
\hline Games entertain me & & & & & & & & \\
\hline $\begin{array}{l}\text { Me lo paso bien } \\
\text { I have fun }\end{array}$ & .65 & & & & & & & \\
\hline $\begin{array}{l}\text { Es divertido } \\
\text { It is entertaining }\end{array}$ & .59 & & & & & & & \\
\hline $\begin{array}{l}\text { Me gustan mucho } \\
\text { I like them much }\end{array}$ & .57 & & & & & & & \\
\hline $\begin{array}{l}\text { Me relaja } \\
\text { It relaxes me }\end{array}$ & .56 & & & & & & & \\
\hline $\begin{array}{l}\text { Alivia mi estrés } \\
\text { It helps me get rid of stress }\end{array}$ & .47. & & .33 & & & & & \\
\hline $\begin{array}{l}\text { Hago nuevos amigos } \\
\text { I make new friends }\end{array}$ & & .89 & & & & & & \\
\hline $\begin{array}{l}\text { Me permite conocer a otras persones } \\
\text { It allows me to meet other people } \\
\text { Mediante el juego estoy en contacto con } \\
\text { mis amigos }\end{array}$ & & .85 & & & & & & \\
\hline $\begin{array}{l}\text { I keep in touch with my friends by } \\
\text { gaming }\end{array}$ & & .82 & & & & & & \\
\hline $\begin{array}{l}\text { Disfruto jugando en grupo } \\
\text { I enjoy playing in group }\end{array}$ & & .64 & & & & & & \\
\hline
\end{tabular}


Me gusta jugar con gente online o en la misma habitación

I like playing with people online or in

the same room

Así encajo en un grupo de gente que me gusta

Thus, I fit in a group I like

Otros jugadores me valoran en el juego

Other players appreciate me in the

game

Así tengo cosas de las que hablar con

mis amigos

Thus I have things to talk about with my

friends

Tengo prestigio por mis éxitos en el

juego

I have prestige because of my successes

in the game

Gusto a los demás si juego

The others like me if I play

Todos mis amigos juegan

All my friends play

Me ayuda a olvidar problemas del día a

día

It help me forget my daily problems

Olvido mis preocupaciones

I forget my worries

Me permite escapar del mundo real

It allowes me to escape from the real

world 
Me permite sentirme mejor cuando

estoy frustrado

Gaming allowes me to feel better when I

am frustrated

Me ayuda a mejorar mi estado de ánimo

Gaming helps me to improve my mood

Me ayuda a liberar mi energía negativa

It helps to release negative energy

Así no me siento excluido

Thus I do not feel excluded

Cuando estoy enfadado o disgustado

con alguien, mediante el juego evito

discutir con esa persona

When I am angry or upset with

someone, through gaming I avoid

arguing with such person

Disfruto de las peleas y luchas violentas

en el juego

I enjoy the violent fights in video game

Me gusta la violencia en el juego,

cuanto más mejor

I like violence in video games, the more

violent the better

En el juego es divertido disparar a

alguien en la cabeza

Shooting someone in the head in a game

is deeply satisfying

Disfruto destrozando cosas en el juego

I enjoy destroying thing in the game

Matando en el juego me siento poderoso 
Killing in the game I feel powerful

Me permite hacer cosas que no puedo

hacer en la vida real

It allowes me to do things I cannot do in

the real life

Me ayuda a canalizar mi agresividad

It helps me channel my aggressivity

Incrementan mis niveles de adrenalina

Games increase my adrenalin levels

Me siento inmerso en un mundo

fantástico/ficticio

I feel immersed in a fantastic/fictitious

world

Me gusta sentirme parte de una historia

I like feeling myself part of a story

Disfruto metiéndome en la piel de un

personaje en cada juego

I enjoy putting myself into a new

character's shoes in each game

Me siento alguien importante en el

juego

Ifeel someone important in the game

Me gusta explorar el mundo del juego

para descubrir cosas nuevas

I like to explore the world to find out

new things

Estimulan mis emociones

Games stimulate my emotions

Son excitantes y emocionantes

Games are exciting 
Disfruto diseñando cosas en el juego

I enjoy customizing things in the game

Me gusta crear cosas en el juego, como

casas u otras construcciones

I like making things in video games,

such as houses or other constructions

Me gusta crear mi propio mundo en el

juego

I like to create my own world in games

En el juego me gusta utilizar distintos

elementos para crear nuevas cosas

In the game I like to use different

elements to create new things

Me gusta diseñar o personalizar la

apariencia de mis personajes

I like designing or customizing the

appearance of my characters

Me agrada derrotar a otros jugadores

I like to defeat other players

Me gusta ganar

I like to win

Me gusta demostrar que soy mejor que

otros jugadores

I like to prove I am better than other

players

Me gusta provocar o picar a otros

jugadores

I like to provoke other players

Me siento poderoso en el juego

I feel myself powerful in the game 
Me suponen un reto mental

Games imply a mental challenge

Me hacen más inteligente

Games make me smarter

Me hacen pensar/calentarme la cabeza

Games make me thing

Agudizan mis sentidos

Games sharpen my senses

Me activan

Games trigger me

Mejoran mis habilidades

Games improve my abilities

Note. Only factors loadings higher than .30 were presented.

Items with factor loading lower than .30 were not depicted: Me gustan las emociones intensas (I like intense feelings), Así los demás no se burlarán de mí ni se meten conmigo por no jugar (Thus the others will not mock me because no gaming), Me siento orgulloso de mi actuación en el juego (Ifeel proud of my in-game performance), Me ayuda a ser menos violento en la vida real (Games help me to be less violent in the real life). 
Study 2: Descriptive data by gender, gender differences and correlation matrix

\begin{tabular}{|c|c|c|c|c|c|c|c|c|c|c|c|c|c|}
\hline & $\begin{array}{l}\text { Males' mean } \\
\text { (SD) }\end{array}$ & $\begin{array}{l}\text { Females' mean } \\
\text { (SD) }\end{array}$ & $\begin{array}{c}\text { Sign. } \\
t\end{array}$ & $\begin{array}{c}\text { Cohen's } \\
d\end{array}$ & 1 & 2 & 3 & 4 & 5 & 6 & 7 & 8 & 9 \\
\hline 1. Recreation & $10.43(2.06)$ & $9.64(2.15)$ & .001 & .38 & - & & & & & & & & \\
\hline 2. Competition & $8.30(2.59)$ & $5.31(2.95)$ & .000 & 1.08 & $.42 * *$ & - & & & & & & & \\
\hline $\begin{array}{l}\text { 3. Cognitive } \\
\text { development }\end{array}$ & $5.93(3.26)$ & $4.50(3.03)$ & .000 & .45 & $.37 * *$ & $.53 * *$ & - & & & & & & \\
\hline 4. Coping & $7.10(3.41)$ & $5.76(3.64)$ & .000 & .38 & $.44 * *$ & $.48 * *$ & $.53 * *$ & - & & & & & \\
\hline 5. Social interaction & $5.70(3.29)$ & $3.23(2.98)$ & .000 & .79 & $.28 * *$ & $.57 * *$ & $.58 * *$ & $.50 * *$ & - & & & & \\
\hline 6. Violent reward & $6.54(3.33)$ & $3.09(3.70)$ & .000 & .98 & $.27 * *$ & $.49 * *$ & $.30 * *$ & $.37 * *$ & $.41 * *$ & - & & & \\
\hline 7. Customization & $6.14(3.66)$ & $6.60(3.90)$ & .250 & .12 & $.26^{* *}$ & $.18^{* *}$ & $.39 * *$ & $.34 * *$ & $.27 * *$ & $.15^{* *}$ & - & & \\
\hline 8. Fantasy & $6.24(3.37)$ & $5.16(3.54)$ & .004 & .31 & $.46^{* *}$ & $.36 * *$ & $.57 * *$ & $.57 * *$ & $.44^{* *}$ & $.34 * *$ & $.55^{* *}$ & - & \\
\hline 9. Gaming hours & $19.49(14.41)$ & $11.16(8.71)$ & .000 & .70 & $.23 * *$ & $.32 * *$ & $.24 * *$ & $.34 * *$ & $.37 * *$ & $.28 * *$ & $.19 * *$ & $.26^{* *}$ & - \\
\hline 10. Disordered gaming & $5.81(5.52)$ & $2.87(3.63)$ & .000 & .63 & $.18^{* *}$ & $.39 * *$ & $.37 * *$ & $.48 * *$ & $.51 * *$ & $.36^{* *}$ & $.18 * *$ & $.31^{* *}$ & $.42 * *$ \\
\hline
\end{tabular}
Note. Gender differences, Student $t$ test.

Cohen's $d$ effect size: small, .20; medium, .50; large, .80 . $* p<.05, * * p<.01$ 
Study 3: Descriptive data by gender, gender differences and correlation matrix

\begin{tabular}{|c|c|c|c|c|c|c|c|c|c|c|c|c|c|}
\hline & $\begin{array}{l}\text { Males' mean } \\
\text { (SD) }\end{array}$ & $\begin{array}{c}\text { Females' mean } \\
\text { (SD) }\end{array}$ & $\begin{array}{c}\text { Sign. } \\
t\end{array}$ & $\begin{array}{c}\text { Cohen's } \\
d\end{array}$ & 1 & 2 & 3 & 4 & 5 & 6 & 7 & 8 & 9 \\
\hline 1. Recreation & $13.85(1.77)$ & $12.57(2.25)$ & .000 & .63 & - & & & & & & & & \\
\hline 2. Competition & $11.21(2.86)$ & $8.88(3.17)$ & .000 & .77 & $.39 * *$ & - & & & & & & & \\
\hline $\begin{array}{l}\text { 3. Cognitive } \\
\text { development }\end{array}$ & $10.28(2.71)$ & $9.23(3.16)$ & .010 & .36 & $.39 * *$ & $.24 * *$ & - & & & & & & \\
\hline 4. Coping & $9.79(2.91)$ & $8.78(3.27)$ & .019 & .33 & $.48 * *$ & $.29 * *$ & $.44 * *$ & - & & & & & \\
\hline 5. Social interaction & $8.34(3.21)$ & $5.70(2.92)$ & .000 & .86 & $.38 * *$ & $.41 * *$ & $.34 * *$ & $.38 * *$ & - & & & & \\
\hline 6. Violent reward & $8.48(3.40)$ & $5.18(2.94)$ & .000 & 1.04 & $.29 * *$ & $.34 * *$ & $.16^{*}$ & $.32 * *$ & $.27 * *$ & - & & & \\
\hline 7. Customization & $9.53(3.39)$ & $10.22(4.03)$ & .174 & .19 & $.36^{* *}$ & .12 & $.27 * *$ & $.35^{* *}$ & $.17 *$ & .13 & - & & \\
\hline 8. Fantasy & $10.39(3.34)$ & $9.10(4.05)$ & .013 & .33 & $.51 * *$ & $.22 * *$ & $.40^{* *}$ & $.47 * *$ & $.30 * *$ & $.40 * *$ & $.60 * *$ & - & \\
\hline 9. Gaming hours & $14.09(13.89)$ & $7.09(10.63)$ & .000 & .57 & $.29 * *$ & $.15^{*}$ & $.12 *$ & $.24 * *$ & $.42 * *$ & $.21 * *$ & $.15^{*}$ & $.24 * *$ & - \\
\hline 10. Disordered gaming & $38.39(11.55)$ & $30.48(9.27)$ & .000 & .76 & $.29 * *$ & $.28 * *$ & $.21 * *$ & $.39 * *$ & $.41 * *$ & $.43 * *$ & .10 & $.34 * *$ & $.43 * *$ \\
\hline
\end{tabular}

Note. Gender differences, Student $t$ test.

Cohen's $d$ effect size: small, .20; medium, .50; large, .80.

$* p<.05, * * p<.01$ 


\subsection{Study 3}

Title: Direct and indirect effects of personality through gaming motives on weekly and disordered gaming on adolescents. 


\begin{abstract}
Different studies have shown relationships between personality and gaming motives with video gaming behaviors. However, the mediating role of gaming motives in the relationships between personality and gaming behaviors has scarcely been examined. The present study explored direct and indirect effects of the Big Five personality traits on weekly and disordered gaming via gaming motives among 364 adolescent players. Structural equation modeling revealed neuroticism was directly and indirectly, via coping motive, related to disordered gaming. Low agreeableness was associated with disordered gaming, through social interaction, and directly with weekly gaming. Furthermore, low conscientiousness was directly related to disordered gaming whereas introversion presented a direct association with weekly gaming. The findings suggest risky personality pathways observed in drug use and abuse are also found in regular and disordered gaming such as the negative affect regulation pathway and the deviance proneness pathway.
\end{abstract}

Keywords: video games; pathological gaming; disordered gaming; problematic gaming; personality; gaming motives; coping; structural equation modeling 


\section{Introduction}

Videogaming is a popular pastime especially among teenagers (AEVI, 2018). Accordingly, the highest prevalence of disordered gaming is found during adolescence (Fam, 2018; Mihara \& Higuchi, 2017; Paulus, Ohmann, von Gontard \& Popow, 2018). Adolescent disordered gaming has been associated to negative outcomes such as poor academic performance or loneliness (Gentile et al., 2011; Lemmens Valkenburg \& Peter, 2011), and to both externalizing and internalizing psychological problems, such as depression, anxiety and social phobias (Gentile et al., 2011; Müller et al., 2015; Wartberg et al., 2017). Therefore, it is important to ascertain which psychological factors are involved in non-disordered and disordered gaming, such as personality and motives to play (Dreier, Wölfling \& Müller, 2013).

\subsection{The Five-Factor Model and videogaming}

Nowadays, the most accepted and employed model of personality is the FiveFactor Model (FFM) (John, Naumann, \& Soto, 2008), which encompasses the basic dimensions of neuroticism, extraversion, openness to experience, agreeableness, and conscientiousness (McCrae \& Costa, 2008). Thus, the FFM has been widely used to study the relationships between personality and disordered gaming. In this sense, disordered gaming is mainly related to low conscientiousness and high neuroticism as well as to low agreeableness, low extraversion and low openness, to a lesser degree in the case of the latter three domains (for three systematic reviews, Gervasi et al., 2017; Mihara \& Higuchi, 2017; Şalvarlı \& Griffiths, 2019). However, the number of studies focused on adolescents is scarce, finding that disordered gaming is mainly related to low conscientiousness (García-Oliva \& Piqueras, 2016; López-Fernández, Mezquita, Griffiths, Ortet, \& Ibáñez, 2020a; Vollmer, Randler, Horzum \& Ayas, 2014; Wang, Ho, 
Chan \& Tse, 2015) and low extraversion (García-Oliva \& Piqueras, 2016; Vollmer et al., 2014).

\subsection{Motives to play and videogaming}

A great number of studies have shown the importance of gaming motives to explain part of disordered gaming through different approaches and scales (e.g., Ryan \& Deci, 2000; Sherry, Lucas, Greenberg \& Lachlan, 2006; Yee, 2006). Thereby, escapismcoping motives, which are related to playing in order to forget daily problems, are the most associated with gaming addiction (Ballabio et al., 2017; Billieux et al., 2013; Hagström \& Kaldo, 2014; Kim et al., 2016; Király et al., 2015; Király, Tóth, Urbán, Demetrovics \& Maraz, 2017; Kircaburun et al., 2019; Kuss, Louws \& Wiers, 2012; Kwon, Chung \& Lee, 2011; Laconi, Pirès, \& Chabrol, 2017; López-Fernández, Mezquita, Griffiths, Ibáñez, Ortet, 2020b; Männikkö, Billieux, Nordström, Koivisto \& Kääriäinen, 2017; Wu, Lai, Yu, Lau \& Lei, 2016; Yee, 2006; Zanetta et al., 2011), and this relationship could be moderated by players' poor coping styles (Bowditch, Chapman \& Naweed, 2018) or psychosocial problems like stress and self-esteem (Kardefelt-Winther, 2014). Additionally, motives related to gaming competence, such as achievement or competition, have also been associated with disordered use recurrently (Ballabio et al., 2017; Billieux et al., 2013; Chang \& Lin, 2019; Király et al., 2015; Kircaburum et al., 2019; Laconi et al., 2017; Männikkö et al., 2017; Montag et al., 2019; Yee, 2006; Zanetta et al., 2011). On the other hand, social motives, those related to playing with others, are strongly linked to higher gaming frequency (Greenberg et al., 2010; Király et al., 2017; López-Fernández et al., 2020b; Sherry et al., 2006; Wu et al., 2016). Furthermore, such motives have a significant role in disordered gaming in some studies (Hilgard et al., 2013; López-Fernández et al., 2020b; Männikkö et al., 2017; Zanetta et al., 2011). 


\subsection{The mediating role of videogaming motives}

Although personality is related to gaming behaviors, they may act through more proximal variables, such as motives. This mediational role of motives between personality and other addictive behaviors have been well stablished, such as in alcohol use and abuse (Mezquita et al., 2018). However, it has been scarcely studied in videogaming.

Supporting this idea, some studies have examined the relationship of FFM personality domains with motivations to play video games (Bean \& Groth-Marnat, 2016; Graham \& Gosling, 2013; Jeng \& Teng, 2008; Park, Song \& Teng, 2011; Shceck, Lee, \& Pyo, 2015). Thereby, higher neuroticism has been frequently associated with immersion or role-playing motivations, for instance, playing to discover the world or to collect accessories (Bean \& Groth-Marnat, 2016; Graham \& Gosling, 2013) and being especially relevant for the escapism dimension (Shceck et al., 2015). Extraversion was mainly related to social and achievement motives, including competition (Bean \& GrothMarnat, 2016; Jeng \& Teng, 2008; Graham \& Gosling, 2013; Shceck et al., 2015). A strong relationship has been observed between immersion motives and openness to experience (Bean \& Groth-Marnat, 2016; Graham \& Gosling, 2013; Jeng \& Teng, 2008; Shceck et al., 2015). In addition, agreeableness displayed significant, positive associations with social motivations (Graham \& Gosling, 2013; Jeng \& Teng, 2008; Park et al., 2011; Shceck et al., 2015). In this sense, gamer profiles have been associated with personality differentially (Tondello et al., 2016). Thus, low neuroticism displayed a strong relationship with free spirits -"I often let my curiosity guide me"- and disruptors -“I like to question the status quo"; high extraversion showed a relevant link with being a socializer -"Interacting with others is important to me"; high openness was associated with being a free spirit; high agreeableness was related to philanthropists -"It makes me 
happy if I am able to help others" and socializers; and high conscientiousness was linked to being an achiever -"I like mastering difficult tasks".

Some relevant studies have explored the associations of personality traits with preferences for in-game behaviors under the HEXACO framework of personality (Worth \& Book, 2014; Worth \& Book, 2015; Zeigler-Hill \& Monica, 2015). This model encompasses six basic domains very similar to those proposed within the FFM framework, i.e. emotionality, extraversion, conscientiousness, openness to experience, agreeableness and honesty-humility, the latter expressing the tendency to exhibit fairness and modesty (Ashton \& Lee, 2007). In these studies, both agreeableness and honestyhumility dimensions were positively associated with behaviors related to helping other players, whereas honesty-humility was negatively linked to competing or damaging other players (Worth \& Book, 2014; Worth \& Book, 2015). Emotionality was positively associated with actions focused on getting in-game achievements (Worth \& Book, 2014; Zeigler-Hill \& Monica, 2015) and negatively related to competitive and aggressive characteristics (Worth \& Book, 2015). Extraversion was strongly related to playing for social aspects of the game (Worth \& Book, 2014; Zeigler-Hill \& Monica, 2015). Conscientiousness was positively associated with playing to accomplish objectives or achievements, and negatively with competing or damaging others (Worth \& Book, 2014; Worth \& Book, 2015; Zeigler-Hill \& Monica, 2015). Finally, openness to experience showed a strong link with in-game exploration and other immersive facets (Worth \& Book, 2014; Zeigler-Hill \& Monica, 2015).

Despite the fact that personality is closely associated with motives for gaming, only a few studies have examined the mediation role of motives between personalityrelated traits and gaming behavior. Kircaburun, Jonason \& Griffiths (2018) showed the mediating role of motives on the relationship between personality traits of the Dark Tetrad 
(Machiavellianism, psychopathy, narcissism and sadism) and problematic gaming. Thus, narcissism and sadism were indirectly associated with disordered gaming through escape and fantasy. Likewise, Kircaburun et al. (2019) observed the mediating role of motives between trait emotional intelligence (EI) and disordered gaming, displaying a direct association of low EI, and an indirect relationship via escape motive, to problematic gaming. However, to date, the mediating role of gaming motives among the relationship between basic personality domains and disordered gaming has not been yet explored.

\subsection{Objectives}

According to these studies, personality traits may influence video gaming behaviors such as weekly gaming and disordered gaming in order to satisfy personal needs (Ryan \& Deci, 2000; Sherry et al., 2006) through the mediating role of gaming motives (Kircaburun et al., 2018; Kircaburun et al., 2019). Therefore, the main objective of the present study was to examine direct and indirect associations of the FFM with regular and disordered gaming via gaming motives. For that purpose, the Videogaming Motives Questionnaire (VMQ) was employed, where the most relevant gaming motives found in the literature are reflected: recreation, social interaction, coping, violent reward, fantasy, cognitive development, customization and competition (López-Fernández et al., 2020b). Regarding the models of mediation, due to insufficient research to establish hypotheses, completely saturated models (James, Mulai \& Brett, 2006) were tested.

\section{Method}

\subsection{Participants and procedure}

The total sample was composed of 364 adolescent players from two Spanish high schools $(69 \%$ males, mean age $=14.97, \mathrm{SD}=1.11$, aged $13-18)$, who reported playing at least once a week and completed all the questionnaires. In accordance with the 
Declaration of Helsinki, parents or legal tutors of the participants gave written informed consent.

\subsection{Measures}

2.2.1. An abridged from of the Junior Spanish version of the NEO PI-R (JS NEOA60)

Personality was assessed using the JS NEO-A60 (Walker, López \& Mezquita, 2018), which is an abridged version of The Junior Spanish version of the NEO-PI-R (Ortet et al., 2010). This scale assesses the five broad personality domains of the FFM in youths, aged between 12 and 17 years with a total of 60 items, 12 per domain. Items are responded to on 5-point Likert scales ranging from 0 ("Strongly disagree") to 4 ("Strongly agree").

\subsubsection{Videogaming Motives Questionnaire (VMQ)}

In order to assess motives for playing, the VMQ was employed (López-Fernández et al., 2020b). The questionnaire assesses 8 motives frequently found in research (recreation, social interaction, coping, violent reward, fantasy, cognitive development, customization and competition) with 3 items per dimension using a 5-point Likert scale $(0$ = strongly disagree $; 4$ = strongly agree $)$.

\subsubsection{Disordered video gaming}

A Spanish adaptation (López-Fernández, Mezquita, Griffiths, Ortet \& Ibáñez, 2020a) of a disordered gaming scale for adolescents was used (Gentile, 2009). The scale comprises 11 items assessing addictive symptomatology: salience, mood modification, tolerance, withdrawal, conflict and relapse; on a 4-point Likert scale $(0=$ "never or almost never" to $3=$ "almost always or always").

\subsubsection{Weekly gaming}

Weekly gaming was obtained collecting the number of daily hours of gaming per week and weekends; and multiplying these by the number of days of such periods. 


\subsection{Data analyses}

Descriptive analyses, Cronbach's alphas and correlations analyses were conducted using the SPSS statistics package, version 21. Those missing values that represented less than $5 \%$ in a questionnaire were replaced with the mean score for the remaining items in that scale.

To test the models, structural equation modeling (Muthen and Muthen, 2018) was performed using Mplus 5.21. The total and indirect effects of each predictor variable on disordered and weekly gaming were examined using bias-corrected bootstrapped estimates (Efron \& Tibshirani, 1993) based on 10,000 bootstrapped samples. This provides a powerful mediation test (Fritz and MacKinnoh, 2007), and one that is robust to small deviation from normality (Erceg-Hurn \& Mirosevich, 2008). To determine statistical significance, $99 \%$ bias-corrected bootstrapped confidence intervals not containing zero were used.

\section{Results}

Descriptive statistics, correlation analyses and Cronbach's alphas for the study variables are shown in Supplementary material.

Figure 1 displays the models in which disordered gaming and weekly gaming are dependent variables. Some strong associations between personality and motives were found. Thus, neuroticism was mainly related to coping; extraversion to competition and violent reward; openness to fantasy, customization and cognitive development; low agreeableness to violent reward and competition; and finally, conscientiousness to customization. Table 1 reveals the indirect and total effects of each model. Neuroticism was directly associated with disordered gaming and indirectly via coping motive. Extraversion was negatively and directly related to weekly gaming. Agreeableness was negatively associated with disordered gaming through social interaction, even though the standardized beta value was out of the confidence interval, and displayed significant total 
effects. In addition, lower agreeableness was directly related to higher weekly gaming. Furthermore, low conscientiousness was directly associated with disordered gaming.

Insert Figure 1 here

Insert Table 1 here

\section{Discussion}

The present study explored the direct and indirect effects of the FFM personality dimensions on weekly and disordered gaming via gaming motives. Thus, neuroticism and low agreeableness were the most relevant personality domains for weekly and disordered gaming, both directly and indirectly through motives. Conscientiousness was also relevant for disordered gaming in a direct manner.

Specifically, neuroticism was directly and via coping motive related to disordered gaming. Accordingly, neuroticism has been associated with escapism motive previously (Shceck et al., 2015). Furthermore, some studies found that such escapism motives highly mediate between psychological variables, such as psychiatric symptoms (Ballabio et al., 2017; Király et al., 2015; Montag et al., 2019), Dark Tetrad traits (Kircaburun et al., 2018) and trait emotional intelligence (Kircaburun et al., 2019); and disordered gaming use. Thus, the relationship escapism-problematic gaming may be moderated by players' coping styles, those players with maladjusted coping strategies would show stronger associations between escapism motives and problematic gaming (Bowditch, 2018). Likewise, players with psychosocial problems may also display a higher association 
between escapism and video gaming-related problems (Kardefelt-Winther, 2014). Therefore, disordered players may play video games in order to forget and cope with life problems by regulating their mood, (Kuss et al., 2017). In this sense, this finding should reflect a negative affect regulation pathway in problematic video gaming (Plante, Gentile, Groves, Modlin \& Blanco-Herrera, 2019; Sher, Grekin \& Williams, 2005), replicating results found in drugs such as alcohol (Mezquita et al., 2018).

On the other hand, low agreeableness was related to higher weekly gaming, and to problematic gaming via social interaction motive. This finding could depict a deviance proneness pathway (Sher et al., 2005) in which higher video gaming and disordered gaming may be seen as an element of a broader deviant pattern. Thus, problematic gaming is usually related to externalizing symptomatology (Müller et al., 2015; Wartberg et al., 2017). In this line, McGrath, Neilson, Lee, Rash \& Rad (2018) found that low honestyhumility and low agreeableness were related to gambling severity partially via gambling motives. In addition, similar to our findings, Király et al. (2015) found a significant indirect association between psychiatric symptoms and problematic gaming through social motives. Nevertheless, other mediation studies between psychological problems and disordered gaming showed no associations via social motives (Ballabio et al., 2017; Montag et al., 2019).

Low conscientiousness was directly associated with disordered gaming but no indirect effects via motives were found. Therefore, as in the case of disordered gambling (McGrath et al., 2018), conscientiousness might influence disordered gaming independently from gaming motives. Thus, players with lower conscientiousness would suffer a higher interfering effect of video gaming among life domains due to their difficulty in self-control (Gervasi et al., 2017; Mihara \& Higuchi, 2017; Şalvarlı \& Griffiths, 2019). 
Finally, introversion was directly associated with higher video gaming but not with disordered gaming. Therefore, according to the present results, higher introversion may enhance video game use to compensate the lack of players' social environment in real life without affecting problematic video game use. In this manner, regarding adolescent disordered gaming, the role of introversion presents inconsistent findings in research (Gervasi et al., 2017; Mihara \& Higuchi, 2017; Şalvarlı \& Griffiths, 2019).

\subsection{Limitations}

The present study is not without limitations. First, the participants were a modest and convenience sample of teenagers and future studies may check the replication of the present findings among other population groups and larger samples. Second, all the data were self-reported measures subjected to well-known biases such as social desirability. Third, the cross-sectional nature of the study prevents us from making causal inferences and therefore future studies may use longitudinal designs to overcome this obstacle.

\subsection{Conclusions}

The current study is the first to show associations between basic personality traits and regular and disordered gaming partially due to gaming motives. Thus, some etiological pathways found in drug use and abuse were observed in video gaming behaviors: the negative affect regulation and deviance proneness pathways (Sher et al., 2005). These results highlight the relevant role of personality and gaming motives in prevention and treatment of disordered gaming.

\section{Acknowledgements}

The authors wish to thank the students, parents, and teachers of the High Schools for making this study possible. 


\section{Declaration of interest}

None

\section{References}

Ashton, M. C., \& Lee, K. (2007). Empirical, theoretical, and practical advantages of the HEXACO model of personality structure. Personality and Social Psychology Review, 11, 150-166

Asociación Española de Videojuegos -AEVI- (2018) [The Yearbook of Videogames 2018]. El anuario del videojuego 2018. Retrieved from: http://www.aevi.org.es/web/wpcontent/uploads/2019/05/AEVI_Anuario_2018.pdf.

Ballabio, M., Griffiths, M. D., Urbán, R., Quartiroli, A., Demetrovics, Z., \& Király, O. (2017). Do gaming motives mediate between psychiatric symptoms and problematic gaming? An empirical survey study. Addiction Research \& Theory, 25, 397-408.

Bean, A., \& Groth-Marnat, G. (2016). Video gamers and personality: A five-factor model to understand game playing style. Psychology of Popular Media Culture, 5, 27.

Billieux J, van der Linden M, Achab S, Khazaal Y, Paraskevopoulos L, Zullino D, Thorens, G. (2013) Why do you play World of Warcraft? An in-depth exploration of self-reported motivations to play online and in-game behaviours in the virtual world of Azeroth. Computers in Human Behavior, 29,103-109.

Bowditch, L., Chapman, J., \& Naweed, A. (2018). Do coping strategies moderate the relationship between escapism and negative gaming outcomes in World of Warcraft (MMORPG) players?. Computers in Human Behavior, 86, 69-76.

Chang, S. M., \& Lin, S. S. (2019). Online gaming motive profiles in late adolescence and the related longitudinal development of stress, depression, and problematic internet use. Computers \& Education, 135, 123-137.

Dreier, M., Wölfling, K., \& Müller, K. (2013). Psychological research and a sociological perspective on problematic and addictive computer game use in adolescence. International Journal of Child and Adolescent Health, 6, 422-435.

Efron, B., \& Tibshirani, R. J. (1993). An introduction to the bootstrap Chapman \& Hall. New York, 436. 
Erceg-Hurn, D. M., \& Mirosevich, V. M. (2008). Modern robust statistical methods: an easy way to maximize the accuracy and power of your research. American Psychologist, 63, 591.

Fam, J. Y. (2018). Prevalence of internet gaming disorder in adolescents: A meta-analysis across three decades. Scandinavian journal of psychology, 59, 524-531.

Fritz, M. S., \& MacKinnon, D. P. (2007). Required sample size to detect the mediated effect. Psychological science, 18, 233-239.

Garcia-Oliva, C., \& Piqueras, J. A. (2016). Experiential avoidance and technological addictions in adolescents. Journal of Behavioral Addictions, 5, 293-303.

Gentile, D. (2009). Pathological video-game use among youth ages 8 to 18: a national study. Psychological Science, 20, 594-602.

Gentile, D. A., Choo, H., Liau, A., Sim, T., Li, D., Fung, D., ... Khoo, A. (2011). Pathological video game use among youths: A two-year longitudinal study. Pediatrics, 127, 319-329.

Gervasi, A. M., La Marca, L., Costanzo, A., Pace, U., Guglielmucci, F., \& Schimmenti, A. (2017). Personality and Internet gaming disorder: a systematic review of recent literature. Current Addiction Reports, 4, 293-307.

Graham, L. T. \& Gosling, S. D. (2013). Personality profiles associated with different motivations for playing world of warcraft. Cyberpsychology, Behavior, and Social Networking, 16, 189-193.

Greenberg, B. S., Sherry, J., Lachlan, K., Lucas, K., \& Holmstrom, A. (2010). Orientations to Video Games Among Gender and Age Groups. Simulation \& Gaming, 41, 238-259.

Hagström, D., \& Kaldo, V. (2014). Escapism among players of MMORPGs Cconceptual clarification, its relation to mental health factors, and development of a new measure. Cyberpsychology, Behavior, and Social Networking, 17, 19-25.

James, L. R., Mulaik, S. A., \& Brett, J. M. (2006). A tale of two methods. Organizational research methods, 9, 233-244.

Jeng, S.P. \& Teng, C.I. (2008). Personality and motivations for playing online games. Social Behavior and Personality, 38: 1053-1060.

John, O. P., Naumann, L. P., \& Soto, C. J. (2008). Paradigm shift to the integrative big five trait taxonomy. Handbook of personality: Theory and research, 3, 114-158. 
Kardefelt-Winther, D. (2014). The moderating role of psychosocial well-being on the relationship between escapism and excessive online gaming. Computers in Human Behaviors, 38, 68-74.

Kim, N. R., Hwang, S. S. H., Choi, J. S., Kim, D. J., Demetrovics, Z., Király, O., ... \& Choi, S. W. (2016). Characteristics and psychiatric symptoms of internet gaming disorder among adults using self-reported DSM-5 criteria. Psychiatry Investigation, $13,58-66$.

Király, O., Tóth, D., Urbán, R., Demetrovics, Z., \& Maraz, A. (2017). Intense video gaming is not essentially problematic. Psychology of Addictive Behaviors, 31, 807817.

Király, O., Urbán, R., Griffiths, M. D., Ágoston, C., Nagygyörgy, K., Kökönyei, G., \& Demetrovics, Z. (2015). The mediating effect of gaming motivation between psychiatric symptoms and problematic online gaming: an online survey. Journal of Medical Internet Research, 17, e88.

Kircaburun, K., Demetrovics, Z., Griffiths, M. D., Király, O., Kun, B., \& Tosuntaş, Ş. B. (2019). Trait emotional intelligence and internet gaming disorder among gamers: The mediating role of online gaming motives and moderating role of age groups. International Journal of Mental Health and Addiction, 1-12.

Kircaburun, K., Jonason, P. K., \& Griffiths, M. D. (2018). The Dark Tetrad traits and problematic online gaming: The mediating role of online gaming motives and moderating role of game types. Personality and Individual Differences, 135, 298303.

Kuss, D. J., Dunn, T. J., Wölfling, K., Müller, K. W., Hędzelek, M., \& Marcinkowski, J. (2017). Excessive Internet use and psychopathology: The role of coping. Clinical Neuropsychiatry: Journal of Treatment Evaluation, 14, 73-81.

Kuss, D. J., Louws, J., \& Wiers, R. W. (2012). Online gaming addiction? Motives predict addictive play behavior in massively multiplayer online role-playing games. Cyberpsychology, Behavior and Social Networking, 15, 480-485.

Kwon, J.-H., Chung, C.-S. \& Lee, J. (2011). The effects of escape from self and interpersonal relationship on the pathological use of Internet games. Community Mental Health Journal, 47, 113-121.

Laconi, S., Pirès, S., \& Chabrol, H. (2017). Internet gaming disorder, motives, game genres and psychopathology. Computers in Human Behavior, 75, 652-659. 
Lemmens, J. S., Valkenburg, P. M. \& Peter, J. (2011). Psychosocial causes and consequences of pathological gaming. Computers in Human Behavior, 27, 144-152. López-Fernández, F.J., Mezquita, L., Griffiths, M.D., Ortet, F. \& Ibáñez, M.I. (2020a). The role of personality on disordered gaming and game genre preferences in adolescence: gender differences and person-environment transactions. Adicciones. Advance publication online. doi: https://doi.org/10.20882/adicciones.0.0

López-Fernández, F.J., Mezquita, L., Griffiths, M.D., Ortet, F. \& Ibáñez, M.I. (2020b). The development and validation of the Videogaming Motives Questionnaire (VMQ). Manuscript in preparation.

Männikkö, N., Billieux, J., Nordström, T., Koivisto, K., \& Kääriäinen, M. (2017). Problematic Gaming Behaviour in Finnish Adolescents and Young Adults: Relation to Game Genres, Gaming Motives and Self-Awareness of Problematic Use. International Journal of Mental Health and Addiction, 15, 324-338.

McCrae, R. R., \& Costa Jr, P. T. (2008). Empirical and theoretical status of the five-factor model of personality traits.

McGrath, D. S., Neilson, T., Lee, K., Rash, C. L., \& Rad, M. (2018). Associations between the HEXACO model of personality and gambling involvement, motivations to gamble, and gambling severity in young adult gamblers. Journal of behavioral addictions, 7, 392-400.

Mezquita, L., Bravo, A. J., Ortet, G., Pilatti, A., Pearson, M. R., \& Ibáñez, M. I. (2018). Cross-cultural examination of different personality pathways to alcohol use and misuse in emerging adulthood. Drug and alcohol dependence, 192, 193-200.

Montag, C., Schivinski, B., Sariyska, R., Kannen, C., Demetrovics, Z., \& Pontes, H. M. (2019). Psychopathological Symptoms and Gaming Motives in Disordered Gaming-A Psychometric Comparison between the WHO and APA Diagnostic Frameworks. Journal of clinical medicine, 8, 1691.

Mihara, S., \& Higuchi, S. (2017). Cross-sectional and longitudinal epidemiological studies of I nternet gaming disorder: A systematic review of the literature. Psychiatry and clinical neurosciences, 71, 425-444.

Müller, K. W., Janikian, M., Dreier, M., Wölfling, K., Beutel, M. E., Tzavara, C., Richardson, C., \& Tsitsika, A. (2015). Regular gaming behavior and internet gaming disorder in European adolescents: results from a cross-national representative survey of prevalence, predictors, and psychopathological correlates. European Child \& Adolescent Psychiatry, 24, 565-574. 
Muthén, B., \& Muthén, L. (2018). Mplus user's guide and diagrammer documentation.

Ortet, G., Escriva, P., Ibanez, M. I., Moya, J., Villa, H., Mezquita, L. y Ruiperez, M. A. (2010). Version corta de la adaptacion espanola para adolescentes del NEO-PI-R (JS NEO-S). International Journal of Clinical and Health Psychology, 10, 327-344.

Park, J., Song, Y. \& Teng, C.I. (2011). Exploring the links between personality traits and motivations to play online games. Cyberpsychology, Behavior, and Social Networks, $14,747-751$.

Paulus, F. W., Ohmann, S., von Gontard, A., \& Popow, C. (2018). Internet gaming disorder in children and adolescents: a systematic review. Developmental Medicine and Child Neurology, 60, 645-659.

Plante, C. N., Gentile, D. A., Groves, C. L., Modlin, A., \& Blanco-Herrera, J. (2019). Video games as coping mechanisms in the etiology of video game addiction. Psychology of Popular Media Culture, 8, 385-394

Ryan, R. M., Rigby, C. S., \& Przybylski, A. (2006). The motivational pull of video games: A self-determination theory approach. Motivation and Emotion, 30, 344-360.

Şalvarlı, Ş. İ., \& Griffiths, M. D. (2019). Internet Gaming Disorder and Its Associated Personality Traits: A Systematic Review Using PRISMA Guidelines. International Journal of Mental Health and Addiction, 1-23.

Shceck, K., Lee, D. Y., \& Pyo, K. B. (2015). The relationship between the Five Factor Personality Model and motivations for play in MMORPGs. Indian Journal of Science and Technology, 8, 1.

Sher, K. J., Grekin, E. R., \& Williams, N. A. (2005). The development of alcohol use disorders. Annual Review of Clinical Psychology, 1, 493-523.

Sherry, J. L., Lucas, K., Greenberg, B. S., \& Lachlan, K. (2006). Video game uses and gratifications as predictors of use and game preference. Playing video games: Motives, responses, and consequences, 24, 213-224.

Tondello, G. F., Wehbe, R. R., Diamond, L., Busch, M., Marczewski, A., \& Nacke, L. E. (2016, October). The gamification user types hexad scale. In Proceedings of the 2016 annual symposium on computer-human interaction in play (pp. 229-243). ACM.

Vollmer, C., Randler, C., Horzum, M. B., \& Ayas, T. (2014). Computer game addiction in adolescents and its relationship to chronotype and personality. SAGE Open, 4. 
Wartberg, L., Kriston, L., Kramer, M., Schwedler, A., Lincoln, T. M., \& Kammerl, R. (2017). Internet gaming disorder in early adolescence: Associations with parental and adolescent mental health. European Psychiatry, 43, 14-18.

Worth, N. C., \& Book, A. S. (2014). Personality and behavior in a massively multiplayer online role-playing game. Computers in Human Behavior, 38, 322-330.

Worth, N. C., \& Book, A. S. (2015). Dimensions of video game behavior and their relationships with personality. Computers in Human Behavior, 50, 132-140.

Wu, A. M., Lai, M. H., Yu, S., Lau, J. T., \& Lei, M. W. (2016). Motives for online gaming questionnaire: Its psychometric properties and correlation with Internet gaming disorder symptoms among Chinese people. Journal of behavioral addictions, 6, 1120.

Yee, N. (2006). Motivations for play in online games. CyberPsychology and Behavior, 9, 772-775.

Zanetta DF, Zermatten A, Billieux J, Thorens G, Bondolfi G, Zullino D, Khazaal Y. (2011). Motivations to play specifically predict excessive involvement in massively multiplayer online role-playing games: evidence from an online survey. Eur Addict Res., 17, 185-9.

Zeigler-Hill, V., \& Monica, S. (2015). The HEXACO model of personality and video game preferences. Entertainment Computing, 11, 21-26. 


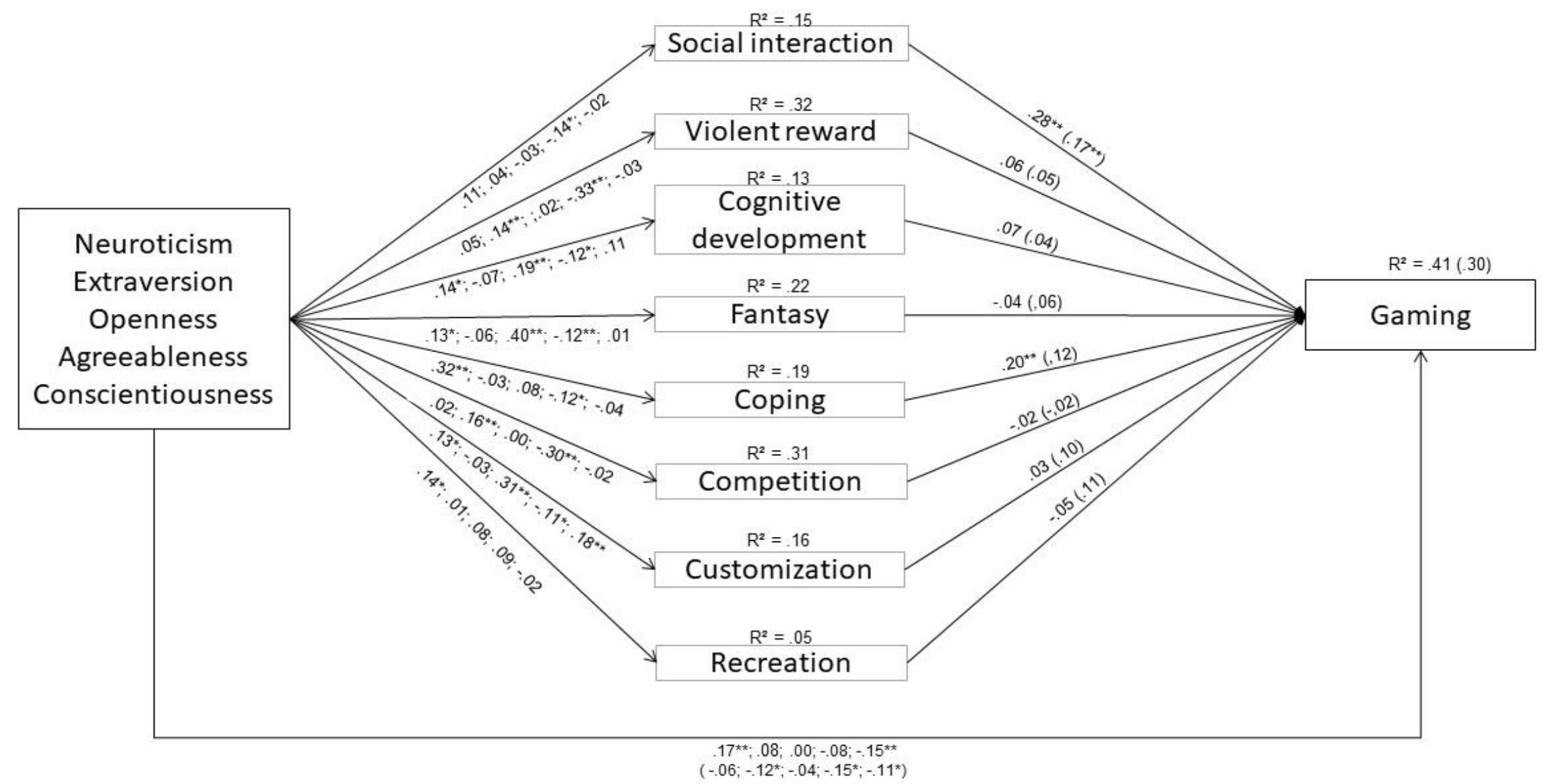

Fig. 1. Final five model (for each personality dimension) of the path coefficients between variables for disordered gaming (values outside of the parentheses) and weekly gaming (values inside of the parentheses) as dependent variables. All variables in the model are observed variables. The first values (left) describe the model's path coefficient in which neuroticism is the independent variable, whereas second, third, fourth and fifth values represent path coefficients of models in which extraversion, openness to experience, agreeableness and conscientiousness are independent variables respectively. Gender and age were included as control variables. For clarity, covariances between errors of mediator variables as well as paths from control variables have not been depicted in the figure. ${ }^{*} \mathrm{p}<.05, * * \mathrm{p}<.01$. 


\section{Table 1}

Indirect and total effect (standardized betas) of the FFM dimensions on disordered and weekly gaming.

\begin{tabular}{|c|c|c|c|c|c|}
\hline & Disordered gaming & Weekly gaming & & Disordered gaming & Weekly gaming \\
\hline $\mathrm{N} \rightarrow$ Total & $.268 * * *$ & .025 & $\mathrm{O} \rightarrow \mathrm{FAN}$ & -.018 & .020 \\
\hline $\mathrm{N} \rightarrow$ Total indirect & $.098 * *$ & $.089 * *$ & $\mathrm{O} \rightarrow \mathrm{COP}$ & .015 & .009 \\
\hline $\mathrm{N} \rightarrow \mathrm{SOC}$ & .032 & .019 & $\mathrm{O} \rightarrow \mathrm{COM}$ & .000 & .000 \\
\hline $\mathrm{N} \rightarrow \mathrm{VIO}$ & .003 & .002 & $\mathrm{O} \rightarrow \mathrm{CUS}$ & .008 & .032 \\
\hline $\mathrm{N} \rightarrow \mathrm{COG}$ & .011 & -.006 & $\mathrm{O} \rightarrow \mathrm{REC}$ & -.004 & .009 \\
\hline $\mathrm{N} \rightarrow \mathrm{FAN}$ & -.006 & .006 & A $\rightarrow$ Total & $-.172 * *$ & $-.204 * * *$ \\
\hline $\mathrm{N} \rightarrow \mathrm{COP}$ & $.063 * *$ & .039 & $\mathrm{~A} \rightarrow$ Total indirect & $-.085^{*}$ & -.050 \\
\hline $\mathrm{N} \rightarrow \mathrm{COM}$ & .000 & .000 & $\mathrm{~A} \rightarrow \mathrm{SOC}$ & $-.038 *$ & -.023 \\
\hline $\mathrm{N} \rightarrow \mathrm{CUS}$ & .004 & .013 & $\mathrm{~A} \rightarrow \mathrm{VIO}$ & -.020 & -.016 \\
\hline $\mathrm{N} \rightarrow \mathrm{REC}$ & -.007 & .016 & $\mathrm{~A} \rightarrow \mathrm{COG}$ & -.009 & .005 \\
\hline $\mathrm{E} \rightarrow$ Total & .084 & $-.115^{*}$ & $\mathrm{~A} \rightarrow \mathrm{FAN}$ & .005 & -.006 \\
\hline $\mathrm{E} \rightarrow$ Total indirect & .007 & .006 & $\mathrm{~A} \rightarrow \mathrm{COP}$ & -.023 & -.014 \\
\hline
\end{tabular}




\begin{tabular}{|c|c|c|c|c|c|}
\hline $\mathrm{E} \rightarrow \mathrm{SOC}$ & .012 & .007 & $\mathrm{~A} \rightarrow \mathrm{COM}$ & .007 & .006 \\
\hline $\mathrm{E} \rightarrow \mathrm{VIO}$ & .008 & .007 & $\mathrm{~A} \rightarrow \mathrm{CUS}$ & -.003 & -.012 \\
\hline $\mathrm{E} \rightarrow \mathrm{COG}$ & -.005 & .003 & $\mathrm{~A} \rightarrow \mathrm{REC}$ & -.004 & .010 \\
\hline $\mathrm{E} \rightarrow \mathrm{FAN}$ & .003 & -.003 & $\mathrm{C} \rightarrow$ Total & $-.150 *$ & -.104 \\
\hline $\mathrm{E} \rightarrow \mathrm{COP}$ & -.007 & -.004 & $\mathrm{C} \rightarrow$ Total indirect & .001 & .003 \\
\hline $\mathrm{E} \rightarrow \mathrm{COM}$ & -.004 & -.003 & $\mathrm{C} \rightarrow \mathrm{SOC}$ & -.006 & -.003 \\
\hline $\mathrm{E} \rightarrow \mathrm{CUS}$ & -.001 & -.003 & $\mathrm{C} \rightarrow \mathrm{VIO}$ & -.002 & -.002 \\
\hline $\mathrm{E} \rightarrow \mathrm{REC}$ & -.001 & .001 & $\mathrm{C} \rightarrow \mathrm{COG}$ & .009 & -.004 \\
\hline $\mathrm{O} \rightarrow$ Total & .008 & .018 & $\mathrm{C} \rightarrow \mathrm{FAN}$ & .000 & .000 \\
\hline $\mathrm{O} \rightarrow$ Total indirect & .009 & .059 & $\mathrm{C} \rightarrow \mathrm{COP}$ & -.008 & -.005 \\
\hline $\mathrm{O} \rightarrow \mathrm{SOC}$ & -.008 & -.005 & $\mathrm{C} \rightarrow \mathrm{COM}$ & .000 & .000 \\
\hline $\mathrm{O} \rightarrow \mathrm{VIO}$ & .001 & .001 & $\mathrm{C} \rightarrow \mathrm{CUS}$ & .005 & .018 \\
\hline $\mathrm{O} \rightarrow \mathrm{COG}$ & .014 & -.007 & $\mathrm{C} \rightarrow \mathrm{REC}$ & .001 & -.002 \\
\hline
\end{tabular}

Significant associations, in bold, were determined by 99\% bias-corrected unstandardized bootstrapped confidence intervals (based on 10,000 bootstrapped samples) that did not contain zero. $\mathrm{N}=$ Neuroticism; $\mathrm{E}=$ Extraversion; $\mathrm{O}=$ Openness to experience; $\mathrm{A}=\mathrm{Agreeableness}$; $\mathrm{C}=$ Conscientiousness; $\mathrm{SOC}=$ Social interaction; $\mathrm{VIO}=$ Violent reward $\mathrm{COG}=$ Cognitive development FAN $=\mathrm{Fantasy} ; \mathrm{COP}=\mathrm{Coping} ; \mathrm{COM}=$ Competition; CUS $=$ Customization; REC $=$ Recreation. $* \mathrm{p}<.05, * * \mathrm{p}<.01, * * * \mathrm{p}<.001$. 


\section{Supplementary material}

Descriptive statistic, Cronbach's alphas and correlation coefficients of the study variables

\begin{tabular}{|c|c|c|c|c|c|c|c|c|c|c|c|c|}
\hline & 1 & 2 & 3 & 4 & 5 & 6 & 7 & 8 & 9 & 10 & 11 & 12 \\
\hline 1. Disordered gaming & - & & & & & & & & & & & \\
\hline 2. Weekly gaming & $.41 * *$ & - & & & & & & & & & & \\
\hline 3. Recreation & $.18 * *$ & $.27 * *$ & - & & & & & & & & & \\
\hline 4. Competition & $.39 * *$ & $.34 * *$ & $.42 * *$ & - & & & & & & & & \\
\hline 5. Cognitive challenge & $.37 * *$ & $.28 * *$ & $.38^{* *}$ & $.53^{* *}$ & - & & & & & & & \\
\hline 6. Coping & $.48 * *$ & $.38 * *$ & $.46^{* *}$ & $.50^{* *}$ & $.54^{* *}$ & - & & & & & & \\
\hline 7. Social interaction & $.51 * *$ & $.39 * *$ & $.29 * *$ & $.59 * *$ & $.60^{* *}$ & $.53 * *$ & - & & & & & \\
\hline 8. Violent reward & $.36 * *$ & $.33 * *$ & $.28^{* *}$ & $.52 * *$ & $.31 * *$ & $.39 * *$ & $.41 * *$ & - & & & & \\
\hline 9. Customization & $.17 * *$ & $.21 * *$ & $.28^{* *}$ & $.20 * *$ & $.40^{* *}$ & $.33 * *$ & $.30 * *$ & $.14 * *$ & - & & & \\
\hline 10. Fantasy & $.30 * *$ & $.32 * *$ & $.46^{* *}$ & $.37 * *$ & $.59 * *$ & $.56^{* *}$ & $.45 * *$ & $.35 * *$ & $.56 * *$ & - & & \\
\hline 11. Neuroticism & $.28 * *$ & .07 & .08 & .00 & $.14^{* *}$ & $.32 * *$ & .08 & .05 & $.17 * *$ & $.18 * *$ & - & \\
\hline 12. Extraversion & .00 & $-.15 * *$ & -.01 & $.12 *$ & -.09 & $-.10^{*}$ & .00 & .09 & -.02 & -.09 & $-.15 * *$ & - \\
\hline
\end{tabular}




\begin{tabular}{|c|c|c|c|c|c|c|c|c|c|c|c|c|c|c|c|}
\hline 13. Openness & -.07 & -.09 & .05 & $-.16^{* *}$ & $.14 * *$ & .04 & $-.12 *$ & $-.13^{*}$ & $.33 * *$ & $.33 * *$ & $.18 * *$ & -.01 & - & & \\
\hline 14. Agreeableness & $-.33 * *$ & $-.28 * *$ & .01 & $-.38 * *$ & $-.18^{* *}$ & $-.26 * *$ & $-.24 * *$ & $-.41 * *$ & -.09 & $-.16^{* *}$ & $-.31 * *$ & .08 & $.11^{*}$ & - & \\
\hline 15. Conscientiousness & $-.26 * *$ & $-.20 * *$ & -.04 & $-.11^{*}$ & .03 & $-.16^{* *}$ & $-.12 *$ & $-.14 * *$ & $.16^{* *}$ & -.03 & $-.21 * *$ & $.20 * *$ & $.16^{* *}$ & $.22 * *$ & - \\
\hline M & 4.91 & 5.88 & 10.19 & 7.39 & 5.45 & 6.67 & 4.93 & 5.42 & 6.30 & 5.98 & 20.49 & 31.65 & 25.05 & 36.07 & 29.04 \\
\hline $\mathrm{SD}$ & 5.20 & 4.38 & 2.12 & 3.05 & 3.27 & 3.56 & 3.42 & 3.79 & 3.76 & 3.46 & 8.78 & 7.48 & 7.94 & 7.53 & 7.78 \\
\hline$\alpha$ & .86 & - & .84 & .77 & .81 & .86 & .79 & .92 & .87 & .82 & .84 & .84 & .76 & .82 & .86 \\
\hline
\end{tabular}




\section{$2.5 \quad$ Study 4}

Title: The role of violent video game exposure, personality and deviant peers in aggressive behaviors among adolescents: a two-wave longitudinal study. 


\begin{abstract}
Many studies have shown a slight, but significant, short-term effect of violent video game exposure (VVE) on aggressive behaviors in adults, but the existence of longlasting effects on aggressiveness, or their impact on adolescents, are still not well established. In addition, the link between VVE and aggression has scarcely been examined by controlling for other important risk variables for aggressive behaviors, such as personality and deviant peers, nor has the moderation role of these risk factors in the link between VVE and aggression been investigated. Therefore, the main aim was to examine the additive and interactive role of VVE, personality and deviant peers in adolescent aggressive behaviors cross-sectionally and longitudinally. Many regression analyses and a cross-lagged autoregressive model were carried out. At both waves, aggressive behavior was closely related to deviant peers and personality domains, especially low agreeableness. VVE was also associated with aggressive behaviors at both waves with a slight effect, which became non significant when controlling for other variables. No long-term effects on the relation between VVE and aggressive behaviors were found. Moderation effects were consistently found at both waves. Therefore when participants reported having more deviant peers, the effects of VVE and low agreeableness on aggressive behaviors significantly increased. These findings suggest that multiple biopsychosocial variables and their complex interplay need to be examined to gain a better understanding of the origin and expression of aggressive behavior.
\end{abstract}

Keywords: Violent video game exposure, aggressive behaviors, five-factor model of personality, deviant peers, adolescents 


\section{Introduction}

Whenever a serious act of violence occurs, the media, lawmakers and other important society sectors tend to focus on the detrimental effects of playing violent video games. ${ }^{1}$ For instance, after the Parkland school shooting episode on 14 February 2018, US President Donald Trump organized a meeting with Congress members, video game executives and other stakeholders to "discuss violent video game exposure and the correlation to aggression and desensitization in children" (according to the White House press release). ${ }^{2}$ During this period, a judge forbade a high school student to play violent video games after he made a school-shooting threat on social media. ${ }^{3}$ In an attempt to tackle this issue, some US politicians have proposed an extra sales tax to be imposed on violent video games. ${ }^{4}$

\section{Theoretical background}

One of the most followed psychological models in the field of violent media is the General Aggression Model (GAM). 5,6 This model focuses on social-cognitive learning processes for explaining aggression, and points out the importance of violent media (e.g., violent videogame exposure; VVE) for provoking short-term increases in aggression. It also posits that repeated exposure to media violence may lead to changes in a person's basic personality structure (e.g. aggressive beliefs and attitudes, perception and expectation schemata, aggressive behavior scripts and aggression desensitization) and may, thus, induce long-term increases in aggressiveness.

Other theoretical proposals have relativized the role of VVE in aggression. For example, the catalyst model has focused the main causes of violent behaviors on more "innate" variables according to the importance of the genetics found in the etiology of aggression. ${ }^{7}$ This model posits that genetic predispositions lead to aggressive personality characteristics that would most likely be catalyzed into aggressive behaviors 
when facilitating environments occurred, such as family violence. In this model environmental factors, such as media or peer violence exposure, do not directly cause aggressiveness, but act as stylistic catalysts: when a high aggressive individual acts violently, this person would model violence according to the aggressive behaviors that (s)he has seen in the media. ${ }^{1}$

Whereas the GAM model focuses mainly on social learning processes and the catalyst model centers on biodispositional personality characteristics, other proposals have highlighted the interplay between both personality and social factors. A specific model for VVE is the Differential Susceptibility to Media Effects Model (DSMEM). ${ }^{8}$ Its main proposal is that the variables which predispose media use may also moderate the effect of that media use. Thus VVE would have a differential impact by producing or increasing aggressive behavior depending on other risk variables, such as dispositional factors, e.g., personality or attitudes, or social contexts, e.g. family environment or peer group, among others.

\section{Empirical evidence}

The bulk of experimental and correlational research has been conducted to elucidate the role of VVE in aggression. Experimental studies show the potential short-term effects of brief exposures to violent video games on experimental aggressive behaviors (e.g. noise blasts or small electric shocks), whereas correlational studies identify associations between VVE and different forms of aggression in the "real world" (e.g. aggressive behavior, delinquency, bullying or physical fights). For both experimental and correlational studies, some systematic meta-analyses confirm that VVE tends to increase aggressive behavior, cognition and affect, although the magnitude of this association tends to be small $(\mathrm{r} \simeq .10-.20) .{ }^{5,9-13}$ Effect size is even smaller when examining its long-term impact in longitudinal studies $(\mathrm{r}=.11) .{ }^{14}$ 
Meta-analyses have reached conflicting conclusions about the impact of VVE on aggression in children and adolescents. Some have suggested that older subjects would be affected by video games more than younger subjects, ${ }^{13}$ but others have concluded that the effect of VVE would be similar for both lifespan stages. ${ }^{5,9,10}$ A meta-analyses specifically focused on children and adolescents found a significant, but very slight, effect of VVE on aggressive behavior $(r=0.06) .{ }^{15}$

To summarize, data indicate a minor, but significant, detrimental effect of VVE on aggressive behavior. Some scholars have interpreted these minor effects as negligible. According to other authors ${ }^{8,16}$ overall minor effects may hide null effects for some people, together with stronger effects for others, if individual differences in susceptibility to VVE exists, for example personality.

Nowadays, the most accepted personality framework of personality is the Five-Factor Model (FFM) ${ }^{17}$ which proposes five basic dimensions: extraversion, neuroticism, agreeableness, conscientiousness, and openness to experience. ${ }^{18}$ These personality domains are in part genetically rooted ${ }^{19}$ and influence a wide range of everyday outcomes, ${ }^{20}$ including aggressiveness and antisocial behavior. ${ }^{21}$ Personality is also relevant for video game-related behaviors ; e.g., low agreeable players tend to prefer competitive and violent video games. ${ }^{22,23}$ The few studies that have assessed FFM domains when exploring the link between VVE and aggression have found that this association tends to decrease, ${ }^{24}$ or even vanish, ${ }^{25}$ when controlling for personality. VVE may also present a strong adverse effect on some individuals with pre-existing personality dispositions, which would make them susceptible to violent media., ${ }^{8,26}$ Accordingly, experimental studies have described moderating effects between the effect of VVE on aggression and traits of aggressiveness, ${ }^{27-30}$ anger ${ }^{31,32}$ psychoticism, ${ }^{30}$ and a combination of high neuroticism, low agreeableness and low conscientiousness, ${ }^{26}$ 
although these effects have not always been replicated. ${ }^{28,32-35}$ As far as we know, the moderation role of FFM personality domains in the link between VVE and aggressive behavior has not yet been examined in teenagers.

Another variable that is closely associated with aggressiveness and other antisocial behaviors is deviant peers. Having peers that present deviant behaviors, like fighting, substance abuse or vandalism, leads to more aggressiveness, antinormative and externalizing behaviors. ${ }^{36,37}$ According to the Social Interaction Model,${ }^{38}$ having deviant peers may lead to aggressive behavior by it facilitating the expression of preexisting aggressive dispositions. Despite this model and the DSMEM specifically predicting interaction effects between risk factors for aggressive behaviors, we are unaware of any study that has examined the possible moderation effect of personality and peers on the link between VVE and aggressive behaviors.

The present study

Whereas data consistently point out a minor detrimental effect of VVE on aggressive behaviors in adults, the existence of long-lasting effects on aggressiveness, and the impact it has on adolescents, are still not well established. Research into VVE and aggression often ignores other well-established factors for aggressive behavior, such as personality and deviant peer influences. Therefore, the main aim of the present study was to examine the additive role of VVE, personality and deviant peers in adolescent aggressive behaviors cross-sectionally and longitudinally, as well as the moderating effects of personality and peers in the link between VVE and aggression. We hypothesized that the main predictors of aggressive behavior would be deviant peers, the personality dimensions of low agreeableness and low conscientiousness and, to a lesser extent, VVE. We also expected to find these personality and social variables to be more associated with aggressiveness (low agreeableness, low conscientiousness and 
deviant peers), which would moderate the effect of VVE on aggression. Finally by using a longitudinal design, we expected to show the long-term effects of playing violent video games on aggressive behaviors 1 year later.

\section{Methods}

\section{Participants}

Participants were high school students who took part in a broader project that examined the psychosocial risk and protective factors involved in mental health in adolescence (for more details, see Moya-Higueras et al. ${ }^{39}$ ). The participants' parents or legal tutors gave written informed consent in accordance with the Declaration of Helsinki. Data were collected through two waves 1 year apart. At wave 1, 542 gamers of the 1161 high school students invited to participate reported their most played games and were considered for the study. The participants' mean age was 14.23 years $(\mathrm{SD}=1.59)$ and $67.7 \%$ of them were males. At wave 2, 427 of the 1233 students invited to participate reported the games they played the most. Their mean age was $14.83(\mathrm{SD}=1.21)$ and $67.8 \%$ were males. Finally, 264 students participated in both waves, of whom $72.3 \%$ were males.

\section{Measures}

Aggressive behavior

The aggressive behaviors scale from the high school self-report version of the SENA ${ }^{40}$ was herein employed. It comprises 7 items (e.g., "I threaten the others to get what I want", "I beat the others when I get angry") that are rated from 0 ("Never or almost never") to 4 (“Always or almost always"). 


\section{Violent Video game Exposure}

Video game use frequencies were assessed with the following points: never or almost never (0); once per month (1); once per week (2); less than 1 hour per day (3); between 1 and 3 hours per day (4); more than 3 hours per day (5). The participants also reported up to five of their most played video games at the time data were collected. Based on the reported games, and as in other studies ${ }^{27}$, an index of violence experienced in gaming $\left(\mathrm{IVEG}_{\mathrm{VEG}}\right)$ was calculated as follows:

$$
\mathrm{IVEG}_{\mathrm{VEG}}=\frac{P E G I 18}{N} \times \mathrm{GF}
$$

$\mathrm{I}_{\mathrm{VEG}}=$ Index of violence experienced in gaming

PEGI $18=$ Number of games with PEGI $18^{1}$

$\mathrm{N}=$ Total reported number of games

$\mathrm{GF}=$ Total gaming frequency

\section{Personality}

Personality was assessed using the JS NEO-A60, ${ }^{41}$ a 60 -item version of the Junior Spanish version of the NEO PI-R. ${ }^{42}$ It allows the FFM personality domains of neuroticism, extraversion, openness to experience, agreeableness and conscientiousness to be assessed in youths aged between 12 and 17 years. Items are responded on 5-point Likert scales ranging from 0 ("Strongly disagree") to 4 ("Strongly agree”).

\section{Deviant Peers}

The Deviant Peer Scale-UJI (DPS-UJI) comprises nine items that ask adolescents about the number of friends they have who have performed deviant and antisocial behaviors in

\footnotetext{
${ }^{1}$ The Pan-European Game Information (PEGI) is the standard age rating system for video games in 38 European countries and Israel, and is supported by major console manufacturers. The adult classification, PEGI 18, is applied when the level of violence reaches a stage at which it depicts gross violence, apparently motiveless killing or violence toward defenseless characters.
} 
the last 6 months (e.g. vandalism, fights, stealing or substance use). ${ }^{43}$ The Likert response scale ranges from 0 (none) to 4 (all).

\section{Statistical analyses}

The descriptive statistics, scale reliabilities, correlations and regression analyses were conducted using version 21 of the SPSS statistical package. Simple slope analyses for depicting interactions were applied. ${ }^{44}$ The Structural Equation Modeling Software, EQS,${ }^{45}$ was used to conduct the cross-lagged autoregressive model. Any missing values that represented less than $5 \%$ in a questionnaire were replaced with the mean score for the items remaining in that scale.

\section{Results}

The descriptive statistics, correlations and scale reliabilities of all the study variables are presented as Supplementary Material. In order to examine the associations of VVE, personality traits and their moderations in aggression, hierarchical regression analyses were conducted for each wave (see Table 1). At both waves, aggressive behaviors were consistently associated with gender (being a boy), a higher IVEG, low agreeableness, low conscientiousness and higher extraversion and deviant peers. Regarding the interactions between the $\mathrm{I}_{\mathrm{VEG}}$ and personality, the combination of the $\mathrm{I}_{\mathrm{VEG}}$ and low conscientiousness was significantly related to aggressive behaviors at wave 1, whereas the IVEG and low agreeableness interacted at wave 2. In addition, and consistently at both waves, aggressive behavior was predicted by an interaction between the IVEG and deviant peers, and between low agreeableness and deviant peers. Figure 1 depicts the consistent moderations effects found at both waves. 
Insert Table 1 here

Insert Figure 1 here

Finally, a cross-lagged autoregressive model was employed to examine the direction between the associations of the IVEG and aggressive behaviors 1 year apart, controlled for each variable at time 1 (see Fig. 2). The model provided a good data fit by robust methods: $\mathrm{S}-\mathrm{B} \chi^{2}(d f=1)=1.09, \mathrm{p}=.30, \mathrm{CFI}=.99, \mathrm{IFI}=.99, \mathrm{NNFI}=.99$, RMSEA $=$ .02 . It was shown that neither violent video game play predicted aggressive behaviors, nor aggressive behaviors increased the use of violent games over time. Stability coefficients and longitudinal links between the rest of variables are reported at Supplementary Material.

Insert Figure 2 here

\section{Discussion}

Aggression is a complex behavior caused and influenced by multiple biopsychosocial variables $^{7}$. Accordingly, the present research transversally and longitudinally explored the interrelations between playing violent video games, a widely studied and debated variable in the field of aggressive behavior, with two of the most well-established factors involved in aggressive behavior: a biodispositional variable such as personality, and a social variable such as deviant peers

The most important variables for explaining individual differences in the aggressive behaviors in the present study were deviant peers and personality, specifically low 
agreeableness and, to a lesser extent, low conscientiousness and high extraversion. The magnitude of such personality associations herein found was virtually the same as those effect sizes indicated in other studies and meta-analyses. ${ }^{21,37}$ VVE was consistently associated at both waves with aggressive behaviors, but effect sizes were small in accordance with the meta-analyses performed in children and adolescents. ${ }^{15}$ When controlling for FFM personality domains and deviant peers variables, the minor effect of VVE slightly attenuated and became non significant, which also falls in line with the scarce research on the topic. ${ }^{24,25}$ Regarding the long-lasting effects of VVE, no longitudinal predictions on aggressive behavior were found 1 year later. Longitudinal studies tend to show very minor long-term effects of VVE on aggressive behaviors ${ }^{14}$ and some longitudinal interventions have found no significant effects on aggression. ${ }^{46-48}$ The fact that VVE does not play a major role in aggression does not necessarily mean that its effect is negligible, as some authors have maintained. ${ }^{15}$ Other scholars have argued that overall minor effects may hide null effects for some people with greater effects for others if individual differences in susceptibility to VVE exist, for instance, according to personality or other social risk factors. ${ }^{8,26}$ Accordingly, it was tested if VVE may affect more negatively to those adolescent with certain personality characteristics, or to those that presented environments that facilitate the expression of aggression, such as having deviant peers.

Moderation effects on aggression were revealed between using violent games and low conscientiousness and low agreeableness, these being the personality variables that are more closely associated with aggression. ${ }^{21}$ However, the moderation effect of low conscientiousness was found only at wave 1 , whereas the moderation effect of low agreeableness were seen only at wave 2. As far as we know, only one study has examined the moderating effects of FFM traits with violent game play. ${ }^{26}$ It found that 
the combination of low agreeableness, low conscientiousness and high neuroticism enhanced the effects of VVE on aggressive outcomes in adults.

A consistent moderation effect across two waves appeared: those adolescents who presented greater VVE showed more aggressive behavior if they reported having deviant friends. Deviant peers seem to not only facilitate the expression of aggressive models learned in video games, but can also facilitate pre-existing aggressive tendencies. Thus low agreeableness presented robust interaction effects with deviant peers at both waves. As far as we are aware, these moderation effects on aggressive behavior have not been previously examined, but other studies have described similar effects of deviant peers on the association between personality and other externalizing behaviors like delinquency. ${ }^{49,50}$

Overall, our data better fitted those approaches to aggression that place more emphasis on the complex interaction effects between biodispositional variables such as personality, together with social variables, such as peers, like the catalyst model, ${ }^{1}$ the biopsychosocial approach proposed by Tremblay et al., ${ }^{7}$ or the DSMEM. ${ }^{8}$ Although VVE did not play a prominent role in our data, it seemed relevant for some adolescents who present high risk factors, such as vulnerable personality or deviant peers, in accordance to the the main hypothesis of the DSMEM. ${ }^{8}$ Therefore, we believe that the DSMEM may constitute an important integrative framework because it promotes richer research that would integrate social-cognitive processes with dispositional, social and developmental factors, and would conciliate contrary views by assuming, according to the GAM, that social-learning processes could be important for some individuals, but also predicting that the overall effect of VVE would be small, according to the catalyst model. 
The present study is not without its limitations. First, although the estimation of VVE is similar to other studies, ${ }^{27}$ a specific frequency measure for each game might be a more accurate approach than an estimation based on general gaming frequencies. Second, although the present data do not support a very relevant role for VVE, this does not necessarily mean that social learning processes for explaining aggression are unimportant, since exposure to other kinds of violence, such as other media or family violence, has not been assessed. Last, moderation effects should be interpreted with caution because effect sizes are small, and corrections for multiple testing may lead to non significant effects. However, the fact that most of the moderations found were replicated in the two waves give us confidence abut the robustness of our results.

To conclude, we show that biodispositional variables, such as personality, and social variables, such as deviant peers and VVE, present additive and interactive effects on the expression of aggressive behavior in adolescence. These results suggest that a comprehensive understanding of aggressive behavior requires taking into account multiple biopsychosocial variables that present complex interrelationships between them. 
1. Ferguson CJ, Rueda SM, Cruz AM, Ferguson DE, Fritz S, Smith SM. Violent video games and aggression: Causal relationship or byproduct of family violence and intrinsic violence motivation?. Criminal Justice and Behavior 2008; 35:311-332.

2. Ducharme J. Trump blames video games for school shootings. Here's what science says. Time 2018 Retrieved October 15, 2018, from http://time.com/5191182/trump-video-games-violence/

3. Campbell C. Judge forbids student from violent games after social media shooting threat. Polygon 2018 Retrieved October 15, 2018, from: https://www.polygon.com/news

4. Makuch E. Violent video games should be taxed extra, lawmaker says, Gamespot 2018. Retrieved October 16, 2018, from https://www.gamespot.com/articles/violent-video-games-should-be-taxed-extralawmaker/1100-6456961/

5. Anderson CA, Bushman BJ. Human aggression. Annual Review of Psychology 2002; 53:27-51.

6. Anderson CA, Bushman BJ. Media violence and the general aggression model. Journal of Social Issues 2018; 74:386-413.

7. Tremblay RE, Vitaro F, Côté SM. Developmental origins of chronic physical aggression: a bio-psycho-social model for the next generation of preventive interventions. Annual review of psychology 2018; 69:383-407.

8. Valkenburg PM, Peter J. The differential susceptibility to media effects model. Journal of Communication 2013; 63:221-243.

9. Anderson CA, Shibuya A, Ihori N, et al.. Violent video game effects on aggression, empathy, and prosocial behavior in Eastern and Western countries: A meta-analytic review. Psychological bulletin 2010; 136:151.

10. Calvert SL, Appelbaum M, Dodge KA, et al.. The American Psychological Association Task Force assessment of violent video games: Science in the service of public interest. American Psychologist 2017; 72:126.

11. Ferguson CJ, Kilburn J. The public health risks of media violence: A metaanalytic review. The Journal of Pediatrics 2009; 154:759-763. 
12. Greitemeyer T., Mügge DO. Video games do affect social outcomes: A metaanalytic review of the effects of violent and prosocial video game play. Personality and social psychology bulletin 2014; 40:578-589.

13. Sherry JL. The effects of violent video games on aggression: A meta-analysis. Human communication research 2001; 27:409-431.

14. Prescott AT, Sargent JD, Hull JG. Metaanalysis of the relationship between violent video game play and physical aggression over time. Proceedings of the National Academy of Sciences 2018; 115:9882-9888.

15. Ferguson CJ. Do angry birds make for angry children? A meta-analysis of video game influences on children's and adolescents' aggression, mental health, prosocial behavior, and academic performance. Perspectives on psychological science 2015 ; 10:646-666.

16. Markey PM. Finding the middle ground in violent video game research: Lessons from Ferguson (2015). Perspectives on psychological science 2015; 10:667-670.

17. John OP, Naumann LP, Soto CJ. Paradigm shift to the integrative big five trait taxonomy. Handbook of personality: Theory and research 2008; 3:114-158.

18. McCrae RR, Costa PT (2008). Empirical and theoretical status of the five-factor model of personality traits. In: Boyle GJ, Matthews G, Sakloske DH, eds. Personality theory and assessment. Personality theories and models. London: Sage, pp. 273-294.

19. Vukasović T, Bratko D. Heritability of personality: a meta-analysis of behavior genetic studies. Psychological bulletin 2015; 141:769.

20. Soto CJ. How replicable are links between personality traits and consequential life outcomes? The Life Outcomes of Personality Replication Project. Psychological Science 2019; 30:711-727.

21. Jones SE, Miller JD, Lynam DR. Personality, antisocial behavior, and aggression: A meta-analytic review. Journal of Criminal Justice 2011; 39:329337.

22. Chory RM, Goodboy AK. Is basic personality related to violent and non-violent video game play and preferences? Cyberpsychology, Behavior, and Social Networking 2011; 14:191-198. 
23. López-Fernández FJ, Mezquita L, Griffiths MD, Ortet G, Ibáñez MI. The role of personality on disordered gaming and game genre preferences in adolescence: gender differences and person-environment transactions. Adicciones (in press).

24. Anderson CA, Carnagey NL, Flanagan M, Benjamin AJ, Eubanks J, Valentine JC. Violent video games: Specific effects of violent content on aggressive thoughts and behavior. Advances in experimental social psychology 2004; 36:200-251.

25. Ferguson CJ, Colwell J, Mlačić B, Milas G, Mikloušić I. Personality and media influences on violence and depression in a cross-national sample of young adults: Data from Mexican-Americans, English and Croatians. Computers in Human Behavior 2011; 27:1195-1200.

26. Markey PM, Markey CN. Vulnerability to violent video games: a review and integration of personality research. Review of General Psychology 2010; 14:8291.

27. Anderson CA, Dill KE. Video games and aggressive thoughts, feelings, and behavior in the laboratory and in life. Journal of Personality and Social Psychology 2000; 78:772-790.

28. Anderson CA, Carnagey NL, Flanagan M, Benjamin AJ, Eubanks J, Valentine JC. Violent video games: Specific effects of violent content on aggressive thoughts and behavior. Advances in experimental social psychology 2004; 36:200-251.

29. Arriaga P, Esteves F, Carneiro P, Monteiro MB. Violent computer games and their effects on state hostility and physiological arousal. Aggressive Behavior: Official Journal of the International Society for Research on Aggression 2006; 32:146-158.

30. Markey PM, Scherer K. An examination of psychoticism and motion capture controls as moderators of the effects of violent video games. Computers in Human Behavior 2009; 25:407-411.

31. Giumetti GW, Markey PM. Violent video games and anger as predictors of aggression. Journal of Research in Personality 2007; 41:1234-1243.

32. Engelhardt CR, Bartholow BD, Saults JS. Violent and nonviolent video games differentially affect physical aggression for individuals high vs. low in dispositional anger. Aggressive Behavior 2011; 37:539-546 
33. Gentile DA, Li D, Khoo A, Prot S, Anderson CA. Mediators and moderators of long-term effects of violent video games on aggressive behavior: Practice, thinking, and action. JAMA Pediatrics 2014; 168:450-457.

34. Saleem M, Anderson CA, Gentile DA. Effects of prosocial, neutral, and violent video games on college students' affect. Aggressive Behavior 2012; 38:263-271.

35. Yao M, Zhou Y, Li J, Gao X. Violent video games exposure and aggression: The role of moral disengagement, anger, hostility, and disinhibition. Aggressive behaviour 2019; 45:662-670.

36. Hoeben EM, Meldrum RC, Walker DA, Young JT. The role of peer delinquency and unstructured socializing in explaining delinquency and substance use: A state-of-the-art review. Journal of Criminal Justice 2016; 47:108-122.

37. Thompson EL, Mehari KR, Farrell AD. Deviant peer factors during early adolescence: cause or consequence of physical aggression?. Child development 2019.

38. Vitaro F, Brendgen M, Lacourse E (2014). Peers and delinquency: A Genetically Informed, Developmentally Sensitive Perspective. In The Development of Criminal and Antisocial Behavior: Theory, Research and Practical Applications, pp. 221.

39. Moya-Higueras J, Cuevas A, Marques-Feixa L, et al.. Recent Stressful Life Events (SLE) and Adolescent Mental Health: Initial Validation of the LEIA, a New Checklist for SLE Assessment According to Their Severity, Interpersonal, and Dependent Nature. Assessment 2018, 1073191118817648.

40. Fernández-Pinto I, Santamaría P, Sánchez-Sánchez F, Carrasco MA, del Barrio V. (2015). SENA. Sistema de evaluación de niños y adolescentes. Manuel de aplicación, corrección e interpretación. Madrid: TEA Ediciones.

41. Walker JO, López FJ, Mezquita L (2018, September). An abridge form of the Junior Spanish version of the NEO PI-R (JS NEO-A60). Submitted at the VII Jornada de la AIIDI, Palma de Mallorca, España.

42. Ortet G, Ibáñez MI, Moya J, Villa H, Viruela A, Mezquita L. Assessing the five factors of personality in adolescents: The junior version of the Spanish NEO-PIR. Assessment 2012; 19:114-130.

43. Gallego-Moya, S. (2019). La contribución de los amigos y la personalidad en el consumo de alcohol y conductas externalizantes en jóvenes (The contribution of 
peers and personality in alcohol consumption and externalyzing behaviors in young people). Doctoral dissertation, Universitat Jaume I.

44. Dawson JF. Moderation in management research: What, why, when, and how. Journal of Business and Psychology 2014; 29:1-19.

45. Byrne BM (2013). Structural equation modeling with Mplus: Basic concepts, applications, and programming. Routledge.

46. Kühn S, Kugler DT, Schmalen K, Weichenberger M, Witt C, Gallinat J. Does playing violent video games cause aggression? A longitudinal intervention study. Molecular Psychiatry 2018; 1.

47. Teng SKZ, Chong GYM, Siew ASC, Skoric MM. Grand Theft Auto IV comes to Singapore: Effects of repeated exposure to violent video games on aggression. Cyberpsychology, Behavior, and Social Networking 2011; 14:597-602.

48. Williams D, Skoric M. Internet fantasy violence: A test of aggression in an online game. Communication Monographs 2005; 72:217-233.

49. Mann FD, Patterson MW, Grotzinger AD, et al.. Sensation seeking, peer deviance, and genetic influences on adolescent delinquency: Evidence for person-environment correlation and interaction. Journal of abnormal psychology 2016; 125:679.

50. Mann FD, Kretsch N, Tackett JL, Harden KP, Tucker-Drob, EM. Person $\times$ environment interactions on adolescent delinquency: Sensation seeking, peer deviance and parental monitoring. Personality and individual differences 2015; 76:129-134. 
Figure 1: Simple slopes showing moderating effects between Deviant Peers (DP) levels with the IVEG and Agreeableness at Waves 1 and 2 on aggressive behaviors
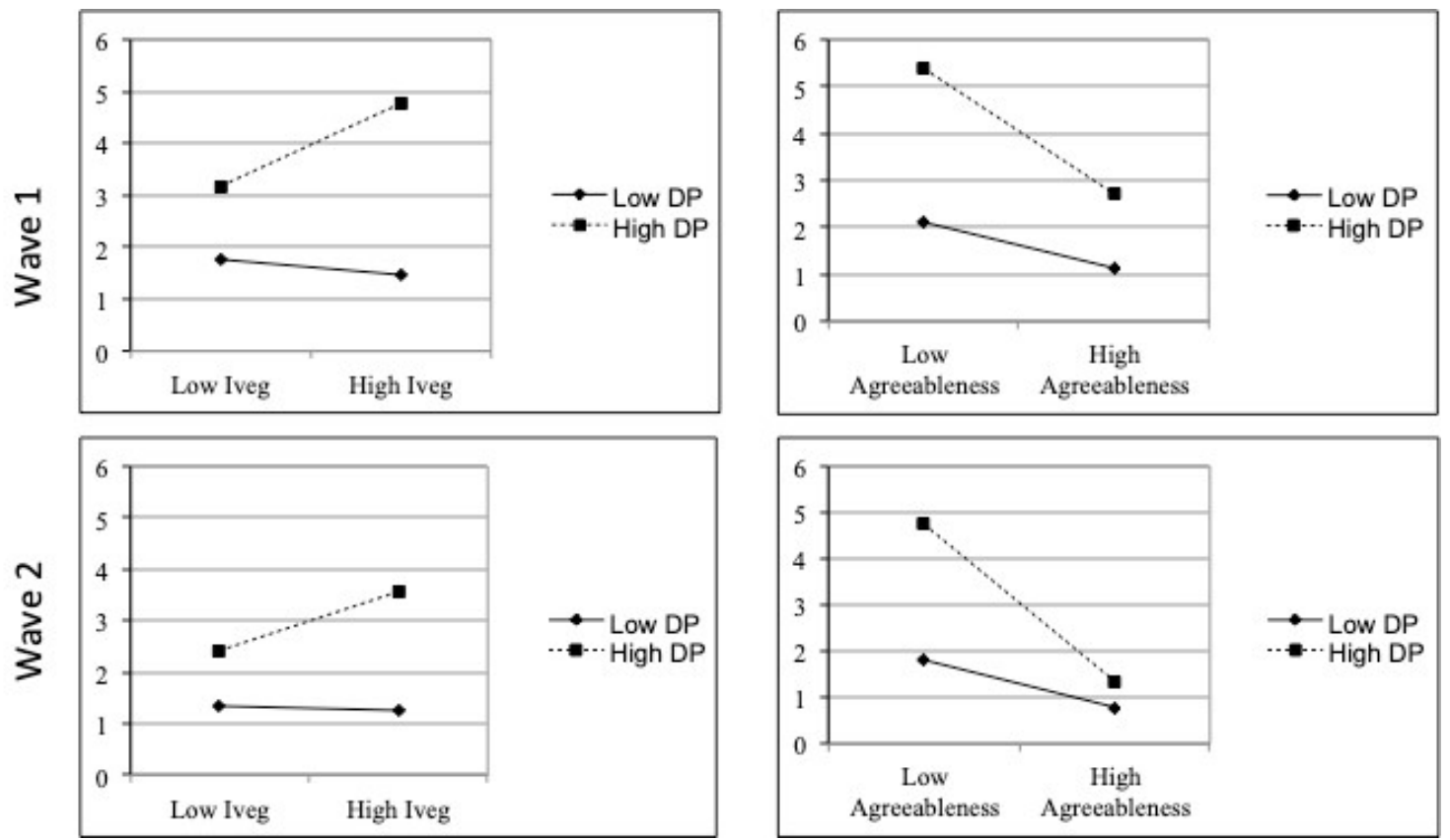
Figure 2: The longitudinal relations between the IVEG and aggressive behaviors

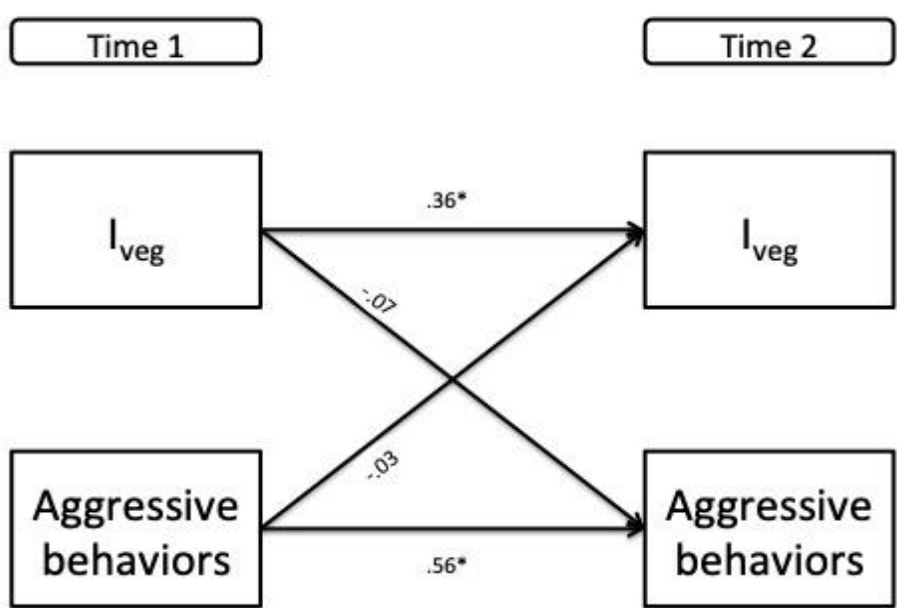

$*=p<.001$ 
Table 1: Multiple regression analyses of aggressive behaviors

\begin{tabular}{|c|c|c|c|c|c|c|c|c|c|c|}
\hline \multirow[t]{3}{*}{ Independent Variables } & \multicolumn{10}{|c|}{ Aggressive behaviors } \\
\hline & \multicolumn{2}{|c|}{ Step1 } & \multicolumn{2}{|c|}{ Step 2} & \multicolumn{2}{|c|}{ Step 3} & \multicolumn{2}{|c|}{ Step 4} & \multicolumn{2}{|c|}{ Step5 } \\
\hline & $\mathrm{W}_{1}$ & $\mathrm{~W}_{2}$ & $\mathrm{~W}_{1}$ & $\mathrm{~W}_{2}$ & $\mathrm{~W}_{1}$ & $\mathrm{~W}_{2}$ & $\mathrm{~W}_{1}$ & $\mathrm{~W}_{2}$ & $\mathrm{~W}_{1}$ & $\mathrm{~W}_{2}$ \\
\hline Gender & $-.10^{*}$ & $-.14^{*}$ & -.03 & -.01 & -.06 & -.01 & -.07 & -.01 & -.05 & -.02 \\
\hline Age & .04 & .06 & -.04 & .00 & $-.09^{*}$ & -.04 & $-.09^{*}$ & -.03 & -.04 & -.02 \\
\hline IVEG & $.11^{*}$ & $.11^{*}$ & .08 & .09 & .06 & .07 & .06 & .06 & .10 & .08 \\
\hline Neuroticism (N) & & & .07 & .06 & .05 & .04 & .06 & .04 & .07 & .02 \\
\hline Extraversion (E) & & & $.10^{*}$ & $.10^{*}$ & .01 & .04 & .02 & .04 & .02 & .03 \\
\hline Openness (O) & & & -.07 & -.08 & -.03 & $-.10^{*}$ & -.02 & -.08 & -.01 & $-.09^{*}$ \\
\hline Agreeableness (A) & & & $-.38^{\star \star \star *}$ & $-.45^{\star \star \star}$ & $-.30^{*+4}$ & $-.36^{*+4}$ & $-.30^{*+*}$ & $-.35^{*+4}$ & $-.25^{*+*}$ & $-.33^{4+*}$ \\
\hline Conscientiousness (C) & & & $-.17^{\star \star \star ~}$ & $-.11^{*}$ & $-.10^{+}$ & -.07 & $-.10^{*}$ & -.08 & $-.10^{*}$ & $-.09^{*}$ \\
\hline Deviant Peers (DP) & & & & & $.40^{* * *}$ & $39^{* * *}$ & $.40^{6 * 6}$ & $.39^{606}$ & $.31^{606}$ & $.26^{606}$ \\
\hline $\mathrm{IVEG}_{\mathrm{VE}} \mathrm{XN}$ & & & & & & & -.02 & -.01 & -.04 & .00 \\
\hline IVEG $_{\mathrm{VE}} \mathrm{XE}$ & & & & & & & .02 & .06 & -.03 & .00 \\
\hline $\mathrm{IVEG}_{\mathrm{VE}} \mathrm{XO}$ & & & & & & & -.01 & .01 & .01 & -.04 \\
\hline $\mathrm{IVEG}_{\mathrm{V}} \mathrm{XA}$ & & & & & & & .03 & $-.10^{*}$ & $.12^{\circ \bullet}$ & -.05 \\
\hline $\mathrm{IVEG}_{\mathrm{V}} \mathrm{XC}$ & & & & & & & $-.09^{*}$ & -.07 & -.05 & -.06 \\
\hline $\mathrm{DPXN}$ & & & & & & & & & -.01 & -.02 \\
\hline DPXE & & & & & & & & & -.04 & .03 \\
\hline $\mathrm{DPXO}$ & & & & & & & & & -.01 & -.02 \\
\hline $\mathrm{DP} \times \mathrm{A}$ & & & & & & & & & $-.13^{\text {} \star}$ & $-.21^{\star \star \star}$ \\
\hline $\mathrm{DPXC}$ & & & & & & & & & -.05 & .01 \\
\hline $\mathrm{DP} X \mathrm{I}_{\mathrm{VEG}}$ & & & & & & & & & $.14^{* *}$ & $.12 *$ \\
\hline$\Delta R^{2}$ & .03 & .04 & .24 & .24 & .13 & .13 & .01 & .01 & .05 & .10 \\
\hline
\end{tabular}

Note. The rest of moderations at Step 5 were omitted to simplify the model. Coefficients are standardized coefficients; $\Delta \mathrm{R}^{2}=$ change in variance;

$*=p<.05, * *=p<.01, * * *=p<.001 . \mathrm{W}_{1}$ and $\mathrm{W}_{2}$ are waves 1 and 2 respectively. $1=$ males, $2=$ females 


\section{Supplementary Material:}

Descriptive data, Cronbach's alphas and correlation coefficients among the study variables

\begin{tabular}{|c|c|c|c|c|c|c|c|c|c|c|c|c|c|c|c|c|}
\hline Variables & 1 & 2 & 3 & 4 & 5 & 6 & 7 & 8 & 9 & 10 & 11 & 12 & 13 & 14 & 15 & 16 \\
\hline 1. IVEG W1 & - & & & & & & & & & & & & & & & \\
\hline 2. Aggressive behaviors W1 & $.13^{*}$ & - & & & & & & & & & & & & & & \\
\hline 3. Neuroticism W1 & $-.10^{*}$ & $.16^{*}$ & - & & & & & & & & & & & & & \\
\hline 4. Extraversion W1 & .01 & .03 & -.10 & - & & & & & & & & & & & & \\
\hline 5. Openness W1 & -.09 & $-.19^{* * *}$ & $-.18^{* *}$ & .11 & - & & & & & & & & & & & \\
\hline 6. Agreeableness W1 & $-.19^{* *}$ & $-.48^{* *}$ & $-.19^{* *}$ & -.03 & $.16^{*}$ & - & & & & & & & & & & \\
\hline 7. Conscientiousness W1 & -.04 & $-.31^{* * *}$ & $-.18^{* *}$ & $.18^{* *}$ & $.22^{* *}$ & $.28^{* *}$ & - & & & & & & & & & \\
\hline 8. Deviant Peers W1 & .10 & $.63^{* *}$ & .09 & $.21^{* *}$ & -.12 & $-.28^{* *}$ & $-.23^{* * *}$ & - & & & & & & & & \\
\hline 9. IVEG W2 & $.37^{* * *}$ & .05 & .00 & -.09 & $-.23^{* * *}$ & -.02 & -.11 & -.04 & - & & & & & & & \\
\hline 10. Aggressive behaviors W2 & .04 & $.57^{* *}$ & $.13^{*}$ & .01 & $-.20^{* * *}$ & $-.45^{* *}$ & $-.25^{* * *}$ & $.44^{* * *}$ & .10 & - & & & & & & \\
\hline 11. Neuroticism W2 & -.01 & .11 & $.60^{* *}$ & $-.16^{*}$ & $.17^{* *}$ & -.03 & $-.21^{* * *}$ & $.13^{*}$ & -.03 & $.14^{*}$ & - & & & & & \\
\hline 12. Extraversion W2 & -.06 & -.05 & -.10 & $.62^{* *}$ & .07 & .02 & $.14^{*}$ & .13 & .00 & .00 & $-.22^{* *}$ & $=$ & & & & \\
\hline 13. Openness W2 & -.06 & -.10 & $.17^{* *}$ & .00 & $.68^{* *}$ & .02 & .04 & -.12 & $-.17^{* * *}$ & $-.14^{*}$ & $.22^{* *}$ & -.02 & $=$ & & & \\
\hline 14. Agreeableness W2 & $-.17^{* *}$ & $-.39^{* * *}$ & -.12 & .05 & $.18^{* *}$ & $.63^{* *}$ & $21^{* *}$ & $-.30^{* *}$ & -.09 & $-.53^{* * *}$ & $-.19^{* *}$ & .06 & .08 & - & & \\
\hline 15. Conscientiousness W2 & -.05 & $-.26^{* * *}$ & $-.21^{*-*}$ & .08 & $.16^{*}$ & $.18^{* *}$ & $.65^{* * *}$ & $-.22^{* *}$ & -.11 & $-.27^{* * *}$ & $-.30^{* *}$ & $.21^{* *}$ & 11 & $.20^{* *}$ & $=$ & \\
\hline 16. Deviant Peers W2 & .04 & $.26^{* *}$ & $.14^{*}$ & $.17^{*}$ & -.01 & $-.25^{* *}$ & $-.15^{*}$ & $.45^{* *}$ & .01 & $.51^{* *}$ & .12 & .06 & .05 & $-.23^{* *}$ & $-.16^{*}$ & $=$ \\
\hline $\mathrm{M}$ & 1.26 & 3.01 & 22.80 & 31.88 & 24.40 & 34.56 & 29.80 & 6.93 & 1.01 & 2.45 & 20.65 & 31.26 & 24.89 & 35.49 & 28.56 & 4.65 \\
\hline SD & 1.61 & 3.83 & 8.80 & 7.76 & 7.72 & 7.76 & 8.25 & 6.23 & 1.36 & 3.38 & 8.73 & 7.45 & 7.94 & 7.52 & 8.16 & 4.78 \\
\hline$\alpha$ & $=$ & .76 & .83 & .83 & .70 & .81 & .83 & .86 & - & .75 & .85 & .84 & .75 & .81 & .86 & .84 \\
\hline
\end{tabular}

$* p<.05$

$* * p<.01$ 
Path coefficients in the longitudinal structural model by estimating stability and cross-

lagged paths from Time 1 to 2

\begin{tabular}{|c|c|}
\hline Stability coefficients between $T_{1}$ and $T_{2}$ & \\
\hline $\mathrm{I}_{\mathrm{VEG}}$ & $.37 * * *$ \\
\hline Aggressive behaviors & $.55 * * *$ \\
\hline Neuroticism & $.58 * * *$ \\
\hline Extraversion & $.62 * * *$ \\
\hline Openness & $.67 * * *$ \\
\hline Agreeableness & $.59 * * *$ \\
\hline Conscientiousness & $.64 * * *$ \\
\hline Deviant Peers & $.42 * * *$ \\
\hline \multicolumn{2}{|l|}{ Cross-lagged paths from $T_{1}$ to $T_{2}$} \\
\hline $\mathrm{I}_{\mathrm{VEG} \rightarrow} \rightarrow$ Aggressive behaviors & -.03 \\
\hline $\mathrm{I}_{\mathrm{VEG}} \rightarrow$ Neuroticism & -.04 \\
\hline $\mathrm{I}_{\mathrm{VEG}} \rightarrow$ Extraversion & -.06 \\
\hline $\mathrm{I}_{\mathrm{VEG}} \rightarrow$ Openness & .00 \\
\hline $\mathrm{I}_{\mathrm{VEG}} \rightarrow$ Agreeableness & -.06 \\
\hline $\mathrm{I}_{\mathrm{VEG}} \rightarrow$ Conscientiousness & -.02 \\
\hline $\mathrm{I}_{\mathrm{VEG} \rightarrow} \rightarrow$ Deviant Peers & -.01 \\
\hline Aggressive behaviors $\rightarrow \mathrm{I}_{\mathrm{VEG}}$ & .10 \\
\hline Neuroticism $\rightarrow \mathrm{I}_{\mathrm{VEG}}$ & .02 \\
\hline 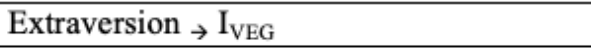 & -.03 \\
\hline Openness $\rightarrow \mathrm{I}_{\mathrm{VEG}}$ & $-.18 * * *$ \\
\hline Agreeableness $\rightarrow \mathrm{I}_{\mathrm{VEG}}$ & .12 \\
\hline Conscientiousness $\rightarrow \mathrm{I}_{\mathrm{VEG}}$ & -.08 \\
\hline Deviant Peers $\rightarrow \mathrm{I}_{\mathrm{VEG}}$ & -.16 \\
\hline
\end{tabular}

Note. Coefficients are standardized coefficients.

$$
\begin{aligned}
& * * * p<.001 \\
& * * p<.01 \\
& * p<.05
\end{aligned}
$$




\section{CHAPTER 3: GENERAL DISCUSSION}

The main aim of the current thesis was to examine the influence of psychological factors, mainly personality, on video game behaviors: disordered gaming, video game use and video game preferences.

For that purpose, the first study examined the role of personality on adolescent disordered gaming and video game preferences. A differential role according to gender was found among the relationships between personality and disordered gaming. Thereby, for boys, disordered gaming was related to low agreeableness, whereas for girls, low extraversion showed relevant links with problematic gaming. Thus, the competitive characteristics of video games may impact boys especially, increasing their perseverance in gaming despite its interference in daily domains (Vollmer et al., 2014); whereas introverted girls with poor social skills would develop a pathological use of video games to cope with such social deficiencies (Garcia-Oliva \& Piqueras, 2016; Vollmer et al., 2014). In addition, for both genders, low conscientiousness was related to disordered gaming and its effects were moderated by higher video game frequency. Therefore, higher use of gaming could be particular risky for those adolescent players with high impulsivity. Thus, they would have more difficulties to deal with game engagement as well as life obligations (Garcia-Oliva \& Piqueras, 2016; Vollmer et al., 2014; Wang et al., 2015). Apart from that, together with gender, personality showed a significant association with video game genre uses, a topic scarcely studied (Braun et al., 2016; Potard et al., 2019). Thus, openness was positively related to fantastic and imaginative games such as RPG, and negatively to those more conventional games such as action-shooter and sports. Extraversion was positively related to social games (action-shooter and sport) and negatively with solitary games (RPG, social simulation and adventure). Low agreeableness showed relationships with competitive games (fighting and strategy). 
Neuroticism was highly related to construction games, which could be explained by a compulsive psychological tendency emerging in the repetitive activity performed in the game. Finally, conscientiousness also displayed a significant role related to higher use of Brain+Skill games and lower RPG and fighting game use.

The second study based on the development and validation of the Videogaming Motives Questionnaire for a sample of adolescents and another of young adults. The scale consisted of eight factors: recreation, social interaction, coping, violent reward, fantasy, cognitive development, customization, and competition. The brief scale, with a total of 24 items, displayed good scores in reliability and the motives were associated with a large set of gaming behaviors and sociodemographic data, showing a suitable criterion validity. In addition, when controlling for other motives and sociodemographic data, the motives more related to disordered gaming in both samples were coping and social interaction, and, to a lesser extent, violent reward. On the other hand, social interaction was the main factor in explaining weekly gaming for both samples. In this manner, coping may be the principal motivational factor for disordered gaming among adults (Kim et al., 2016; Király et al., 2017a; Laconi et al., 2017; Montag et al., 2019; Moudiab \& Spada, 2019; Wu et al., 2016) and adolescents (Männikkö et al., 2017). Thus, playing to forget and cope with life problems may clearly express a higher pathological gaming use. Furthermore, social interaction, playing to hang out with friends and make new ones, should increase the engagement in video gaming in adults (Király et al., 2017a; Wu et al., 2016) as well as adolescents (Greenberg, et al., 2010; Sherry et al., 2006). Apart from that, social interaction seems to be another key motive in understanding disordered gaming (Hilgard et al., 2013; Männikkö et al., 2017). In this sense, players motivated by social interaction could reflect a poor social competence or cohesion in real life that has an impact on the development of disordered gaming (Gentile et al., 2011; Lemmens et 
al., 2011a; Peeters et al., 2018; Rehbein \& Baier, 2013). The effect of violent reward on disordered gaming may be explained because more aggressive and antisocial players may play video games to release such violent feelings (Hussain, Williams, \& Griffiths, 2015; Rehbein et al., 2010) showing externalizing symptomatology (e.g., Andreassen et al., 2016; Müller et al., 2015) that would develop a pathological use.

With regard to video game genres:

- Coping is highly related to MMORPGs (Hilgard et al., 2013; Kim et al., 2016).

- Social interaction is mainly associated with social games (Greenberg et al., 2010) such as MMOs (Kim et al., 2016).

- Violent reward may be related to higher use of violent games such as shooters (Hilgard et al., 2013).

- Fantasy motives display significant associations with uses of FPS, RPG and action adventure games (Greenberg et al., 2010; Ghuman \& Griffiths, 2012; Hilgard et al., 2013; Kim et al., 2016; Scharkow et al., 2015).

- Customization has an extensive relationship with social simulation games and RPGs (Hilgard et al., 2013).

- Recreation was mainly associated with uses of shooters and RPGs.

- Competition motive has been positively related to competitive genres such as shooters, MOBA or sports; and negatively to noncompetitive genres, such as casual games like puzzles (Greenberg et al., 2010; Scharkow et al., 2015).

- Cognitive development may have an important impact on games in which performance is improved by experience, for example, shooters and MOBAs (Kim et al., 2016). 
In the third study, the direct and indirect effect of FFM traits through motives on video gaming behaviors was explored among adolescents. Thus, neuroticism was related to disordered gaming partially due to its effect on coping motives. In this sense, some studies have found that escapism motives mediate between internalizing problems and pathological gaming (Ballabio et al., 2017; Király et al., 2015b; Montag et al., 2019; Plante et al., 2018). It may reflect a negative affect regulation pathway in disordered gaming found in other addictions such as alcohol (Sher, Grekin, \& Williams, 2005). Low agreeableness was directly related to higher video gaming and via social motives to disordered gaming, depicting a deviance proneness pathway in video gaming (Sher et al., 2005). Thus, players with deviant behaviors may be more prone to display higher video gaming and pathological gaming (Müller et al., 2015; Wartberg et al., 2017). Similarly, low agreeableness has been related to gambling severity partially via gambling motives (McGrath, Neilson, Lee, Rash, \& Rad, 2018). Low conscientiousness was directly associated with disordered gaming. Thus, as happens with disordered gambling (McGrath et al., 2018), low conscientiousness may have an important effect on disordered gaming independently from motives to play (Gervasi et al., 2017; Mihara \& Higuchi, 2017; Şalvarlı \& Griffiths, 2019). Finally, introversion was directly associated with higher video gaming. Thereby, the low introversion may boost the engagement in players, preferring nonsocial hobbies, without having an effect on the development of disordered gaming. It should explain the inconsistent results found in the relationship between low extraversion and disordered gaming (Gervasi et al., 2017; Mihara \& Higuchi, 2017; Şalvarlı \& Griffiths, 2019).

To sum up, the findings indicate personality and motives are relevant variables in video game behaviors. Thus, to date, the current research is the first to analyze the mediation effects between basic personality traits and motives on video gaming 
behaviors, and the moderating effects between personality and gaming frequency on disordered gaming. In addition, it is also the first time that a differential role according to gender in the relationship between personality and disordered gaming is found. These results add empirical data that bring a deeper knowledge in understanding the variability observed in gaming behaviors.

Apart from examining the role of personality and motives on video game behaviors, this thesis also focused on exploring the effect of VVE on adolescent aggressive behaviors controlled for and in combination with risk factors related to aggressiveness.

Thus, in the fourth study, the most important variables relating to adolescent aggressive behaviors were deviant peers and low agreeableness, in line with other studies (Jones, Miller, \& Lynam, 2011; Thompson et al., 2019). VVE was associated with aggressive behaviors slightly but significantly, the relationship became non-significant when controlled for personality and deviant peers, replicating results found in the scarce research on the topic (Anderson et al., 2004; Ferguson, Colwell, Mlačić, Milas, \& Mikloušić, 2011). In addition, no longitudinal relationships were shown between VVE and aggression one year apart. This minor effect of VVE on aggressive behaviors may hide null effects for some people with greater effects for others who may present susceptibilities to VVE such as particular personality traits or social factors (Markey, 2015; Valkenburg \& Peter, 2013). Thus, moderating effects between VVE and personality traits and deviant peers were examined in adolescent aggressive behaviors. As a result, those people with greater VVE displayed more aggressive behaviors if they reported having more deviant friends. Furthermore, the combination of having deviant friends and low agreeableness increased aggressive behaviors. Therefore, aggression is a complex behavior explained by the interplay of multiple biodispositional variables, such 
as personality, and social variables, such as deviant peers (Valkenburg \& Peter, 2013) in which VVE may not play an important role but it could be relevant for some people who present particular risk factors.

\subsection{Applicability of the results}

The fact of knowing the impact of individual differences on disordered gaming in detail may be useful to develop better prevention and treatment programs. In this manner, regarding treatment programs, Cognitive Behavior Therapy (CBT) presents the largest evidence compared to other therapies in IGD severity reduction (King et al., 2017). Thus, a meta-analysis displayed that CBT shows high efficacy in reducing IGD symptoms and comorbid depression (Stevens, King, Dorstyn, \& Delfabbro, 2019). Accordingly, Young \& Brand (2017) focused on three phases of CBT for IGD: behavior modification (e.g., encouraging daily social activities outside the Internet), cognitive restructuring based on changing maladaptive cognitions and expectancies. In this sense, King \& Delfabbro, (2014) through a systematic review, embedded maladaptive cognitions related to IGD in 4 groups: beliefs about game reward value and tangibility, maladaptive and inflexible rules about gaming behavior, over-reliance on gaming to meet self-esteem needs, and gaming as a method of gaining social acceptance. And finally, harm reductions, treatment of co-occurring problems such as depression or social anxiety. Therefore, the present research suggests personalized treatments according to gender could be developed. For instance, among boys, the therapy could be focus on changing maladaptive cognitions with regard to in-game competition; whereas for girls, the promotion of social hobbies would have a higher positive effect. Apart from this, knowing the gaming motivations of problematic gamers could reveal which potential replacement behaviors can be selected in therapy (Steadman, 2019). For example, competitive gamers enjoy more sport activities, social gamers prefer to be engaged in social and organized 
groups; and gamers who display high scores in cognitive development and immersion may show interest in intellectual activities such as reading (Steadman, 2019). In addition, the learning of an adaptive way to cope with individual problems may be a key element to reduce IGD symptoms.

What can do governments to face problematic video gaming? The concern of disordered gaming has led some countries, especially in Asia, to develop legislations in order to deal with it. In this sense, Király et al. (2017c) through a systematic review classified policy responses to problematic video gaming into 3 groups: limiting availability, establishing shutdown systems for some periods of time a day or when the gamer has played for some time continually; reducing risk and harm, through the use of in-game warning messages related to the risk of excessive gaming by gaming companies; and providing help services for gamers in order to prevent and treat problematic gaming. Likewise, in relation to prevention strategies, King et al. (2017) carried out a review of policy and prevention strategies in problematic gaming and Internet use implemented internationally. They established 3 kinds of prevention strategies:

- Universal prevention, targeting the general population. They include: 1) educational resources, such as information on healthy use or promotion of other activities; 2) legislative action, such as regular shutdowns of Internet gaming services at certain times daily; 3) technological measures, e.g. parental locks or time-limit settings; 4) public awareness, to spread knowledge about technological addictions; 5) behavioral measures, such as reducing the number of devices available or usage time.

- Selective prevention, focused on individuals at risk, including 1) regular screening, researches in schools and high schools to identify emerging cases; 2) mental health checks, screening psychological problems that could increase maladaptive coping mechanisms through gaming and Internet uses; 3) school-based educational programs, 
teaching healthy use and engagement in other hobbies that could improve their selfesteem and empowerment; 4) workplace Internet policy, rules for Internet access privileges.

- Indicated prevention, for individuals already addicted, where the following points are included: 1) support groups, 2) outpatient medical and mental health services, treatment of mental disorders that may contribute to or underlie the addiction or hazardous use; 3) psychosocial rehabilitation, focused on socialization and on the engagement in alternative interests; 4) psycho-education, information about symptoms and strategies to lower the use.

The findings of this thesis could potentially contribute to selective prevention, by giving important data to observe which individuals are at risk of suffering IGD and intervene in a personalized way to avoid the development of problematic gaming.

Concerning the relationships between violent video games and aggressive behaviors, researchers and especially journalists and policy makers would do well to convey strong statements linking video gaming and violence because aggression's genesis is due to multiple biopsychosocial variables and their interactions. Thus, VVE can be relevant in some situations to increase aggressive behaviors but there are other, much more important factors such as personality predispositions or social environments. 


\subsection{Limitations and future lines of research}

The current research is not without limitations. Firstly, the studies based on heterogeneous high school student samples, except the second study which added another young adult sample, mainly of undergraduates. Therefore, the results in adolescents could be generalized across western countries. Thus, the first study displayed a teenager and adolescent prevalence of disordered gaming similar to those found in USA and EU (Gentile, 2009; Müller et al., 2015). Nevertheless, further research on young adults as well as national representative samples among the general population is needed in order to check whether adolescent findings are replicated among other age groups.

Furthermore, the studies present cross-sectional designs except the fourth study, which impedes causal inferences. Thus, even though personality is generally considered a steady variable, this could be modified by video game use. In this manner, playing violent video games seems to increase sadism (Greitemeyer \& Sagioglou, 2017), sensation seeking and rebelliousness (Hull, Draghici, \& Sargent, 2012; Hull, Brunelle, Prescot, \& Sargent, 2014) in a small but significant way. In contrast, in our fourth study, when longitudinal relationships between VVE and FFM traits were examined, low openness predicted higher VVE but no FFM trait was predicted by VVE. Future studies should make use of prospective longitudinal designs in order to establish causal relationships between psychological variables and video game related behaviors.

When studying VVE and aggressive behaviors, researchers should look into the combination of biodispostional factors, such as genetics or expectations, and social variables, such as family attachment or best friend's aggressive behaviors, due to the complexity in the nature of aggression.

Finally, the video game genre categorization is somehow artificial because games usually display mixed features from different genres. In addition, the way in which 
players reported their most played games had a significant range restriction (participants were allowed to mention up to five games).

\subsection{Conclusions}

- Study 1

- Low conscientiousness was related to disordered gaming in both genders and its effects were moderated by video game frequency.

- Low agreeableness was associated with disordered gaming in boys.

- High introversion was related to problematic gaming in girls.

- Personality and gender showed significant associations among video game genre preferences.

\section{- Study 2}

- The VMQ consisted of 8 motivational factors (recreation, social interaction, coping, violent reward, fantasy, cognitive development, customization, and competition).

- The scale displayed suitable scores in reliability and the motives were linked to gaming-related variables, demonstrating good concurrent validity.

- Coping and social interaction were extensively associated with disordered gaming.

- Social interaction showed a strong relationship with gaming time. 
- Study 3

Direct effects of personality on gaming-related behaviors:

- High neuroticism and low conscientiousness were related to disordered gaming.

- Low agreeableness and high introversion were associated with weekly gaming.

$\underline{\text { Mediation effects: }}$

- Coping partially mediated between neuroticism and disordered gaming.

- Social interaction partially mediated between low agreeableness and disordered gaming.

\section{- Study 4}

- Deviant peers and low agreeableness were closely related to adolescent aggressive behavior.

- VVE showed a small but significant link with aggressive behaviors, which became non-significant when controlled for personality and deviant peers.

- No longitudinal relationships were found between VVE and aggressive behaviors.

- VVE showed a higher association with aggressive behaviors when individuals had more deviant peers.

- Players with low agreeableness and with deviant peers presented more aggressive behaviors. 


\section{REFERENCES}


Achab, S., Nicolier, M., Mauny, F., Monnin, J., Trojak, B., Vandel, P., ... \& Haffen, E. (2011). Massively multiplayer online role-playing games: comparing characteristics of addict vs non-addict online recruited gamers in a French adult population. BMC psychiatry, 11, 144-155.

Allen, J. J., \& Anderson, C. A. (2018). Satisfaction and frustration of basic psychological needs in the real world and in video games predict internet gaming disorder scores and well-being. Computers in Human Behavior, 84, 220-229.

American Psychiatric Association. (2013). Diagnostic and statistical manual of mental disorders (DSM-5®). American Psychiatric Pub.

Anderson, C. A., \& Bushman, B. J. (2002). Human aggression. Annual review of psychology, 53, 27-51.

Anderson, C. A., \& Bushman, B. J. (2018). Media violence and the general aggression model. Journal of Social Issues, 74, 386-413.

Anderson, C. A., Carnagey, N. L., Flanagan, M., Benjamin, A. J., Eubanks, J., \& Valentine, J. C. (2004). Violent video games: Specific effects of violent content on aggressive thoughts and behavior. Advances in experimental social psychology, 36, 200-251.

Anderson, C. A., \& Dill, K. E. (2000). Video games and aggressive thoughts, feelings, and behavior in the laboratory and in life. Journal of personality and social psychology, 78, 772-790.

Anderson, C. A., Shibuya, A., Ihori, N., Swing, E. L., Bushman, B. J., Sakamoto, A., ... \& Saleem, M. (2010). Violent video game effects on aggression, empathy, and prosocial behavior in Eastern and Western countries: A meta-analytic review. Psychological bulletin, 136, 151-173.

Andreassen, C. S., Billieux, J., Griffiths, M. D., Kuss, D. J., Demetrovics, Z., Mazzoni, E., \& Pallesen, S. (2016). The relationship between addictive use of social media and video games and symptoms of psychiatric disorders: A large-scale crosssectional study. Psychology of Addictive Behaviors, 30, 252-262.

Andreassen, C. S., Griffiths, M. D., Gjertsen, S. R., Krossbakken, E., Kvam, S., \& Pallesen, S. (2013). The relationships between behavioral addictions and the fivefactor model of personality. Journal of behavioral addictions, 2, 90-99.

Argyriou, E., Davison, C. B., \& Lee, T. T. (2017). Response inhibition and Internet gaming disorder: A meta-analysis. Addictive behaviors, 71, 54-60. 
Ashton, M. C., \& Lee, K. (2007). Empirical, theoretical, and practical advantages of the HEXACO model of personality structure. Personality and Social Psychology Review, 11, 150-166.

Asociación Española de Videojuegos (AEVI) (2018) [The Yearbook of Videogames 2018]. El anuario del videojuego 2018. Retrieved from: http://www.aevi.org.es/web/wpcontent/uploads/2019/05/AEVI_Anuario_2018.pdf.

Ballabio, M., Griffiths, M. D., Urbán, R., Quartiroli, A., Demetrovics, Z., \& Király, O. (2017). Do gaming motives mediate between psychiatric symptoms and problematic gaming? An empirical survey study. Addiction Research \& Theory, 25, 397-408.

Bartle, R. (1996). Hearts, clubs, diamonds, spades: Players who suit MUDs. Journal of MUD research, 1, 19-45.

Bean, A., \& Groth-Marnat, G. (2016). Video gamers and personality: A five-factor model to understand game playing style. Psychology of Popular Media Culture, 5, 27-38.

Bechara, A. (2005). Decision making, impulse control and loss of willpower to resist drugs: a neurocognitive perspective. Nature Neuroscience, 8, 1458-1463.

Billieux, J., Van der Linden, M., Achab, S., Khazaal, Y., Paraskevopoulos, L., Zullino, D., \& Thorens, G. (2013). Why do you play World of Warcraft? An in-depth exploration of self-reported motivations to play online and in-game behaviours in the virtual world of Azeroth. Computers in Human Behavior, 29, 103-109.

Billieux, J., Chanal, J., Khazaal, Y., Rochat, L., Gay, P., Zullino, D., et al. (2011). Psychological predictors of problematic involvement in Massively Multiplayer Online Role Playing Games (MMORPG): Illustration in a sample of male cybercafés players. Psychopathology, 44, 165-171.

Billieux, J., Deleuze, J., Griffiths, M. D., \& Kuss, D. J. (2015). Internet gaming addiction: The case of massively multiplayer online role-playing games. In Textbook of addiction treatment: International perspectives (pp. 1515-1525). Springer Milan.

Billieux, J., Potenza, M. N., Maurage, P., Brevers, D., Brand, M., \& King, D. L. (2020). Cognitive factors associated with gaming disorder. In Cognition and Addiction (pp. 221-230). Academic Press.

Blum, K., Oscar-Berman, M., Demetrovics, Z., Barh, D., \& Gold, M. S. (2014). Genetic addiction risk score (GARS): molecular neurogenetic evidence for predisposition to reward deficiency syndrome (RDS). Molecular neurobiology, 50, 765-796. 
Bowditch, L., Chapman, J., \& Naweed, A. (2018). Do coping strategies moderate the relationship between escapism and negative gaming outcomes in World of Warcraft (MMORPG) players?. Computers in Human Behavior, 86, 69-76.

Brand, M., Young, K. S., Laier, C., Wölfling, K., \& Potenza, M. N. (2016). Integrating psychological and neurobiological considerations regarding the development and maintenance of specific Internet-use disorders: An Interaction of Person-AffectCognition-Execution (I-PACE) model. Neuroscience \& Biobehavioral Reviews, 71, 252-266.

Braun, B., Stopfer, J.,Müller, K., Beutel, E. \& Egloff, B. (2016). Personality and video gaming: Comparing regular gamers, non-gamers, and gaming addicts and differentiating between game genres. Computers in Human Behavior, 55, 406-412.

Brunborg, G. S., Hanss, D., Mentzoni, R. A., \& Pallesen, S. (2015). Core and peripheral criteria of video game addiction in the game addiction scale for adolescents. Cyberpsychology, Behavior, and Social Networking, 18, 280-285.

Brunborg, G. S., Mentzoni, R. A., \& Frøyland, L. R. (2014). Is video gaming, or video game addiction, associated with depression, academic achievement, heavy episodic drinking, or conduct problems?. Journal of behavioral addictions, 3, 27-32.

Buiza-Aguado, C., Alonso-Canovas, A., Conde-Mateos, C., Buiza-Navarrete, J. J., \& Gentile, D. (2018). Problematic video gaming in a young Spanish population: association with psychosocial health. Cyberpsychology, Behavior, and Social Networking, 21, 388-394.

Burleigh, T. L., Stavropoulos, V., Liew, L. W., Adams, B. L., \& Griffiths, M. D. (2018). Depression, internet gaming disorder, and the moderating effect of the gamer-avatar relationship: An exploratory longitudinal study. International Journal of Mental Health and Addiction, 16, 102-124.

Calvert, S. L., Appelbaum, M., Dodge, K. A., Graham, S., Nagayama Hall, G. C., Hamby, S., ... \& Hedges, L. V. (2017). The American Psychological Association Task Force assessment of violent: Science in the service of public interest. American Psychologist, 72, 126-143.

Carras, M. C., \& Kardefelt-Winther, D. (2018). When addiction symptoms and life problems diverge: A latent class analysis of problematic gaming in a representative multinational sample of European adolescents. European child \& adolescent psychiatry, 27, 513-525. 
Carras, M. C., Porter, A. M., Van Rooij, A. J., King, D., Lange, A., Carras, M., \& Labrique, A. (2018). Gamers' insights into the phenomenology of normal gaming and game "addiction": A mixed methods study. Computers in human behavior, 79, 238-246.

Chang, S. M., \& Lin, S. S. (2019). Online gaming motive profiles in late adolescence and the related longitudinal development of stress, depression, and problematic internet use. Computers \& Education, 135, 123-137.

Charlton, J. P., \& Danforth, I. D. (2007). Distinguishing addiction and high engagement in the context of online game playing. Computers in Human Behavior, 23, 15311548.

Charlton, J. P., \& Danforth, I. D. (2010). Validating the distinction between computer addiction and engagement: online game playing and personality. Behaviour \& Information Technology, 29, 601-613.

Chumbley, J., \& Griffiths, M. (2006). Affect and the Computer Game Player: The Effect of Gender, Personality, and Game Reinforcement Structure on Affective Responses to Computer Game-Play. CyberPsychology \& Behavior, 9, 308-316.

Cole, S. H., \& Hooley, J. M. (2013). Clinical and personality correlates of MMO gaming: Anxiety and absorption in problematic internet use. Social science computer review, 31, 424-436.

Collins, E., Freeman, J. \& Chamarro-Premuzick, T. (2012). Personality traits associated with problematic and non-problematic massively multiplayer online role playing game use. Personality and Individual Differences, 52, 133-138.

Costa, P. T., \& McCrae, R. R. (1992). Normal personality assessment in clinical practice: The NEO Personality Inventory. Psychological assessment, 4, 5-13.

De Grove, F., Cauberghe, V., \& Van Looy, J. (2016). Development and validation of an instrument for measuring individual motives for playing digital games. Media Psychology, 19, 101-125.

De Lecea, L.; Jones, B.E.; Boutrel, B.; Borgland, S.L.; Nishino, S.; Bubser, M.; DiLeone, R (2006). Addiction and arousal: Alternative roles of hypothalamic peptides. $J$. Neurosci., 26, 10372-10375.

de Raad, B. E., \& Perugini, M. E. (2002). Big five assessment. Hogrefe \& Huber Publishers.

Deleuze, J., Christiaens, M., Nuyens, F., \& Billieux, J. (2017). Shoot at first sight! First person shooter players display reduced reaction time and compromised inhibitory 
control in comparison to other video game players. Computers in Human Behavior, 72, 570-576.

Deleuze, J., Long, J., Liu, T. Q., Maurage, P., \& Billieux, J. (2018). Passion or addiction? Correlates of healthy versus problematic use of videogames in a sample of Frenchspeaking regular players. Addictive behaviors, 82, 114-121.

Demetrovics, Z., Urbán, R., Nagygyörgy, K., Farkas, J., Zilahy, D., Mervó, B., ... Harmath, E. (2011). Why do you play? The development of the motives for online gaming questionnaire (MOGQ). Behavior Research Methods, 43, 814-825.

Desai, R. A., Krishnan-Sarin, S., Cavallo, D., \& Potenza, M. N. (2010). Video-gaming among high school students: health correlates, gender differences, and problematic gaming. Pediatrics, 126(6), e1414-e1424.

Di Chiara, G.; Bassareo, V. (2007). Reward system and addiction: What dopamine does and doesn't do.Curr. Opin. Pharmacol., 7, 69-76.

Dong, G., \& Potenza, M. N. (2014). A cognitive-behavioral model of Internet gaming disorder: theoretical underpinnings and clinical implications. Journal of psychiatric research, 58, 7-11.

Dreier, M., Wölfling, K., \& Müller, K. (2013). Psychological research and a sociological perspective on problematic and addictive computer game use in adolescence. International Journal of Child and Adolescent Health, 6, 422-435.

Dreier, M., Wölfling, K., Duven, E., Giralt, S., Beutel, M. E., \& Müller, K. W. (2017). Free-to-play: about addicted Whales, at risk Dolphins and healthy Minnows. Monetarization design and internet gaming disorder. Addictive behaviors, 64, 328333.

Eichenbaum, A., Kattner, F., Bradford, D., Gentile, D. A., \& Green, C. S. (2015). Roleplaying and real-time strategy games associated with greater probability of Internet Gaming Disorder. Cyberpsychology, Behavior, and Social Networking, 18, 480-485. Elliott, L., Golub, A., Ream, G., \& Dunlap, E. (2012). Video Game Genre as a Predictor of Problem Use. Cyberpsychology, Behavior, and Social Networking, 15, 155-161.

Engelhardt, C. R., Bartholow, B. D., \& Saults, J. S. (2011). Violent and nonviolent video games differentially affect physical aggression for individuals high vs. low in dispositional anger. Aggressive Behavior, 37, 539-546.

Entertainment Software Association (ESA) (2018). Essential facts about the computer and videogame industry. Retrieved from: http://www.theesa.com/wpcontent/uploads/2018/05/EF2018_FINAL.pdf. 
Estévez, A., Jáuregui, P., Sánchez-Marcos, I., López-González, H., \& Griffiths, M. D. (2017). Attachment and emotion regulation in substance addictions and behavioral addictions. Journal of behavioral addictions, 6, 534-544.

Eysenck, H. J., y Eysenck, M. W. (1985). Personality and individual differences. A natural science approach (Plenum.). Nueva York.

Fam, J. Y. (2018). Prevalence of internet gaming disorder in adolescents: A meta-analysis across three decades. Scandinavian journal of psychology, 59, 524-531.

Feng, W., Ramo, D., Chan, S., \& Bourgeois, J. (2017). Internet gaming disorder: trends in prevalence 1998-2016. Addictive behaviors, 75, 17-24.

Ferguson, C. J., Colwell, J., Mlačić, B., Milas, G., \& Mikloušić, I. (2011). Personality and media influences on violence and depression in a cross-national sample of young adults: Data from Mexican-Americans, English and Croatians. Computers in Human Behavior, 27, 1195-1200.

Ferguson, C. J., \& Kilburn, J. (2009). The public health risks of media violence: A metaanalytic review. The Journal of pediatrics, 154, 759-763.

Festl, R., Scharkow, M., \& Quandt, T. (2013). Problematic computer game use among adolescents, younger and older adults. Addiction, 108, 592-599.

Finserås, T. R., Krossbakken, E., Pallesen, S., Mentzoni, R., King, D. L., Griffiths, M. D., \& Molde, H. (2018). Near Miss in a Video Game: an Experimental Study. International Journal of Mental Health and Addiction, 1-11.

Fisher, S., \& Griffiths, M. D. (1995). Current trends in slot machine gambling: Research and policy issues. Journal of Gambling Studies, 11, 239-247.

Floros, G., \& Siomos, K. (2012). Patterns of Choices on Video Game Genres and Internet Addiction. Cyberpsychology, Behavior, and Social Networking, 15, 417-424.

Fuster, H., Carbonell, X., Pontes, H. M., \& Griffiths, M. D. (2016). Spanish validation of the Internet Gaming Disorder-20 (IGD-20) Test. Computers in Human Behavior, 56, 215-224.

Fuster, H., Chamarro, A., Carbonell, X., \& Vallerand, R. J. (2014). Relationship between passion and motivation for gaming in players of massively multiplayer online roleplaying games. Cyberpsychology, Behavior, and Social Networking, 17, 292-297.

Fuster, H., Oberst, U., Griffiths, M., Carbonell, X., Chamarro, A., \& Talarn, A. (2012). Psychological motivation in online role-playing games: A study of Spanish World of Warcraft players. Anales de Psicología/Annals of Psychology, 28, 274-280. 
Garcia-Oliva, C., \& Piqueras, J. A. (2016). Experiential avoidance and technological addictions in adolescents. Journal of behavioral addictions, 5, 293-303.

Gentile, D. A., Bailey, K., Bavelier, D., Brockmyer, J. F., Cash, H., Coyne, S. M., ... Young, K. (2017). Internet Gaming Disorder in children and adolescents. Pediatrics, 140, S81-S85.

Gentile, D. A., Choo, H., Liau, A., Sim, T., Li, D., Fung, D., et al. (2011). Pathological video game use among youths: A two-year longitudinal study. Pediatrics, 127, 319329.

Gervasi, A. M., La Marca, L., Costanzo, A., Pace, U., Guglielmucci, F., \& Schimmenti, A. (2017). Personality and Internet gaming disorder: a systematic review of recent literature. Current Addiction Reports, 4, 293-307.

Ghuman, D., \& Griffiths, M. (2012). A Cross-Genre Study of Online Gaming. International Journal of Cyber Behavior, Psychology and Learning, 2, 13-29.

Giumetti, G. W., \& Markey, P. M. (2007). Violent video games and anger as predictors of aggression. Journal of Research in Personality, 41, 1234-1243.

González-Bueso, V., Santamaría, J., Fernández, D., Merino, L., Montero, E., \& Ribas, J. (2018). Association between internet gaming disorder or pathological video-game use and comorbid psychopathology: a comprehensive review. International journal of environmental research and public health, 15, 668-687.

Graham, L. T. \& Gosling, S. D. (2013). Personality profiles associated with different motivations for playing world of warcraft. Cyberpsychology, Behavior, and Social Networking, 16, 189-193.

Gray, J. A. (1991). The neuropsychology of Temperament. In J. Strelau y A. Angleitmer (Ed.), Explorations in temperament (pp. 105-128). Nueva York: Plenum Press.

Gray, J. A., y McNaughton, N. (2000). The neuropsychology of anxiety. Oxford, England: Oxford University Press.

Greenberg, B. S., Sherry, J., Lachlan, K., Lucas, K., \& Holmstrom, A. (2010). Orientations to Video Games Among Gender and Age Groups. Simulation \& Gaming, 41, 238-259.

Greitemeyer, T., \& Mügge, D. O. (2014). Video games do affect social outcomes: A meta-analytic review of the effects of violent and prosocial video game play. Personality and social psychology bulletin, 40, 578-589. 
Greitemeyer, T., \& Sagioglou, C. (2017). The longitudinal relationship between everyday sadism and the amount of violent video game play. Personality and individual differences, 104, 238-242.

Griffiths, M. D. (2005). A ‘components' model of addiction within a biopsychosocial framework. Journal of Substance Use, 10, 191-197.

Griffiths, M. D., Van Rooij, A. J., Kardefelt-Winther, D., Starcevic, V., Király, O., Pallesen, S., ... \& King, D. L. (2016). Working towards an international consensus on criteria for assessing internet gaming disorder: a critical commentary on Petry et al.(2014). Addiction, 111, 167-175.

Griffiths, M., J Kuss \& L King. (2012). Video game addiction: Past, present and future. Current Psychiatry Reviews, 8, 308-318.

Haagsma, M. C., Caplan, S. E., Peters, O., \& Pieterse, M. E. (2013). A cognitivebehavioral model of problematic online gaming in adolescents aged 12-22 years. Computers in human behavior, 29, 202-209.

Hagström, D., \& Kaldo, V. (2014). Escapism among players of MMORPGs-conceptual clarification, its relation to mental health factors, and development of a new measure. Cyberpsychology, Behavior, and Social Networking, 17, 19-25.

Håkansson, A., Kenttä, G., \& Åkesdotter, C. (2018). Problem gambling and gaming in elite athletes. Addictive behaviors reports, 8, 79-84.

Hamutoğlu, N. B., Topal, M., Samur, Y., Gezgin, D. M., \& Griffiths, M. D. (2020). The Development of the Online Player Type Scale: Construct Validity and Reliability Testing. International Journal of Cyber Behavior, Psychology and Learning (IJCBPL), 10, 15-31.

Han, D. H., Lee, Y. S., Yang, K. C., Kim, E. Y., Lyoo, I. K. \& Renshaw, P. F. (2007). Dopamine genes and reward dependence in adolescents with excessive internet video game play. Journal of Addiction Medicine, 1, 133-138.

Hilgard, J., Engelhardt, C. R., \& Bartholow, B. D. (2013). Individual differences in motives, preferences, and pathology in video games: the gaming attitudes, motives, and experiences scales (GAMES). Frontiers in Psychology, 4, 608-620.

Hull, D. C., Williams, G. A., \& Griffiths, M. D. (2013). Video game characteristics, happiness and flow as predictors of addiction among video game players: A pilot study. Journal of behavioral addictions, 2, 145-152. 
Hull, J. G., Brunelle, T. J., Prescott, A. T., \& Sargent, J. D. (2014). A longitudinal study of risk-glorifying video games and behavioral deviance. Journal of personality and social psychology, 107, 300-325.

Hull, J. G., Draghici, A. M., \& Sargent, J. D. (2012). A longitudinal study of riskglorifying video games and reckless driving. Psychology of Popular Media Culture, $1,244-253$.

Hussain, Z., Williams, G. A., \& Griffiths, M. D. (2015). An exploratory study of the association between online gaming addiction and enjoyment motivations for playing massively multiplayer online role-playing games.Computers in Human Behavior, 50, 221-230.

Jeng, S.P. \& Teng, C.I. (2008). Personality and motivations for playing online games. Social Behavior and Personality, 38: 1053-1060.

Jeong, E. J., Lee, H. R., \& Yoo, J. H. (2015). Addictive use due to personality: focused on big five personality traits and game addiction. International Journal of Social, Behavioral, Educational, Economic, Business and Industrial Engineering, 9, 19951999.

Jiménez-Murcia, S., Fernández-Aranda, F., Granero, R., Chóliz, M., La Verde, M., Aguglia, E., ... \& del Pino-Gutiérrez, A. (2014). Video game addiction in gambling disorder: clinical, psychopathological, and personality correlates. BioMed research international, 2014.

John, O. P., Naumann, L. P., \& Soto, C. J. (2008). Paradigm shift to the integrative big five trait taxonomy. Handbook of personality: Theory and research, 3, 114-158.

Jones, S. E., Miller, J. D., \& Lynam, D. R. (2011). Personality, antisocial behavior, and aggression: A meta-analytic review. Journal of Criminal Justice, 39, 329-337.

Kahn, A. S., Shen, C., Lu, L., Ratan, R. A., Coary, S., Hou, J., ... Williams, D. (2015). The Trojan Player Typology: A cross-genre, cross-cultural, behaviorally validated scale of video game play motivations. Computers in Human Behavior, 49, 354-361.

Kardefelt-Winther, D. (2014a). Problematizing excessive online gaming and its psychological predictors. Computers in Human Behavior, 31, 118-122.

Kardefelt-Winther, D. (2014b). The moderating role of psychosocial well-being on the relationship between escapism and excessive online gaming. Computers in Human Behaviors, 38, 68-74.

Kardefelt-Winther, D. (2015). A critical account of DSM-5 criteria for internet gaming disorder. Addiction Research \& Theory, 23, 93-98. 
Kardefelt-Winther, D., Heeren, A., Schimmenti, A., van Rooij, A., Maurage, P., Carras, M., ... \& Billieux, J. (2017). How can we conceptualize behavioural addiction without pathologizing common behaviours?. Addiction, 112, 1709-1715.

Kim, N. R., Hwang, S. S. H., Choi, J. S., Kim, D. J., Demetrovics, Z., Király, O., ... \& Choi, S. W. (2016). Characteristics and psychiatric symptoms of internet gaming disorder among adults using self-reported DSM-5 criteria. Psychiatry investigation, $13,58-66$.

Kim, S. H., Baik, S. H., Park, C. S., Kim, S. J., Choi, S. W., \& Kim, S. E. (2011). Reduced striatal dopamine D2 receptors in people with Internet addiction. Neuroreport, 22, 407-411.

Kim, Y., \& Ross, S. D. (2006). An exploration of motives in sport video gaming. International Journal of Sports Marketing and Sponsorship, 8, 28-40.

King, D. L., \& Delfabbro, P. H. (2014). The cognitive psychology of Internet gaming disorder. Clinical psychology review, 34, 298-308.

King, D. L., Delfabbro, P. H., Doh, Y. Y., Wu, A. M., Kuss, D. J., Pallesen, S., ... \& Sakuma, H. (2017). Policy and prevention approaches for disordered and hazardous gaming and Internet use: An international perspective. Prevention Science, 1-17.

King, D. L., Gainsbury, S. M., Delfabbro, P. H., Hing, N., \& Abarbanel, B. (2015). Distinguishing between gaming and gambling activities in addiction research. Journal of Behavioral Addictions, 4, 215-220.

King, D. L., Herd, M. C., \& Delfabbro, P. H. (2018). Motivational components of tolerance in Internet gaming disorder. Computers in Human Behavior, 78, 133-141.

King, D., Delfabbro, P., \& Griffiths, M. (2010). Video Game Structural Characteristics:

A New Psychological Taxonomy. International Journal of Mental Health and Addiction, 8, 90-106.

Király, O., Griffiths, M. D., \& Demetrovics, Z. (2015a). Internet Gaming Disorder and the DSM-5: Conceptualization, debates, and controversies. Current Addiction Reports, 2, 254-262.

Király, O., Griffiths, M. D., King, D. L., Lee, H. K., Lee, S. Y., Banyai, F., ... \& Demetrovics, Z. (2017c). Policy responses to problematic video game use: A systematic review of current measures and future possibilities. Journal of Behavioral Addictions, 7, 503-517.

Király, O., Sleczka, P., Pontes, H. M., Urbán, R., Griffiths, M. D., \& Demetrovics, Z. (2017b). Validation of the ten-item internet gaming disorder test (IGDT-10) and 
evaluation of the nine DSM-5 internet gaming disorder criteria. Addictive Behaviors, 64, 253-260.

Király, O., Tóth, D., Urbán, R., Demetrovics, Z., \& Maraz, A. (2017a). Intense video gaming is not essentially problematic. Psychology of Addictive Behaviors, 31, 807817.

Király, O., Urbán, R., Griffiths, M. D., Ágoston, C., Nagygyörgy, K., Kökönyei, G., \& Demetrovics, Z. (2015b). The mediating effect of gaming motivation between psychiatric symptoms and problematic online gaming: an online survey. Journal of Medical Internet Research, 17, e88.

Kirby, A., Jones, C., \& Copello, A. (2014). The impact of Massively Multiplayer Online Role Playing Games (MMORPGs) on psychological wellbeing and the role of motivations and problematic use. International Journal of Mental Health and Addiction, 12, 36-51.

Kircaburun, K., Demetrovics, Z., Griffiths, M., Király, O., Kun, B., \& Tosuntaş, Ş. B. (in press). Trait emotional intelligence and internet gaming disorder among gamers: The mediating role of online gaming motives and moderating role of age groups. International Journal of Mental Health and Addiction.

Kircaburun, K., Griffiths, M. D., \& Billieux, J. (2019). Trait emotional intelligence and problematic online behaviors among adolescents: The mediating role of mindfulness, rumination, and depression. Personality and Individual Differences, 139, 208-213.

Kircaburun, K., Jonason, P. K., \& Griffiths, M. D. (2018). The Dark Tetrad traits and problematic online gaming: The mediating role of online gaming motives and moderating role of game types. Personality and Individual Differences, 135, 298303.

Klimmt, C., \& Hartmann, T. (2006). Effectance, self-efficacy, and the motivation to play video games. Playing video games: Motives, responses, and consequences, 133-145.

Kneer, J. \& Glock, S. (2013). Escaping in digital games: The relationship between playing motives and addictive tendencies in males. Computers in Human Behavior, 29, $1415-1420$.

Ko, C. H., Yen, J. Y., Chen, S. H., Wang, P. W., Chen, C. S., \& Yen, C. F. (2014). Evaluation of the diagnostic criteria of Internet gaming disorder in the DSM-5 among young adults in Taiwan. Journal of psychiatric research, 53, 103-110. 
Koepp, M.J.; Gunn, R.N.; Lawrence, A.D.; Cunningham, V.J.; Dagher, A.; Jones, T.; Brooks, D.J.; Bench, C.J.; Grasby, P.M. (1998). Evidence for striatal dopamine release during a videogame. Nature, 393, 266-268.

Koo, H. J., Han, D. H., Park, S. Y., \& Kwon, J. H. (2017). The structured clinical interview for DSM-5 Internet gaming disorder: development and validation for diagnosing IGD in adolescents. Psychiatry investigation, 14, 21-29.

Kotyuk, E., Farkas, J., Magi, A., Eisinger, A., Király, O., Vereczkei, A., ... \& SasváriSzékely, M. (2018). The psychological and genetic factors of the addictive behaviors (PGA) study. International journal of methods in psychiatric research, e1748.

Kuss DJ, Louws J, Wiers RW (2012) Online gaming addiction? Motives predict addictive play behavior in massively multiplayer online role-playing games. Cyberpsychol Behav Soc Netw, 15, 480-485.

Kuss, D. J., \& Griffiths, M. D. (2012a). Internet and Gaming Addiction: A Systematic Literature Review of Neuroimaging Studies. Brain Sciences, 2, 347-374.

Kuss, D. J., \& Griffiths, M. D. (2012b). Internet gaming addiction: A systematic review of empirical research. International Journal of Mental Health and Addiction, 10, 278-296.

Kuss, D. J., Griffiths, M. D., \& Pontes, H. M. (2017). Chaos and confusion in DSM-5 diagnosis of Internet Gaming Disorder: Issues, concerns, and recommendations for clarity in the field. Journal of Behavioral Addictions, 6, 103-109.

Kuss, D. J., Pontes, H. M., \& Griffiths, M. D. (2018). Neurobiological correlates in Internet Gaming Disorder: A systematic literature review. Frontiers in psychiatry, 9, 166-177.

Laconi, S., Pirès, S., \& Chabrol, H. (2017). Internet gaming disorder, motives, game genres and psychopathology. Computers in Human Behavior, 75, 652-659.

Lafreniere, M. A. K., Vallerand, R. J., Donahue, E. G., \& Lavigne, G. L. (2009). On the costs and benefits of gaming: The role of passion. CyberPsychology \& Behavior, 12, 285-290.

Lafrenière, M. A. K., Verner-Filion, J., \& Vallerand, R. J. (2012). Development and validation of the Gaming Motivation Scale (GAMS). Personality and individual differences, 53, 827-831. 
Larche, C. J., Musielak, N., \& Dixon, M. J. (2017). The Candy Crush Sweet Tooth: How 'near-misses' in Candy Crush increase frustration, and the urge to continue gameplay. Journal of gambling studies, 33, 599-615.

Lee, D., \& LaRose, R. (2007). A socio-cognitive model of video game usage. Journal of Broadcasting \& Electronic Media, 51, 632-650.

Lehenbauer-Baum, M., \& Fohringer, M. (2015). Towards classification criteria for internet gaming disorder: Debunking differences between addiction and high engagement in a German sample of World of Warcraft players. Computers in Human Behavior, 45, 345-351.

Lehenbauer-Baum, M., Klaps, A., Kovacovsky, Z., Witzmann, K., Zahlbruckner, R., \& Stelina, B. U. (2015). Addiction and engagement: an explorative study toward classification criteria for internet gaming disorder. Cyberpsychology, Behavior, and Social Networking, 18, 343-349.

Lemmens, J. S., \& Hendriks, S. J. (2016). Addictive online games: Examining the relationship between game genres and internet gaming disorder. Cyberpsychology, Behavior, and Social Networking, 19, 270-276.

Lemmens, J. S., Valkenburg, P. M. \& Peter, J. (2011a). Psychosocial causes and consequences of pathological gaming. Computers in Human Behavior, 27, 144152.

Lemmens, J. S., Valkenburg, P. M., \& Gentile, D. A. (2015). The Internet gaming disorder scale. Psychological assessment, 27, 567-582.

Lemmens, J. S., Valkenburg, P. M., \& Peter, J. (2011b). The effects of pathological gaming on aggressive behavior. Journal of Youth and Adolescence, 40, 38-47.

Li, D. D., Liau, A. K., Gentile, D. A., Khoo, A., \& Cheong, W. D. (2013). Construct and predictive validity of a brief MMO player motivation scale: Cross-sectional and longitudinal evidence based on Singaporean young gamers. Journal of Children and Media, 7, 287-306.

Liew, L. W., Stavropoulos, V., Adams, B. L., Burleigh, T. L., \& Griffiths, M. D. (2018). Internet Gaming Disorder: the interplay between physical activity and user-avatar relationship. Behaviour \& Information Technology, 1-17.

Lim, J. A., Lee, J. Y., Jung, H. Y., Sohn, B. K., Choi, S. W., Kim, Y. J., ... \& Choi, J. S. (2016). Changes of quality of life and cognitive function in individuals with Internet gaming disorder: A 6-month follow-up. Medicine, 95. 
López Fernández, F., \& Avila, C. (2017). La conectividad funcional entre el estriado derecho e izquierdo en estado de reposo se asocia a sensibilidad a la recompensa. Àgora de Salut, 4, 207-2014.

Lopez-Fernandez, O., Honrubia-Serrano, M. L., Baguley, T., \& Griffiths, M. D. (2014). Pathological video game playing in Spanish and British adolescents: Towards the exploration of Internet Gaming Disorder symptomatology. Computers in Human Behavior, 41, 304-312.

Loton, D., Borkoles, E., Lubman, D., \& Polman, R. (2016). Video game addiction, engagement and symptoms of stress, depression and anxiety: The mediating role of coping. International Journal of Mental Health and Addiction, 14, 565-578.

Männikkö, N., Billieux, J., Nordström, T., Koivisto, K., \& Kääriäinen, M. (2017). Problematic Gaming Behaviour in Finnish Adolescents and Young Adults: Relation to Game Genres, Gaming Motives and Self-Awareness of Problematic Use. International Journal of Mental Health and Addiction, 15, 324-338.

Markey, P. M. (2015). Finding the middle ground in violent video game research: Lessons from Ferguson (2015). Perspectives on psychological science, 10, 667-670.

Markey, P. M., \& Markey, C. N. (2010). Vulnerability to violent video games: A review and integration of personality research. Review of General Psychology, 14, 82-91.

Markey, P. M., \& Scherer, K. (2009). An examination of psychoticism and motion capture controls as moderators of the effects of violent video games. Computers in Human Behavior, 25, 407-411.

Markon, K. E., Krueger, R. F., \& Watson, D. (2005). Delineating the structure of normal and abnormal personality: an integrative hierarchical approach. Journal of personality and social psychology, 88, 139-157.

McCrae, R. R., and Costa, P. T. (2008). Empirical and theoretical status of the five-factor model of personality traits. In: G. J. Boyle, G.Matthews, \& D. H. Sakloske (eds.). Personality theory and assessment. Personality theories and models, Vol. 1, (pp. 273-294). London: Sage.

McGrath, D. S., Neilson, T., Lee, K., Rash, C. L., \& Rad, M. (2018). Associations between the HEXACO model of personality and gambling involvement, motivations to gamble, and gambling severity in young adult gamblers. Journal of behavioral addictions, 7, 392-400. 
Meng, Y., Deng, W., Wang, H., Guo, W., \& Li, T. (2015). The prefrontal dysfunction in individuals with Internet gaming disorder: a meta-analysis of functional magnetic resonance imaging studies. Addiction biology, 20, 799-808.

Metcalf, O., \& Pammer, K. (2011). Attentional bias in excessive massively multiplayer online role-playing gamers using a modified Stroop task. Computers in Human Behavior, 27, 1942-1947.

Mezquita Guilamón, L. (2011). El papel del maltrato, la personalidad y los motivos en el consumo de alcohol: un estudio prospectivo de cinco años en adultos jóvenes. Universitat Jaume I.

Mihara, S., \& Higuchi, S. (2017). Cross-sectional and longitudinal epidemiological studies of I nternet gaming disorder: A systematic review of the literature. Psychiatry and clinical neurosciences, 71, 425-444.

Montag, C., Flierl, M., Markett, S., Walter, N., Jurkiewicz, M., \& Reuter, M. (2011). Internet addiction and personality in first-person-shooter video gamers. Journal of Media Psychology: Theories, Methods, and Applications, 23, 163-173.

Montag, C., Schivinski, B., Sariyska, R., Kannen, C., Demetrovics, Z., \& Pontes, H. M. (2019). Psychopathological Symptoms and Gaming Motives in Disordered Gaming-A Psychometric Comparison between the WHO and APA Diagnostic Frameworks. Journal of Clinical Medicine, 8, 1691-1708.

Mößle, T., \& Rehbein, F. (2013). Predictors of problematic video game usage in childhood and adolescence. Sucht, 59, 153-164.

Moudiab, S., \& Spada, M. M. (2019). The relative contribution of motives and maladaptive cognitions to levels of Internet Gaming Disorder. Addictive behaviors reports, 9, 100160.

Müller, K. W., Beutel, M. E., Egloff, B., \& Wölfling, K. (2014). Investigating risk factors for Internet Gaming Disorder: A comparison of patients with addictive gaming, pathological gamblers and healthy controls regarding the Big Five personality traits. European Addiction Research, 20, 129-136.

Müller, K. W., Janikian, M., Dreier, M., Wölfling, K., Beutel, M. E., Tzavara, C., Richardson, C., \& Tsitsika, A. (2015). Regular gaming behavior and internet gaming disorder in European adolescents: results from a cross-national representative survey of prevalence, predictors, and psychopathological correlates. European Child \& Adolescent Psychiatry, 24, 565-574. 
Na, E., Lee, H., Choi, I., \& Kim, D. J. (2017). Comorbidity of Internet gaming disorder and alcohol use disorder: A focus on clinical characteristics and gaming patterns. The American journal on addictions, 26, 326-334.

Nacke, L. E., Bateman, C., \& Mandryk, R. L. (2014). BrainHex: A neurobiological gamer typology survey. Entertainment computing, 5, 55-62.

Nije Bijvank, M., Konijn, E. A., \& Bushman, B. J. (2012). "We don’t need no education": Video game preferences, video game motivations, and aggressiveness among adolescent boys of different educational ability levels. Journal of Adolescence, 35, 153-162.

Nuyens, F., Kuss, D. J., Lopez-Fernandez, O., \& Griffiths, M. D. (2017). The experimental analysis of problematic video gaming and cognitive skills: A systematic review. Journal de Thérapie Comportementale et Cognitive, 27, 110117.

Olson, C. K. (2010). Children's Motivations for Video Game Play in the Context of Normal Development. Review of General Psychology, 14, 180-187.

Park, J., Song, Y. \& Teng, C.I. (2011). Exploring the links between personality traits and motivations to play online games. Cyberpsychology, Behavior, and Social Networks, 14: 747-751.

Paulus, F. W., Ohmann, S., von Gontard, A., \& Popow, C. (2018). Internet gaming disorder in children and adolescents: a systematic review. Developmental Medicine and Child Neurology, 60, 645-659.

Pearcy, B. T. D., McEvoy, P. M., \& Roberts, L. D. (2017). Internet gaming disorder explains unique variance in psychological distress and disability after controlling for comorbid depression, OCD, ADHD, and anxiety. Cyberpsychology, Behavior, and Social Networking, 20, 126-132.

Peeters, M., Koning, I., \& van den Eijnden, R. (2018). Predicting Internet Gaming Disorder symptoms in young adolescents: A one-year follow-up study. Computers in Human Behavior, 80, 255-261.

Peters, C. S., \& Malesky, L. A. (2008). Problematic usage among highly-engaged players of massively multiplayer online role playing games. CyberPsychology \& Behavior, $11,481-484$.

Petry, N. M., Rehbein, F., Ko, C. H., \& O’Brien, C. P. (2015). Internet gaming disorder in the DSM-5. Current psychiatry reports, 17, 72-80. 
Petry, N. M., Zajac, K., \& Ginley, M. K. (2018). Behavioral addictions as mental disorders: To be or not to be?. Annual review of clinical psychology, 14, 399-423.

Plante, C. N., Gentile, D. A., Groves, C. L., Modlin, A., \& Blanco-Herrera, J. (2019). Video games as coping mechanisms in the etiology of video game addiction. Psychology of Popular Media Culture, 8, 385-394.

Plomin, R., DeFries, J. C., Knopik, V. S., \& Neiderhiser, J. M. (2013). Behavioral Genetics. 6h Edition edn.

Pontes, H. M. (2017). Investigating the differential effects of social networking site addiction and Internet gaming disorder on psychological health. Journal of behavioral addictions, 6, 601-610.

Pontes, H. M., Kiraly, O., Demetrovics, Z., \& Griffiths, M. D. (2014). The conceptualisation and measurement of DSM-5 Internet Gaming Disorder: The development of the IGD-20 Test. PloS one, 9, e110137.

Pontes, H. M., Schivinski, B., Sindermann, C., Li, M., Becker, B., Zhou, M., \& Montag, C. (2019). Measurement and conceptualization of Gaming Disorder according to the World Health Organization framework: The development of the Gaming Disorder Test. International Journal of Mental Health and Addiction, 1-21.

Potard, C., Henry, A., Boudoukha, A.-H., Courtois, R., Laurent, A., \& Lignier, B. (2019). Video game players' personality traits: An exploratory cluster approach to identifying gaming preferences. Psychology of Popular Media Culture. Advance online publication. https://doi.org/10.1037/ppm0000245

Porter, G., Starcevic, V., Berle, D., \& Fenech, P. (2010). Recognizing problem video game use. Australian and New Zealand Journal of Psychiatry, 44, 120-128.

Prescott, A. T., Sargent, J. D., \& Hull, J. G. (2018). Metaanalysis of the relationship between violent video game play and physical aggression over time. Proceedings of the National Academy of Sciences, 115, 9882-9888.

Puerta-Cortés, D. X., Panova, T., Carbonell, X., \& Chamarro, A. (2017). How passion and impulsivity influence a player's choice of videogame, intensity of playing and time spent playing. Computers in Human Behavior, 66, 122-128.

Rehbein, F., \& Baier, D. (2013). Family-, Media-, and School-Related Risk Factors of Video Game Addiction. Journal of Media Psychology, 25, 118-128.

Rehbein, F., Kleimann, M. \& Mößle, T. (2010). Prevalence and risk factors of video game dependency in adolescence: Results of a German nationwide survey. CyberPsychology, Behavior and Social Networking, 13, 269-277. 
Rehbein, F., Kliem, S., Baier, D., Mößle, T., \& Petry, N. M. (2015). Prevalence of internet gaming disorder in German adolescents: Diagnostic contribution of the nine DSM5 criteria in a state-wide representative sample. Addiction, 110, 842-851.

Rodríguez de Sepúlveda, D. e Igartua, J. J. (2011). Creación y validación de una escala de motivos para videojugar. En F. Ortega y L. Cardeñosa (Eds.), Nuevos medios, nueva comunicación (pp. 217-234). Salamanca: II Congreso Internacional Comunicación 3.0.

Ryan, R. M., Rigby, C. S., \& Przybylski, A. (2006). The motivational pull of video games: A self-determination theory approach. Motivation and emotion, 30, 344-360.

Şalvarlı, Ş. İ., \& Griffiths, M. D. (2019). Internet Gaming Disorder and Its Associated Personality Traits: A Systematic Review Using PRISMA Guidelines. International Journal of Mental Health and Addiction, 1-23.

Scharkow, M., Festl, R., \& Quandt, T. (2014). Longitudinal patterns of problematic computer game use among adolescents and adults - a 2-year panel study. Addiction, 109, 1910-1917.

Scharkow, M., Festl, R., Vogelgesang, J., \& Quandt, T. (2015). Beyond the "coregamer": Genre preferences and gratifications in computer games. Computers in Human Behavior, 44, 293-298.

Schmidt, J.-H., Drosselmeier, M., Rohde, W., \& Fritz, J. (2011). Problematische Nutzung und Abh_ngigkeit von Computerspielen [Problematic use and addiction of video games]. In J. Fritz, C. Lampert, J.-H. Schmidt, \& T. Witting (Eds.), Kompetenzen und exzessive Nutzung bei Computerspielern: Gefordert, gefçrdert, gef_hrdet (61st ed., pp. 201-252). Berlin: Vistas Verlag.

Shceck, K., Lee, D. Y., \& Pyo, K. B. (2015). The relationship between the Five Factor Personality Model and motivations for play in MMORPGs. Indian Journal of Science and Technology, $8,1$.

Sher, K. J., Grekin, E. R., \& Williams, N. A. (2005). The development of alcohol use disorders. Annu. Rev. Clin. Psychol., 1, 493-523.

Sherry, J. L. (2001). The effects of violent video games on aggression: A meta-analysis. Human communication research, 27, 409-431.

Sherry, J. L., Lucas, K., Greenberg, B. S., \& Lachlan, K. (2006). Video game uses and gratifications as predictors of use and game preference. Playing video games: Motives, responses, and consequences, 24, 213-224. 
Skoric, M. M., Teo, L. L. C., \& Neo, R. L. (2009). Children and video games: addiction, engagement, and scholastic achievement. Cyberpsychology \& behavior, 12, 567572.

Smahel, D., li, O. (2008). Playing MMORPGs: connections between addiction and identifying with a character. Cyberpsychology \& Behavior, 11, 715-718.

Smillie, L. D., Pickering, A. D., \& Jackson, C. J. (2006). The new reinforcement sensitivity theory: Implications for personality measurement. Personality and Social Psychology Review, 10, 320-335.

Starcevic, V., \& Khazaal, Y. (2017). Relationships between behavioural addictions and psychiatric disorders: What is known and what is yet to be learned?. Frontiers in psychiatry, 8, 53-59.

Steadman, J. L. (2019). Gaming Motivations as a Guide to Treating Problematic Gaming Behaviors. Journal of Technology in Behavioral Science, 1-8.

Stevens, M. W., King, D. L., Dorstyn, D., \& Delfabbro, P. H. (2019). Cognitivebehavioral therapy for Internet gaming disorder: A systematic review and metaanalysis. Clinical psychology \& psychotherapy, 26, 191-203.

Subramaniam, M., Chua, B. Y., Abdin, E., Pang, S., Satghare, P., Vaingankar, J. A., ... \& Chong, S. A. (2016). Prevalence and Correlates of Internet Gaming Problem among Internet Users: Results from an Internet Survey. Ann Acad Med Singapore, 45, 17483.

Sussman, S.; Leventhal, A.; Bluthenthal, R.N.; Freimuth, M.; Forster, M.; Ames, S.L. (2011). A Framework for the Specificity of Addictions. Int. J. Environ. Res. Public Health, 8, 3399-3415.

Thompson, E. L., Mehari, K. R., \& Farrell, A. D. (2020). Deviant peer factors during early adolescence: cause or consequence of physical aggression?. Child development, 91, e415-e431.

Tondello, G. F., Wehbe, R. R., Diamond, L., Busch, M., Marczewski, A., \& Nacke, L. E. (2016, October). The gamification user types hexad scale. In Proceedings of the 2016 annual symposium on computer-human interaction in play (pp. 229-243). ACM.

Teng, Z., Griffiths, M.D., Nie1, Q., Xiang, G. \& Guo, C (2020). Parent-adolescent attachment and peer attachment associated with Internet Gaming Disorder: A longitudinal study of first-year undergraduate students. Journal of Behavioral Addictions, Advance online publication. doi: 10.1556/2006.2020.00011. 
Teng, C. T. (2008). Personality differences between online game players and nonplayers in a student sample. CyberPsychology \& Behavior, 11, 232-234.

Tremblay, R. E., Vitaro, F., \& Côté, S. M. (2018). Developmental origins of chronic physical aggression: A bio-psycho-social model for the next generation of preventive interventions. Annual review of psychology, 69, 383-407.

Valkenburg, P. M., \& Peter, J. (2013). The differential susceptibility to media effects model. Journal of Communication, 63, 221-243.

Vallerand, R. J., Salvy, S. J., Mageau, G. A., Elliot, A. J., Denis, P. L., Grouzet, F. M., \& Blanchard, C. (2007). On the role of passion in performance. Journal of personality, $75,505-534$.

van Rooij, A. J., Kuss, D. J., Griffiths, M. D., Shorter, G. W., Schoenmakers, T. M., \& van de Mheen, D. (2014). The (co-)occurrence of problematic video gaming, substance use, and psychosocial problems in adolescents. Journal of Behavioral Addictions, 3, 157-165.

Vink, J. M., van Beijsterveldt, T. C. E. M., Huppertz, C., Bartels, M., \& Boomsma, D. I. (2016). Heritability of compulsive Internet use in adolescents. Addiction Biology, $21,460-468$.

Vollmer, C., Randler, C., Horzum, M. B. \& Ayas, T. (2014). Computer game addiction in adolescents and its relationship to chronotype and personality. SAGE Open, 4, 19.

Wallenius, M., Rimpelä, A., Punamäki, R. L., \& Lintonen, T. (2009). Digital game playing motives among adolescents: Relations to parent-child communication, school performance, sleeping habits, and perceived health. Journal of applied developmental psychology, 30, 463-474.

Walther, B., Morgenstern, M., \& Hanewinkel, R. (2012). Co-occurrence of addictive behaviours: personality factors related to substance use, gambling and computer gaming. European addiction research, 18, 167-174.

Wan, C. S., \& Chiou, W. B. (2006). Psychological motives and online games addiction: Atest of flow theory and humanistic needs theory for taiwanese adolescents. CyberPsychology \& Behavior, 9, 317-324.

Wang, C. C., \& Chu, Y. S. (2007). Harmonious passion and obsessive passion in playing online games. Social Behavior and Personality: an international journal, 35, $997-$ 1006. 
Wang, C. W., Ho, R. T., Chan, C. L., \& Tse, S. (2015). Exploring personality characteristics of Chinese adolescents with internet-related addictive behaviors: trait differences for gaming addiction and social network addiction. Addictive behaviors, 42, 32-35.

Wartberg, L., Kriston, L., \& Thomasius, R. (2020). Internet gaming disorder and problematic social media use in a representative sample of German adolescents: Prevalence estimates, comorbid depressive symptoms and related psychosocial aspects. Computers in Human Behavior, 103, 31-36.

Wartberg, L., Kriston, L., Kramer, M., Schwedler, A., Lincoln, T. M., \& Kammerl, R. (2017). Internet gaming disorder in early adolescence: Associations with parental and adolescent mental health. European Psychiatry, 43, 14-18.

Wartberg, L., Kriston, L., Zieglmeier, M., Lincoln, T., \& Kammerl, R. (2019). A longitudinal study on psychosocial causes and consequences of Internet gaming disorder in adolescence. Psychological medicine, 49, 287-294.

Weinstein, A., \& Lejoyeux, M. (2015). New developments on the neurobiological and pharmaco-genetic mechanisms underlying internet and videogame addiction. The American Journal on Addictions, 24, 117-125.

Weinstein, A., Livny, A., \& Weizman, A. (2017). New developments in brain research of internet and gaming disorder. Neuroscience \& Biobehavioral Reviews, 75, 314330.

Westwood, D., \& Griffiths, M. D. (2010). The role of structural characteristics in videogame play motivation: A Q-methodology study. Cyberpsychology, Behavior, and Social Networking, 13, 581-585.

Wichstrøm, L., Stenseng, F., Belsky, J., von Soest, T., \& Hygen, B. W. (2019). Symptoms of Internet gaming disorder in youth: Predictors and comorbidity. Journal of abnormal child psychology, 47, 71-83.

Williams, D., Yee, N., \& Caplan, S. E. (2008). Who plays, how much, and why? Debunking the stereotypical gamer profile. Journal of Computer-Mediated Communication, 13, 993-1018.

Witt, E. A., Massman, A. J., \& Jackson, L. A. (2010). Trends in youth's videogame playing, overall computer use, and communication technology use: the impact of self-esteem and personality factores. Computers in Human Behavior, 27, 763-769. 
Wittek, C. T., Finserås, T. R., Pallesen, S., Mentzoni, R. A., Hanss, D., Griffiths, M. D., \& Molde, H. (2016). Prevalence and predictors of video game addiction: A study based on a national representative sample of gamers. International Journal of Mental Health and Addiction, 14, 672-686.

Wood, R. T. A., Griffiths, M. D., Chappell, D., \& Davies, M. N. O. (2004b). The structural characteristics of video games: A psycho-structural analysis. CyberPsychology \& Behavior, 7, 1-10.

Wood, R. T., Gupta, R., Derevensky, J. L., \& Griffiths, M. (2004a). Video game playing and gambling in adolescents: Common risk factors. Journal of Child \& Adolescent Substance Abuse, 14, 77-100.

World Health Organization (WHO) (2017). ICD-11 Beta Draft. Mental, behavioural or neurodevelopmental disorders. Retrieved July 14, 2017, from https://icd.who.int/dev11/1-m/en.

Worth, N. C., \& Book, A. S. (2014). Personality and behavior in a massively multiplayer online role-playing game. Computers in Human Behavior, 38, 322-330.

Worth, N. C., \& Book, A. S. (2015). Dimensions of video game behavior and their relationships with personality. Computers in Human Behavior, 50, 132-140.

Wu, A. M., Chen, J. H., Tong, K. K., Yu, S., \& Lau, J. T. (2018). Prevalence and associated factors of Internet gaming disorder among community dwelling adults in Macao, China. Journal of behavioral addictions, 7, 62-69.

Wu, A. M., Lai, M. H., Yu, S., Lau, J. T., \& Lei, M. W. (2016). Motives for online gaming questionnaire: Its psychometric properties and correlation with Internet gaming disorder symptoms among Chinese people. Journal of behavioral addictions, 6, 1120.

Wu, J. H., Wang, S. C., \& Tsai, H. H. (2010). Falling in love with online games: The uses and gratifications perspective. Computers in Human Behavior, 26, 1862-1871.

Xuan, Y. H., Li, S., Tao, R., Chen, J., Rao, L. L., Wang, X. T., \& Zheng, R. (2017). Genetic and Environmental Influences on Gambling: A Meta-Analysis of Twin Studies. Frontiers in psychology, 8, 2121.

Yee, N. (2006a). Motivations for play in online games. Cyberpsychology and Behavior, 9, 772-775.

Yee, N. (2006b). The demographics, motivations, and derived experiences of users of massively multi-user online graphical environments. Presence: Teleoperators and virtual environments, 15, 309-329. 
Yee, N., Ducheneaut, N., Nelson, L., \& Likarish, P. (2011, May). Introverted elves \& conscientious gnomes: the expression of personality in world of warcraft. In Proceedings of the SIGCHI Conference on Human Factors in Computing Systems (pp. 753-762). ACM.

Yee, N.; Ducheneaut, N.; Nelson, L (2012). Online gaming motivations scale: development and validation. Proceedings of the ACM International Conference on Human Factors in Computing Systems (CHI 2012), 2803-2806. NY: ACM.

Young, K. S., \& Brand, M. (2017). Merging theoretical models and therapy approaches in the context of Internet gaming disorder: a personal perspective. Frontiers in psychology, 8, 1853.

Zanetta DF, Zermatten A, Billieux J, Thorens G, Bondolfi G, Zullino D, Khazaal Y. (2011). Motivations to play specifically predict excessive involvement in massively multiplayer online role-playing games: evidence from an online survey. European Addiction Research,17,185-9.

Zeigler-Hill, V., \& Monica, S. (2015). The HEXACO model of personality and video game preferences. Entertainment Computing, 11, 21-26.

Zhou, X., Wu, R., Liu, C., Kou, J., Chen, Y., Pontes, H. M., ... \& Montag, C. (2019). Dimensional neuroimaging:(Internet) Gaming Disorder symptoms according to the WHO and APA frameworks associate with lower striatal volume. bioRxiv, 852855. 
ANNEXES 


\section{JS NEO-A60}

\section{INSTRUCCIONES}

Marca con una $\mathrm{X}$, la opción que más se ajuste a ti y a tu forma de comportarte. No existen respuestas buenas o malas. Para responder utiliza la siguiente tabla:

\begin{tabular}{|c|c|c|c|c|}
\hline 0 & 1 & 2 & 3 & 4 \\
\hline $\begin{array}{c}\text { En total } \\
\text { Desacuerdo }\end{array}$ & Desacuerdo & Neutro & De acuerdo & $\begin{array}{c}\text { Totalmente de } \\
\text { acuerdo }\end{array}$ \\
\hline
\end{tabular}

\begin{tabular}{|c|c|c|c|c|c|c|}
\hline 1. & A menudo me siento tenso/a e inquieto/a. & 0 & 1 & 2 & 3 & 4 \\
\hline 2. & Disfruto mucho hablando con la gente. & 0 & 1 & 2 & 3 & 4 \\
\hline 3. & Tengo mucha fantasía. & 0 & 1 & 2 & 3 & 4 \\
\hline 4. & Me vuelvo desconfiado/a cuando alguien es agradable conmigo. & 0 & 1 & 2 & 3 & 4 \\
\hline 5. & No me tomo muy en serio mis obligaciones en clase. & 0 & 1 & 2 & 3 & 4 \\
\hline 6. & $\begin{array}{l}\text { A veces me he sentido amargado/a, resentido/a y con ganas de tomarme la } \\
\text { revancha. }\end{array}$ & 0 & 1 & 2 & 3 & 4 \\
\hline 7. & Huyo de las multitudes. & 0 & 1 & 2 & 3 & 4 \\
\hline 8. & Tengo poco interés por el arte y la belleza artística. & 0 & 1 & 2 & 3 & 4 \\
\hline 9. & Si es necesario, estoy dispuesto a manipular a la gente para conseguir lo que quiero. & 0 & 1 & 2 & 3 & 4 \\
\hline 10. & Tengo mis cosas bien cuidadas y limpias. & 0 & 1 & 2 & 3 & 4 \\
\hline 11. & A veces las cosas me parecen demasiado tristes y sin esperanza. & 0 & 1 & 2 & 3 & 4 \\
\hline 12. & En las conversaciones tiendo a ser el/la que más habla. & 0 & 1 & 2 & 3 & 4 \\
\hline 13. & $\begin{array}{l}\text { Cosas raras o especiales (como ciertos olores o fotos de lugares lejanos) pueden } \\
\text { despertar en mí emociones intensas. }\end{array}$ & 0 & 1 & 2 & 3 & 4 \\
\hline 14. & Nunca hago nada si a cambio no recibo un beneficio. & 0 & 1 & 2 & 3 & 4 \\
\hline 15. & Trato de realizar a conciencia todas las cosas que se me encargan. & 0 & 1 & 2 & 3 & 4 \\
\hline 16. & Al tratar con los demás siempre temo meter la pata. & 0 & 1 & 2 & 3 & 4 \\
\hline 17. & Soy una persona muy activa. & 0 & 1 & 2 & 3 & 4 \\
\hline 18. & Disfruto resolviendo problemas o puzles. & 0 & 1 & 2 & 3 & 4 \\
\hline 19. & Puedo ser malo/a y duro/a con mis compañeros/as si es necesario. & 0 & 1 & 2 & 3 & 4 \\
\hline 20. & Hago todo lo que puedo para sacar las mejores notas. & 0 & 1 & 2 & 3 & 4 \\
\hline 21. & A veces hago las cosas sin pensar y luego me arrepiento. & 0 & 1 & 2 & 3 & 4 \\
\hline 22. & Me gusta estar donde está la acción. & 0 & 1 & 2 & 3 & 4 \\
\hline 23. & Si todos pensáramos de la misma forma, las cosas irían mejor. & 0 & 1 & 2 & 3 & 4 \\
\hline 24. & Soy mejor que la mayoría de la gente, y yo lo sé. & 0 & 1 & 2 & 3 & 4 \\
\hline 25. & Soy bastante bueno/a en organizarme para terminar las cosas a tiempo. & 0 & 1 & 2 & 3 & 4 \\
\hline 26. & Con frecuencia me siento indefenso/a y quiero que otro/a resuelva mis problemas. & 0 & 1 & 2 & 3 & 4 \\
\hline 27. & A veces reboso felicidad. & 0 & 1 & 2 & 3 & 4 \\
\hline 28. & Disfruto y paso muchos ratos dejando libre mi imaginación y fantasía. & 0 & 1 & 2 & 3 & 4 \\
\hline 29. & Creo que todos los seres humanos merecen respeto. & 0 & 1 & 2 & 3 & 4 \\
\hline 30. & Pienso muy bien las cosas antes de tomar una decisión. & 0 & 1 & 2 & 3 & 4 \\
\hline
\end{tabular}




\begin{tabular}{|c|c|c|c|c|}
\hline 0 & 1 & 2 & 3 & 4 \\
\hline $\begin{array}{c}\text { En total } \\
\text { Desacuerdo }\end{array}$ & Desacuerdo & Neutro & De acuerdo & $\begin{array}{c}\text { Totalmente de } \\
\text { acuerdo }\end{array}$ \\
\hline
\end{tabular}

\begin{tabular}{|c|c|c|c|c|c|c|}
\hline 31. & A veces me vienen a la cabeza pensamientos aterradores. & 0 & 1 & 2 & 3 & 4 \\
\hline 32. & Me siento muy unido/a a mis amigos/as. & 0 & 1 & 2 & 3 & 4 \\
\hline 33. & Me aburre ver ballet o danza moderna. & 0 & 1 & 2 & 3 & 4 \\
\hline 34. & $\begin{array}{l}\text { A veces consigo engah̆ar a mis compañeros/as o familiares para que hagan lo que yo } \\
\text { quiero. }\end{array}$ & 0 & 1 & 2 & 3 & 4 \\
\hline 35. & Muchas veces preparo con antelación lo que tengo que hacer. & 0 & 1 & 2 & 3 & 4 \\
\hline 36. & $\begin{array}{l}\text { Hasta las mínimas molestias me pueden resultar frustrantes (tremendamente } \\
\text { fastidiosas). }\end{array}$ & 0 & 1 & 2 & 3 & 4 \\
\hline 37. & Me gusta tener mucha gente alrededor. & 0 & 1 & 2 & 3 & 4 \\
\hline 38. & $\begin{array}{l}\text { A veces pierdo el interés cuando la gente habla de cuestiones muy complejas o } \\
\text { profundas. }\end{array}$ & 0 & 1 & 2 & 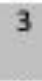 & \\
\hline
\end{tabular}

39. A veces hago cosas sin tener en cuenta a los demás (o sin importarme cómo afecta a $\quad \begin{array}{lllll}0 & 1 & 2 & 3 & 4\end{array}$ los demás) para obtener lo que quiero.

40. Parece que nunca soy capaz de organizarme. $\quad 0 \begin{array}{llll}2 & 3 & 4\end{array}$

41. Con demasiada frecuencia, cuando las cosas van mal, me siento desanimado/a y a $\quad \begin{array}{lllll}0 & 1 & 2 & 3 & 4\end{array}$ punto de tirar la toalla.

42. Soy una persona animada y con mucha vitalidad. $\quad 0 \quad 1 \quad 2 \quad 34$

43. Me gusta hacer puzles 0 juegos de los que me hacen estrujar el cerebro. $\quad \begin{array}{lllll}0 & 1 & 2 & 3 & 4\end{array}$

44. Soy una persona superior. $\quad \begin{array}{llllllll}0 & 1 & 2 & 3 & 4\end{array}$

45. Trato de hacer mis deberes o trabajos escolares con cuidado, para no tener que $\quad \begin{array}{lllllll}0 & 1 & 2 & 3 & 4\end{array}$ repetirlos.

46. En ocasiones he estado tan avergonzado/a que he querido esconderme. $\quad \begin{array}{lllll}0 & 1 & 2 & 3 & 4\end{array}$

47. Soy una persona alegre y animada. $\quad \begin{array}{llllll}0 & 1 & 2 & 3 & 4\end{array}$

48. Las formas y figuras que aparecen en el arte y en la naturaleza despiertan $\mathrm{mi} \quad \begin{array}{lllll}0 & 1 & 2 & 3 & 4\end{array}$ curiosidad.

49. Muchos mendigos son pobres porque se lo merecen. $\quad$\begin{tabular}{lllll}
\hline & 1 & 2 & 3 & 4
\end{tabular}

50. Me esfuerzo para que todo lo que hago sea lo más perfecto posible. $\quad \begin{array}{lllllll}0 & 1 & 2 & 3 & 4\end{array}$

51. Ante situaciones de mucha tensión, a veces pienso que me voy a hundir. $\quad \begin{array}{llllll}0 & 2 & 3 & 4\end{array}$

52. Disfruto en las fiestas en las que hay mucha gente. $\quad \begin{array}{llllll}0 & 1 & 2 & 3 & 4\end{array}$

53. A veces, cuando leo poesía o contemplo una obra de arte (un cuadro, una escultura, $\quad 0 \begin{array}{lllll}0 & 1 & 2 & 3 & 4\end{array}$ ...). siento una profunda emoción o sensación.

54. Según convenga, amenazo o "hago la pelota" a los demás para que hagan lo que yo $\begin{array}{llllll}0 & 1 & 2 & 3 & 4\end{array}$ quiera.

55. Si puedo, prefiero acabar las actividades de la escuela antes que dejarlas a medias. $\quad \begin{array}{lllll}0 & 1 & 2 & 3 & 4\end{array}$

56. A menudo me siento inferior a los demás. $\quad 0 \begin{array}{lllll}0 & 2 & 3 & 4\end{array}$

57. Me río con facilidad. $\quad 0 \begin{array}{lllll} & 1 & 2 & 3 & 4\end{array}$

58. Tengo mucha curiosidad intelectual. $\quad 0 \begin{array}{llll}2 & 3 & 4\end{array}$

59. A veces actúo de forma egoista y pensando sólo en $\mathrm{mi}$. $\quad \begin{array}{lllllll}0 & 1 & 2 & 3 & 4\end{array}$

60. Antes de hacer algo, siempre considero sus consecuencias. $\quad \begin{array}{llllll} & 1 & 2 & 3 & 4\end{array}$ 


\section{$\underline{\text { RPGS }}$}

\section{INSTRUCCIONES}

A continuación te presentamos una serie de motivos por los que se juega a videojuegos. Pensando en las razones por las que TÚ juegas, marca con una $\mathrm{X}$ el grado de acuerdo o de desacuerdo con cada uno de estos motivos:

\begin{tabular}{|c|c|c|c|c|}
\hline 0 & 1 & 2 & 3 & 4 \\
\hline Muy en desacuerdo & En desacuerdo & Ni de acuerdo ni en desacuerdo & De acuerdo & Muy de acuerdo \\
\hline
\end{tabular}

\section{JUEGO A VIDEOJUEGOS PORQUE...}

\begin{tabular}{|c|c|c|c|c|c|c|}
\hline 1 & Disfruto jugando & & 1 & 2 & 3 & $\overline{4}$ \\
\hline 2 & Me gusta ganar & 0 & 1 & 2 & 3 & 4 \\
\hline 3 & Me hacen pensar/calentarme la cabeza & 0 & 1 & 2 & 3 & 4 \\
\hline 4 & Alivia mi estrés & 0 & 1 & 2 & 3 & 4 \\
\hline 5 & Hago nuevos amigos & 0 & 1 & 2 & 3 & 4 \\
\hline 6 & Me gusta la violencia en el juego, cuanto más mejor & 0 & 1 & 2 & 3 & 4 \\
\hline 7 & Disfruto diseñando cosas en el juego & 0 & 1 & 2 & 3 & 4 \\
\hline 8 & Disfruto metiéndome en la piel de un nuevo personaje en cada juego & 0 & 1 & 2 & 3 & 4 \\
\hline 9 & Me lo paso bien & 0 & 1 & 2 & 3 & 4 \\
\hline 10 & Me gusta demostrar que soy mejor que otros jugadores & 0 & 1 & 2 & 3 & 4 \\
\hline 11 & Me suponen un reto mental & 0 & 1 & 2 & 3 & 4 \\
\hline 12 & Me ayuda a mejorar mi estado de ánimo & 0 & 1 & 2 & 3 & 4 \\
\hline 13 & Mediante el juego estoy en contacto con mis amigos & 0 & 1 & 2 & 3 & 4 \\
\hline 14 & En el juego es divertido disparar a alguien en la cabeza & 0 & 1 & 2 & 3 & 4 \\
\hline 15 & Me gusta crear cosas en el juego, como casas u otras construcciones & 0 & 1 & 2 & 3 & 4 \\
\hline 16 & Me gusta sentirme parte de una historia & 0 & 1 & 2 & 3 & 4 \\
\hline 17 & Es divertido & 0 & 1 & 2 & 3 & 4 \\
\hline 18 & Disfruto compitiendo con otros & 0 & 1 & 2 & 3 & 4 \\
\hline 19 & Me hacen más inteligente & 0 & 1 & 2 & 3 & 4 \\
\hline 20 & Me permite sentirme mejor cuando estoy frustrado & 0 & 1 & 2 & 3 & 4 \\
\hline 21 & Así encajo en un grupo de gente que me gusta & 0 & 1 & 2 & 3 & 4 \\
\hline 22 & Disfruto de las peleas y luchas violentas en el juego & 0 & 1 & 2 & 3 & 4 \\
\hline 23 & Me gusta crear mi propio mundo en el juego & 0 & 1 & 2 & 3 & 4 \\
\hline 24 & Me siento inmerso en un mundo fantástico/ficticio & 0 & 1 & 2 & 3 & 4 \\
\hline
\end{tabular}




\section{DISORDERED GAMING SCALE FOR YOUTHS}

\section{Disordered gaming scale for youths}

\section{INSTRUCCIONES}

Indica aproximadamente cuántas horas AL DÍA sueles JUGAR A VIDEOJUEGOS (a través de una consola, ordenador, móvil o Tablet). Los juegos de apuestas (como el póker online) NO cuentan como Videojuego:

a. Videojuegos en línea

b. Videojuegos SIN conexión a internet

Entre semana

horas al día

Fin de semana

Marca con una $\mathrm{X}$ las veces que te ha pasado cada una de estas cuestiones relacionadas con el uso de los videojuegos durante los últimos 12 MESES. Para responder utiliza la siguiente tabla:

\begin{tabular}{|c|c|c|c|}
\hline 0 & 1 & 2 & 3 \\
\hline $\begin{array}{c}\text { Casi nunca } \\
\text { /Nunca }\end{array}$ & Algunas & Bastantes & Casi siempre/ \\
Veces & Veces & Siempre \\
\hline
\end{tabular}

En los últimos 12 meses, con qué frecuencia te ha pasado que

Has pasado cada vez más tiempo pensando en videojuegos, aprendiendo a jugar a videojuegos o planeando la siguiente ocasión para jugar

Has necesitado aumentar el tiempo o gastar más dinero en videojuegos para sentir el mismo nivel de emoción

3 Has probado a jugar a videojuegos con menos frecuencia o por períodos más cortos de tiempo, pero no lo conseguiste

4 Te has sentido inquieto/a o irritable al tratar de reducir o parar de jugar a videojuegos

5 Has jugado a videojuegos para tratar de escapar de los problemas o del malestar emocional

6 Has mentido a la familia o amigos sobre cuánto juegas a los videojuegos

Has mentido a la familia o amigos sobre cuánto juegas a los videojuegos

7 videojuego

8 Has dejado de hacer tareas que te correspondían en casa para jugar más tiempo a los videojuegos

9 Has dejado de hacer los deberes para jugar más tiempo a los videojuegos

$\begin{array}{llll}0 & 1 & 2 & 3\end{array}$

10 Has hecho mal un trabajo escolar o examen porque pasaste demasiado tiempo jugando a

10 videojuegos

11 Has necesitado que amigos o familiares te diesen dinero extra porque gastaste demasiado dinero 11 en equipamiento para los videojuegos, software o cargos de juegos/internet 
$\underline{\text { IGD-20 }}$

\section{INSTRUCCIONES}

Las siguientes afirmaciones refieren a tu actividad con videojuegos durante el último año (ÚLTIMOS 12 MESES). Por actividad con videojuegos nos referimos a cualquier conducta con videojuegos llevada a cabo mediante computadora, consola y cualquier otro dispositivo, de forma online u offline.

\begin{tabular}{|c|c|c|c|c|}
\hline 0 & 1 & 2 & 3 & 4 \\
\hline $\begin{array}{c}\text { En total } \\
\text { Desacuerdo }\end{array}$ & Desacuerdo & Neutro & De acuerdo & $\begin{array}{c}\text { Totalmente de } \\
\text { acuerdo }\end{array}$ \\
\hline
\end{tabular}

\begin{tabular}{|c|c|c|c|c|c|c|}
\hline & ego & & & & & \\
\hline 2 & Nunca juego a videojuegos para sentirme mejor & 0 & & & & 4 \\
\hline 3 & $\begin{array}{l}\text { Durante el último año he aumentado significativamente la cantidad } \\
\text { de horas de juego a videojuegos }\end{array}$ & 0 & 1 & 2 & 3 & 4 \\
\hline 4 & 10 estoy jug & 0 & 1 & 2 & 3 & 4 \\
\hline 5 & He pe & 0 & 1 & 2 & 3 & 4 \\
\hline 6 & Me gust & 0 & 1 & 2 & 0 & a \\
\hline 7 & cima sesión de juego cuando no estoy & 0 & 1 & & & \\
\hline 8 & er & 0 & 1 & & & \\
\hline 9 & tiempo jugando a videojuegos & 0 & 1 & 2 & 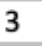 & 4 \\
\hline 10 & Me si & 0 & 1 & 2 & & 4 \\
\hline 11 & e $n$ & 0 & 1 & & & \\
\hline 12 & No $\mathrm{cr}$ & 0 & + & 2 & 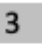 & 4 \\
\hline 13 & $\begin{array}{l}\text { Creo que } \\
\text { consume }\end{array}$ & 0 & 1 & & & \\
\hline 14 & Juego & 0 & 1 & 2 & 3 & 4 \\
\hline 15 & $\begin{array}{l}\text { A me } \\
\text { todo }\end{array}$ & 0 & 1 & $?$ & & \\
\hline 16 & Tiendo & 0 & 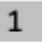 & 2 & 3 & 4 \\
\hline 17 & Creo & 0 & 1 & 2 & 3 & \\
\hline 18 & A menudo me propongo jugar menos $p$ & 0 & & & & 4 \\
\hline 19 & $\begin{array}{l}\text { Sé que mis actividades cotidianas (trabajo, educ } \\
\text { domésticas, etc.) no se han visto negativamente }\end{array}$ & 0 & & 2 & & \\
\hline 20 & $\begin{array}{l}\text { Creo que jugar está afectando negativamente áreas importantes de } \\
\text { mi vida }\end{array}$ & 0 & & & & \\
\hline
\end{tabular}




\section{FREE TIME ACTIVITIES}

\section{INSTRUCCIONES}

Marca con una $\mathrm{X}$ el tiempo que habitualmente dedicas a cada una de estas actividades:

\begin{tabular}{|c|c|c|c|c|c|}
\hline \multirow{2}{*}{$\begin{array}{c}\text { NUNCA o } \\
\text { casi nunca }\end{array}$} & \multirow{2}{*}{$\begin{array}{c}\text { Alguna vez } \\
\text { al MES }\end{array}$} & \multirow{2}{*}{$\begin{array}{c}\text { Alguna vez a } \\
\text { la SEMANA }\end{array}$} & \multicolumn{3}{|c|}{ TODOS casi todos los dias } \\
\cline { 4 - 6 } & & $\begin{array}{c}\text { Menos de 1 } \\
\text { hora al DIA }\end{array}$ & $\begin{array}{c}\text { Entre 1 y 3 } \\
\text { horas al DIA }\end{array}$ & $\begin{array}{c}\text { Más de 3 horas } \\
\text { al DíA }\end{array}$ \\
\hline 0 & 1 & 2 & 3 & 4 & 5 \\
\hline
\end{tabular}

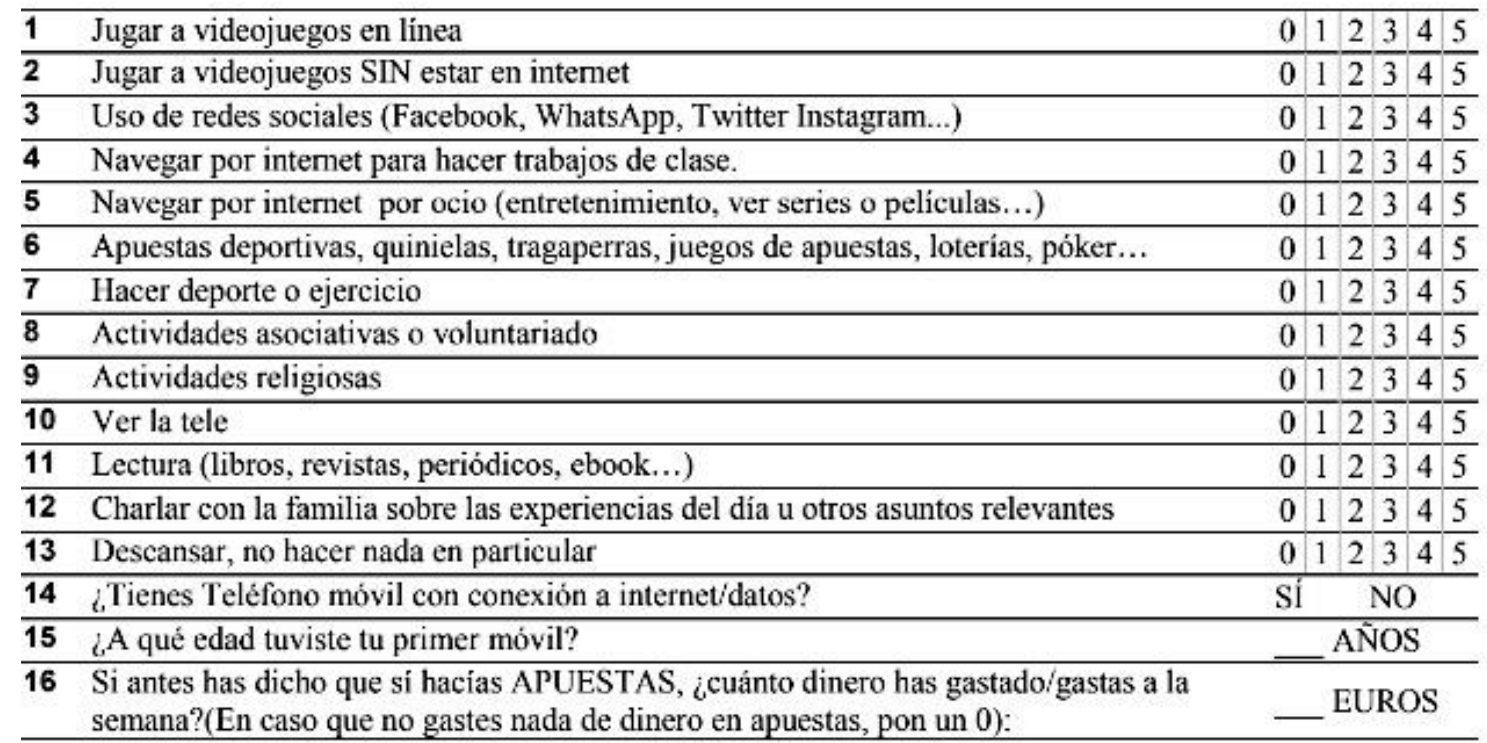

17 Si antes has dicho que jugabas a videojuegos, indica por orden, aquellos a los que más juegas:

(En caso que hayas jugado a 2 juegos, no hace falta que rellenes todos los espacios)
1 -
$2-$
$3-$
$4-$
$5-$ 


\section{SENA}

\section{INSTRUCCIONES}

Marca con una X, la opción que más se ajuste a ti y a tu forma de comportarte. No existen respuestas buenas o malas. Para responder utiliza la siguiente tabla:

\begin{tabular}{|c|c|c|c|c|}
\hline 0 & 1 & 2 & 3 & 4 \\
\hline $\begin{array}{c}\text { Nunca o } \\
\text { casi nunca }\end{array}$ & Pocas veces & $\begin{array}{c}\text { Algunas } \\
\text { veces }\end{array}$ & Muchas veces & $\begin{array}{c}\text { Siempre o } \\
\text { casi siempre }\end{array}$ \\
\hline
\end{tabular}

\begin{tabular}{|c|c|c|}
\hline & Me cuesta permanecer sentado & \begin{tabular}{l|l|l|l|l}
0 & 1 & 2 & 3 & 4
\end{tabular} \\
\hline 2 & Me despierto cansado por las mañanas & $\begin{array}{llllll}0 & 1 & 2 & 3 & 4\end{array}$ \\
\hline 3 & Soy vergonzoso & $\begin{array}{lllll}0 & 1 & 2 & 3 & 4\end{array}$ \\
\hline 4 & Tengc & $\begin{array}{lllll}0 & 1 & 2 & 3 & 4\end{array}$ \\
\hline 5 & Me distraigo fácilmente & $\begin{array}{lllll}0 & 1 & 2 & 3 & 4\end{array}$ \\
\hline 6 & Me enfado o enojo con los demás & $\begin{array}{lllll}0 & 1 & 2 & 3 & 4\end{array}$ \\
\hline 7 & $\begin{array}{l}\text { Me pongo nervioso cuando hay mucha } \\
\text { gente alrededor }\end{array}$ & $\begin{array}{llllll}0 & 1 & 2 & 3 & 4\end{array}$ \\
\hline 8 & Me siento cansado & 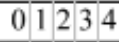 \\
\hline 9 & Se me olvidan las cosas & $\begin{array}{llllll}0 & 1 & 2 & 3 & 4\end{array}$ \\
\hline 10 & $\mathrm{Me} \mathrm{cu}$ & $\begin{array}{llll}0 & 1 & 2 & 3 \\
4\end{array}$ \\
\hline 11 & menos que & $\begin{array}{lllll}0 & 1 & 2 & 3 & 4\end{array}$ \\
\hline 12 & Piens & $\begin{array}{lllll}0 & 1 & 2 & 3 & 4\end{array}$ \\
\hline 13 & Me c & $\begin{array}{llllll}0 & 1 & 2 & 3 & 4\end{array}$ \\
\hline 14 & Me duele la cabeza & $\begin{array}{lllll}0 & 1 & 2 & 3 & 4\end{array}$ \\
\hline 15 & e miro al espejo no me gusta & $\begin{array}{llllll}0 & 1 & 2 & 3 & 4\end{array}$ \\
\hline 16 & $\begin{array}{l}\text { ha vergüenza hablar de } \\
\text { as que me han pasado }\end{array}$ & $\begin{array}{llll}0 & 1 & 2 & 3 \\
4\end{array}$ \\
\hline 17 & Grit & $\begin{array}{lllll}0 & 1 & 2 & 3 & 4 \\
\end{array}$ \\
\hline 18 & Mis & $\begin{array}{lllll}0 & 1 & 2 & 3 & 4\end{array}$ \\
\hline 19 & Me c & 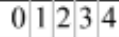 \\
\hline 20 & $\begin{array}{l}\text { Me d } \\
\text { pesad }\end{array}$ & $2-1$ \\
\hline 21 & Hago & $\begin{array}{lllll}0 & 1 & 2 & 3 & 4 \\
\end{array}$ \\
\hline 22 & $\begin{array}{l}\text { Me cue } \\
\text { cosas }\end{array}$ & $\begin{array}{lllll}0 & 1 & 2 & 3 & 4\end{array}$ \\
\hline 23 & los demás & \begin{tabular}{ll|l|l|l}
0 & 1 & 2 & 4
\end{tabular} \\
\hline 24 & $\mathrm{Med}$ & $\begin{array}{llll}0 & 1 & 2 & 3 \\
4\end{array}$ \\
\hline 25 & Las preocupaciones me duran mucho & $0 \longdiv { 1 } \overline { 2 } \overline { 4 }$ \\
\hline 26 & $\begin{array}{l}\text { Algunos compañeros me obligan a } \\
\text { hacer cosas que no quiero }\end{array}$ & 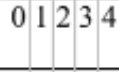 \\
\hline 27 & Sufro mucho & $\begin{array}{lllll}0 & 1 & 2 & 3 & 4 \\
\end{array}$ \\
\hline 28 & $\begin{array}{l}\text { Me dicen que } \\
\text { me hablan }\end{array}$ & \\
\hline 29 & Miento para conseguir lo que quiero & $\begin{array}{llllll}0 & 1 & 2 & 3 & 4\end{array}$ \\
\hline 30 & $\begin{array}{l}\text { Me vienen imágenes desagradables de } \\
\text { cosas que me han pasado }\end{array}$ & 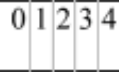 \\
\hline 51 & Tengo & $\begin{array}{llll}0 & 1 & 2 & 3 \\
4\end{array}$ \\
\hline 32 & Digo o hago la & $\begin{array}{llllll}0 & 1 & 2 & 3 & 4 \\
\end{array}$ \\
\hline 33 & areo & 01 \\
\hline
\end{tabular}

\begin{tabular}{|c|c|c|}
\hline 7 & Mo & ( \\
\hline 35 & $\begin{array}{l}\text { Siento que a nadie le importa lo que } \\
\text { hago }\end{array}$ & \begin{tabular}{ll|l|l|l|l}
0 & 1 & 2 & 34
\end{tabular} \\
\hline$\overline{36}$ & $\begin{array}{l}\text { ervioso cuando me hablan } \\
\text { s }\end{array}$ & \begin{tabular}{ll|l|l|l}
0 & 1 & 2 & 3 & 4
\end{tabular} \\
\hline 37 & Creo que mi cuerpo es horrible & $\begin{array}{lllll}0 & 1 & 2 & 3 & 4 \\
\end{array}$ \\
\hline 38 & Exploto con facilidad & $\begin{array}{lllll}0 & 1 & 2 & 34\end{array}$ \\
\hline 39 & Tengo & 0012334 \\
\hline 40 & 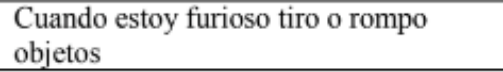 & \begin{tabular}{l|l|l|l|l}
0 & 1 & 2 & 3 & 4
\end{tabular} \\
\hline 41 & Odio algunas partes de mi cuerpo & \begin{tabular}{l|l|l|l}
0 & 1 & 2 & 3
\end{tabular} \\
\hline$\overline{42}$ & $\begin{array}{l}\text { Cont } \\
\text { prof }\end{array}$ & 17 \\
\hline 43 & Mes & 4 \\
\hline$\overline{44}$ & $\begin{array}{l}\text { Me t } \\
\text { grup }\end{array}$ & 01234 \\
\hline$\overline{45}$ & $\begin{array}{l}\text { Me c } \\
\text { está }\end{array}$ & \begin{tabular}{ll|l|l|l}
0 & 1 & 2 & 34 & 4
\end{tabular} \\
\hline 46 & Me d & $\begin{array}{llllll}0 & 1 & 2 & 3 & 4 \\
\end{array}$ \\
\hline 47 & $\begin{array}{l}\text { Tomo dir } \\
\text { sepan }\end{array}$ & \begin{tabular}{ll|l|l|l}
0 & 1 & 2 & 3 & 4
\end{tabular} \\
\hline 48 & $\begin{array}{l}\text { Teng } \\
\text { algur }\end{array}$ & \\
\hline 49 & Los & \\
\hline 50 & Mes & $\begin{array}{llllll}0 & 1 & 2 & 3 & 4 \\
\end{array}$ \\
\hline 51 & Estoy & 001234 \\
\hline 52 & $\begin{array}{l}\text { Me b } \\
\text { diver }\end{array}$ & 01234 \\
\hline 53 & Me si & $\begin{array}{llllll}0 & 1 & 2 & 3 & 4 \\
\end{array}$ \\
\hline 54 & $\begin{array}{l}\text { Doy } \\
\text { cabe: }\end{array}$ & \\
\hline 55 & Sients & $\begin{array}{llllll}0 & 1 & 2 & 3 & 4 \\
\end{array}$ \\
\hline 56 & Me han $\mathrm{p}$ & $\begin{array}{llllll}0 & 1 & 2 & 3 & 4\end{array}$ \\
\hline 57 & Me aterroriza la i & $\begin{array}{lllllll}0 & 1 & 2 & 3 & 4 \\
\end{array}$ \\
\hline 58 & $\begin{array}{l}\text { Pierdo el control cuando me enfado o } \\
\text { enojo }\end{array}$ & \begin{tabular}{l|l|l|l}
0 & 12 & 3 & 4
\end{tabular} \\
\hline 59 & $\begin{array}{l}\text { Me cuesta mantener la atención durante } \\
\text { mucho tiempo }\end{array}$ & \\
\hline 60 & pañeros me insultan o & \\
\hline 61 & $\begin{array}{l}\text { Me afectan mucho algunas cosas que } \\
\text { me han pasado }\end{array}$ & 01 \\
\hline
\end{tabular}




\begin{tabular}{|c|c|c|c|c|}
\hline 0 & 1 & 2 & 3 & 4 \\
\hline $\begin{array}{c}\text { Nunca o } \\
\text { casi nunca }\end{array}$ & Pocas veces & $\begin{array}{c}\text { Algunas } \\
\text { veces }\end{array}$ & Muchas veces & $\begin{array}{c}\text { Siempre o } \\
\text { casi sicmpre }\end{array}$ \\
\hline
\end{tabular}

\begin{tabular}{|c|c|c|}
\hline 62 & Tengo miedo de hacer el ridículo & \begin{tabular}{l|l|l|l|l}
0 & 1 & 2 & 3 & 4 \\
\end{tabular} \\
\hline 63 & $\begin{array}{l}\text { Me llaman la atención en clase porque } \\
\text { no paro de moverme }\end{array}$ & \begin{tabular}{l|l|l|l|l}
0 & 1 & 2 & 3 & 4 \\
\end{tabular} \\
\hline 64 & Falto a clase sin permiso & \begin{tabular}{l|l|l|l|l}
0 & 1 & 2 & 3 & 4 \\
\end{tabular} \\
\hline 65 & $\begin{array}{l}\text { Amenazo a otros para conseguir lo que } \\
\text { quiero }\end{array}$ & \begin{tabular}{l|l|l|l|l}
0 & 1 & 2 & 3 & 4 \\
\end{tabular} \\
\hline 66 & Duermo mal & \begin{tabular}{llll|l}
0 & 1 & 2 & 3 & 4 \\
\end{tabular} \\
\hline 67 & Me llevo cosas de las tiendas sin pagar & \begin{tabular}{l|l|l|l|l}
0 & 1 & 2 & 3 & 4 \\
\end{tabular} \\
\hline 68 & $\begin{array}{l}\text { Lo paso mal cuando estoy con } \\
\text { desconocidos }\end{array}$ & \begin{tabular}{ll|l|l|l}
0 & 1 & 2 & 3 & 4 \\
\end{tabular} \\
\hline 69 & Tengo ganas de llorar & \begin{tabular}{l|l|l|l|l}
0 & 1 & 2 & 3 & 4 \\
\end{tabular} \\
\hline 70 & $\begin{array}{l}\text { Tengo ataques de nervios o de } \\
\text { ansiedad }\end{array}$ & \begin{tabular}{l|l|l|l|l}
0 & 1 & 2 & 3 & 4
\end{tabular} \\
\hline 71 & Pierdo el control en las peleas & \begin{tabular}{l|l|l|l|l}
0 & 1 & 2 & 3 & 4 \\
\end{tabular} \\
\hline 72 & Me insultan en el colegio o instituto & \begin{tabular}{l|l|l|l|l}
0 & 1 & 2 & 3 & 4 \\
\end{tabular} \\
\hline 73 & Me cuesta concentrarme & \begin{tabular}{l|l|l|l|l}
0 & 1 & 2 & 3 & 4 \\
\end{tabular} \\
\hline 74 & $\begin{array}{l}\text { Insulto a los demás durante las } \\
\text { discusiones }\end{array}$ & \begin{tabular}{ll|l|l|l}
0 & 1 & 2 & 3 & 4 \\
\end{tabular} \\
\hline 75 & Me duele el estómago o la tripa & \begin{tabular}{l|l|l|l|l}
0 & 1 & 2 & 3 & 4 \\
\end{tabular} \\
\hline 76 & $\begin{array}{l}\text { Siento que las cosas que me rodean son } \\
\text { irreales y extrañas }\end{array}$ & \\
\hline 77 & Quiero morirme & \begin{tabular}{l|l|l|l|l}
0 & 1 & 2 & 3 & 4 \\
\end{tabular} \\
\hline 78 & $\begin{array}{l}\text { Hago lo que me da la gana aunque me } \\
\text { castiguen }\end{array}$ & \begin{tabular}{l|l|l|l|l|l}
0 & 1 & 2 & 3 & 4
\end{tabular} \\
\hline 79 & $\begin{array}{l}\text { Siento como si me viera a mí mismo } \\
\text { desde fuera, como en una película }\end{array}$ & 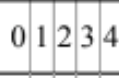 \\
\hline 80 & Me angustian o agobian mis problemas & \begin{tabular}{l|l|l|l|l}
0 & 1 & 2 & 3 & 4 \\
\end{tabular} \\
\hline 81 & Pienso en vomitar para no engordar & \begin{tabular}{l|l|l|l|l}
0 & 1 & 2 & 3 & 4 \\
\end{tabular} \\
\hline 82 & Me dicen que no sé estar quieto & \begin{tabular}{l|l|l|l|l}
0 & 1 & 2 & 3 & 4 \\
\end{tabular} \\
\hline 83 & Me dicen que me preocupo demasiado & \begin{tabular}{l|l|l|l|l}
0 & 1 & 2 & 3 & 4 \\
\end{tabular} \\
\hline 84 & $\begin{array}{l}\text { Me da vergüenza hablar con } \\
\text { desconocidos }\end{array}$ & \begin{tabular}{l|l|l|l|l}
0 & 1 & 2 & 3 & 4 \\
\end{tabular} \\
\hline 85 & Paso la noche fuera de casa sin avisar & \begin{tabular}{l|l|l|l|l}
0 & 1 & 2 & 3 & 4 \\
\end{tabular} \\
\hline 86 & Me siento solo & \begin{tabular}{l|l|l|l|l}
0 & 1 & 2 & 3 & 4 \\
\end{tabular} \\
\hline 87 & Pego a otros cuando me enfado o enojo & \begin{tabular}{l|l|l|l|l|l|l}
0 & 1 & 2 & 3 & 4 \\
\end{tabular} \\
\hline 88 & Siento que estoy en peligro & \begin{tabular}{l|l|l|l|l}
0 & 1 & 2 & 3 & 4 \\
\end{tabular} \\
\hline 89 & Pienso que mi vida no tiene sentido & \begin{tabular}{l|l|l|l|l}
0 & 1 & 2 & 3 & 4 \\
\end{tabular} \\
\hline 90 & Se me duermen los brazos o las piernas & \begin{tabular}{l|l|l|l|l|l|l|l|l}
0 & 1 & 2 & 3 & 4 \\
\end{tabular} \\
\hline 91 & Me pegan en el colegio o instituto & \begin{tabular}{l|l|l|l|l}
0 & 1 & 2 & 3 & 4 \\
\end{tabular} \\
\hline
\end{tabular}

\begin{tabular}{|c|c|c|}
\hline 92 & $\begin{array}{l}\text { Me enfado o enojo mucho cuando las } \\
\text { cosas no salen como quiero }\end{array}$ & \begin{tabular}{l|l|l|l|l}
0 & 1 & 2 & 3 & 4
\end{tabular} \\
\hline$\overline{93}$ & $\begin{array}{l}\text { Mis profesores dicen que no presto } \\
\text { atención en clase }\end{array}$ & \begin{tabular}{ll|l|l|l}
0 & 1 & 2 & 3 & 4 \\
\end{tabular} \\
\hline$\overline{94}$ & $\begin{array}{l}\text { Cuando me siento mal pienso en darme } \\
\text { un atracón de comida }\end{array}$ & \begin{tabular}{lll|l|l|l}
0 & 1 & 2 & 3 & 4
\end{tabular} \\
\hline$\overline{95}$ & $\begin{array}{l}\text { Hago lo primero que se me pasa por la } \\
\text { cabeza }\end{array}$ & $\begin{array}{lllllll}0 & 1 & 2 & 3 & 4\end{array}$ \\
\hline 96 & $\begin{array}{l}\text { Me dicen que tengo que poner más } \\
\text { atención en las cosas que hago }\end{array}$ & \begin{tabular}{ll|l|l|l}
0 & 1 & 2 & 3 & 4
\end{tabular} \\
\hline$\overline{97}$ & $\begin{array}{l}\text { Cuando mis padres me mandan algo, } \\
\text { digo que no me da la gana }\end{array}$ & \begin{tabular}{l|l|l|l|l}
0 & 1 & 2 & 3 & 4
\end{tabular} \\
\hline 98 & Hago cosas que no son del todo legales & $\begin{array}{llllll}0 & 1 & 2 & 3 & 4 \\
\end{array}$ \\
\hline 99 & $\begin{array}{l}\text { Me dicen que interrumpo a los demás y } \\
\text { no dejo hablar }\end{array}$ & \begin{tabular}{llll|l|l|l}
0 & 1 & 2 & 3 & 4
\end{tabular} \\
\hline 100 & Estoy triste & \begin{tabular}{l|l|l|l|l}
0 & 1 & 2 & 3 & 4 \\
\end{tabular} \\
\hline 101 & Me amenazan en el colegio o instituto & \begin{tabular}{l|l|l|l|l}
0 & 1 & 2 & 3 & 4 \\
\end{tabular} \\
\hline 102 & $\begin{array}{l}\text { Tengo dolores en la espalda o los } \\
\text { hombros }\end{array}$ & \begin{tabular}{l|l|l|l|l}
0 & 1 & 2 & 3 & 4
\end{tabular} \\
\hline 103 & $\begin{array}{l}\text { Rompo o estropeo a propósito cosas de } \\
\text { otras personas }\end{array}$ & \begin{tabular}{l|l|l|l|l}
0 & 1 & 2 & 3 & 4 \\
\end{tabular} \\
\hline 104 & Me preocupo o me agobio & \begin{tabular}{l|l|l|l|l}
0 & 1 & 2 & 3 & 4 \\
\end{tabular} \\
\hline 105 & $\begin{array}{l}\text { Tengo miedo de que nos pase algo } \\
\text { malo a mi o a mi familia }\end{array}$ & \begin{tabular}{l|l|l|l|l}
0 & 1 & 2 & 3 & 4
\end{tabular} \\
\hline 106 & $\begin{array}{l}\text { Rompo o estropeo cosas de la calle } \\
\text { (papeleras, cristales...) }\end{array}$ & \begin{tabular}{l|l|l}
2 & 3 & 4
\end{tabular} \\
\hline$\overline{107}$ & $\begin{array}{l}\text { Doy portazos o golpes cuando me } \\
\text { enfado o enojo }\end{array}$ & 234 \\
\hline 108 & $\begin{array}{l}\text { Cuando empiezo a comer siento que no } \\
\text { puedo parar }\end{array}$ & \begin{tabular}{l|l|l|l|l|l|l|l|l|l|l}
0 & 1 & 2 & 3 & 4 \\
\end{tabular} \\
\hline$\overline{109}$ & $\begin{array}{l}\text { Hay cosas que no me puedo quitar de } \\
\text { la cabeza }\end{array}$ & \begin{tabular}{ll|l|l|l}
0 & 1 & 2 & 3 & 4
\end{tabular} \\
\hline 110 & Me aprovecho de los demás si puedo & \begin{tabular}{ll|l|l|l}
0 & 1 & 2 & 3 & 4 \\
\end{tabular} \\
\hline$\overline{111}$ & $\begin{array}{l}\text { Algunos compañeros me ponen en } \\
\text { ridículo }\end{array}$ & \begin{tabular}{l|l|l|l}
0 & 1 & 2 & 3
\end{tabular} \\
\hline 112 & $\begin{array}{l}\text { Me despisto y cometo muchos errores } \\
\text { sin darme cuenta }\end{array}$ & \begin{tabular}{l|l|l|l|l|l}
0 & 1 & 2 & 3 & 4 \\
\end{tabular} \\
\hline 113 & $\begin{array}{l}\text { Me vienen pensamientos o imágenes a } \\
\text { la cabeza que se repiten una y otra vez }\end{array}$ & \begin{tabular}{ll|l|l|l}
0 & 1 & 2 & 3 & 4 \\
\end{tabular} \\
\hline 114 & $\begin{array}{l}\text { Me cuesta estar sin hacer nada porque } \\
\text { me pongo nervioso }\end{array}$ & \begin{tabular}{l|l|l|l|l|l}
0 & 1 & 2 & 3 & 4 \\
\end{tabular} \\
\hline
\end{tabular}




\section{$\underline{\text { DPS }}$}

\section{INSTRUCCIONES}

Marca con una X, la opción que mejor represente la cantidad de tus amigos que hayan realizado cada una de estas conductas en los ÚLTIMOS 6 MESES. Para responder utiliza la siguiente tabla:

\begin{tabular}{|c|c|c|c|c|}
\hline 0 & 1 & 2 & 3 & 4 \\
\hline Ninguno & Pocos & Bastantes & Muchos & Todos \\
\hline
\end{tabular}

En los últimos 6 meses, ¿cuántos de tus amigos...

\begin{tabular}{|c|c|c|}
\hline 1 & Se han saltado un día de clase sin tener ninguna excusa? & 011234 \\
\hline 2 & Han mentido, desobedecido, o replicado a algún adulto? & 01234 \\
\hline 3 & Han robado algo por menos de 5 euros de valor? & 01234 \\
\hline 4 & Han robado algo por más de 5 euros pero por menos de 100 euros de valor? & 011234 \\
\hline 5 & Han robado algo por más de 100 euros de valor? & 011234 \\
\hline 6 & Han entrado o han intentado entrar en un edificio para robar algo? & 011234 \\
\hline 7 & Han cogido sin permiso un automóvil (bicicleta, moto, etc.) y lo han conducido? & 011234 \\
\hline 8 & Han pegado a alguien con la idea de hacer daño a esa persona? & 01234 \\
\hline 9 & Han vendido drogas blandas como marihuana o hachís? & 012334 \\
\hline 10 & Han tenido problemas con la policía? & 01234 \\
\hline & Se han escapado de casa? & 011234 \\
\hline 12 & Han sido expulsados de la escuela? & $0 1 \longdiv { 2 3 4 }$ \\
\hline & Se han visto envueltos en peleas de pandillas? & 01234 \\
\hline 14 & Han pegado a alguien sin razón? & 012234 \\
\hline 15 & Ha copiado de algún compañero o ha usado chuletas en algún examen? & 011234 \\
\hline & Han consumido drogas blandas como marihuana o hachís? & 01234 \\
\hline
\end{tabular}

